\title{
Common Property Resource
}

\section{Management In Vanuatu - Perspectives}

\section{From A Community}

\author{
Amanda Leathers \\ School of Earth Sciences \\ Victoria University of Wellington \\ Wellington, Aotearoa New Zealand
}

Submitted in partial fulfillment of the

Master of Development Studies (MSD) Degree

April 2008 


\section{Abstract}

Vanuatu's common property natural resources provide essential ecological services for the global community and sustain the livelihoods of $80 \%$ of the Vanuatu population. Sustainable management of natural resources is dependent on locally developed systems that govern common property resources. Understanding the drivers of commons management problems from local resource-users' perspectives is essential to know how local governance systems can be supported and strengthened. I explore locally identified drivers of commons management problems using a case study of the Tangoa Island community of South Santo, Vanuatu. Methods include participatory rural appraisal (PRA) techniques and 31 interviews with local people. Literature from Vanuatu as well as 18 interviews with Vanuatu government departments, NGOs, and aid donors informs how relevant the issues identified in the case study are for other communities across Vanuatu. I found that drivers at different contextual scales, from local to global, affect two main elements of a community's cooperative capacity for commons management - social cohesion and governance systems. The issues identified by the Tangoa Island community affect many Vanuatu communities because they are driven by wider processes of social, cultural, economic, and institutional change. Approaches to support and strengthen local social and governance systems can target drivers at multiple contextual scales. 


\section{Acknowledgements}

The Tangoa people taught me so much more than this thesis begins to reflect. Their hospitality, support, warmth and humor made my first field research experience truly enjoyable. The new perspectives on life that I gained from my stay on Tangoa Island will be an enduring source of energy and inspiration. Thanks especially to Vetabe and the family for taking such good care of us. Thanks to Ioan Viji for inviting us to Tangoa. Thanks to Meto for providing essential research support and translation.

My principle advisor Dr. Michael Gavin provided essential guidance, motivation, and encouragement throughout the research. I appreciate of all his work giving clear advice and focus, which has kept me on track and enabled me to finish this thesis. My secondary adviser Dr. Sean Weaver is always a source of energy and inspiration. I am thankful for the positive relationship that he has built with the Tangoa community since 2005. The high regard and fondness that many Tangoan people hold for Sean provided an excellent foundation from which to establish our own relationships.

The quality and quantity of research has been greatly benefited by my co-researcher Olivia Warrick. Her collaboration and support has been extremely valuable. I am grateful that I had Olivia to share the fieldwork experience, and to reminisce and discuss ideas with since leaving Tangoa Island. Thanks also to Isabel Heymanns for all her help with digital map making.

I thank my family - Dad, Matt, Cali and Jill - for believing in me and reminding me to believe in myself. Special thanks to my mother, who let me rant my confusion into clarity on many occasions, for always offering sound advice, and for her help with editing.

Thanks to my partner Roger Young for being so patient, for sharing me with "Thesis", and providing much emotional and livelihood support throughout. Thanks to my friends that still love me after months of my neglect. I'm looking forward to making it up to you!

Thanks to the staff and students of the School of Geography, Environmental Studies and Earth Sciences who donated some beautiful children's books which were much appreciated by the Tangoa Community. 


\section{Table Of Contents}

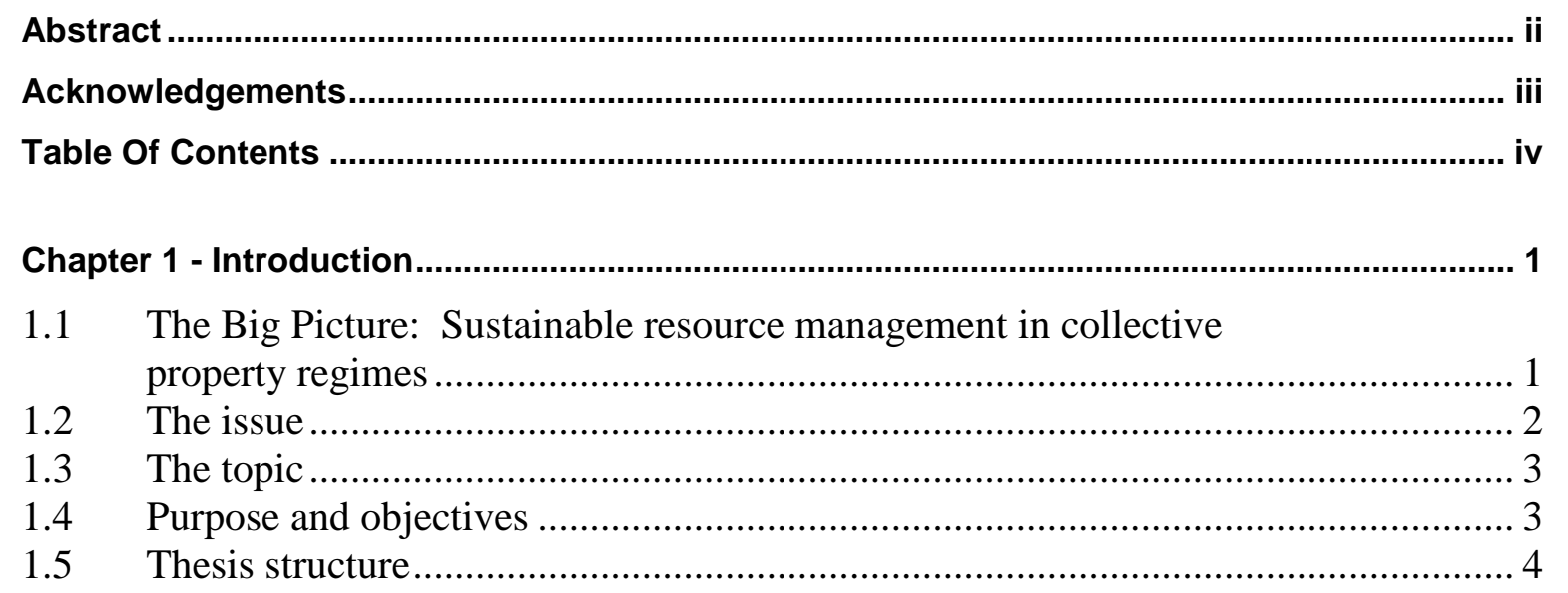

Chapter 2 - Literature review: the findings of commons research ....................................... 6

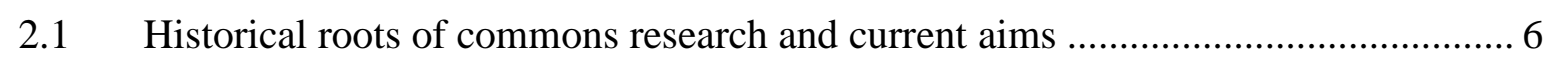

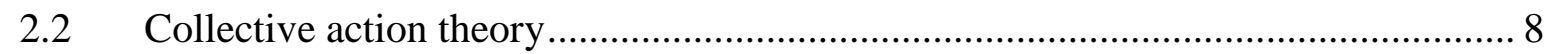

2.3 Important factors affecting commons management ….................................... 15

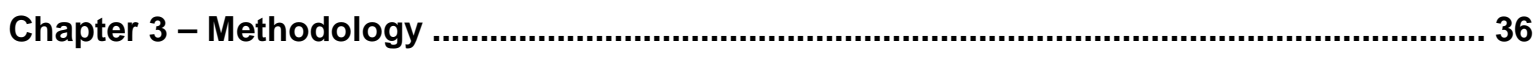

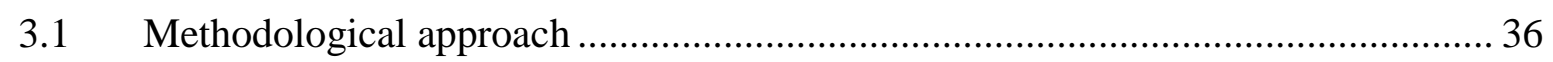

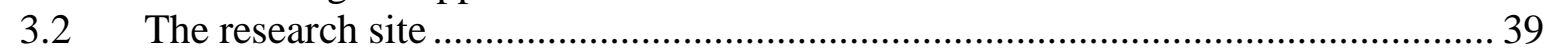

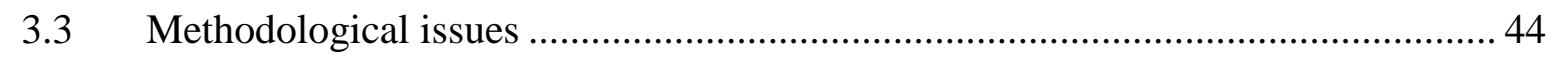

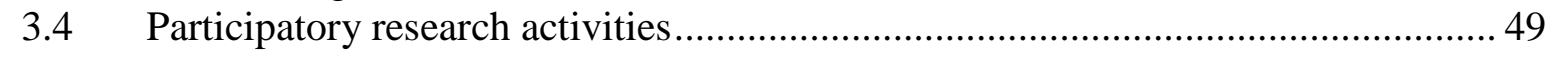

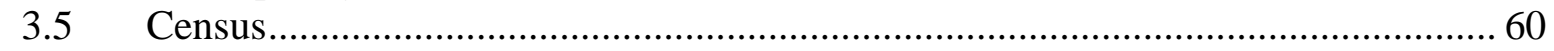

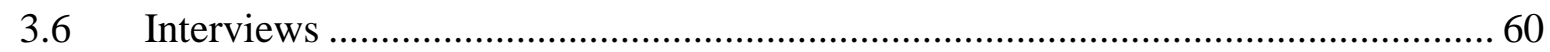

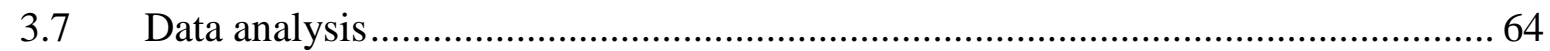

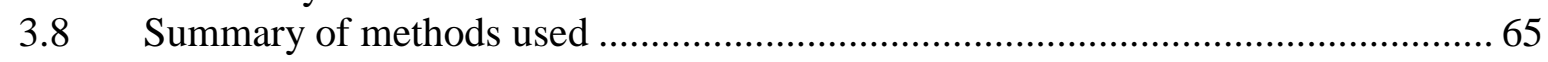

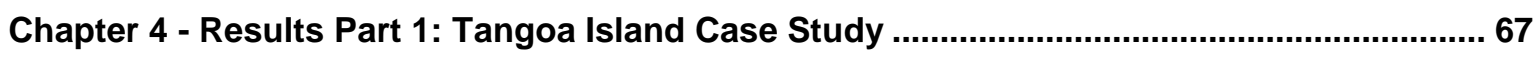

4.1 Where are the important natural resources that the Tangoa community uses? ....... 67

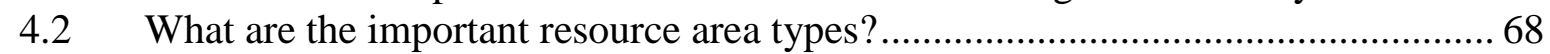

4.3 How are Tangoa's natural resources used? ....................................................... 70

4.4 Who uses and manages Tangoa natural resources and how? ................................ 75

4.5 What are the threats to Tangoa's natural resources? ........................................... 83

4.6 What are the causes of resource degradation? ................................................. 91

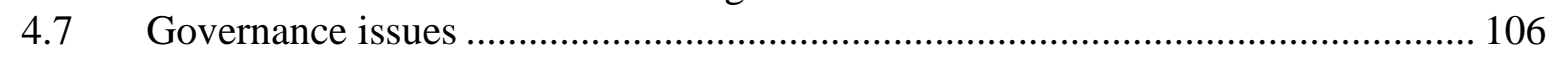

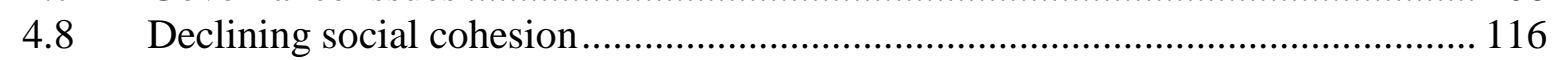

Chapter 5 - Results Part 2: Relevance of Case-Study Findings for the Wider

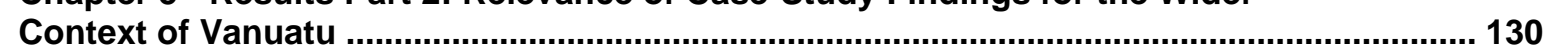

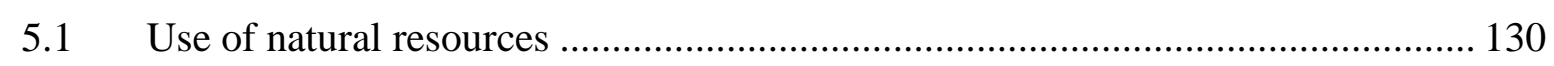

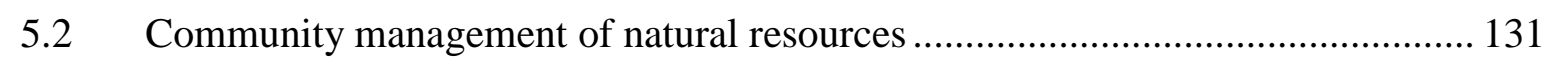

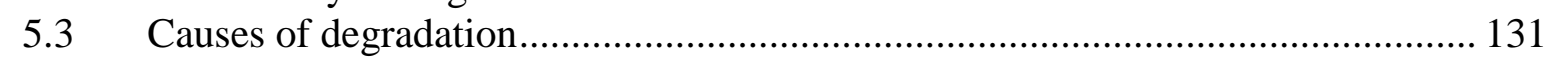




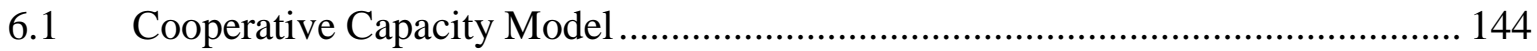

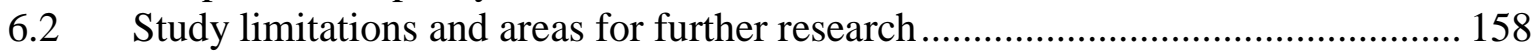

6.3 Finding solutions and an appropriate development pathway ............................... 160

Chapter 7 - Conclusion and Recommendations ................................................................... 169

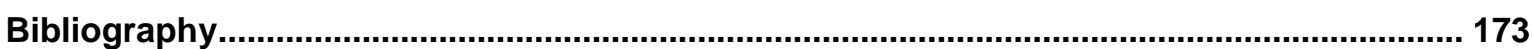




\section{Tables}

Table 2.1, Critical enabling conditions for sustainability on the commons.......................................17

Table 3.1, Case-study objective question and corresponding methods .......................................... 50

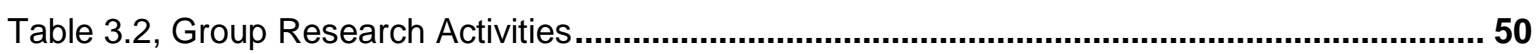

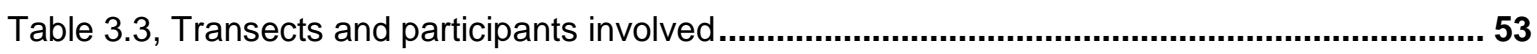

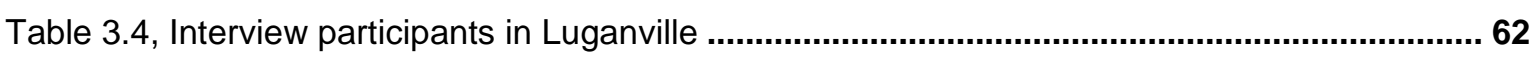

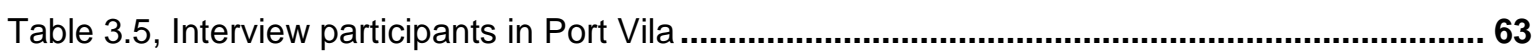

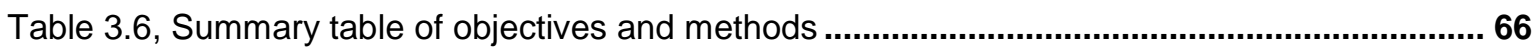

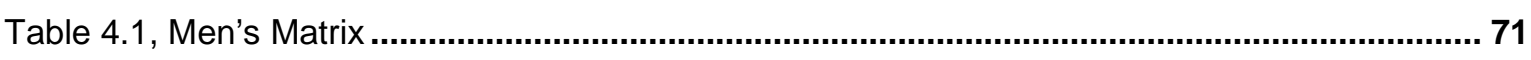

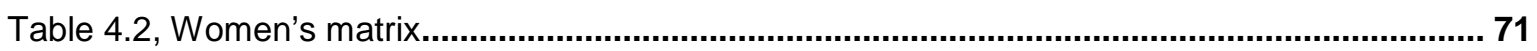

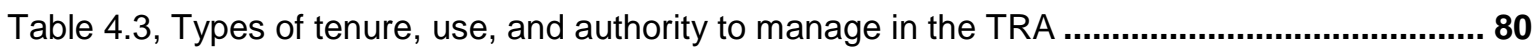

Table 4.4, Select natural resource management practices.......................................................... 83

Table 4.5 Resource use practices and resources affected ...........................................................90 


\section{Figures}

Figure 2.1, Multiple equilibria of intra-community cooperation (Kahan, 2002, p.5)......................... 13

Figure 2.2, Heterogeneity of collective action dispositions (Kahan, 2002, p.10) ........................... 14

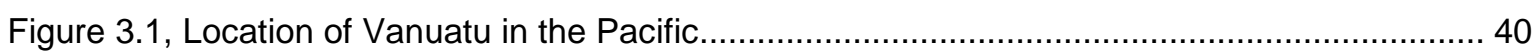

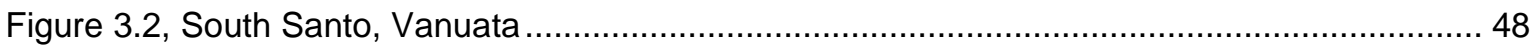

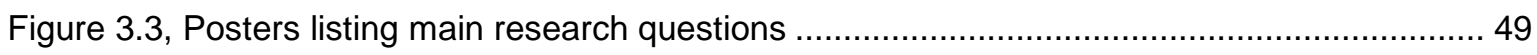

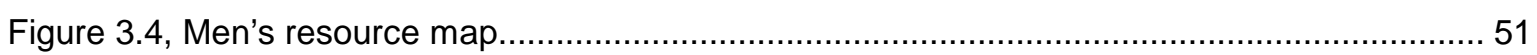

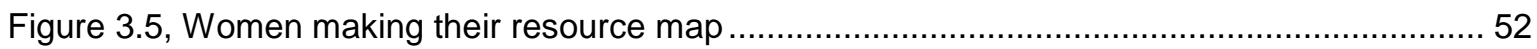

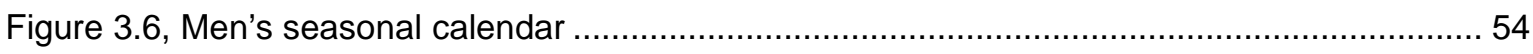

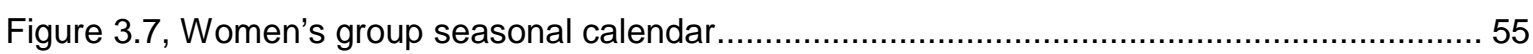

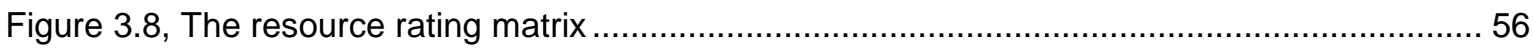

Figure 4.1, Boundaries of the Tangoa resource area shown on a men's resource map................ 68

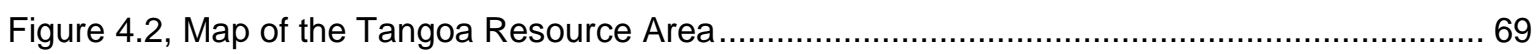

Figure 4.3, Map showing tenure types within the Tangoa Resource Area ................................... 77

Figure 4.4, Social map of Tangoa Island showing clan areas (made by three men) ....................... 78

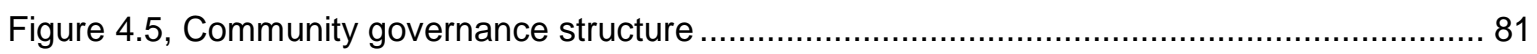

Figure 4.6, Focus group poster (mixed gender) "What destroys the dark-bush: logging" ............... 84

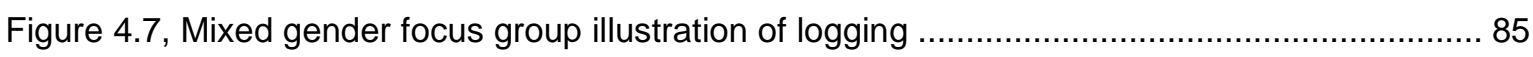

Figure 4.8, Trend analysis of the abundance of wild animals by two informants........................... 86

Figure 4.9, Women's focus group poster illustrating degradation of marine resources:

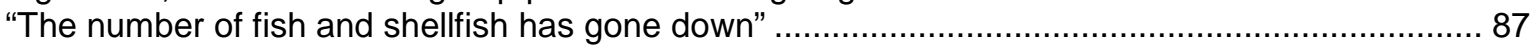

Figure 4.10, Trend analysis of change in fish stocks (by an old fisherman (black line) and a young fisherman (blue line)

Figure 4.11 Mixed gender focus group poster identifying causes of marine resource degradation.

Figure 4.12, Mixed gender focus group poster identifying causes of fresh water resource degradation: Buluk (cattle); Katem wut (cutting wood); mining; wasem klos (washing clothes)...... 90

Figure 4.13 Women's focus group problems analysis ("The population is too high, many

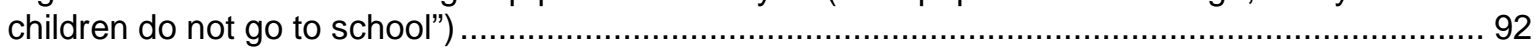

Figure 4.14, Women's seasonal calendar - showing activities for January and February............... 94

Figure 4.15, Estimate family expenses for households in the Sanma province

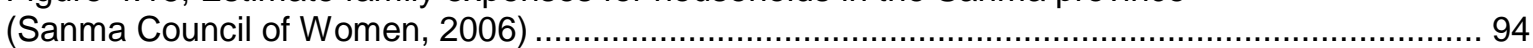

Figure 4.16, Trend line of need for cash for the Tangoa community over time ........................... 96

Figure 4.17, Illustration of diminishing land resources per family ................................................ 96

Figure 4.18, Women's group poster identifying issue of increasing land use intensity................... 97

Figure 4.19, Mixed gender focus group poster identifying environmental threats .......................... 98

Figure 4.20, Flow of food and money after a cyclone for families with gardens and families

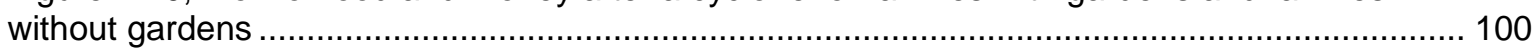

Figure 4.23, Drivers of economic pressures, local strategies and constraints............................ 106 
Figure 4.24, Youth group poster identifying the involvement of leaders in land disputes 110

Figure 4.25, Trend analysis of use of customary medicine ................................................... 112

Figure 4.26, Drivers of governance issues, local strategies and constraints .............................. 116

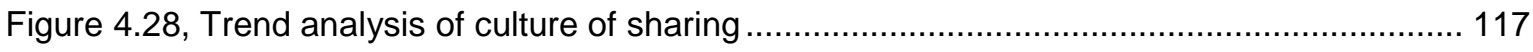

Figure 4.29, Women's group poster identifying social conflict ("raurau") as main community problem .

Figure 4.30, Women's group poster identifying link between land disputes, social conflict, selfishness, and lack of trust

Figure 4.31, Youth group poster identifying main community groups.

Figure 4.32, Women's group poster identifying main leaders 126

Figure 4.33, Women's ideas about the process required to help the community "work together" 127

Figure 4.34, Drivers of social cohesion problems, and locally identified strategy. 129

Figure 5.1, Population increase from 1999-2006 for Vanuatu, the provinces, and Tangoa 132

Figure 5.2, Comparison of garden land and coconut endowments between Vanuatu and Tangoa. (Data from NSO, 2006; and Tangoa key informants and local population census) ........ 134

Figure 6.1 Model of community cooperative capacity for Tangoa, Vanuatu. 144

Table 6.1 Global level, national level and local level factors that influence community cooperative capacity

Figure 6.2, Model of cooperative capacity for local commons management in Vanuatu.......... 146

Figure 6.3, Feedback loops between social cohesion, economic pressures and socioeconomic heterogeneity

Figure 6.4, Feedback loop between governance problems, conflict and social cohesion 154

Figure 6.6, The relationship between resource degradation, cash dependency and livelihood vulnerability.

Figure 6.7, Relationship between resource degradation, loss of TEK and livelihood vulnerability. 158 


\section{Chapter 1 - Introduction}

\subsection{The Big Picture: Sustainable resource management in collective property regimes}

Just as people are dependent on natural resources for their livelihoods, they are also dependent on each others' cooperation for natural resource management. For as long as people have managed natural resources, they have engaged in forms of collective action, collaborating on management of farm, forest, grassland, and aquatic resources.

Collective action is particularly important for "common pool resources" also referred to as "commons resources", which are communally used and managed by a group of owners under common property regimes. The term "common property regime" (CPR) represents a set of institutions, regulations and management practices subject to collective-decision-making. ${ }^{1}$ It is the common property regime that distinguishes commons resources from open access resources, which are unregulated and free for anyone to use (Adhikari, 2001). This thesis is about how communities cooperate, and take collective action to manage their natural resources.

Collective action is the basis for management of commons resources around the world. The term "collective action" can refer to people working together or participating in activities for the purpose of producing collective or shared benefits (Garcia et al., 2006, p. 83). The sustainability of shared resources is dependent on the cooperation of local people who communally use and manage them.

\footnotetext{
${ }^{1}$ The term common property refers to the kind of tenure that exists, not the resource itself (Fuys et al., 2006). Common property is said to be similar to private property in a sense that there is exclusion of nonowners (Adhikari, 2001). Common property regimes are also distinct from (but related to) communal tenure, which refers more broadly to community-based tenure systems, in which some form of customary authority (e.g. and extended family, clan or other social grouping) holds allocation rights. Resources under communal tenure may, in practice, be used and controlled individually or collectively. Common property can take up a large share of communal lands (Fuys et al., 2006).
} 
The importance of collective action for commons management may be increasing. Many countries around the world are implementing policies of decentralisation, where control over natural resources is shifted from governments to local resource users (Agrawal, 2003). In fact, a global survey of forest policies (FAO, 1999) reported that governments in over 50 countries claim to be decentralising control over forest resources, placing the onus on local people to manage them.

Common property resources provide essential ecological services, as well as sustaining millions of commons resource dependent livelihoods (Beck and Nesmith, 2001; Adhikari, 2005; Fuys et al., 2006). Access to natural resources through common property regimes has been shown to sustain and enhance the livelihoods of the rural poor, by fulfilling subsistence and commercial needs. Common property regimes also often act as a resource safety net for vulnerable households during difficult times. They are especially important for those who might be excluded from land and resources if the commons were individualised (Fuys et al. 2006). For example, in many parts of the world where women are not able to own land and resources or only have secondary access through their husbands, access through common property regimes provides essential livelihood security (Ibid).

\subsection{The issue}

Collective action problems are a major barrier to sustainable natural resource management. Failure to overcome collective action problems contributes to the degradation and destruction of natural resources in many parts of the world. At the community level, collective action problems prevent the sustainable use and development of the communities' natural resources. When people are unable to work together and equitably share the benefits from their cooperation, the common property resources may be treated as open access where use is unregulated. Open access results from the absence or breakdown of management and authority systems (Adhikari, 2001). In these situations the incentives described by Hardin's (1968) "tragedy of the commons" are at work. People 
may harvest unsustainably and/or sell resource rights (e.g. to logging companies) to gain benefits before anyone else does. ${ }^{2}$

\subsection{The topic}

This thesis studies commons management in Vanuatu, and focuses on one community in particular. The study has been designed to align with the current emphasis of commons research on finding appropriate solutions to context specific commons management problems.

The research for this study is in three parts: a literature review; a community case study; and resource management research at a national level. The research results are analysed to determine the factors that affect one particular community's management of shared resources. A case study of the Tangoa community of South Santo, Vanuatu specifically explores the factors that affect collective action for commons management in this setting. The purpose of this study is not to hypothesise about preconceived determinants, but to allow the important determining factors to emerge from participatory research with the Tangoa community. Context specificity is further explored by looking at how widely other communities in Vanuatu experience the same issues. Vanuatu based literature and interviews with government, NGOs, and aid donors provide information about the wider Vanuatu context.

Like most commons research, my study is also concerned with using the understanding gained from analysis of local commons management problems to identify solutions and opportunities to support more sustainable and effective management.

\subsection{Purpose and objectives}

The purpose of this thesis is: to determine the locally identified issues affecting the Tangoa Island community's management of common pool resources; to put the case study results into the wider Vanuatu context; and to identify

\footnotetext{
${ }^{2}$ In an open access situation, over harvesting and resource degradation is common, and as individuals cannot capture the benefits of investments in resources - investment in any kind of development is very low (Adhikari, 2001).
} 
opportunities for supporting communities to overcome commons management problems.

This purpose can be broken down into four main objectives in the form of questions to be answered:

1. What are the important factors that affect local level commons management?

2. What are the locally identified factors that affect the ability of the Tangoa community in South Santo, Vanuatu, to manage their commons resources?

3. How widely relevant are the case study findings for other Vanuatu communities?

4. How can information from the case study and wider Vanuatu based research inform how external assistance (from NGOs, donor organisations, researchers, and government) can support sustainable commons management in Vanuatu?

\subsection{Thesis structure}

Chapter two addresses the first objective by reviewing the literature on common property resource management. An overview of collective action theory is provided, and factors that affect local communities' ability to sustainably manage common pool resources are identified.

Chapter three describes the methodology for this study and the reasons for using a case study, grounded theory, and participatory research. An introduction to Vanuatu and the case study community provides some essential background information about the history, geography, social, cultural and natural characteristics of the study site. Various methodological issues are outlined and the main research activities are described.

Chapter four and five presents the results in two parts. Chapter four addresses objective two by presenting the case study results. Chapter five addresses objective three by presenting the findings from wider Vanuatu based research. 
This allows analysis of the wider relevance of case study results and the interaction between national policies and community issues.

In Chapter six, I incorporate the results of the literature review, the case study, and the wider Vanuatu research into a model and discuss their significance for local livelihoods. The analysis is used to identify opportunities to support the Tangoa community, and other communities that are experiencing similar issues, to manage their shared resources effectively and sustainably. I highlight potential areas where external support and assistance from NGOs, donor agencies, researchers, and governments could benefit local commons management.

Finally, Chapter seven summarises what I learned from this study and outlines some recommendations for individuals, organisations, government and researchers who are interested in supporting local communities to sustain the social and environmental systems upon which livelihoods depend. 


\section{Chapter 2 - Literature review: the findings of commons research}

Literature has established that commons management is largely dependent on local people's "cooperative capacity" - their ability to act collectively to achieve shared goals, and to solve collective action problems (McCarthy et al., 2002, p7). Empirically informed theory about collective action has been developed, and scholarship has focused on studying the factors that affect local commons management.

This literature review first provides an overview of some basic theories about collective action. Then the key factors that affect collective action for management of commons resources are identified. The review provides information about why the different factors are important for commons management and the discussion highlights areas of agreement and debate in the literature. Since the purpose of this study is to allow the local data to inform what factors are important in the context of the case study community, literature related to the contextually relevant factors identified in this study will be further explored in the discussion chapter.

\subsection{Historical roots of commons research and current aims}

For almost two decades, twentieth century ecologist Garrett Hardin's (1968) theory of the "tragedy of the commons" was the basis for a mainstream understanding of commons management problems. Hardin envisioned a pasture open to all in which each herder received a direct benefit from adding animals to graze on the pasture and suffered only delayed costs from overgrazing. The theory describes how people that are dependant on the use of common-property resources will act "rationally" without restraint to maximise their personal shortterm gain by over exploiting the resource (Hardin, 1968, p. 1244). ${ }^{3}$ Hardin's theory has been used in policy justifications for centralisation and privatisation

\footnotetext{
${ }^{3}$ The intellectual roots of the "tragedy of the commons" argument trace back to Aristotle who noted that "what is common to the greatest number has the least care bestowed upon it" (cited in Ostrom, 1990)
} 
of the commons. Advocates of these policies see local resource users are a major threat to natural resource user systems. They accept, as a central tenet, that institutional change must come from the outside and be imposed on the individuals affected (Ostrom, 1990). ${ }^{4}$

The field of study that we know today as 'commons research' arose as a response to the failures of privatisation and exclusionary conservation, and to meet the pressing need for more empirically based and effective mechanisms to support sustainable management of commons resources (Ostrom, 1990). The focus of commons research has developed, evolved, and influenced policy perspectives concerning natural resource management.

Early research was focused on finding examples and case studies of sustainable and effective locally developed common property resource regimes. A growing body of evidence shows that, in spite of various incentives against cooperation, local resource-user groups often find local solutions to collective dilemmas and devise institutions that manage commons resources and allocate benefits equitably and relatively efficiently over the long term (Ostrom, 1990; Agrawal and Gibson, 1999; Gautam and Shivakoti, 2005; Gibson and Becker, 2000). Evidence not only shows that local institutions can manage natural resources successfully, but also that when resources are privatised or appropriated by the state, traditional users rights are seldom recognised. The result of this is the destruction of traditional entitlements systems and efficient arrangements that have evolved to suit local needs (Baland and Platteau 1996; Maggs and Hoddinott, 1999). Ostrom (1990) provides an example where the imposition of state control of the Nova Scotian fisheries resulted in disruption of local systems of management, conflict between different user groups and government authorities, and acceleration of unsustainable fish harvest.

This research has played an important part in challenging Hardin's longdominant concept and arguments for centralisation and privatisation of the

\footnotetext{
${ }^{4}$ Arguments for an interventionalist state can be traced to Thomas Hobbes (1651) who stated the need for a "leviathan" - a coercive force outside of the individual's psyche that will impose order in society and thus preventing "the war of all against all" (Cited in Ostrom, 1990)
} 
commons. Research has supported a growing focus on conservation and development approaches which see local resource-users as the appropriate locus for interventions and emphasise 'local participation' and 'empowerment' (Mohan and Stokke, 2000). Such an approach includes community-based conservation where "natural resources or biodiversity protection by, for, and with the local community" (Western et al., 1994, p. 7). ${ }^{5}$ Community can be broadly defined as "a group of people who interact directly, frequently and in multifaceted ways" (Bowels and Gintis, 2001, p. 3).

Commons research has now moved away from its original aim of finding a generalised model for solving commons management problems. The new focus is on 'diagnosing' which variables are relevant to particular problems in particular social-ecological systems (Ostrom, 2007). This aim is based on recent consensus in the literature that commons management problems are highly context specific. The key factors that affect one community's ability to manage commons resources at a particular time and place may not be important for a different community, or at a different time and place (Agrawal, 2003; Ostrom, 2007). There is also a recent emphasis on analysing how the wider sociopolitical and economic contextual processes have shaped local situations (Agrawal, 2003). This focus derives from criticisms suggesting that a heavy research focus on local drivers of collective action has resulted in a lack of understanding of the wider context.

\subsection{Collective action theory}

Collective action theory provides a good starting point for understanding the dynamics of cooperation, from which commons management regimes are built. Some well established theory about what affects people's decisions to cooperate is described by Ostrom's (1990) framework of an institutional-choice situation. She uses a general concept of rational choice where people will weigh expected costs and benefits which are affected by their internal norms and discount rates, and select strategies that are expected to result in greater benefit than cost.

\footnotetext{
${ }^{5}$ Although there has been a trend in increasing preference for community-based NRM in mainstream environmental and development discourse, there are still strong arguments for state enforced protected areas (Lovejoy, 2006; Terborgh, 1999), and privitisation of natural resources (Armstrong, 2001).
} 
Ostrom also explains how people adopt contingent strategies, where choices of action are contingent on the actions and behaviors of others. When multiple users of a common-pool resource are dependent on that resource, each user is affected by the actions of others. People will choose to work cooperatively towards sustainable management of common-pool resources under certain conditions (e.g. "I'll do this, if you do that,") and if they expect the long-term benefit of cooperation to be greater than the long-term costs. Game theorists describe this as an equivalent retaliation or "tit for tat" strategy ${ }^{6}$ (Levi, 1988; Ostrom 1990).

Recent theoretical developments have lead to a greater understanding about the processes involved in making contingent strategies related to the cost and benefits of cooperating. Several assumptions underlying Hardin's (1968) Tragedy of the Commons, and Mancur Olson's (1965) Logic of Collective Action, have been revised. The new theoretical understandings are described in Kahan's (2002) "reciprocity theory." The reciprocity theory makes four important contributions to collective action theory. It asserts that:

- $\quad$ People are emotional reciprocators instead of wealth maximisers.

- $\quad$ Trust among people may promote cooperation better than imposed material incentives.

- The rate of cooperation among a group can have multiple equilibria.

- $\quad$ Tendencies towards cooperation vary between individuals in a group.

\subsubsection{People are emotional reciprocators instead of wealth maximisers}

Hardin (1968) and Mancur Olson (1965) assumed that people are, by nature, selfish wealth maximisers, and will choose to free-ride on the contributions of others rather than contributing to public good themselves. These assumptions are challenged by Kahan's reciprocity theory, which draws on evidence from

\footnotetext{
${ }^{6}$ A contingent cooperator is a person or agent who is willing to act in the collective interest, rather than his/her short-term selfish interest, if he/she observes a majority of the other agents in the collective doing the same. 'Tit for tat' is equivalent to the concept of reciprocal altruism in the context of biology (Moore, 1984).
} 
"public good" experiments. These experiments show that people's decisions to act selfishly for personal gain, or cooperatively for the collective good, are highly conditional on what others are doing. Further research into reciprocity theory shows individuals reciprocate the behaviour of others to give (or not give) to charity (Reingen, 1982), to refrain (or not) from littering (Aronson, 1995 and Cialdini et al., 1990), to wait their turn (or not) in lines (Schmitt et al, 1992).

This evidence supports and builds upon Ostrom's idea of contingent strategies, which strengthening understanding that people's decisions are emotionally nuanced and based on individual sense of morals (Ostrom, 1990). When people perceive that others are behaving cooperatively, they are moved by honour and altruism $^{7}$ to contribute to public goods, even without material incentives. In contrast, when individuals perceive that others are taking advantage of them they are moved by resentment and pride to retaliate. They may choose not to cooperate in order to avoid feeling exploited, even if doing so exposes them to significant material disadvantage (Gintis et al., 2005). ${ }^{8}$

\subsubsection{Trust among people may promote cooperation better than imposed material incentives}

There is increased emphasis on the importance of trust as a natural social incentive for cooperation rather than externally imposed material incentives (such as fines, rewards and sanctions) (Ostrom, 2000; Kahan, 2002; Seabright, 1993). Empirical and theoretical work indicates that social interactions between people can build trust, and that people will only accept rules that restrict their involvement in an economically important activity if they trust that others will too (Adhikari and Lovett, 2006; Janssen and Ostrom, 2001). People that share norms that restrain opportunistic behavior and encourage trust will be more able to agree on resource management rule changes, and adopt changes that will be less costly to operate (Ostrom, 1990). This is supported by Seabright's (1993)

\footnotetext{
${ }^{7}$ Altruism can be defined as "a benefit conferred on others at a cost to oneself (Bowles and Gintis, 2001, p.10).

${ }^{8}$ This is supported by "public good" experiments - labouratory constructs designed to simulate collective action problems, as well as empirical studies of real-world behaviour. Individuals have been shown to reciprocate the behaviour of others to give (or not give) to charity, to refrain (or not) from littering, to wait their turn (or not) in lines. For a review of this literature see (Kahan, 2002).
} 
model of 'habit forming' cooperation, which demonstrates that the more people trust in each other, the more they are willing to cooperate with one another. ${ }^{9}$

Kahan (2002) reviews literature from the fields of economics, law, and social policy to show that provision of material incentives can actually have an adverse effect on cooperation. The review showed incentives such as fines result in: increased abuse of day care centre rules by parents (Gneezy and Rustichini, 2000a); decreased performance of individuals soliciting charitable donations (Gneezy and Rustichini, 2000b); and suppressed donations of blood (Titmuss, 1971). These studies show that the existence of an incentive scheme can be seen as a cue that other individuals are not inclined to cooperate voluntarily. If they were, incentives would not be necessary. This inference can, in turn, trigger people to withhold voluntary cooperation. In addition, incentives can mask voluntary contributions to public goods, thereby diluting the power of such contributions to trigger reciprocal cooperation. Incentives can also crowd out dispositions such as altruism by denying the opportunity of individuals to demonstrate (to themselves and others) that they are willing to sacrifice material gain for the public good (Kahan, 2002).

Material incentives do not always have a negative effect on cooperation or contribution to a public good. Rather, the effect is contextually variable. Imposed incentives are most likely to have a negative effect when trust - the belief that most people are likely to contribute voluntarily - already exists within a group. Then material incentives can result in cueing, masking and crowding out such trust (Kahan, 2002). However if there is not a great deal of trust within a group, and most people believe that others are likely to free-ride, then rewards or penalties may be needed to more strongly enforce cooperation in order to positively change people's impression of the willingness of others to cooperate (Kahan, 2002).

\footnotetext{
${ }^{9}$ A core aspect of most definitions of "trust" is the "intention to accept vulnerability based upon positive expectations of the intentions of the behaviour of another" (Rousseau et al., 1998). Trust is affected by the amount of information people have about each other, the likelihood that they will be interacting with one another in the future, the identity and similarities between individuals involved (Janssen and Ostrom, 2001).
} 


\subsubsection{The rate of cooperation among a group can have multiple equilibria}

Previously, it was assumed that among a particular group of social actors a single equilibrium exists where cooperation is at a relatively stable state, and that this equilibrium could be upset when compliance drops to a level that triggers a domino effect of rule breaking (Levi, 1988). ${ }^{10}$ Kahan's reciprocity theory, on the other hand, explains that the interdependent and contingent nature of individual choice tends to generate patterns of multiple equilibria punctuated by tipping points. If people in a collective action setting perceive that around half of the other people involved will contribute to a public good, then about half will chose to contribute also. However as Fig. 2.1 shows, this middle equilibrium is unstable and can be tipped to start a chain reaction of positive or negative contribution. If more than half of a group, say $60 \%$, decided to contribute, then even more people will be willing to contribute (70\%), and contributions will increase until a high cooperation equilibrium is reached (top right corner of graph). Similarly, if less than half cooperate, a process of declining cooperation is triggered, and will continue until it reaches a low cooperation equilibrium (bottom left corner).

\footnotetext{
${ }^{10}$ The critical compliance rate will differ from one setting to the next and over time - depending on the socio-economic and environmental circumstances. For an example, people may be more tolerant of rule breaking during a depression as long as the higher rate is temporary and will not destroy the survival of the CPR (Ostrom, 1990).
} 


\section{Multiple Equilibria and Tipping Points}

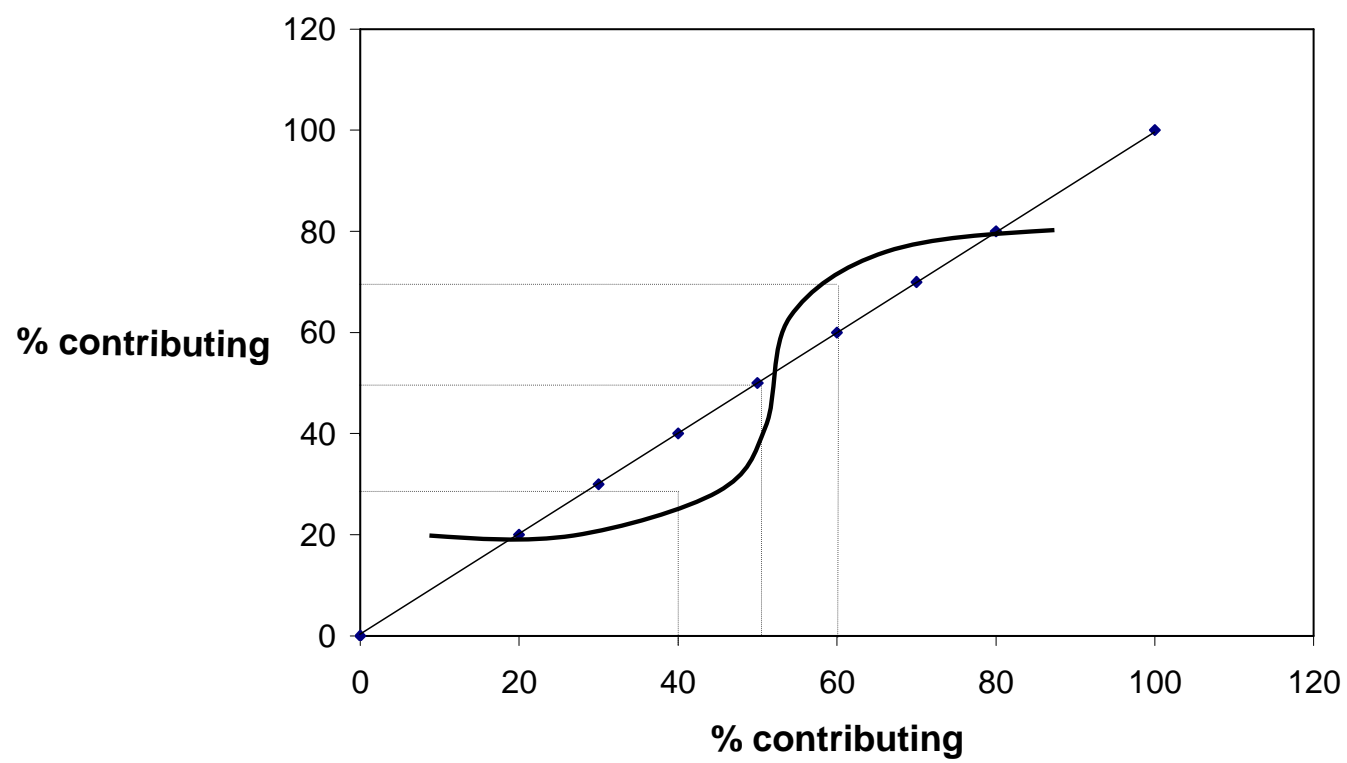

Figure 2.1, Multiple equilibria of intra-community cooperation (adapted from Kahan, 2002, p.5).

\subsubsection{Tendencies towards cooperation vary between individuals in a group}

Hardin (1968) and Olson (1965) assume that the disposition to act self interestedly and free-ride is relatively uniform throughout a group. The reciprocity theory suggests that the disposition to cooperate varies across a population. A small number of people are likely to be "committed free-riders" who shirk no matter what anyone else does. Another small amount of people are likely to be "dedicated cooperators" who contribute no matter what (Kahan, 2002, p.9). Some people may be quite intolerant, defecting as soon as they see anyone free-riding. Others are more tolerant, continuing to contribute even when they see a relatively modest degree of defection. A large proportion of people, termed by Kahan, (2002, p.9) "neutral reciprocators," fall somewhere in between. The distribution of preferences to cooperate within a community is illustrated in Fig. 2.2 below. 


\section{Heterogeneity of Collective Action Dispositions}

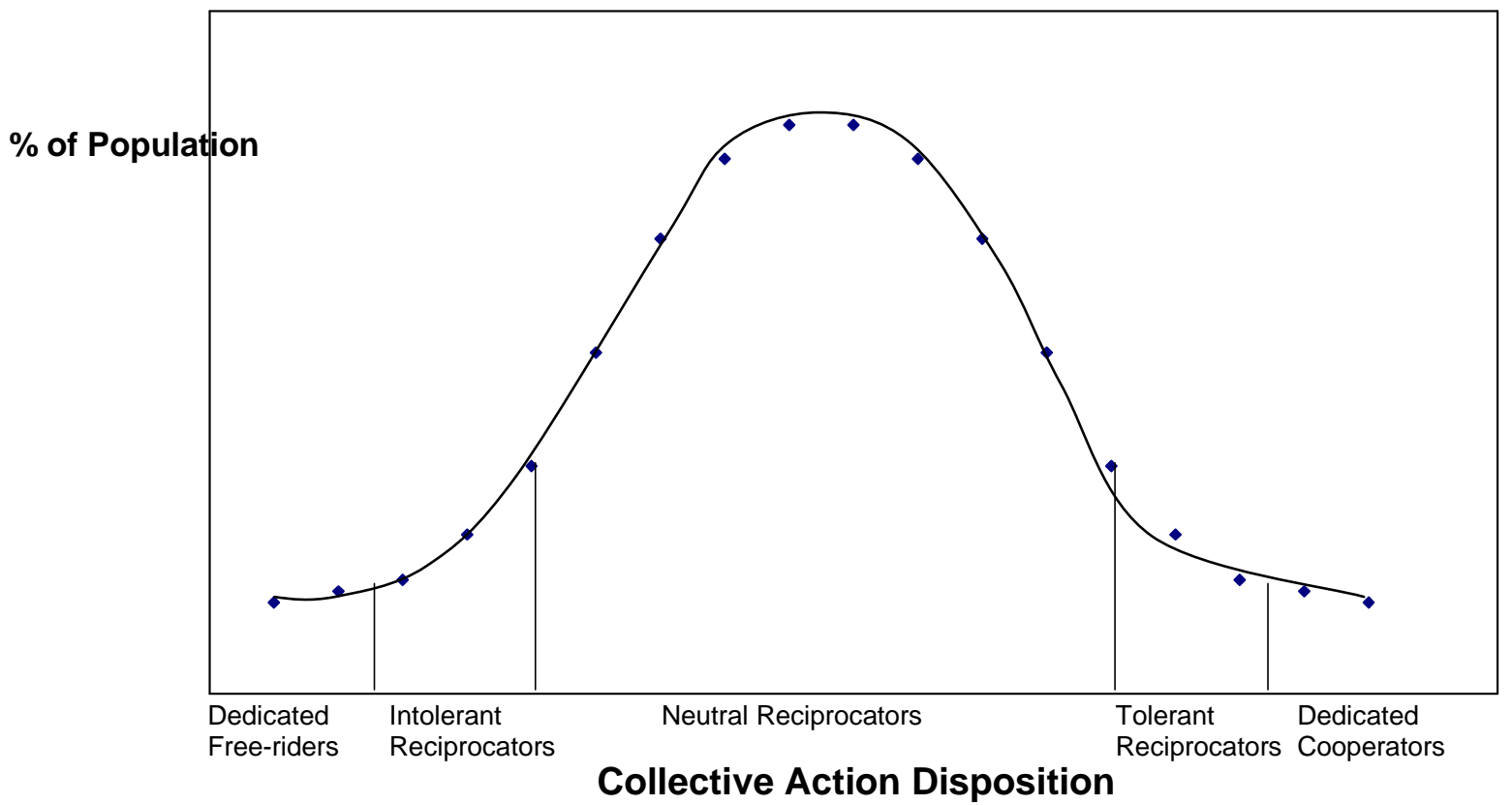

Figure 2.2, Heterogeneity of collective action dispositions (adapted from Kahan, 2002, p.10)

Understanding how dispositions towards cooperation vary indicates the importance of "appropriately tailored incentives" (Kahan, 2002, p.11) such as penalties that specifically target persistent free-riders. These people are the biggest threat to cooperation because their non-cooperative behaviour is likely to affect the less tolerant reciprocators whose decision not to cooperate may prompt even the neutral reciprocators to stop cooperating. The existence of penalties that can push the persistent free-riders into line will assure the less tolerant reciprocators that their cooperation will not be exploited. Because people are generally aware (from social experience) that there are some committed free-riders out there, penalties aimed at these types do not create the cuing, masking, or crowding out effects associated with more generalised incentive regimes (Kahan, 2002).

The concept of appropriate incentives can be seen in studies of campaigns against tax evasion. The most successful campaigns against tax evasion are those that balance the information that most people pay their taxes, and that only a few do not, and are punished for it (Cowell, 1990; Adreoni et al, 1998). The least successful campaigns are those that communicate there is a problem with tax 
evasion, suggesting there is a strong norm not to comply and therefore encouraging others to not comply (ibid).

\subsection{Important factors affecting commons management}

The theory of collective action discussed above provides the basis for understanding this topic. This section will outline the important factors that affect local community cooperation for commons management, and the effectiveness of local commons institutions. Agrawal (2001) synthesises what he considers to be the three most significant analyses of local, community-based efforts to manage common-pool resources. The works of Baland and Platteau (1996), Ostrom (1990), and Wade (1988) are comprehensive attempts to provide theoretically informed generalisations about the conditions under which groups of self-organised resource users are successful in managing their common resources. ${ }^{11}$ Each author arrives at a summary set of conditions and conclusions believed to be critical to successful commons institutions. "Success" can be generalised across the three works as the ability of institutions to sustain common-pool resources and to sustain resource user compliance to management rules (Agrawal, 2003). ${ }^{12}$

Collectively, the three works identify 24 different factors that affect successful management of the commons. Much of the more recent literature has challenged and built upon the conclusions of these works (Agrawal, 2003; Gautam and Shivakoti, 2005). ${ }^{13}$ Table 2.1 provides a full list of variables identified in the

\footnotetext{
${ }^{11}$ Wade (1988) uses primary data from his studies of 31 South Indian Villages to examine when institutions arise in these villages and what makes them successful in resolving commons dilemmas. Ostrom (1990) analyses 14 detailed studies that others have generated - examining each case using the same set of variables to look at where resource users attempted, with varying degrees of success, to build, adapt, and sustain institutions to manage the commons. Baland and Platteau (1996) use a wide ranging review of economic literature on property rights and use a variety of different case studies with no specific model or set of variables.

${ }^{12}$ Wade (1994, p.215) is concerned with institutions "success in resolving commons dilemmas." Ostrom (1990, p. 90) looks for 'design principles' which account for "the success of institutions in sustaining the common pool resources and gaining compliance of generation after generation of appropriators to the rules in use." Baland and Platteau (1996 p.343) consider successful institutions those which "achieve cooperation for the sustainable management of natural resources."

${ }^{13}$ Gautam and Shivakoti (2005) have studied the role of local institutions in forest management assessing whether Ostrom's design principles are applicable in common pool forest management. They ask two key questions including: what roles the local institutions play in determining condition of a forest, and how to evaluate the institutional robustness of a local forest governance system.
} 
works of Baland and Platteau (1996), Ostrom (1990), and Wade (1988). The important factors identified in the three works are organised under four broad categories including: resource system characteristics; group characteristics; institutional arrangements; and external environment (Agrawal, 2003). Each of these four categories will be explained in more detail in the remainder of this section. 
Table 2.1, Critical factors enabling sustainability of the commons (adapted from Agrawal, 2003)

Abbreviations: Wade (1994) - RW, Ostrom (1990) - EO, and Baland and Platteau (1996) - BandP. (Table adapted from Agrawal, 2003)

1) Resource system characteristics

i) Small size (RW)

ii) Well-defined boundaries (RW, EO)

iii) Low levels of mobility

iv) Possibilities of storage of benefits from the resource

v) Predictability

2) Group characteristics

i) Small size (RW, BandP)

ii) Clearly defined boundaries (RW, EO)

iii) Shared norms (BandP)

iv) Past successful experiences-social capital (RW, BandP)

v) Appropriate leadership_-young, familiar with changing external environments, connected to local traditional elite (BandP)

vi) Interdependence among group members (RW, BandP)

vii) Heterogeneity of endowments, homogeneity of identities and interests (BandP)

viii) Low levels of poverty

(1 and 2) Relationship between resource system characteristics and group characteristics

i) Overlap between user-group residential location and resource location (RW, BandP)

ii) High levels of dependence by group members on resource system (RW)

iii) Fairness in allocation of benefits from common resources (BandP)

iv) Low levels of user demand

v) Gradual change in levels of demand

3) Institutional arrangements

i) Rules are simple and easy to understand (BandP)

ii) Locally devised access and management rules (RW, EO, BandP)

iii) Ease in enforcement of rules (RW, EO, BandP)

iv) Graduated sanctions (RW, EO)

v) Availability of low-cost adjudication (EO)

vi) Accountability of monitors and other officials to users (EO, BandP)

(1 and 3) Relationship between resource system and institutional arrangements

i) Match restrictions on harvests to regeneration of resources (RW, EO)

4) External environment

i) Technology

a) Low-cost exclusion technology (RW)

b) Time for adaptation to new technologies related to the commons

ii) Low levels of articulation with external markets

iii) Gradual change in articulation with external markets

iv) State
a) Central governments should not undermine local authority (RW, EO)
b) Supportive external sanctioning institutions (BandP)
c) Appropriate levels of external aid to compensate local users for conservation activities (BandP)
d) Nested levels of appropriation, provision, enforcement, governance (EO) 


\subsubsection{Resource system characteristics}

Characteristics of a resource system that studies show to be conducive to sustainable management include small size, well-defined boundaries, low levels of mobility, possibilities for storage of benefits from the resource, and predictability. Large resource systems are often more difficult to monitor and manage, which raises the cost of management (Wade, 1994). Clarity of resource system boundaries improves collective understanding of where (in the landscape) management responsibly starts and ends (Ostrom, 1990; Wade, 1994). Clear boundaries can enable greater certainty and authority to exclude outsiders, which is often essential for effective commons management regimes (Fuys et al., 2006; Ostrom, 1990).

Information about the condition of the resource and how the flow of benefits from it might change in the future is needed for people to make to contingent strategies to cooperate with management rules (Ostrom, 1990). Incentives to invest in management will be low if people are uncertain about whether restriction on resource-use is really necessary, and whether it will secure future benefits (Gibson and Becker, 2000). Information is also needed in order to determine how the resource can be sustained (i.e. appropriate harvest rates). The cost of obtaining accurate information can be a major barrier to collective action (Ostrom 1990). ${ }^{14}$

Costs of obtaining information can vary depending on the mobility and predictability of the resource system (Agrawal, 2003). If the resource units are highly mobile (e.g. migratory fish), the costs of obtaining information about resource scarcity and abundance are likely to be higher than when there are low levels of mobility (ibid). Predictability of the resource system can determine the difficulty that resource users face in creating, sustaining and adapting resource management systems that will ensure sustainability (ibid).

\footnotetext{
${ }^{14}$ Game theorists use 'assurance games' to illustrate how coordination for natural resource management becomes difficult, despite common goals, when there is a lack of information about the resource systems and the social environment (Poteete and Ostrom, 2004).
} 


\subsubsection{Group characteristics}

Characteristics of the resource user group that are considered favorable for sustainable commons management include: clarity of group membership; shared norms; social capital built on past successful experiences; appropriate leadership; and interdependence among group members (Agrawal, 2003; Ostrom 1990; Wade, 1994; Baland and Plateau, 1996). Group size, various forms of intra-community heterogeneity, and poverty are also widely recognised as important factors that affect commons management. However, conflicting evidence about these last three factors has lead to debate about their effect.

\section{Clarity of group membership}

Just as the resource system needs to be clearly defined for sustainable management, the resource user group must also be defined. A shared understanding of who has access and use rights and what rules apply to whom is essential to prevent commons resources from becoming open access resources (where there are no rules to manage resources) (Wade 1994; Ostrom 1990).

\section{Shared norms}

People that share norms that restrain opportunistic behavior and encourage trust will be more able to agree on resource management rule changes, and adopt changes that will be less costly to operate (Ostrom, 1990). Shared norms can be identified in two ways. One way is to study how groups function. This may include looking at the structure of communication within and between different people and groups. The second is to study how people interact with each other looking at such things as norms of politeness and how people show respect (Plummer and Fitzgibbon, 2006).

Shared norms arise where people that have a shared past and expect to have a shared future, where they live side by side and use the same resource area, and where they expect that their resources will have to sustain the livelihoods of their children and grandchildren. In these situations it is often important for people to share social norms that help them to maintain good relationships and 
to maintain their reputations as reliable members of the community (Gibson and Becker, 2000; Ostrom, 1990).

\section{Social capital}

Many studies show that social capital is an essential factor in the capacity for collective action in the context of commons management (Krishna, 2003; Plummer and Fitzgibbon; 2006; Ostrom and Ahn, 2003; Pretty et al., 2004). Social capital is the "quality of human relations within some well-defined social group that enables members of this group to act in cooperation with one another for achieving mutual benefits" (Krishna, 2003). More formally, it is defined as "networks together with shared norms, values and understandings that facilitate cooperation within or among groups" (OECD, 2001, p. 41). ${ }^{15}$

Four important features of social capital assist in cooperation for commons management including: relations of trust; reciprocity and exchanges; common rules, norms, and sanctions, and connectedness in networks and groups (Pretty and Ward, 2001). In simple terms, reciprocity can be considered the exchange between individuals for mutual benefit (Plummer and Fitzgibbon, 2006). Specific reciprocity refers to simultaneous exchanges of goods and knowledge of roughly equal value. Diffuse reciprocity refers to a continued relationship of exchange that is eventually repaid (Pretty et al., 2003). Common rules, norms, and sanctions are the mutually agreed upon or handed-down norms of behavior that ensure a group's interests are complimentary with those of individuals (ibid).

Social capital is classified in various ways. Social capital can be "institutional" based on transactions governed by roles, rules, procedures, and organisations; or "relational" - governed by norms, values, attitudes, and beliefs (Westermann et al., 2005). Commonly, there are considered to be three kinds of social capital defined by the important connections people have in networks within, between,

\footnotetext{
${ }^{15}$ Other definitions include: "features of social organization such as networks, norms and social trust that facilitate cooperation and coordination for mutual benefit." (Putnam 1995, p67).
} 
and beyond communities. These include bonding, bridging and linking types of social capital (Woolcock, 2001).

Bonding social capital describes the close association among people such as friends or members of a particular sub-group, who are likely to have similar outlooks and objectives (Plummer and Fitzgibbon, 2006). Strong bonding social capital includes stocks of trust, shared norms, values, attitudes, and beliefs which provide the incentives to cooperate and maintain positive social relationships (Westermann et al., 2005). Bridging social capital describes the capacity of people to develop relationships between individuals of greater social distance such as colleagues or other community members, who may have quite different views (Plummer and Fitzgibbon, 2006; Pretty and Smith, 2004). Linking social capital describes the ability of groups to engage vertically with external agencies, either to influence their policies or to draw on useful resources (Plummer and Fitzgibbon, 2006; Pretty and Smith, 2004).

\section{Appropriate leadership}

Baland and Platteau (1996) emphasise that often the most appropriate leaders are young and familiar with the changing external environment, as well as connected with local traditional elites. They explain that leadership should enable change and adaptation to address modern issues as well as sustaining the benefits of traditional authorities. This is supported by Krishna's (2003) study of 69 north Indian village communities. Is the study, the presence of a new set of young village leaders, termed 'village agents" ${ }^{16}$ enabled the relative success of some villages in comparison with others in terms of development performance ${ }^{17}$ and commons management. These village agents characteristically have relatively high literacy and other types of skills and knowledge that assist their communities. For example, they know what programs are available with state agencies, what market opportunities exist, and they can connect with these external resources and opportunities.

\footnotetext{
16 "Village agents" are defined according to Sen's (1999: 18-19) understanding of agent as "someone who acts and brings about change, and whose achievements can be judged in terms of their on values and objectives, whether or not we asses them in terms of some external criteria as well.")

${ }^{17}$ Development performance was measured by factors such as livelihood stability, poverty assistance, employment generation and quality of basic services (Krishna, 2003)
} 


\section{Interdependence among group members}

People are most likely to act cooperatively when they are highly interdependent and socially connected. This means they are reliant on each-other for economic activities, daily social support, and for solidarity in times of emergency or extreme need (Wade, 1994; Baland and Plateau, 1996, Garcia et al., 2006). A study by Garcia et al. (2006) about prosocial behavior in Bolivian Amazonian communities shows that bonding social capital is usually strong and resilient in socially and economically interdependent groups. Interdependence results in low discount rates on future returns of cooperation (Garcia et al., 2006). Commitment to collective action for sustainable resource management is, in economic terms, associated with low discount rates (Ostrom, 1990). Discount rates are a measure of how much the value or benefit of a choice/action/investment is expected to decrease in the future.

\section{Group size}

Group size is defined as "the number of individuals in a group that could engage in collective action" (Poteete and Ostrom, 2004a, p444). This is one of the characteristics where conflicting evidence leads to debate about the effect of group size on commons management. Some studies show that increasing group size has a negative effect on collective action. Scholars explain that small groups encourage social interaction, trust, reputations, and social norms (Bowles and Gintis, 2001). ${ }^{18}$ Opportunities for frequent social interaction increase as the group size decreases, and frequent interactions create opportunities to build reputations. Reputations offer a sense of predictability which can be useful for people trying to decide on contingent strategies and whether to cooperate with management rules (Ostrom, 1990).

Group size also affects people's perceptions of how much difference their contribution is going to make to the collective outcome, which affects incentives

\footnotetext{
${ }^{18}$ The importance of group size for the building of social norms has been argued by scholars of the commons since Mancur Olson's seminal work The logic of Collective Action in which he states 'social pressure and social incentives operate only in groups of smaller size, in the groups so small that the members can have face-to-face contact with one another' (Olsen, 1965: 62)
} 
to contribute. Perception that contributions are important often decline as group size increases (Poteete and Ostrom, 2004). Furthermore, transaction costs of management increase with group size, as it becomes increasingly difficult to organise greater numbers of people (Poteete and Ostrom, 2004). And finally, small groups are expected to be more homogenous in terms of natural resource management (NRM) interests. Many studies have found that homogeneity in NRM interests is conducive to cooperation (Adhikari, 2005; Adhikari and Lovett, 2006; Cooke, 2000; Kant, 2000; Mearns and Scoones 1999; Poteete, and Ostrom, 2004a).

Other studies show that larger groups are better able to manage commons resources as they have more resources to draw from than smaller groups (Agrawal, 2003; Nagendra et al., 2003). This means that the individual contribution needed to provide collective goods decreases as the size of the group increases (Sandler, 1992: pp49-51). This is supported by evidence from Nepal which shows that higher population concentrations facilitate greater human and financial resource mobilisation for management and monitoring of forest commons (Nagendra et al., 2003). A study of twenty-eight village councils involved in community forest management in the Kumaon Hills in India shows that resource mobilisation (measured in total budgets and per household contribution) is inhibited when the group size is too small, or too big $^{19}$ (Agrawal and Goyle, 2001; Varughese, 2000).

\section{Heterogeneity of endowments and homogeneity of identities and interests}

The effect of intra-community heterogeneity on commons management is complicated and subject to debate. Research has shown that different types of heterogeneity affect the sustainability, equity, and efficiency of commons management. This has helped to dismantle outdated assumptions underlying the concept of "community" and of the concept that there exists (or once existed) a natural state of equilibrium and harmony in the relationship between resource

\footnotetext{
${ }^{19}$ Across the councils (which have memberships that range from 10 to 175 households), those with sixtyone to eighty households made the highest resource contributions to management of forests. These figures drop off sharply for smaller and larger villages (Agrawal and Goyle, 2001)
} 
dependent communities and the natural environment (Agrawal and Gibson, 1999; Leach et al, 1999). ${ }^{20}$ Factors such as ethnicity, gender, age, origins, caste, religion, wealth, occupation, location relative to resource-use areas, reliance on the resource system, and patterns of resource use, divide and crosscut "community" (Poteete, and Ostrom, 2004b). Velded (2000) specifies the diversity of forms of heterogeneity by identifying five variables including: heterogeneity in endowments; political heterogeneity; wealth and entitlements; cultural heterogeneity; and economic interests.

Baland and Platteau (2000) assert that heterogeneity of endowments can be a trigger for collective action. They build from the work of Mancur Olsen (1965) who hypothesised that those with more endowments usually have the most economic interests in collective action, and therefore will often pay the start-up costs to initiate it. Baland and Platteau (1997) explain that those with less interests or ability to contribute to the costs of collective action will, nevertheless, cooperate because they can free-ride on the contributions of others. Molinas (1998 p. 421) explains that voluntary contributions from some help to raise everybody's expectations about the likely aggregate level of co-operation: "The existence of organisational entrepreneurs may signal to the rest of the community adequate interest and may act as a catalyst for other's cooperative behavior." In a study of 104 local peasant committees in a poorer region of Paraguay, Molinas finds that in "highly equal communities a coordination problem may arise among peasants because nobody has a differentiated incentive to be the committee's organiser" (1998, p. 420).

Whereas some argue that heterogeneity of endowments may encourage cooperation for NRM, others argue that endowment disparities are associated with heterogeneity of NRM interests, which has a negative effect on commons management (Adhikari and Lovett, 2006). Divergent interests are often associated with wealth and income disparities which result from heterogeneity in

\footnotetext{
${ }^{20}$ Those concerned with heterogeneity criticise conceptualisations of a "community" as a cohesive social unit or closed social system where people are united by culture, morals, common interests and mutual dependence derive. This image of a community comes from early theories in the fields of sociology and anthropology and can still be found in literature about community based natural resource management today (Agrawal and Gibson, 1999; Leach et al, 1999).
} 
resource endowments and entitlements (Kurian and Dietz, 2004; Leach et al., 1999). ${ }^{21}$

Some specific studies that illustrate commons management problems associated with divergent NRM interests include:

- farmer-managed irrigation systems in Mexico (Dayton-Johnson, 1998), and in Haryana, India (Kurian and Dietz, 2004);

- maintaining community-managed irrigation canals in India (Bardhan, 2000);

- community forestry management in Nepal (Richards et al, 1998; Adhikari and Lovett, 2006);

- capacity for collective action of forest councils (the Van Panchayat system) for the management of pine forests in the Kumaun and Garhwal regions, Northern India (Somanathan et al, 2002).

\footnotetext{
${ }^{21}$ Endowments, are "the rights and resources that social actors have," (for example, environmental goods, land, labour, and skills). Resource entitlements are the legitimate and effective command over these resources. Entitlements enhance people's capacity to use their endowments e.g. customary forest access rights allow people to gather fuel wood (Leach et al, 1999, p233; Gasper, 1993).
} 
These studies highlighted that divergent interests are problematic because they can:

- be a barrier to developing shared NRM goals as those with divergent interests compete to have their interests prioritised in management regimes;

- $\quad$ create and exacerbate NRM cost-benefit distribution issues; ${ }^{22}$

- $\quad$ negatively affect trust;

- increase transaction costs of processes aimed at accommodating diverse interests (Adhikari and Lovett, 2002; Zak and Knack, 2001); and

- lead to conflict about how resources are used, which has a negative effect on cooperation generally (Buckles and Rusnak, 1999). ${ }^{23}$

\section{Poverty}

There is considerable debate about the effect of poverty on commons management. Some argue that poverty is positively correlated with environmental destruction and that economic development is the means for improved natural resource management. Grossman and Krueger's (1991) environmental Kuznets curve $(\mathrm{EKC})^{24}$ is a hypothesised relationship of various indicators of environmental degradation (mostly pollutant emissions) and income per capita. The EKC shows that in early stages of economic growth, degradation and pollution increase, but that when incomes reach a certain level, environmental management improves. In the early 1990's the EKC strengthened an argument that the path of economic development need not be impeded by environmental concerns (Stern, 2004). ${ }^{25}$

\footnotetext{
${ }^{22}$ Game theorists use "Chicken games" describe how if multiple solutions to resource management exist but have different distributions consequences, competition over distributional issues (distribution of the costs and benefits of management activities) often inhibit cooperation (Poteete and Ostrom, 2004b). ${ }^{23}$ There are different types of NRM related conflict. Some may be minor conflicts about the routine working of the management rules. Some may be more serious - with the potential to disrupt the functioning of the management system, and some may be so pervasive and deep rooted (such as when there are deep divisions within communities and violent feuds) that the emergence of cooperative arrangements may be prevented altogether. See Warner (2000) for summary of different types and forms of NRM related conflict.

${ }^{24}$ The EKC was named after Kuznets (1955) who hypothesized that income inequality first rises and then falls as economic development proceeds (Stern, 2004).

${ }^{25}$ EKC concept was introduced as a background study for the 1992 World Development Report. It was well accepted into the report (IBRD, 1992) and attracted enthusiastic advocates who forcefully claimed:
} 
Authors also argue that poverty is associated with high discount rates and low levels of concern about sustainable NRM (Adhikari 2005; Baland and Platteau, 1996; Tisdell, 2005). When people are in poverty, their most immediate priority is to survive day-to-day, and they are less concerned with the future state of resources (Adhikari, 2005) ${ }^{26}$ or cooperating for the good of the collective (Diekmann and Franzen, 1999).

Critics of these arguments point out that only a few studies of a very limited range of pollutants and environmental impacts support the EKC claim, and that "the statistical analysis on which the Kuznets curve is based is not robust" (Stern, 2004, p. 1435). The 'relative needs hypothesis' also asserts that poverty can have a positive effect on discount rates (Wade, 1994). Studies have found that the rural poor often depend more heavily on commons resources, such as forests (Angelsen and Wunder, 2003). Wade (1994) suggests that this dependence means that people are more acutely affected by resource degradation, and therefore more motivated to ensure their sustainability (Wade, 1994).

\subsubsection{Relationship between resource system characteristics and group characteristics}

Relationships between resource system characteristics and group characteristics that support commons management include: high levels of dependence on the resource system; user group residential proximity to resource system; fairness in the allocation of benefits from commons resources; low levels of user demand or gradual change in levels of demand (Agrawal, 2003; Baland and Platteau, 1996; Wade, 1994)

\footnotetext{
"there is clear evidence that, although economic growth usually leads to environmental degradation in the early stages of the process, in the end the best - and probably the only - way to attain a decent environment is to become rich." (Beakerman, 1992, p491).

${ }^{26}$ In economic terms, poverty tends to result in high individual rate of 'time preference' and shorter 'time horizons' (Adhikari, 2005).
} 


\section{User group residential proximity to resource system}

Proximity can determine which resource areas people benefit from most. This affects perceptions about the value of different resource areas, which in turn, influence which areas will receive most management effort (Varughese and Ostrom, 2001). Gunatilake (1998) found that substantial differences in the distances that households live from a forest can lead to conflict when users are discussing the allocation of duties and benefits. People who live close to forests spend less time and money traveling to and harvesting from forests, as well as carrying out management duties such as monitoring, weeding, and replanting. Therefore these people benefit more than people who have to travel further (Gunatilake, 1998).

\section{Dependence on resource system}

Dependence on the resource system can create direct incentives for local people to protect biodiversity and sustainable management of natural resources (Salafsky and Wollenberg, 2000; Wade, 1994). Dependence can be affected by opportunities for income generation outside of common pool resource-use, termed "exit options" (Kurian and Dietz, 2004). Those with exit options tend to be less concerned about the sustainability of resources (Bardhan 2000; DaytonJohnson, 2000; Adhikari and Lovett, 2006). Diversity in access to exit options can be a barrier to defining common objectives for regulating the commons, and a barrier to participation and cooperation (Baland and Platteau, 1996; Varughese, 2000).

\section{Fairness in the allocation of benefits from commons resources}

Cost/benefit distributional issues related to commons management can be a serious barrier to the sustainability and effectiveness of institutions. Distributional issues may lead to conflict between those who are benefiting and those who are not. Conflict weakens local management institutions (Leach et al, 1999; Poteete and Ostrom, 2004; Kurian and Dietz, 2004) and has a negative effect on cooperation generally (Buckles and Rusnak, 1999). 
Cost/benefit distributional issues can arise from political and power inequalities which determine the norms of social inclusion and exclusion. ${ }^{27}$ The most powerful people in society usually hold the most rights and entitlements in decision-making processes. Those who are excluded from decision-making processes involving natural resource management are likely to gain fewer benefits and will often be less motivated to cooperate in management regimes. Adhikari and Lovett (2006) provide a good example of how poor cooperation in one Nepalese forest user group (FUGs) resulted because some members felt that they would not be able to change the inequitable distribution of NRM costs and benefits because a relatively clearly defined interest group of 'more wealthy' people were able to influence decisions in their favor. Dissatisfaction due to equity issues resulted in conflict within this FUG.

While power inequalities can negatively affect participation and motivation to cooperate, power can also coerce people into cooperating even if they are marginalised from decision-making processes, and even when decisions are not in their interests. There is a "dark side" to social capital, where social norms can reinforce and reproduce unequal power relations, resulting in the continued exclusion and exploitation of marginalised groups (Pretty and Smith, 2004; Krishna, 2003).

\subsubsection{Institutional arrangements}

The importance of institutional arrangements for NRM is well established in commons literature. In this thesis institutions refer to the rules, arrangements, and regularised patterns of behaviour that are developed by local people for the management of common property resources.Much of the literature analyses common property institutions and factors that affect their emergence, sustainability, and effectiveness at managing resource systems. Most studies have an implicit sense of successful commons institutions as "those that last

\footnotetext{
${ }^{27}$ Political and power inequality can derive from socio-economic inequality, socio-cultural inequality, and other power defining social norms. Some common indicators of political heterogeneity are: leadership status of individuals and different subgroups in the decision-making authority; extent of agreement over legitimacy of local leaders; level of agreement on authority structure and support from community members; and inequalities in decision-making power between different individuals and within and between different groups (Adhikari and Lovett, 2006; Baland and Platteau, 1996)
} 
over time, constrain users to safeguard the resource, and produce fair outcomes" (Agrawal, 2003 p. 1650). In a very broad sense, institutions can be seen as "regularised patterns of behaviour between individuals and groups in society" (Mearns, 1995, p. 103). They emerge from underlying structures or sets of 'rules in use' which are constantly made and remade though people's practices (Leach et al, 1999). ${ }^{28}$

There is relative consensus in the literature that rules about access and management of commons resources should be simple and easy to understand, locally devised, and easy to enforce. There should be graduated sanctions, low cost adjudication and dispute resolutions mechanisms, and monitors and officials should be accountable to users (Ostrom, 1990, Baland and Platteau, 1999). Recent and widely supported findings include that institutional arrangements play a vital role in mediating the effect of many other factors such as heterogeneity in endowments and interests (Adhikari and Lovett, 2006).

\section{Graduated sanctions}

Graduated sanctions refer to sanctions that are lenient for small infringements, and first time rule breakers, and increase in severity for serious infringements and persistent rule breakers. Scholars argue that sanctioning should also be lenient in extreme circumstances where people may need to break rules and ignore responsibilities (e.g. when a family member is sick). This can encourage participation in cooperative institutions by assuring people that they will not be severely punished or disadvantaged by such arrangements (Ostrom, 1990). There is also evidence that sanctions should avoid masking or undermine reciprocity, and other social motives (Kahan, 2002; Cardenas, et al., 2000).

\section{Mutual monitoring}

Monitoring systems provide the information about the rate of cooperation which people need to make contingent strategies. This information can enable

\footnotetext{
${ }^{28}$ Formal institutions may be thought of as rules that require external enforcement by a third-party organisation. The rule of law is and example of a formal institution that is upheld by the state though law courts and prisons etc. Informal institutions may be internally enforced and upheld by mutual agreement by social actors involved, or by relations of power and authority between them (Leach et al, 1999, p238).
} 
normative pressures to work as incentives for cooperation (Kahan, 2002). The costs of monitoring can be reduced by institutional designs that allow resource users to engage in mutual monitoring of each other. Ostrom (1990) provides an example where monitoring was especially successful in a Spanish irrigation system where the rules brought together those who would be tempted to cheat and those who would be particularly harmed by such cheating. In this case, irrigators in Murcia and Orihuela were assigned time slots where they could receive the water for their fields. Each irrigator was motivated to be sure to receive the full time slot of water, and to watch that the next irrigator does not try to take water too soon (Ostrom, 1990).

\section{The mediating effect of institutions}

Examples of how institutions can mediate the affects of heterogeneity are provided by studies of forest user groups in Nepal (Adhikari and Lovett, 2006). One group was able to manage inequality in costs and benefits associated with proximity to common-pool resources. A system allowed those who lived further away from community forests to pay an extra fee in exchange for reduced monitoring duties. Another group was able to develop organisational arrangements to ensure women's representation. A major barrier to women's participation was that they were generally too busy with household and other livelihood duties to attend meetings. Efforts to addressed unequal gender representation included ensuring that one or two women, who could represent the concerns of other women members, attended each meeting.

\subsubsection{External environment}

Commons resource management is affected by technology, markets, and state governments in complex ways. Conflicting evidence has resulted in debate about how some of these factors affect commons management.

\section{Technology}

It is generally agreed that management can be supported by low cost exclusionary technologies (Wade, 1994), and when resource user communities have time to adapt to new technologies related to the commons (Agrawal, 2003). 
However, introduction of new harvesting technologies (such as mobile chainsaws, new fishing boats and nets) can lead to rapid increase in harvest rates (Vadez et al., 2004).

Other research shows that new technologies and NRM practices can allow increased productivity of resource systems, which has slowed the clearing of forest for agriculture in some tropical forest margins (Angelsen and Kaimowitz, 2001). Agro-forestry has provided slash and burn farmers with a more productive way to use commons land (van Noordwijk et al., 2002), and new technologies and practices (such as planting legumes) can regenerate soil fertility (Angelsen and Kaimowitz, 2001).

\section{Market integration}

Agrawal, (2001) identifies low levels of integration with external markets and gradual change in articulation with external markets as conducive to sustainable management. Market integration can negatively affect local commons management institutions. Especially when change occurs at a faster rate than institutions can adapt to meet new challenges associated with markets (Oates, 1999).

As local economies become better connected to larger markets, subsistence users tend to increase harvesting levels as people exploit resources for cash income (Oates, 1999; Young, 1994). Closer links between rural areas, towns and urban centers can also create pressure to change use of the commons (conversion to agricultural land) and the form of tenure that governs them (e.g., conversion to private property) (Fuys et al., 2006).

A study by Vadez et al, (2004) shows that as Tsimane' Indian households integrated into the market economy, they deforest about twice as much to cultivate rice (the main cash crop) compared with more autarkic (economic selfsufficient) households. There are similar findings from Cameroon (Mertens et al., 2000). Out of 41 case studies from 20 countries in Africa, Asia, Europe and Latin America, commercialisation of natural resources and the products derived 
from them was the most frequently discussed pressure on commons property systems (Fuys et al., 2006). However, there are also examples where commercialisation can create new incentives for joint management of the commons. An example is the case of Nepal's leaseholder forests where poor communities are restoring degraded forests, planting timber trees and growing herbal plants for sale in local markets (Shrestha, 2005).

Commercialisation is also associated with a trend of growing wealth inequality both within and between resource user communities (Fuys et al., 2006). In this way markets impact social capital (including trust and reciprocity) (Godoy, et al., 2005; Putsche, 2000). Market integration resulting from gold mining in Peru eroded inter-household social capital and created distrust, social differentiation and conflict between households (Bury, 2004). Contrary evidence from Ghana shows that traditional forms of kin group reciprocity remain important forms of credit and economic insurance as they permeate and adapt to new institutions (La Ferrara, 2003).

Recent literature from the field of anthropology highlight that markets impact traditional use of resources, social capital, and traditional ecological knowledge (TEK) (Godoy, et al., 2005). This can be a problem for commons management as TEK is the basis for many traditional common property regimes. Empirical evidence from Mexico (Benz et al., 2000), and Venezuela (Zent, 2001), shows that acculturation (the acquiring new language skills, attitudes, and values ${ }^{29}$ ) associated with integration into new economic markets can cause the loss of traditional knowledge (TEK). Loss of TEK can occur as markets provide access to substitutes for traditional products (Godoy, et al., 2005). On the other hand, literature also suggests that integration into market economies through an activity based on use of the natural environment could accelerate the acquisition of local ecological knowledge (Guest, 2002).

\footnotetext{
${ }^{29}$ Standard proxies for acculturation include language skills, years of schooling, and direct measures of values (Godoy et al., 2004)
} 


\section{State}

It is widely accepted that central governments should not undermine the ability of local authorities to manage resources (Wade, 1994; Ostrom 1990). Statesupported policies such as privatisation or nationalisation tend to challenge the authority of customary systems, with negative impacts for both security of access to the commons as well as to their sustainable management (Ostrom, 1990, Fuys et al., 2006).

States can also play a positive role in supporting local institutions with external sanctioning as well as providing appropriate levels of external aid to compensate local users for conservation activities (Baland and Platteau, 1996). Ostrom (1990) shows that nested levels of appropriation, provision, enforcement, and governance can support local commons management institutions. Governments can support local autonomy and build social capital by promoting development of civil society, democracy, and true decentralisation - where communities decide for themselves what kind of 'development' they want (Evens, 1996; Heller, 1996). Heller (1996) shows that high levels of social development and social capital in Kerala are the products of mutually reinforcing relations between a democratic state and a well organised labour movement. Karim (1999) details the work of NGOs in Bangladesh that pressed for reform of the government's decentralisation program to make it genuinely devolved and responsive. Having done this, the structures were in place for more integrated, co-operative and large-scale rural development.

\subsubsection{Summary}

This chapter has outlined the research on commons management, collective action theory and the factors that drive community cooperation. Commons research has enabled greater understanding of how various factors affect the ability of local commons regimes to sustainably manage resources. However there is still considerable debate due to conflicting evidence. The conflicting evidence alludes to the complexity and interlinked nature of the factors. The effect of one factor on commons management is often dependent on other factors and varies across different contexts (Poteete and Ostrom, 2004b). 
Researchers have decided that instead of working to develop "final conclusions" about their direction of influence, it is more useful to study how they interrelate in causal links (Poteete and Ostrom, 2004; Agrawal, 2003).

Leading commons scholars have also highlighted a gap in understanding about how local commons problems are affected by wider socio-economic, political, and ecological processes (Ostrom, 2007; Perrings, 2007). My thesis addresses this identified gap by looking at how the results of my case study fit within the wider local, national and global context.

The next chapter describes the methodology used to study the factors that affect commons management in the particular context of Tangoa Island community, and the wider context of Vanuatu. 


\section{Chapter 3 - Methodology}

This chapter describes the research methods used for the Tangoa Island study. The first section explains and justifies the choice of methodological approach. The next section then introduces the study site, providing some background information about Vanuatu and Tangoa Island. The third section outlines some methodological issues and considerations including ethics, positionality and biases, translation issues and managing expectations. The two main methods for collecting data - participatory research activities and interviews - are described in the next two sections. Finally, the method of data analysis is outlined with a summary and a table of all the methods used.

\subsection{Methodological approach}

\subsubsection{Case study approach}

The second objective of this study as set out in Chapter 1, section 1.6 was to answer the question about what factors affect the Tangoa community's management of commons resources. A qualitative, case study research approach was used to answer this question. Due to the complexity and context specificity of commons management problems, detailed case studies are a widely used methodology in commons research (McCarthy, 2002). Case studies are valuable because they can provide context specific detail and variation in causal relationships that multiple cross-case analysis may not identify (Gerring, 2007). Case study research was undertaken over five weeks during June and July 2006.

The literature review in Chapter 2 identified a drawback of a qualitative case study. It was that it is difficult to know whether the findings have wider relevance beyond the particular setting (Poteete and Ostrom, 2004). The third objective of my study is to determine whether the Tangoa study is relevant for other communities. I address this issue through the use of interviews and literature-based research to examine the case study findings in the wider context of Vanuatu. Interviews were undertaken with government officials, NGOs and donors during January and February 2007. 


\subsubsection{Grounded theory and participatory research approach}

Underlying the methodology used for the case study is the idea that theory related to commons management should emerge from local perspectives and knowledge. Connell and Waddell (2007) argue that appropriate rural environmental management and development should be grounded in local empirical knowledge, rather than unsophisticated and ungrounded scientific or universal generalisations. Such an approach requires a powerful contextual understanding of the behavior of rural communities, of their knowledge and actions, with respect to social and natural environments. According to Charmaz, (2006) and Cresswell (2006), theoretical development concerning contextually situated processes (i.e. commons management) should be generated from local people's perspectives and experiences of those processes. Grounded theory is a qualitative research design that compliments this focus on local perspectives and knowledge and provides a framework for analysis of qualitative data (Strauss and Corbin, 1998).

Using a grounded theory approach, the enquirer generates a general explanation (a theory) of a process, action or interaction shaped by the views of a number of participants (Strauss and Corbin, 1998). In this case, the study generates a theory of commons management in the Tangoa community. A key idea is that this theory-development does not come from existing literature or from testing of hypotheses conceived prior to field research, but rather is generated or "grounded" in data from participants who have experienced the process (ibid).

Grounded theory is considered particularly useful where models and theories exist in literature, but were developed and tested on samples and populations other than those of interest for a particular study (Cresswell, 2006). This is the case here, because the literature review shows a gap in collective action research in Vanuatu. Grounded theory can therefore be useful for studies of local-level commons management situations, considering that there is no one-size-fits-all theory about the factors that affect commons management (Poteete and Ostrom, 2004). 
Commons scholars also argue that studies of hypothesised relationships of certain variables can mean that other important variables are missed, and that hypothesis-based studies must therefore be based on some prior understanding of the study socio-ecological system (Poteete and Ostrom, 2004; Ostrom 2007). Since I had little pre-field research knowledge and information about the Tangoa socio-ecological system from which to develop informed hypotheses, grounded theory approach allows the most important factors affecting commons management to arise from local perspectives and collective analysis, without the discrimination of pre-defined hypotheses.

A participatory research approach is effective with grounded theory as the combination can generate contextually relevant theory, developed from local perspectives and knowledge. A participatory research approach was also chosen because the research process can potentially benefit research participants by engaging local people in collective learning and analysis of issues that are of importance and concern to them (Chambers, 1994). Participatory research approaches have been effectively used in Vanuatu in recent years, with proven benefits for local communities, including increased motivation and action to achieve local goals concerning natural resource management and development (Bronson et al., 1995).

The main methodological tools used include interviews and group activities commonly employed in Participatory Rural Appraisal (PRA). PRA is a set of methods for ascertaining features of local groups and situations in ways that are meant to empower the people being researched, as well as being faster to carry out and to analyse than other techniques (Brockington and Sullivan, 2003)

The research in this study was designed to overcome some identified weaknesses in PRA. Careful selection of participant group composition, and triangulation of findings (by using multiple research tools) were two strategies employed. One weakness is that some people and groups may not feel comfortable expressing their views the public forum where PRA exercises take place (Mohan, 2001). Participatory methodologies often seek community consensus, which means that diversity of perspectives can be lost. Also, 
consolidation of dominant perspectives and norms as "legitimated" participatory knowledge can result in the marginalisation of more "quiet" or less powerful voices (ibid). ${ }^{30}$ Knowledge produced in research "are always versions of the truth, representing one out of other possible truths" (Mohammad, 2001, p114). To reduce power-related data distortions, PRA activities were done with groups of men, women, youth and elders separately. Data from different group activities were triangulated and compared with data from individual interviews in order to elicit the diversity of views and perspectives, and to calibrate the informative value of any given assessment.

\subsection{The research site}

\subsubsection{Vanuatu}

Vanuatu is a Y-shaped archipelago, roughly $1000 \mathrm{~km}$ long, located in the western South Pacific (Fig.3.1). There are 82 islands, mostly volcanic in origin. Highly productive fringing reefs surround most islands. ${ }^{31}$ Forests cover about $75 \%$ of total land area (Rosillo-Calle and Woods, 2003). Due to high levels of endemic biodiversity, Vanuatu is part of the East Melanesian Islands biodiversity hotspot (Conservation International 2005).

Vanuatu has a total population of 221,507 (National Statistics Office, 2006). There is great linguistic and cultural diversity in Vanuatu, with approximately 106 Austronesian languages spoken by a predominantly Melanesian population (which is the greatest number of languages per capita in the world) (Lynch and Crowley 2001). Bislama is the national language, and is widely spoken and taught in schools. Vanuatu is one of the youngest independent countries in the Pacific region, having achieved political independence from the joint AngloFrench condominium in 1980.

\footnotetext{
${ }^{30}$ The social and institutional dynamics of a community affect how different social groups within a community participate in the process of constructing "social knowledge". It has been claimed that "because participation is a social act that springs from a pre-existing set of social relations it is more readily applied in situations that condone and reinforce the set of social relations (da Cunha et al., 1997) ${ }^{31}$ For a good source of information about marine resources of Vanuatu see: Chillaurren E., David, G., and Grandperin R., 2001, Coastal fisheries atlas of Vanuatu: A 10-year development assessment. Paris, IRD editions.
} 


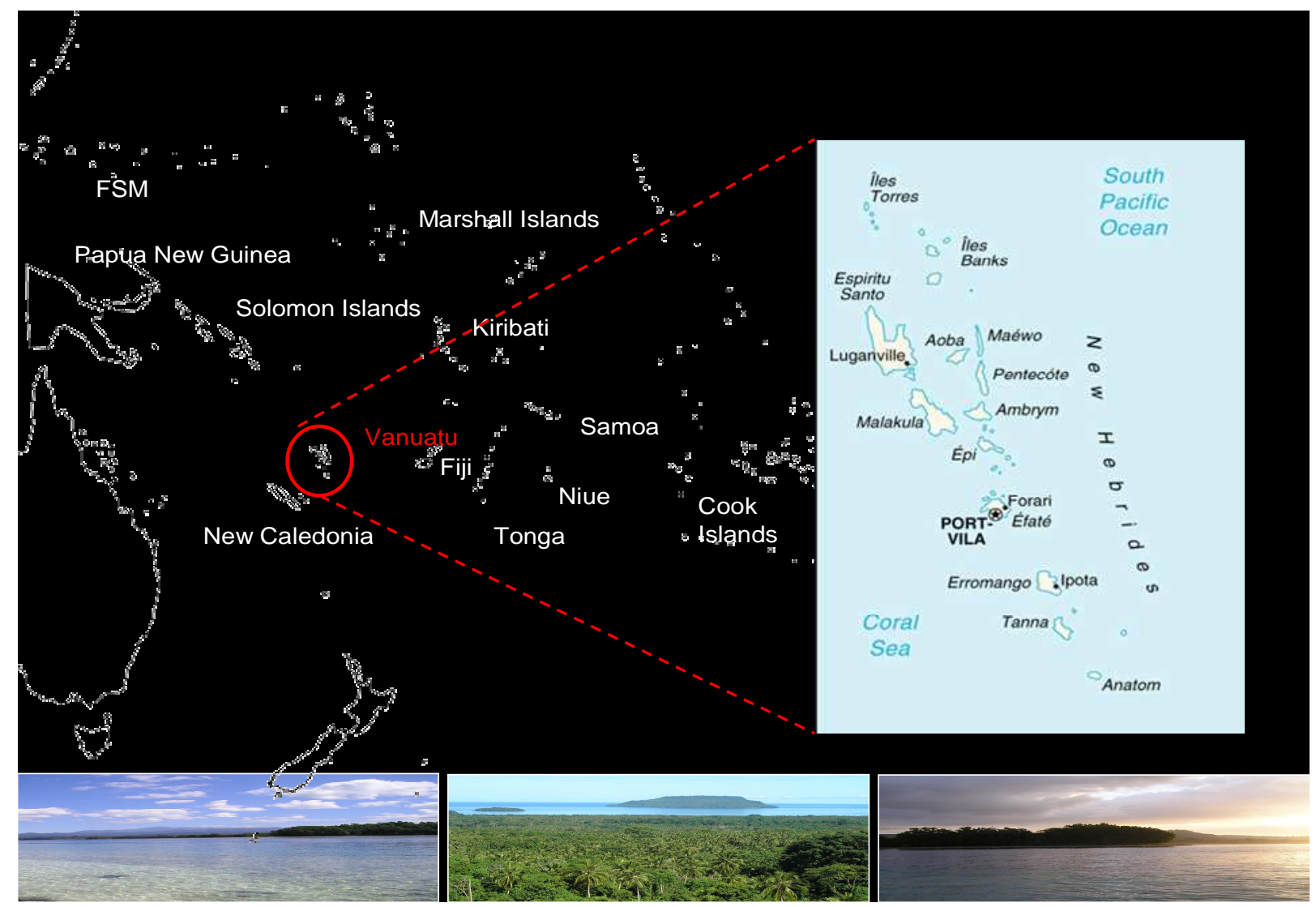

Figure 3.1, Location of Vanuatu in the Pacific

The economy in Vanuatu is dominated by subsistence agriculture, however there are two main commercial centres, one on the island of Efate, where the capital Port Vila is situated, and the island of Santo, which has the town of Luganville and a port. The great majority of the population uses minimal amounts of cash, but are supported by the traditional subsistence economy (Baezely and Mullen, 2006).

Around 80 percent of Vanuatu's population lives in rural villages with other members of their traditional extended families on land which is theirs under the rules of 'kastom' (which translates to 'custom') ${ }^{32}$ (Regnevanu, 2007). About $90 \%$ of land in Vanuatu is customarily owned, with the balance owned by the government and a small portion by the private sector (FAO, 2005). Indigenous land ownership is protected in the constitution. "True" customary landowners

\footnotetext{
32 'Kastom' in Vanuatu refers to "the traditional beliefs, values and common law that underpins the life of ni-Vanuatu (the indigenous people of Vanuatu)." Kastom differs widely and has evolved over millennia (Whyte et al, 1999, p.5)
} 
are ni-Vanuatu ${ }^{33}$ whose origins are linked to the nakamal (men's house), varea (village), or nasara (dancing grounds, public square, ritual clearing or place) associated with that land. In parts of the country the right to own land is held by women, but in the majority of cases, the right is given to men.

Under customary communal tenure systems, each family in a community is allocated rights to land for gardening (Rockell, 2007). This provides important livelihood security. Land can be obtained by non-indigenous people through long-term leases ranging from 50-75 years. Much of the prime cultivable land in Vanuatu is devoted to agricultural leases which result in the transformation of land into agricultural production, predominantly for cattle, coconut and cocoa (FAO, 2000).

\subsubsection{Tangoa Island}

Tangoa Island is situated in South Santo, $50 \mathrm{~km}$ south of Luganville (see fig. 3.2). Luganville is the largest town on Santo (and second largest in Vanuatu after Port Vila), with a population of 10,738. Two of the most important industries for the South Santo region are cattle and copra. ${ }^{34}$

Tangoa is a raised coral island, approximately $1.35 \mathrm{~km}$ long and $0.56 \mathrm{~km}$ wide about 230 metres off shore (see fig. 3.2). Seven different clan groups (extended family) with a total of 500 people live on Tangoa Island. Tangoans speak a local vernacular language unique to South Santo. Tangoan people travel by locally crafted outrigger canoe from their village on the Island to the mainland, where they carry out their subsistence and income generating activities. Tangoan livelihoods are predominantly dependent on gardening/farming, fishing, and working on copra and cocoa plantations.

A fence dissects Tangoa Island, marking the boundary between Tangoa village land and Presbyterian Church land. The Church's side of the island is used for the Bible Translator's house, a primary school, coconut plantations and cattle.

\footnotetext{
${ }^{33}$ In common use 'ni-Vanuatu' refers to an indigenous citizen of Vanuatu. The Vanuatu Constitution defines ni-Vanuatu as a person who has had 4 grandparents who belong to a tribe of communities indigenous to Vanuatu (Whyte et al. 1999, p.6)

${ }^{34}$ Copra is the dried meat (or kernel) of a coconut. It is processed and made into various products.
} 
The benefits of the copra and cattle raised on Church land go to the Church. These tenure arrangements reflect a colonial history. The first missionaries set foot on Tangoa in 1887 and established the first church in 1895. During the colonial government, the cultivable land surrounding the Tangoa resource area was allocated to the Presbyterian Church and several 'mission traders', 35 who established farms and plantations of predominantly coconuts and coffee. Mission traders were entrepreneurs who also harvested sandalwood, and imported and traded labour (Melanesian, Chinese and Vietnamese).

While indigenous ownership of all land in Vanuatu was written into the Constitution at independence (1980), ${ }^{36}$ no land owner registry system was put in place, and much of the land in the South Santo region stayed with the church and mission traders. Land was transferred into long term leases. ${ }^{37}$ Leasehold provisions were established to allow land users to pay custom owners for the use of the land (Rockell, 2007). However in Tangoa's case, small fees were paid by the leaseholders to the Vanuatu government as indigenous ownership has not yet been determined.

\footnotetext{
${ }^{35}$ Mission traders were entrepreneurs who established plantations, farms, imported and traded labour (Melanesian, Chinese and Vietnamise, harvested sandalwood etc. they were not necessarily missionaries, or part of a church, but were associated with missionaries as they would set up their bases or homes near missions (because they were safer places) and traded with and sold stuff too the missionaries.

(MacClancy, 2002)

${ }^{36}$ Articles 71-72 state that "All land in the Republic belongs to the indigenous custom owners and their decedents" and the "The rules of custom shall form the basis of ownership and use of land in the Republic."

${ }^{37}$ Leases were initially for thirty years; however the most productive farmers were given the opportunity to extend to fifty. Leases were extended to 75 years under the 1988 Land Lease Act (Rockell, 2007).
} 


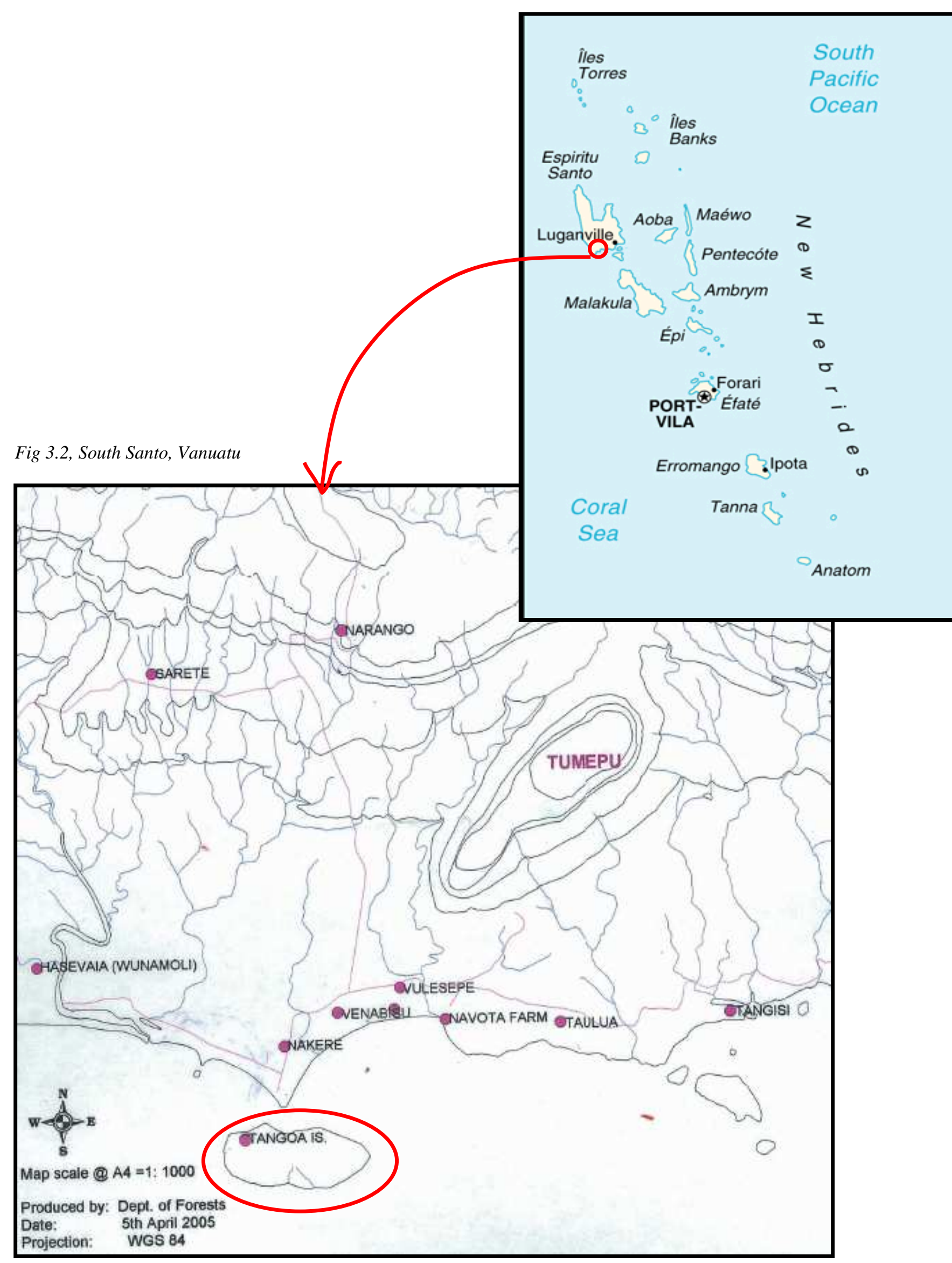




\subsubsection{Background history of the relationship between Tangoa Island and Victoria University of Wellington}

The Tangoa Island community was chosen as a site for research because a relationship had already been built between Victoria University and the community when Dr. Sean Weaver from Victoria University stayed with the community in 2005. Olivia Warrick (co-researcher) and I were invited to Tangoa Island by the Pelviji family to conduct participatory research with the Tangoa community during June and July 2006. Olivia and I conducted all the field research as a team even though our research focus is different. Olivia is focusing on local adaptation to climate change and my focus is on the four objectives outlined in Chapter 1.

\subsection{Methodological issues}

\subsubsection{Ethics}

The Human Ethics Committee of Victoria University of Wellington approved my research with the Tangoa Island community and research interviews with government and NGOs in Luganville and Port Vila (Approval number 43/2006). Contributions from individual Tangoan research participants from the Tangoa Island will remain confidential, which means that individual participants are not identifiable in my thesis. Interviews with Provincial government and NGOs in Luganville, as well as interviews with government representatives in Port Vila, are also confidential except in cases where participants' permission was expressly gained to use their names. The permission to use the names of several Port Vila based interviewees was sought where referring to them by name would add context and relevance to important quotes.

In addition to gaining formal ethics approval from my university, several ethical considerations related to doing cross-cultural field research were integral to my research design and practice. My concerns were related to some ethical issues and possible negative effects for the people that are being 'researched.' There is the potential for research to be used to legitimise of the voices of Western 'experts' while undermining those of local people, and to represent local 
knowledge in a way that colonises it reinforces patterns of domination (Scheyvens and Storey, 2003). ${ }^{38}$

Several steps were incorporated in this study to maximise the benefit of the research for the Tangoa community and to avoid acting and carrying out research in a way that was intrusive and exploitative. These steps included:

- Ensuring that we had the permission of the community to do the research, which involved meeting with the community leaders;

- Involving several leaders and other people that offered research support, in deciding what kind of research would be useful for the community, and how would be the best way out carry the research;

- $\quad$ Not asking too much of people's time;

- $\quad$ Arranging group activities in times that suited the participants;

- $\quad$ Being aware of sensitive issues and avoiding questions that are intrusive and inappropriate;

- Being aware of when to stop asking questions (e.g. when, or before, people were tired of answering questions);

- Helping our host family with household activities when possible and where appropriate (e.g. cooking dinner etc); and

- $\quad$ Communicating respect and gratitude by reciprocating where possible. This included giving appropriate gifts of thanks at the end of the research, and giving the research back in a variety of locally appropriate forms. ${ }^{39}$

\subsubsection{Positionality and Biases}

According to the interpretive paradigm in social science research, the social world is "local, temporal and historically situated, fluid, context-specific and

\footnotetext{
${ }^{38}$ Colonial research has been described as research that promotes, deliberately or inadvertently, a colonising (and now globalising) agenda that includes political, economic, and cultural imperialism and neo-colonialism; national, transnational, and global exploitation and comodification of resources (natural and human). Colonial research also promotes Western or other colonial discourses about 'civilisation', 'development', or 'conservation'; Western conceptions of 'science'; and a Western over-preoccupation with 'self' and self-gratification. (Stevens, and Howitt, 2000)

${ }^{39}$ Gifts included offering the local kindergarten and primary schools story books, art supplies, and exercise books. These had been donated by the staff and students at Victoria University). We also gave framed photos to our host family and friends.
} 
shaped in conjunction with the researcher" (Guba and Lincoln, 1994, p109). Positionality, in terms of race, nationality, age, gender, social and economic status, and sexuality, may influence the data (Madge, 1993; Walsh, 1996, Rose, 1997). Important characteristics that determined mine and my co-researcher's status or positionality include: young females, relatively educated and wealthy, and from a western culture.

Our positionality influenced how people related to us and would have affected what people were willing to talk to us about, and their portrayals of reality. ${ }^{40}$ Bias may have come from factors such as the willingness of people to please us by giving us the information that they knew we wanted. Although we were interested in eliciting local knowledge and perspectives, my personal values, assumptions, experiences and priorities have, to an immeasurable extent, affected how I have interpreted and given meaning to data.

There is also a risk that this study has been affected by bias associated with interacting with some people more than others. Even though we tried to separate our research time and our family or social time, the many conversations over the dinner table provided a richer understanding of the particular concerns and perspectives of our host family. There may be also biases associated with interviewing more Tangoan men (18) than women (13), and more adults than youth. We had more male interviewees as women had less time available for interviews, and also because our research assistant/translator told many of his male friends to come meet us for an interview. We tried to mediate this bias as much as possible by actively seeking women participants and ensuring that women and youth were involved in focus group activities.

We tried to manage bias by triangulating data, and ensuring that we did not lead questions or prompt answers. We also minimised bias through the timing of activities and data collection. For example, we chose to do a focus group exercise that explored key community issues in general before an exercise where

\footnotetext{
40 'Reflexivity' is, in part, critically thinking about how one's status characteristics, values, and history as well as the numerous choices one has made during the research, affects the results (Bailey, 2007).
} 
people analysed major threats to the environment. This was done so people would identify and talk about their priority issues - whether they are economic, social or environmental. This was to ensure the groups would not be influenced by our focus on environmental issues and our underlying conservation values. This seemed to work as most of the issues raised in the first exercise were of a social/economic nature rather than purely environmental.

\subsubsection{Translation issues}

Language barriers were an initial difficulty in the first few weeks of the research. Tangoan people speak their local language as well as Bislama. A translator/research assistant was assigned by our host family to assist us. Acting as both gatekeeper and translator, he helped us gain access to research participants and acceptance into the community. There are some biases associated with utilising a translator/research assistant, including his influence over the choice of participants. Efforts to minimize this bias included ensuring that our assistant understood that we wanted to get a good cross section of people, and also seeking our own interview participants.

We were also aware of bias that could arise from our assistant's translation. To mitigate this risk, we communicated clearly to him the importance of letting participants answer the questions themselves and to translate the participant responses as closely as possible. Our translator was not used during any group activities with women in order to avoid biases related to gender power relations. In situations where a male translator might influence how women feel about discussing certain topics (Kumar, 2002), several women participants helped with translating during women's group activities.

\subsubsection{Managing expectations}

Managing expectations was an important ethical responsibility, which was vital for ensuring that our participants could give informed consent. Managing expectations involved building understanding about why we were there, the intent of the research, what will come from the research, and especially what will not come from the research. This understanding was necessary to avoid any deception and suspicion, and to avoid being associated with community politics. 
We worked out a communication strategy to ensure that the purpose of the research was as clear and transparent as possible, and to facilitate easy access to all the information that participants would need in order to make an informed decision to participate. When we met people, we explained this information to them face-to-face. We also translated an information sheet into Bislama and put it up on the notice board of the local store, on a tree at the canoe landing area, and on a notice board on the mainland. The information sheet contained the following points:

1. We are Amanda Leathers and Olivia Warrick, we are students from Victoria University in New Zealand.

2. We have been invited to Tangoa by Ioan Viji to do some research about how people use natural resources; what threatens the environment; the main problems that concern Tangoa people; and their ideas to solve the problems.

3. We will be staying at the Vetabe Guest house for 5 weeks, and anyone is welcome to come to talk with us and to ask us any questions about the research.

4. Anyone can participate in the research if they want to.

5. Details about the research activities (i.e. when and where they will be held) will be announced during the Tangoa Church services.

6. We plan to use the research to write theses for our university study.

7. We will present the results of the research to the community at the end of our stay.

8. Once we go home we will write a report which compiles the local knowledge generated through the research and send the report to the community.

9. Information that people personally contribute in interviews will be confidential - no individual names will be included in the presentation, or published in the report or our theses. 
We made posters in both English and Bislama that listed the main research questions (see figure 3.3). These posters were displayed on the walls in the meeting area outside the guesthouse.

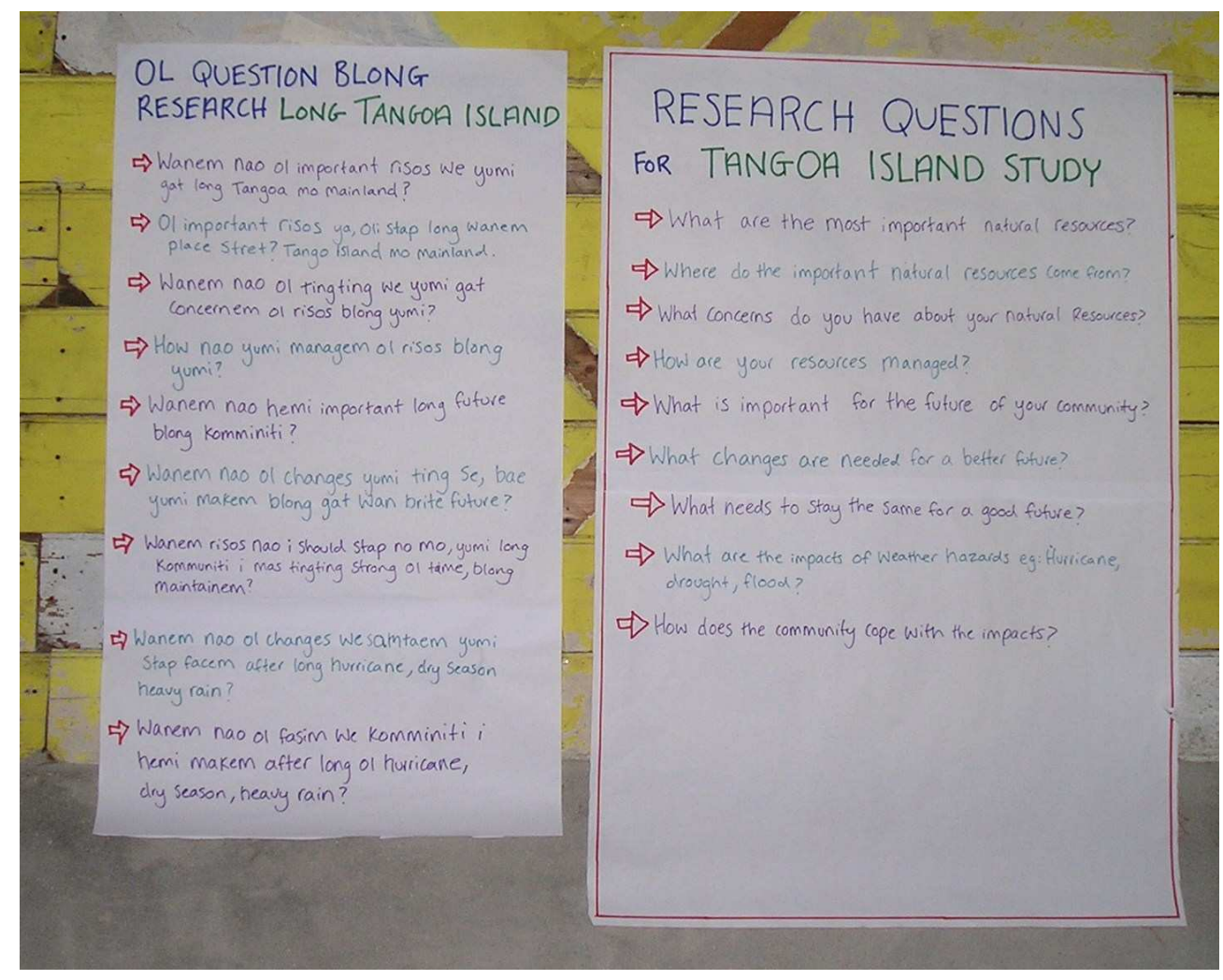

Figure 3.3, Posters listing main research questions

\subsection{Participatory research activities}

The information gathered in the Tangoa case study and field work is the primary source of data to meet the second main objective of this thesis (see Chapter 1, section 1.6). That objective was to determine the "locally identified factors affecting the ability of the Tangoa community to manage their commons resources". Within this thesis objective, eight specific case study objectives were developed to provide the focus for gathering data from participants.

Participatory Rural Appraisal methods were used in answering the eight case study objective questions. PRA methodologies use various participatory research techniques when involving groups of participants. Table 3.1 lists the objective questions that were used to guide case study field work. Table 3.2 lists the group research activities, which objectives they address, and some summary details about participants. 
Table 3.1, Case-study objective questions and corresponding methods

\begin{tabular}{|c|l|}
$\begin{array}{c}\text { Objective } \\
\text { numbers }\end{array}$ & \multicolumn{1}{c|}{ Objective questions } \\
\hline $\mathrm{a}$ & Where are the important natural resources that the Tangoa community uses? \\
\hline $\mathrm{b}$ & What are the important resource area (or land-use) types? \\
\hline $\mathrm{c}$ & How are Tangoa's natural resource used and valued? \\
\hline $\mathrm{d}$ & Who uses and manages Tangoa natural resources and how? \\
\hline $\mathrm{e}$ & What are the threats to Tangoa's natural resources? \\
\hline $\mathrm{f}$ & What are the causes of resource degradation? \\
\hline $\mathrm{g}$ & $\begin{array}{l}\text { What are the locally identified strategies and solutions to the problems that drive } \\
\text { resource degradation? }\end{array}$ \\
\hline $\mathrm{h}$ & What are the strategy constraints and barriers to over-coming problems? \\
\hline
\end{tabular}

Table 3.2, Group Research Activities

\begin{tabular}{|c|c|c|c|c|}
\hline Research activity & $\begin{array}{l}\text { Objective } \\
\text { questions }\end{array}$ & $\begin{array}{l}\text { Number of } \\
\text { activities }\end{array}$ & $\begin{array}{l}\text { Participant } \\
\text { groups }\end{array}$ & $\begin{array}{c}\text { Gender } \\
\text { composition }\end{array}$ \\
\hline Participatory mapping & $2 a-2 e$ & $\begin{array}{c}6 \\
\text { (Includes maps of } \\
\text { Tangoa resource } \\
\text { area, marine } \\
\text { maps, social } \\
\text { map) }\end{array}$ & $\begin{array}{l}\text { Women } \\
\text { Men } \\
\text { Mixed }\end{array}$ & $\begin{array}{l}20 \text { women } \\
30 \text { men }\end{array}$ \\
\hline Transects & $2 a-2 e$ & 4 & $\begin{array}{l}\text { Women } \\
\text { Men } \\
\text { Mixed }\end{array}$ & $\begin{array}{l}4 \text { women } \\
10 \text { men }\end{array}$ \\
\hline Seasonal calendar & $2 b-2 c$ & 2 & $\begin{array}{l}\text { Women } \\
\text { Men }\end{array}$ & $\begin{array}{l}13 \text { women } \\
12 \text { men }\end{array}$ \\
\hline Resource rating matrix & $2 b-2 c$ & 2 & $\begin{array}{l}\text { Women } \\
\text { Men }\end{array}$ & $\begin{array}{l}15 \text { women } \\
15 \text { men }\end{array}$ \\
\hline $\begin{array}{l}\text { Focus group activity } 1 \text { : } \\
\text { goals identification }\end{array}$ & $2 b-2 g$ & 2 & $\begin{array}{l}\text { Women } \\
\text { Youth }\end{array}$ & $\begin{array}{c}13 \text { women } \\
35 \text { youth } \\
\text { (mixed gender) }\end{array}$ \\
\hline $\begin{array}{c}\text { Focus group activity } 2: \\
\text { Problems and } \\
\text { solutions cognitive } \\
\text { mapping }\end{array}$ & $2 f-2 h$ & 2 & $\begin{array}{l}\text { Women } \\
\text { Youth }\end{array}$ & $\begin{array}{c}15 \text { women } \\
37 \text { youth } \\
\text { (mixed gender) }\end{array}$ \\
\hline $\begin{array}{l}\text { Focus group activity } 3: \\
\text { Resource threats } \\
\text { identification }\end{array}$ & $2 d-2 e$ & 2 & $\begin{array}{l}\text { Mixed men, } \\
\text { women, youth } \\
\text { and children }\end{array}$ & $30-40$ \\
\hline
\end{tabular}




\subsubsection{Mapping}

Community mapping is a means of gathering information about natural resources, special sites and local perceptions within a shared geographical framework (Sheil et al, 2002) ${ }^{41}$. Separate groups of men and women were involved in making maps of the Tangoa Resource area. We asked them to illustrate important areas that they use and to explain to us what they are used for, how they are managed, and what resource threats might exist (field work objectives 2a-2f).

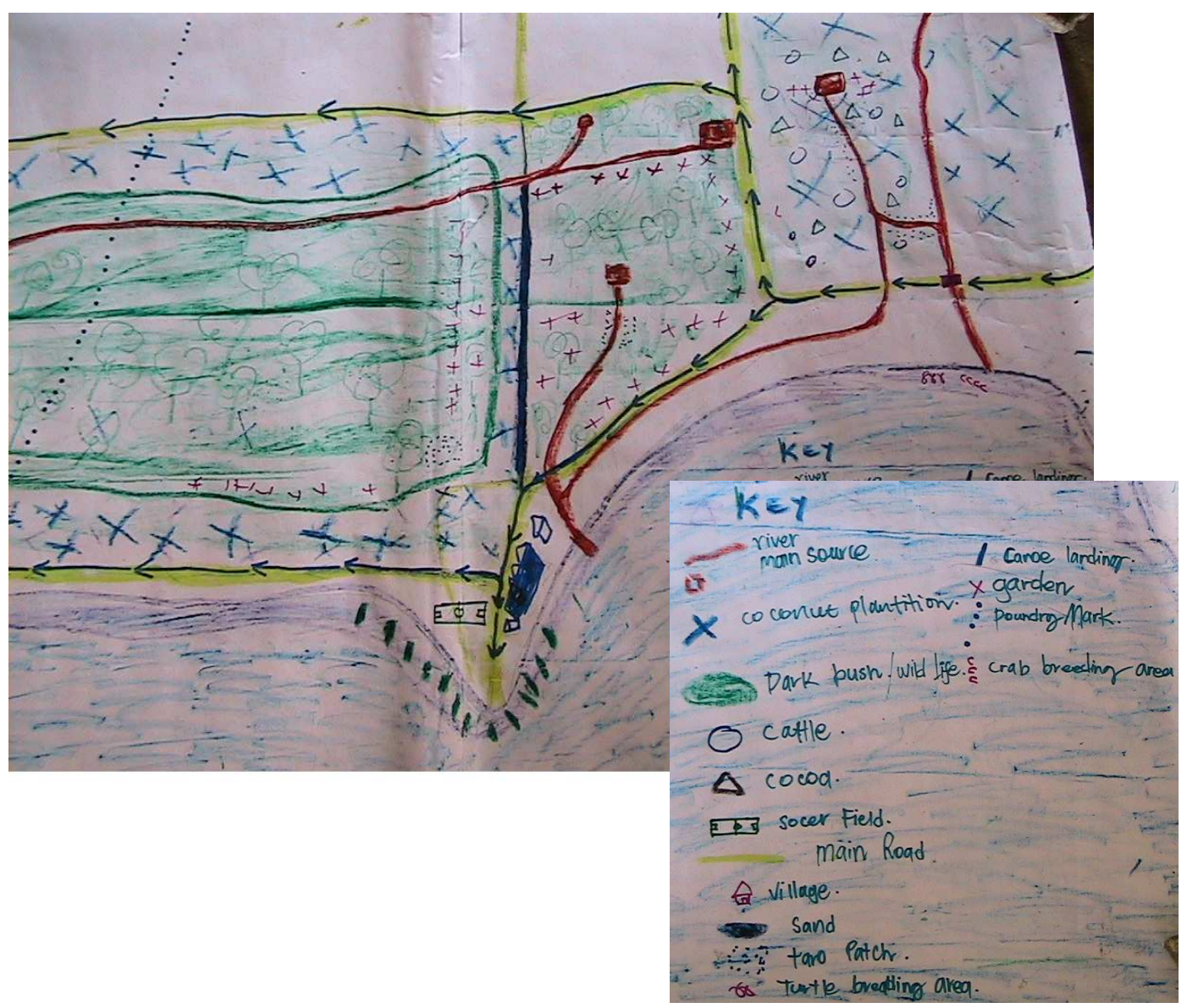

Figure 3.4, Men's resource map

${ }^{41}$ Also see Sheil and Liswanti, 2006. 
Several fishermen and women made marine resource maps, showing important fishing areas including reefs, islands, fish and crab breeding areas, and areas where they collect palolo worms (a type of sea worm with the scientific name Eunice viridis) and shellfish. These maps served as a good focal point for discussion about the environmental and social factors that affect fishing-based livelihoods, what the major threats are and how people cope with them, as well as ideas about how threats might be mitigated (case study objectives $2 \mathrm{a}-2 \mathrm{f}$ ). The marine maps were used as a basis for discussion during interviews, and were revised over time as a consequence of people's input.

Some key informants made a map of Tangoa Island which shows where the different extended families live and where important infrastructure and cultural sites are, such as water pipes and tanks, church buildings, schools, and cemeteries. This social map was used in discussions with several key informants about intra-community socio-economic and wellbeing variation.

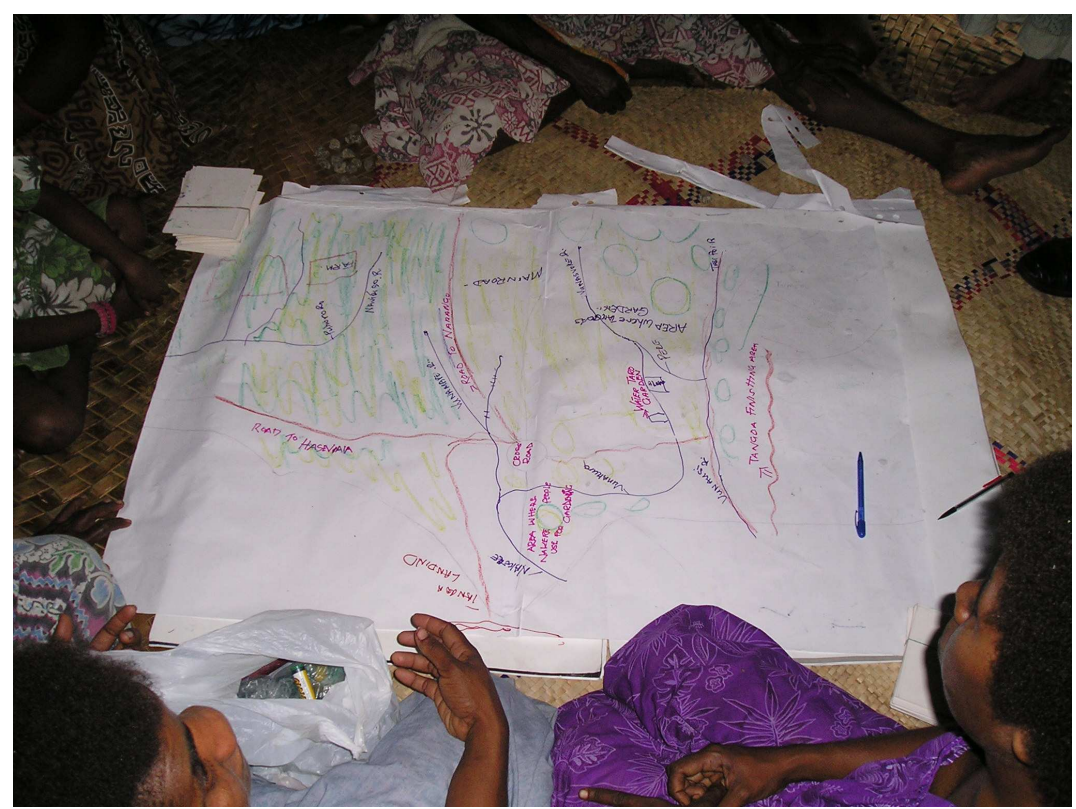

Figure 3.5, Women making their resource map

\subsubsection{Transects}

Transect walks involve walking with participants through major zones of landuse and resource types within the community's resource area, observing, discussing and noting details of specific characteristics. The walks are an 
excellent method of gathering data on the interactions between human activities and the physical environment (Kumar, 2002). Transect activities can also help local people to recognise the issues confronting them, increase awareness about destructive behaviors, and create awareness of the need for change (Bronson et al. 1995). During transect activities participants provided information about: how different areas and resources are used and governed; who uses and manages them; social or environmental issues; and land-use history and environmental change over time. This provided data for case study objectives $2 \mathrm{a}-2 \mathrm{e}$.

Over five weeks we did three transect walks and one transect drive. ${ }^{42}$ Table 3.3 below provides the details of where the transect took place and what participants were involved.

Table 3.3, Transects and participants involved

\begin{tabular}{|c|c|c|}
\hline & Transect & Participants \\
\hline 1 & Through the garden area & Elderly Tangoan couple \\
\hline 2 & Through the garden area & Four young men and two women \\
\hline 3 & $\begin{array}{l}\text { Through the whole Tangoa } \\
\text { resource area }\end{array}$ & Three men \\
\hline 4 & $\begin{array}{l}\text { Through the South Santo } \\
\text { province on the bus from } \\
\text { Tangoa to Luganville Town }\end{array}$ & One woman and one man \\
\hline
\end{tabular}

\subsubsection{Seasonal calendar}

Seasonal calendars are a popular PRA method for analysis of annual cycles and seasonal variation in social and natural resource use (Kumar, 2002). A group of 12 men (ages ranged from 26-75) and 13 women (ages 19-60) were involved in making seasonal calendars. These activities were used to further explore how resources are used and valued, who uses them, and how they are managed (objective questions 2b-2c).

\footnotetext{
${ }^{42}$ The transect drive provided about the social, political and economic processes going on in the wider regional context.
} 
Participants were asked to describe the seasonal cycles of community activities such as when in the year different activities take place and how different groups (i.e. men women and children) are involved. The calendars showed how community activities are determined by natural resources use patterns and seasonal cycles; and how social, cultural and governance activities also related to seasonal cycles and natural resource-use patterns. Figure 3.6 is the men's calendar and figure 3.7 is the women's group calendar.

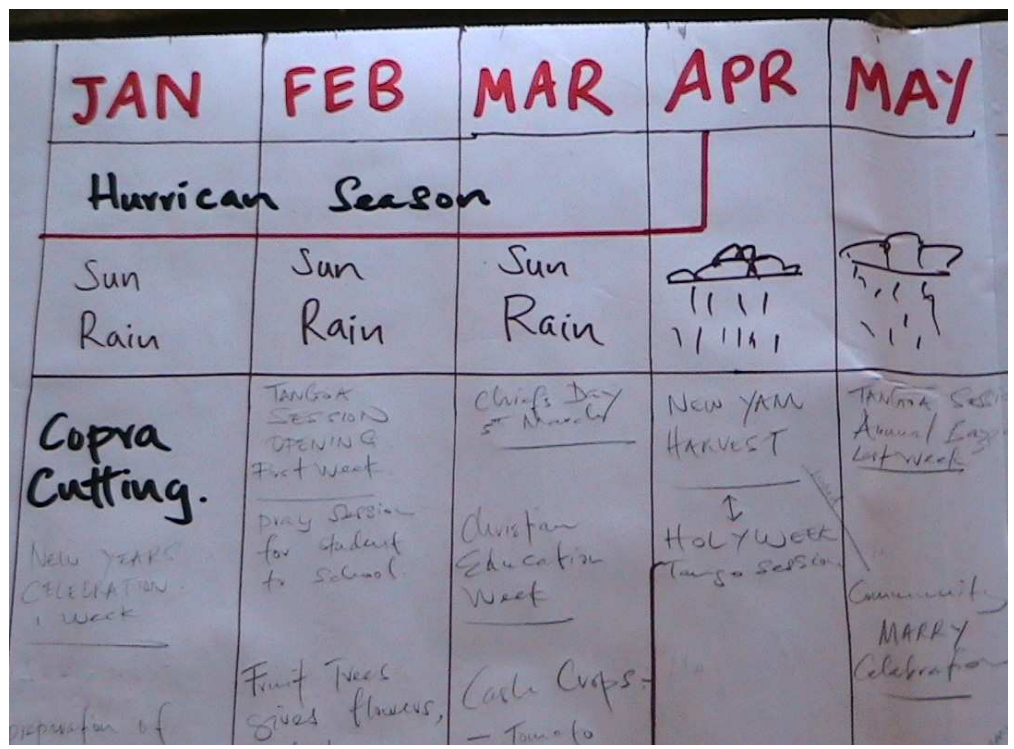

Figure 3.6, Men's seasonal calendar

During the activity, discussion was focused on what times of year are most busy and/or difficult, why, and how people cope. This highlighted issues of food security, livelihood needs, and gender roles in fulfilling needs. When the calendar was finished, participants explained to us what they had drawn and written. 


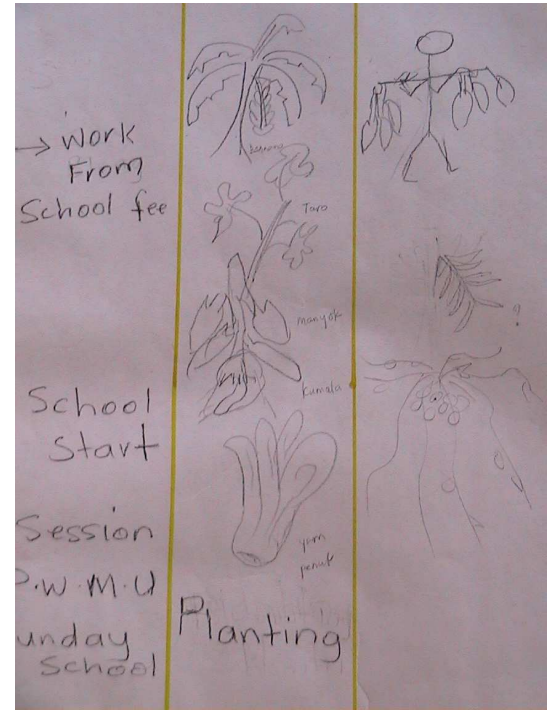

Figure 3.7, Women's group seasonal calendar

\subsubsection{Rating landscape areas}

Resource rating activities are regarded as simple tools for generating information about how and why people make choices, and what choices they make (Nemarundwe, 2002, p179; Sheil D. and Liswanti N., 2006). The tool was used to explore how people value different landscape/resource areas and why, and for determining the main preference and priorities of gender groups for landscape areas and resources-uses. This information directly addressed objective $2 b-2 c$, (what are the important resource area types and how are they used and valued). Discussion throughout the exercise also contributed to objectives $2 \mathrm{~d}-2 \mathrm{~g}$ (about resource governance, resource management problems and threats, and local perceptions about how to solve them).

One group of fifteen men (ages 20-60 years) and one group of fifteen women (ages 24-55) were involved in a rating activity to ascertain what landscape areas are most important for what uses. The rating activity involved three steps or activities that are explained in more detail below: a mapping of area types and resource use categories; a matrix table with ratings; and the explanation of how to use the matrix table and map. 


\section{Defining resource area types and resource-use categories}

The numerous conversations with people about resource use and group activities, such as an initial mapping of resource area by key informants, gave a clear picture of various general resource area types. From this we were able to define some broad resource-use categories. These categories were checked with the participant group and participants added or changed the categories as they saw fit. It was important to make sure that participants had a shared understanding of the categories.

\section{Making a matrix table}

The matrix (see figure 3.8) was made from picture cards with Bislama labels to represent each of the resource area types and resource-use categories, with resource area cards on one axis and resource-use cards on the other axis. The pictures ensured that even non-literate participants would have a shared understanding of what the categories were.

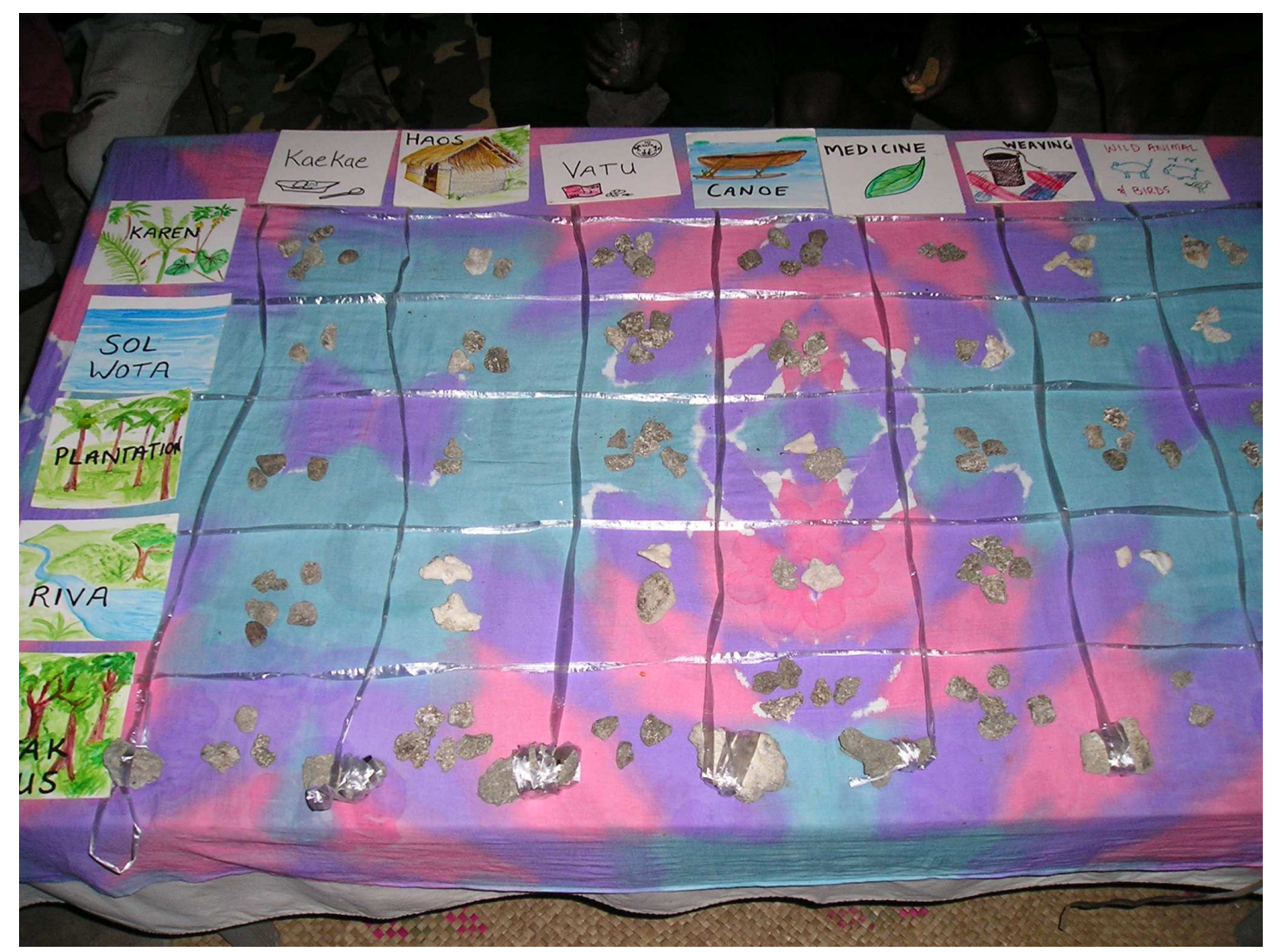

Figure 3.8, The resource rating matrix 


\section{Facilitating the exercise}

We asked participants to place 0 to 5 markers in each square, explaining that zero markers meant that an area is 'not important' for a particular use, 1 marker would be 'a little important' and 5 markers represented 'very important'. Along the lines of Sheil et al. (2002), we assumed that 'importance' can be expressed as relative preference and usefulness. We used prompting questions like "how important are the plantation areas for medicine? Do you use medicines from plantation areas more than river areas? And "are the medicines that you get from the plantations better than the medicine in the dark-bush?"

At the end of the activity participants explained the results.

\subsubsection{Trend analysis}

Trend analysis was used to obtain data about the causes of resource degradation (objective 2f). Trend lines are a useful method of analyzing perceptions of change over time, and facilitating discussion of the factors affecting change (Kumar, 2002). Trend lines were mostly utilised during interviews with individuals to explore aspects of both social and environmental change that participants brought up

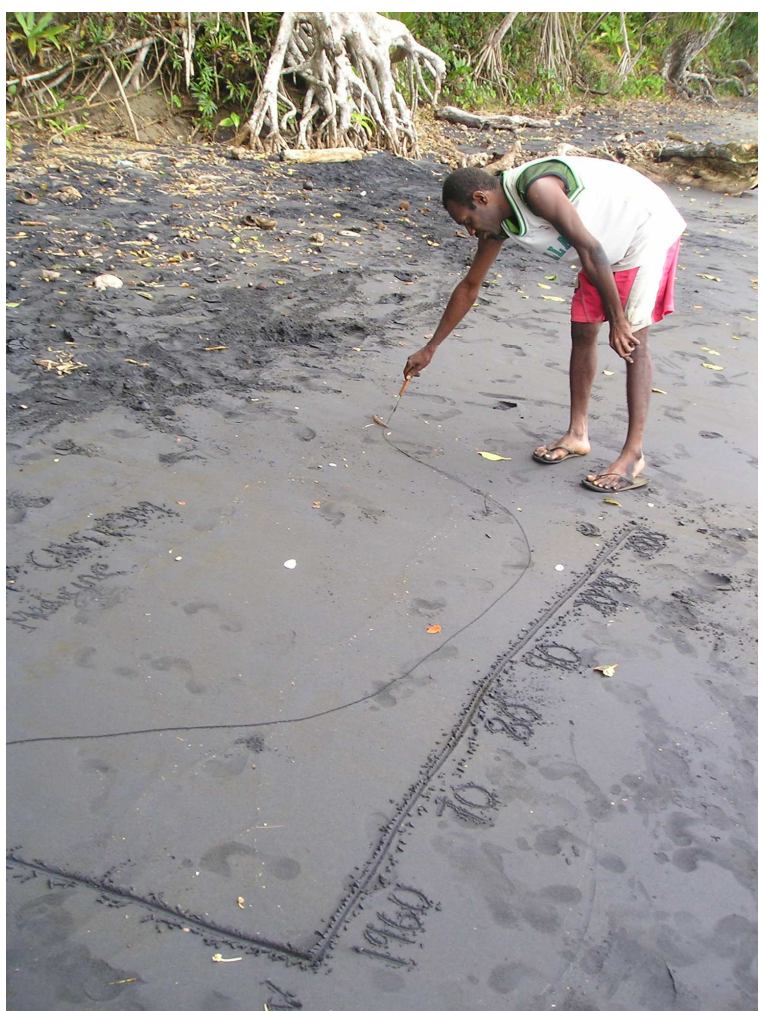

Figure 3.9, Traditional medicine specialist making a trend line (use of custom medicine) in the sand in discussion.

Trend lines were most often started at 1950 because the participants were confident about their knowledge back 50-60 years. 


\subsubsection{Focus groups}

Focus group activities are useful to engage groups of people, usually about 6-8 participants per group, in collective discussion and analysis of specific topics (Margoluis and Salafsky, 1998). Focus group activities were undertaken with sub-sets of the Tangoa population including groups of men, women, youth and elders. These groupings were based on methodological recommendations that these groups often have distinctive perspectives, and that people are often more comfortable interacting with their "peers" than in groups of mixed age and gender. Therefore these groups are more able to engage in rich discussions and generate new and valuable thoughts (Kumar, 2002). Tangoa's church system already organises people into groupings of men, women, youth and elders. Therefore this structure was utilised to organise most group activities. Three different focus activities were carried out with participants. Each activity took

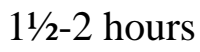

\section{Focus group activity 1: Identification of community values and goals}

The first focus group activity was designed to explore Tangoan people's goals, and to provides a foundation from which to further explore community issues in the second group activity. Thirty five members of the youth group (aged 10-25) and 13 women aged (19-60) participated. In order to explore people's goals, these focus groups of youth and women discussed two questions: "What do people value about life on Tangoa?"; and "What changes would make life on Tangoa even better?".

\section{Focus group activity 2: Problems and solutions cognitive mapping}

The second activity built from the first to elicit data for three case study objectives: to understand the underlying causes of community problems, including resource degradation (objective 2f); local strategies and solutions (objective 2g); and strategy constraints and barriers to overcoming problems (objective 2h). It involved 37 youth and 15 women in exploring focus questions: "What are the main issues and problems that people of Tangoa are concerned with?"; and "How can the problems be solved?". In relation to the 
second question, we asked groups to explain the steps of any solution processes and who would be involved.

Both focus group activities 1 and 2 followed a similar methodological format which involved:

- An introduction to ensure that participants understood the purpose of the activity;

- Dividing participants into groups. The youth group leader divided youth into four groups (ranging from 5-8 per group) by counting $1-4$ around the group. The women divided themselves into three groups for the first exercise and four groups for the second (group sizes ranged from 4-5);

- Supplying groups with large sheets of paper, colored pens and large colored crayons;

- Asking the groups to discuss the first question together and write and draw on the paper to explain and illustrate their ideas; and

- Asking the groups to present their ideas (after about working for $15-20$ minutes).

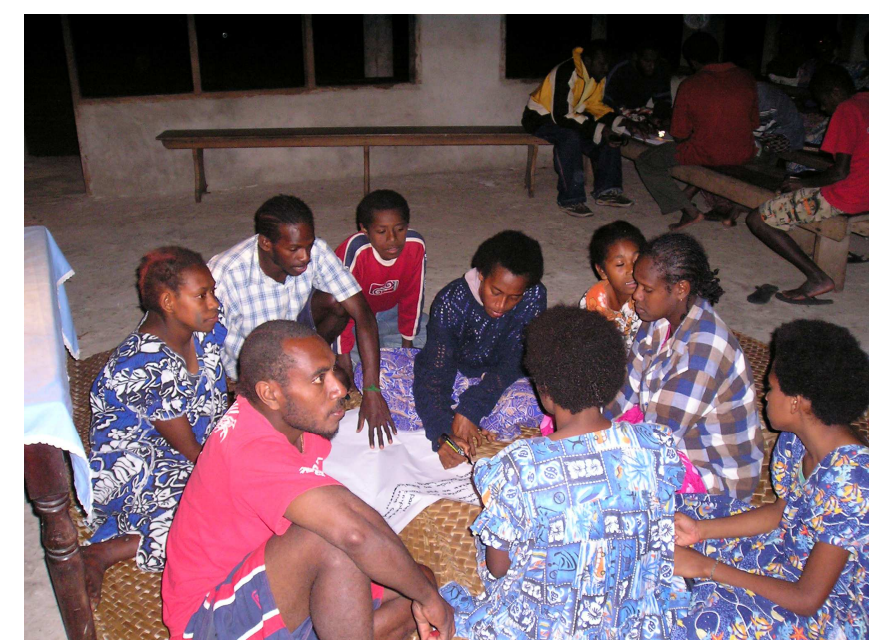

Figure 3.10, Youth group working

\section{Focus group activity three: Resource threats identification}

The final focus group activity was designed to elicit data about what local people perceive as threats to the environment and natural resources (objectives $2 \mathrm{e}$ and $2 \mathrm{f}$ ). The question was focused on the main locally defined conceptualisations of 'environment' including: sea, reef, rivers, and forest. In order to attract as many participants as possible, we carried out the activity in an 
open outdoor area where an old community meeting house once stood. About 28 people actively participated from the beginning and another 10-12 people joined as the exercise progressed. Participants were divided into four mixed gender and mixed aged groups ranging from 5 to 12 participants in each. Paper, crayons and colored pens were provided, and groups worked together to write and illustrate their ideas on the large sheets of paper.

\subsection{Census}

At the time of the research there had not been an official census of the Tangoa population since the National census in 1999. Therefore, to ascertain the Tangoa population it was necessary to do our own census. We were fortunate that Chairman of the development committee offered to carry out the census for us. He visited representative from each clan and recorded the clans' population of men women and children. Age categories included: $<5 ;<20 ;<50$; and $>50$.

\subsection{Interviews}

Besides the participatory methods described above, interviews were the other key methodology used for this study. Interviews were carried out with: Tangoa community members; provincial government and NGOs in Luganville; and Government, NGOs and aid donors in Port Vila.

\subsubsection{Interviews with Tangoans}

Thirty one interviews were undertaken with local Tangoans. These interviews were either unstructured, where no particular set or order of questions was used, or semi-structured, where a set of ordered questions was used to guide the interview (Bernard, 2002, p.205). These interview styles were used because they allow a conversational flow and flexibility of topic (Davidson and Tolich, 1999). The purpose of these interviews was to triangulate group activity data, to explore the objective questions in more detail and depth, and to investigate diversity in individual perspectives and responses. In both unstructured and semi-structured interviews, participants were encouraged to talk about ideas and issues of particular interest and importance to them. Interviewees were recruited with help of our translator who introduced us to people and then through 'snowballing', 
where participants introduced and connected us with other willing participants (Davidson and Tolich, 1999).

The topics covered in interviews had relevance to all case study objectives ( $2 \mathrm{a}-$ 2h) and included:

- $\quad$ livelihood practices of the particular informant;

- the most important resources for their livelihoods;

- $\quad$ where the important resource areas are;

- what threatens the resources or what affects the abundance and quality of the resources over time and seasonally;

- what rules and management practices exist to protect resources;

- $\quad$ how well are these rules respected and why; and

- $\quad$ how the management of the resources can be improved.

\subsubsection{Interviews with provincial government and NGOs in Luganville}

We carried out semi-structured interviews with people from non-governmental organisations and Provincial Government departments in Lugainville (see table 3.4 for a list of participant organisations). The purpose of these interviews was to gain some understanding of the wider socio-economic, political and institutional context in which Tangoa community is situated. These interviews also contributed to the third thesis objective, which asks how applicable the commons management issues identified in the local case study are for other communities in Vanuatu. The interview topics covered:

- the role of the institutions or organisations and how they are involved in community level development and environmental management; and

- $\quad$ participant perspectives about the main environmental threats and locallevel community issues in the region and the main drivers of these problems. 
Table 3.4, Interview participants in Luganville

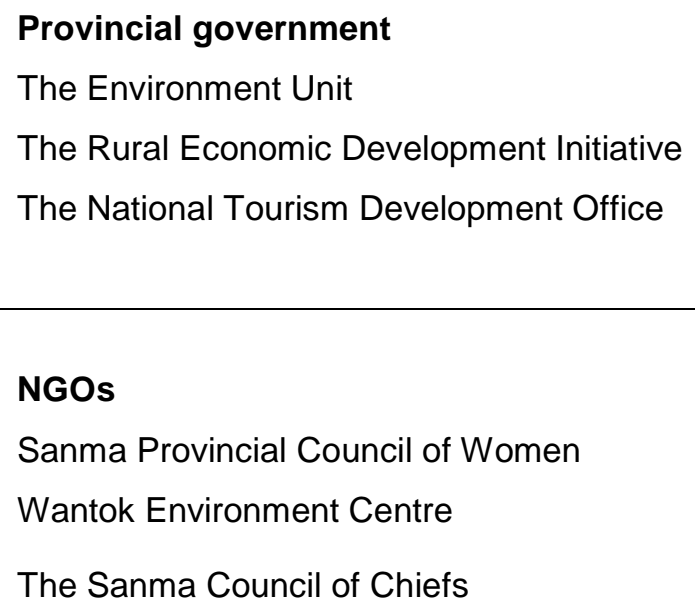

\subsubsection{Interviews with government, NGOs and donor agencies in Port Vila}

During a second trip to Vanuatu over four weeks during January and February 2007, we carried out semi-structured interviews based in Port Vila with government (see table 3.5 for list of participant organisations). Key interview questions elicited data that contributes to answering thesis objective three which asks how widely experienced the commons management issues seen in the local case study are for other communities in Vanuatu. The aim was to gain a national level perspective of local commons management problems. Interviews covered topics including:

- The role of the institutions or organisations and how they are involved in community level development and environmental management;

- $\quad$ Main issues affecting community level development and sustainable management of natural resources in Vanuatu. This question was focused so that it related to the various community-based conservation and development initiatives that the interviewees had been involved with (which ranged from marine and land-based conservation, protected areas, sustainable forestry, agricultural developments, and other income generating projects); and

- Underlying causes of problems, and opportunities for overcoming problems. 
Table 3.5, Interview participants in Port Vila

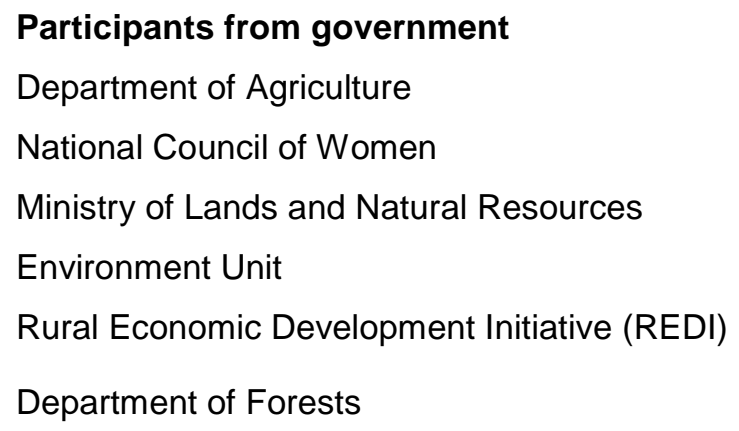

\subsubsection{Giving the Tangoa based research results back to the community}

We were able to compile the community's research and give a presentation at the conclusion of the field trip as well as providing a report of the research results. The presentation covered the following:

- $\quad$ things people value about life on Tangoa;

- main problems affecting the Tangoa Community;

- ideas about how to solve the problems;

- $\quad$ main threats to natural resources; and

- ideas about how threats to natural resources could be managed. 
The research report was presented during a return trip to Tangoa in February 2007. The report compiled the main results from the group activities in the same structure as the presentation, and included some photographs and diagrams showing trend-lines and maps. Several color copies were given to the Paramount Chief, the Pastor, the youth group and women's group leaders. Our research assistant/translator and the Chairman of the Development Committee also each received a copy.

\subsection{Data analysis}

As discussed at the beginning of this chapter, this study uses a grounded theory approach to data analysis because it allows theories and insights to emerge from data, while avoiding potential biases in research associated with testing preconceived hypotheses (Strauss and Corbin, 1998). Grounded theory data analysis was used with all case study data, as well as interview data collected in Port Vila. Following the systematic approach to grounded theory described by Strauss and Corbin (1990), analysis progressed along three stages of coding: open coding; axial coding; and selective coding.

Open coding - Data was initially coded through a process of "breaking down, examining, comparing, conceptualising, and categorising data." (Strauss and Corbin, 1990, p61) Data was organised into nine major categories, ${ }^{43}$ and within each category subcategories were determined by their different dimensions (range of variations).

Axial coding - Data was further categorised, re-organised and linked through analysis of causal conditions, responses/strategies, intervening conditions, and outcomes.

Selective coding - Hypotheses that describe the interrelationships of selected categories were developed in a final process of data analysis.

\footnotetext{
${ }^{43}$ A category represents a unit of information composed of events, happenings, and instances (Strauss and Corbin, 1990).
} 


\subsection{Summary of methods used}

This chapter has described the methods used for a case study of the factors that affect Tangoa community's management of commons resources (objective 2), and how relevant the case study data is for the wider context of Vanuatu (objective 3). A participatory research and grounded theory approach was the foundation for the methodology.

For the case study, multiple participatory research tools were employed to allow for the triangulation of data and identification of diversity in perspectives and knowledge. Group activities were supplemented and triangulated with interviews with local people. Interviews and the review of secondary, literaturebased research from Vanuatu allows me to answer the question of how widely the issues identified by the Tangoa community are relevant for other communities across Vanuatu. These results will be discussed in more detail in the results, Chapters 4 and 5. Table 3.6 provides a summary of the different methods used to explore each objective. 
Table 3.6, Summary table of objectives and methods

\begin{tabular}{|c|c|c|}
\hline $\begin{array}{l}\text { Objective } \\
\text { numbers }\end{array}$ & Objective questions & Methods \\
\hline 2 & $\begin{array}{l}\text { What are the factors that affect Tangoa } \\
\text { community's management of commons } \\
\text { resources? }\end{array}$ & $\begin{array}{l}\text { Case study using a participatory } \\
\text { research and grounded theory } \\
\text { approach }\end{array}$ \\
\hline $2 a$ & $\begin{array}{l}\text { Where are the important natural resources } \\
\text { that the Tangoa community uses? }\end{array}$ & $\begin{array}{l}\text { Participatory mapping } \\
\text { Transects } \\
\text { Interviews }\end{array}$ \\
\hline $2 b$ & $\begin{array}{l}\text { What are the important resource area (or } \\
\text { land-use) types? }\end{array}$ & $\begin{array}{l}\text { Participatory mapping } \\
\text { Transects } \\
\text { Seasonal calendar } \\
\text { Resource rating matrix } \\
\text { Interviews }\end{array}$ \\
\hline 2c & $\begin{array}{l}\text { How are Tangoa's natural resource used and } \\
\text { valued? }\end{array}$ & $\begin{array}{l}\text { Participatory mapping } \\
\text { Transects } \\
\text { Seasonal calendar } \\
\text { Resource rating matrix } \\
\text { Interviews }\end{array}$ \\
\hline $2 d$ & $\begin{array}{l}\text { Who uses and manages Tangoa natural } \\
\text { resources and how? }\end{array}$ & $\begin{array}{l}\text { Participatory mapping } \\
\text { Transects } \\
\text { Seasonal calendar } \\
\text { Resource rating matrix } \\
\text { Focus group activity } 3 \\
\text { Interviews }\end{array}$ \\
\hline $2 e$ & $\begin{array}{l}\text { What are the threats to Tangoa's natural } \\
\text { resources? }\end{array}$ & $\begin{array}{l}\text { Participatory mapping } \\
\text { Transects } \\
\text { Interviews }\end{array}$ \\
\hline $2 f$ & $\begin{array}{l}\text { What are the causes of resource } \\
\text { degradation? }\end{array}$ & $\begin{array}{l}\text { Focus group activity } 1 \\
\text { Focus group activity } 2 \\
\text { Focus group activity } 3 \\
\text { Interviews }\end{array}$ \\
\hline $2 g$ & $\begin{array}{l}\text { What are the locally identified strategies and } \\
\text { solutions to the issues and problems that } \\
\text { drive resource degradation? }\end{array}$ & $\begin{array}{l}\text { Focus group activity } 1 \\
\text { Focus group activity } 2 \\
\text { Interviews }\end{array}$ \\
\hline $2 \mathrm{~h}$ & $\begin{array}{l}\text { What are the strategy constraints and } \\
\text { barriers to over-coming problems? }\end{array}$ & $\begin{array}{l}\text { Focus group activity } 2 \\
\text { Interviews }\end{array}$ \\
\hline 3 & $\begin{array}{l}\text { How applicable or relevant are the case study } \\
\text { data is for the wider context of Vanuatu } \\
\text { (objective 3). }\end{array}$ & $\begin{array}{l}\text { Interviews and literature based } \\
\text { research }\end{array}$ \\
\hline
\end{tabular}




\section{Chapter 4 - Results Part 1: Tangoa Island Case Study}

This chapter presents the case study data, which is focused on answering the second objective question identified in Chapter 1: "What factors affect the ability of the Tangoa community in South Santo, Vanuatu, to manage their commons resources?" The case study results are based on local perceptions of commons management issues. Findings are presented according to eight subquestions:

- Where are the important natural resources that the Tangoa community uses?

- What are the important resource area (or land-use) types?

- How are Tangoa's natural resource used and valued?

- Who uses and manages Tangoa natural resources and how?

- What are the threats to Tangoa's natural resources?

- What are the causes of resource degradation?

- What are the locally identified strategies and solutions to the issues and problems that drive resource degradation?

- What are the strategy constraints and barriers to over-coming problems?

\subsection{Where are the important natural resources that the Tangoa community uses?}

The Tangoa resource area (TRA) is the area that Tangoa people use for their livelihoods, as well as for their subsistence and cash needs. During mapping activities with groups of men and groups of women, the boundaries of the TRA were explained. Figure 4.1 shows a men's map of the resource area on the mainland (Tangoa Island is not on this map, but see fig. 4.2 to see where Tangoa Island is in relation to the TRA). At the top of the map a road marks the end of the TRA and the beginning of Narongo community's resource area. To the left, the boundary is met by the Hasavia people's territory and to the right the TRA stops where church land starts. 


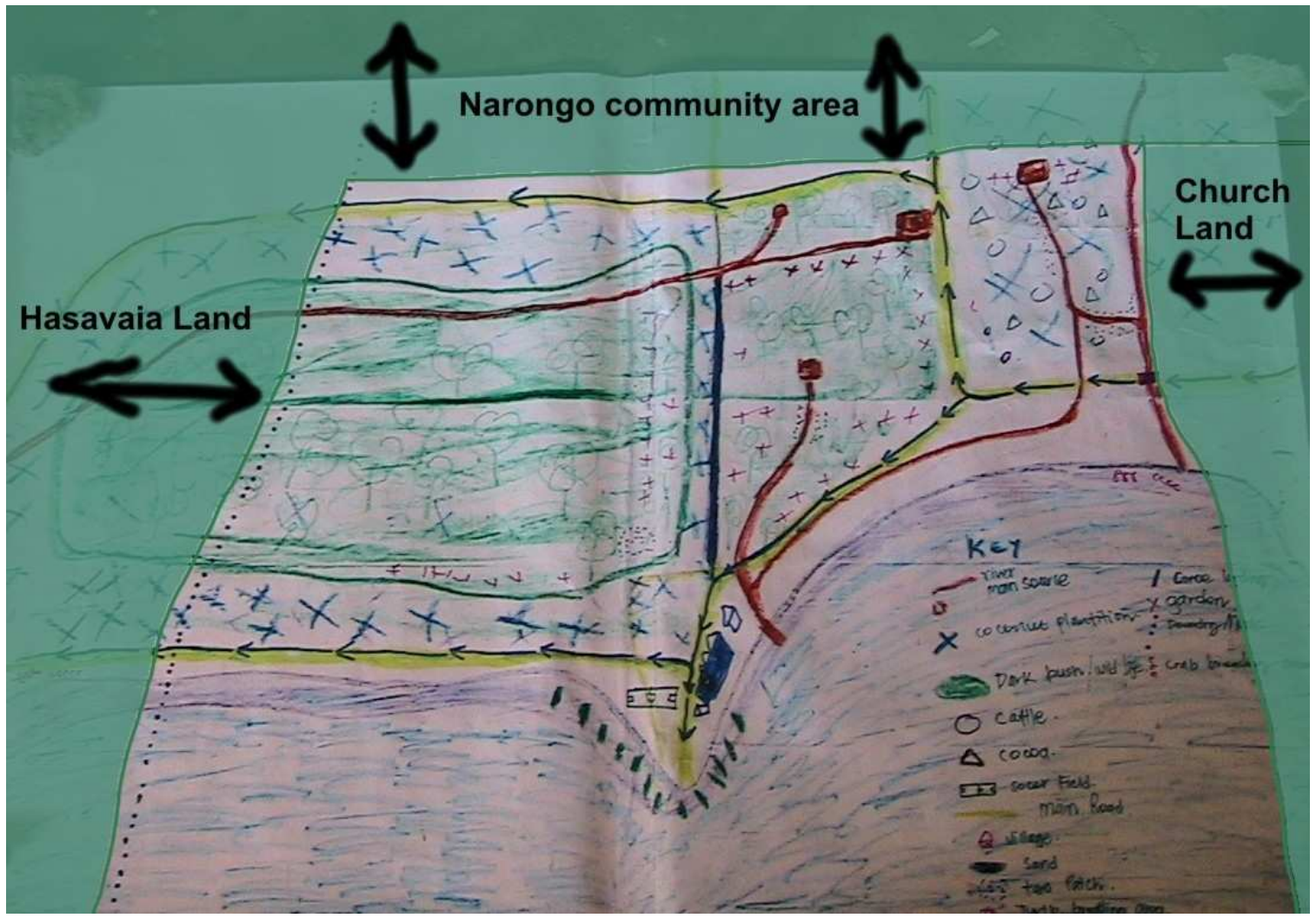

Figure 4.1, Boundaries of the Tangoa resource area shown on a men's resource map

\subsection{What are the important resource area types?}

The major resource types identified during mapping, transect walks, and resource rating excercises include: dark-bush ${ }^{44}$, gardens (including water taro plots), plantations (coconut and mixed coconut, cocoa and cattle), rivers, water sources, beaches, crab breeding and turtle breeding areas, reefs, and ocean. Fig 4.2 is a map of the TRA and the different resource areas. The map has been created by combining maps drawn by separate women's and men's focus groups and displaying the information on a digital map. ${ }^{45}$ The most notable difference between the men's and women's maps was their depiction of garden land and dark-bush boundaries. This ambiguity reflects that gardens transition into darkbush on a continuum. Once an area of dark-bush is planted, it starts to transition into the category of "garden". These areas of transition are represented in fig. 4.2 by the purple diagonal lines.

\footnotetext{
44 'Dark-bush' is the local term for lowland tropical forest. Dark-bush is defined by its use and level of cultivation. By different informants, dark-bush has been described as "natural areas, forest that has grown by itself" and "free-use". Dark-bush is generally uncultivated; it grows naturally and is not cleared or planted with crops. This differentiates it from other types of bush areas which are more closely defined as agro-forestry or gardens, where crops and trees are planted.

${ }^{45}$ The digital map is sourced from the VANRIS database (Landuse and Planning Office, Vanuatu Government, 1998)
} 


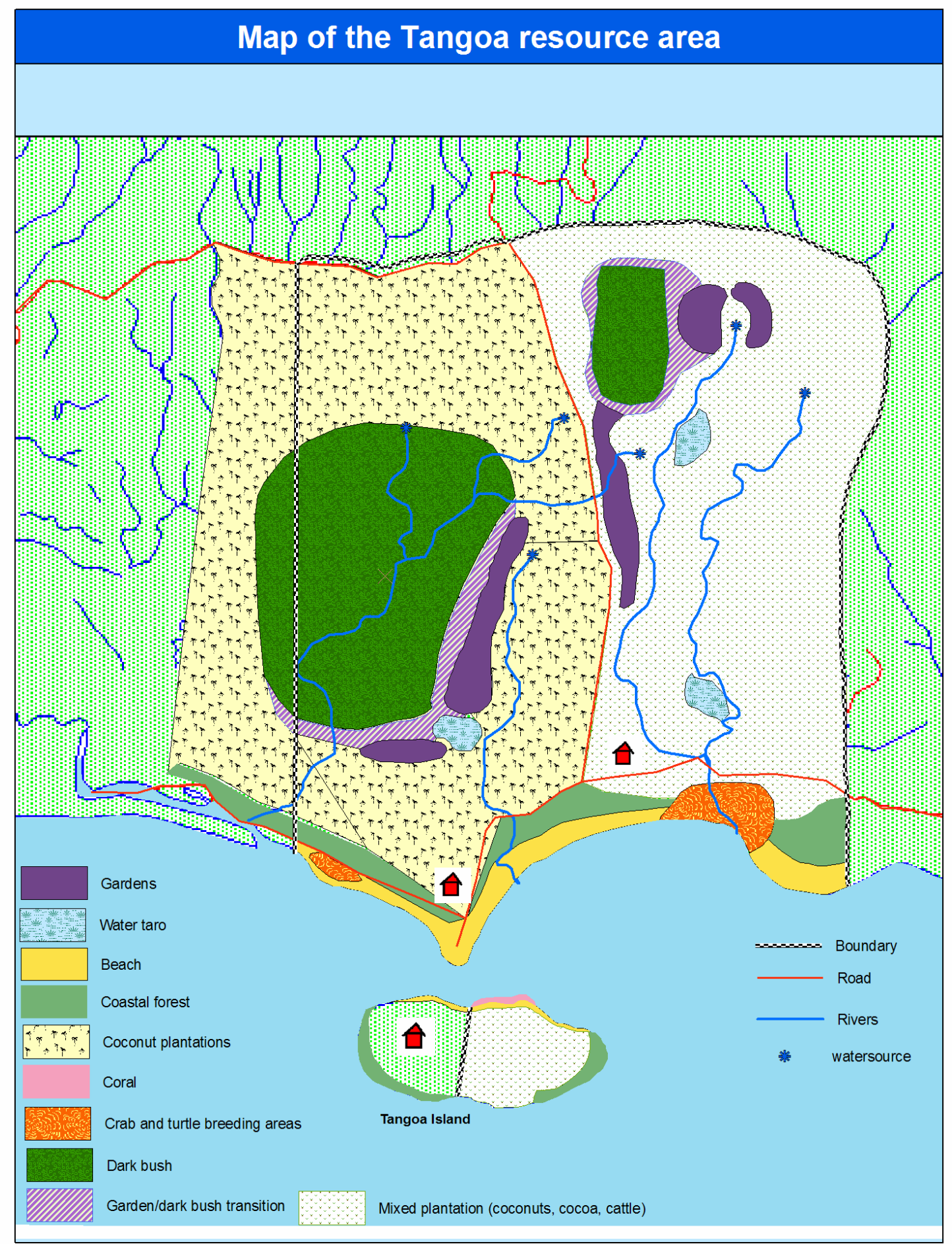

Figure 4.2, Map of the Tangoa Resource Area 


\subsection{How are Tangoa's natural resources used?}

The main resource-use categories that emerged from interviews and mapping exercises were: food; money; house-building; canoe building; weaving; and medicine. During the resource rating exercise, the men's focus group decided to include hunting as an additional important category.

Tables 4.1 and 4.2 show the results from the resource rating exercises. Results from men and women vary. This is because they utilise different areas in different ways, and hence value them differently. The main findings of the resource rating excercises are discussed below. The differences in how men and women use and value different resources are also explained. The matrix scores have relative values from 0 (not at all important) to 5 (very important).

One unexpected outcome was that some participants saw relationships within and between the categories of resource areas and uses. Instead of just considering how important garden areas or ocean and marine areas are for canoe building, the men also considered the importance of canoes for fishing, and to transport garden produce to their homes on Tangoa Island. This may indicate that we did not clearly explain that we were asking what resource areas are important for canoe building. This may affect the informative value of comparing the ratings of men and women. However, the information provided in discussions during the rating exercise helps to clarify and explain the results.

\section{Gardens}

Both men and women scored gardens as the second most important resource area type over all, after forests. Both men and women gave gardens the highest value score of five for the use-categories of food and money. The essential staple foods are grown in the garden. Tangoan staples include varieties of yams, bananas, and other fruits and vegetables. Surplus subsistence produce from the gardens is sold at local markets and in the main market at Luganville. Women are usually in charge of selling garden produce at the markets. 
Women also highly value gardens for house building, medicine, and weaving. People plant in their gardens important resources for these uses. Men explained that gardens attract wild animals (such as pigs and birds) and are therefore valuable hunting grounds.

Table 4.1, Men's Matrix

\begin{tabular}{|c|c|c|c|c|c|c|c|c|}
\hline & Food & House & Money & Canoe & Medicine & Weaving & Hunting & Total \\
\hline Gardens & 5 & 2 & 5 & 5 & 2 & 3 & 2 & 24 \\
\hline $\begin{array}{l}\text { Ocean and } \\
\text { marine areas }\end{array}$ & 2 & 3 & 5 & 5 & 2 & 1 & 2 & 20 \\
\hline Rivers & 3 & 2 & 5 & 2 & 3 & 4 & 3 & 22 \\
\hline $\begin{array}{l}\text { Plantations } \\
\text { (coconut } \\
\text { cocoa) }\end{array}+$ & 5 & 2 & 2 & 2 & 5 & 2 & 3 & 21 \\
\hline $\begin{array}{l}\text { Forest (dark- } \\
\text { bush) }\end{array}$ & 3 & 5 & 3 & 5 & 5 & 2 & 5 & 28 \\
\hline
\end{tabular}

Table 4.2, Women's matrix

Food House Money Canoe Medicine Weaving Total

\begin{tabular}{|l|c|c|c|c|c|c|c|}
\hline Gardens & 5 & 5 & 5 & 3 & 5 & 5 & 28 \\
\hline Ocean and marine areas & 5 & 2 & 5 & 1 & 2 & 1 & 16 \\
\hline Rivers & 5 & 5 & 5 & 1 & 0 & 2 & 18 \\
\hline $\begin{array}{l}\text { Plantations (coconut + } \\
\text { cocoa) }\end{array}$ & 5 & 5 & 5 & 5 & 1 & 3 & 24 \\
\hline Forest (dark-bush) & 5 & 5 & 5 & 2 & 5 & 5 & 27 \\
\hline
\end{tabular}

\section{Marine resources}

Marine resources are valuable for family subsistence and for cash generation. Both men and women harvest marine resources but do so in different ways. Men often fish with nets from canoes and dive to spear fish and collect crustaceans. Women generally collect crabs and shellfish from the shore or coastal forest areas (the important crab breeding areas are shown on fig. 4.2). Fish and crabs 
are an important source of protein for local diets, and seasonal calendars indicate the cultural significance of harvesting the palolo worm (a type of sea worm) in the seven days after the full moon in October. ${ }^{46}$ Fishing was considered by many interviewees as the most lucrative income generating activity. This is reflected in a "money" score of 5 from both men and women. According to the local primary school teacher: "Children from families that fish mostly [rather than work cutting copra] are healthier, dressed better, and can often stay in school longer because they can pay school fees."

\section{Plantations}

Families earn cash from coconut plantations, where they work cutting, drying and transporting copra. ${ }^{47}$ Coconut foliage is locally used for weaving mats while the fruit and coconut milk is a staple ingredient in cooking. Coconut can also be used in medicinal preparations. Coconut timber from old non-productive plantations is used for house and fence building.

Several interviewees explained that historically, those who owned coconut plantations were usually wealthier than those later migrants to the Tangoa area who did not have plantations. Coconut trees are still an essential element in the lives and culture of Tangoans. However, market prices for copra are volatile and currently very low. This means that the returns from copra production are low and unreliable. One man explained: "All the coconuts lay on the ground. People don't bother with them because the price is too low now. It is better to feed them to the pigs."

Other important cash crops are cocoa, vanilla and kava. ${ }^{48}$ While the market value of these products far outweighs that of copra, the area planted in these crops is relatively small. Vanilla, in particular, has only recently been planted and the vines have not yet reached maturity. Economic data about the relative values of copra and cocoa was gathered from an interview with an owner of a

\footnotetext{
${ }^{46}$ A certain type of yam (soft yam) is planted so that its harvesting coincides with that of the sea worm. The harvesting of the sea worm was an important event on both men's and women's calendars.

${ }^{47}$ Copra is the flesh of a coconut. It is first cut out of the shell, then dried in a large oven (copra dryer), and then it is transported to the processing plants in Luganville.

${ }^{48}$ A mildly tranquilizing, ceremonial drink made from the root of Piper methysticum.
} 
copra plantation, as well as a meeting with a group of three women. The women explained that cocoa is three times more valuable than copra by weight. One big bag of copra fetches a price of about 1000 Vatu, (\$14) where as a big bag of cocoa earns 3,000 Vatu (\$42). However cocoa crops tend to be smaller because it is much harder work. The women explained that the young shoots on a cocoa plant need to be cleaned every day, or the yield will be small.

While it would have been valuable to do a full agricultural census of the Tangoa population, this was beyond the scope of this study. However, several key informants provided some estimates about the number of households that had their own coconuts. Five estimates ranged from about $40 \%$ to about $65 \%$. These informants estimated that over $50 \%$ of households were growing kava, about $20 \%-30 \%$ of households were growing cocoa, and a smaller number were growing vanilla. An increasing number of people are also planting timber crops such as white wood, mahogany, and nangai ${ }^{49}$.

Interviews with a group of three women and a Tangoan man who owned a coconut plantation provided information that Tangoans that have cocoa usually harvest two big bags per year, which earns 6,000 vatu annually. Those that have their own coconut trees mostly have about 0.5 hectares, which can produce about one tone of copra four times a year. Currently, the annual earning from four tones of copra is about 76,000 Vatu (\$5429 NZD). This becomes 52,000 Vatu (3714\$NZD) after labour expenses are paid. ${ }^{50} \mathrm{~A}$ plantation owner explained that 6000 Vatu is paid to about 10-15 men who work for one week when it is time to cut copra. Copra is cut four times a year.

\section{Freshwater resources}

Freshwater resources such as noura (freshwater crayfish) and watercress have both subsistence and market value. These resources related to the 'river' resource category result in a rating of 5 for the use category of "money" by both men and women. This rating reflects the cash component from selling to the

\footnotetext{
${ }^{49}$ Nangai is a nut tree of the scientific name: Canarium indicum.

${ }^{50}$ The average price in the past for one ton of copra was 29,000, (2070\$NZD) now it is about 19,000 Vatu $(1357 \$ N Z D)$
} 
market. 'River' also includes riparian vegetation and water taro patches. Although water taro has little market value, women explained that it is a very important subsistence crop, especially in hard times (e.g. after cyclones). This explains their score of 5 for 'food' as a use category.

Women also considered rivers important for house building materials, explaining that after collecting vines used to secure thatch roofs, they soak them in the river to improve their flexibility. Men gave rivers a high score for the use category of 'weaving'. This is because men see women soaking weaving materials in rivers to soften them. Women generally do the weaving, so they have a better idea of where the important weaving materials come from and scored the 'garden' and 'dark-bush' resource areas as most important.

\section{Dark-bush}

Dark-bush is a resource type that is valuable for all resource-uses defined by participants. Both men and women gave 'dark-bush' the highest possible score for the use categories 'house building' and 'medicine'. Women also gave it a score of five for 'food', 'money', and 'weaving'. Men gave it a score of five for 'canoe building' and 'hunting'. Discussions and activities revealed that men generally build canoes, and hunt more than women.

Products from the dark-bush are gathered for household consumption as well as to sell at the local markets. Wild yams grow in the dark-bush and are an essential food source in times of emergency, such as after cyclones when garden crops have been damaged. The dark-bush also provides plentiful and diverse types of fruit and medicinal products. It is the habitat for wild animals that are most valued by hunters such as flying fox (bat), wild pig, wild bull, and a variety of birds. House-building timbers, thatches and vines grow in the dark-bush, as well as trees for making canoes such as blue-water, mahogany, and mango.

The forest provides timber for firewood and many weaving materials. Some weaving materials, such as natangora, are planted in gardens. However the most 
culturally and economically valued material for the fine craft baskets and mats the fibrous nalu vine - is only gathered from the dark-bush.

\subsection{Who uses and manages Tangoa natural resources and how?}

\subsubsection{Tenure arrangements}

Access to, use, and authority to manage various resources within the TRA is largely defined by tenure arrangements. Today, the land that Tangoa people live on has the official (government recognised) tenure status of leased land (Landuse and Planning Office, Vanuatu Government, 2000). As discussed in the introduction to the research site (section 3.2.2), Tangoa resource area is leased from the government by private investors and the Presbyterian Church. Indigenous ownership has not yet been determined. Despite this, the area is largely governed under a community-based tenure system. Under communal tenure, the allocation rights for land and resources are held under various forms of customary authority. In the case of Tangoa, resources under communal tenure may be used and controlled individually or collectively

Access rights to common property resources, and to individual lands under communal tenure are based on group membership (clan affiliation) and longterm residency on Tangoa. Land and resource allocation and distribution is the function of customary institutions, and current demographic pressures. In the past, the Chiefly authority could allocate land to new migrants. Rights are now generally restricted to members who share a common lineage. During a transect walk a Tangoan elder explained: "If you have no land you can make an agreement with someone to get some land for a garden...but now most land is taken already and there is not much space to share." One informant explained that rights to land are recognised on a long-term basis and are transferred in families by inheritance: "This will always be my family's land." However, another informant explained that the duration of rights can be determined by evidence of continuous use. One Tangoan man explained that after being away from Tangoa for 10 years, his inherited land had been used by his brothers. Now he has no land for his family, and must make a living by running several small businesses. 
Several key informants explained that one important result of these tenure arrangements is that more recent migrants, such as those that came in the early 1980s, have less quality and quantity of land for gardens. Local data suggested that women's access to land is indirect, through their husbands or sons. ${ }^{51}$

Research results about management and tenure of different resource areas show that types of resources within the TRA fall under four broad tenure categories. This data was gathered from transect walks, mapping exercises with groups of men and women and interviews with 3 key informants. There are three forms of communal tenure: common property; areas that are controlled by clans (extended family groups); and areas controlled by Tangoa households. The fourth type of tenure is privately controlled land and resources by nonindigenous individuals or organisations. The individuals with tenure over land are primarily investors and the most important organisation holding land is the Presbyterian Church. Some details about the different tenure arrangements, how they are used, and who has the authority to manage them is provided below. Figure 4.3 illustrates this information on a map, and it is summarised in table 4.3.

\footnotetext{
${ }^{51}$ Land transfer is complex. While local informants presented a simplistic explanation for us (i.e. from father to son), traditions of matrilineal transfer may still be practiced. If so, this would mean that women have access to land through their mother's brother.
} 


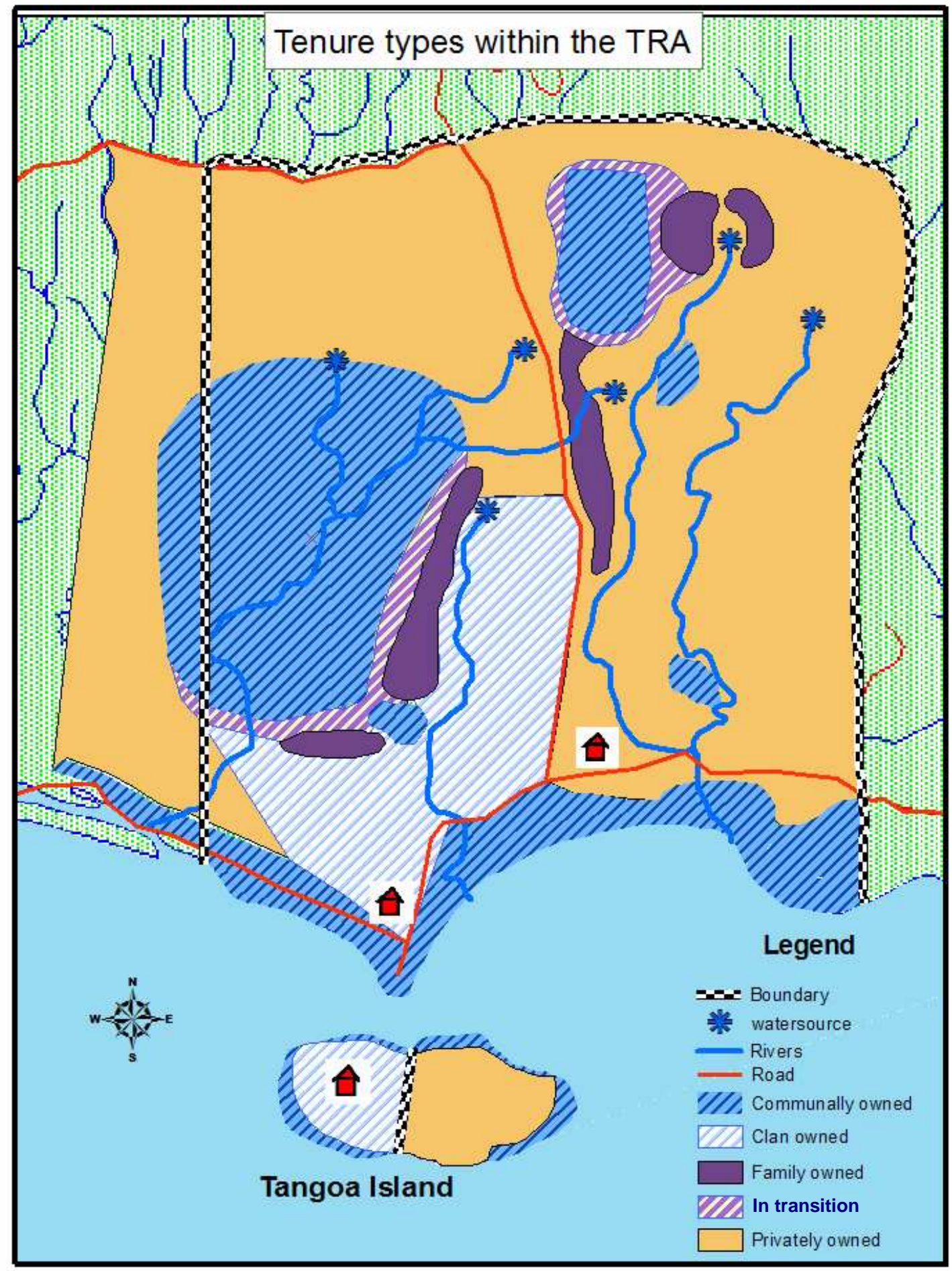




\section{Common property}

Areas and resources that fall under common property or shared resource tenure include: marine areas; rivers; water sources; dark-bush (forest areas); and water taro patches. During mapping exercises it was established that anyone from the Tangoa community can harvest and use these resources (see figure 4.3). The common property areas are governed by a customary governance regime which is a set of institutions, regulations and management practices which is subject to collective decision-making by Tangoan people, lead by Chiefly authority.

\section{Clan owned}

Clan owned areas within the TRA include some coconut plantaions, the clan villages on Tangoa Island where the households belonging to particular clans are situated and marked by gardens, hedges and other forms of landscaping. Figure 4.4 is picture of a social map made by three men. The circular lines mark clan area boundaries. Some clans also have claim to certain areas at the back of the island, which is a narrow forested area between the villages and the shore. This area is used to keep pigs and one clan has built a meeting house on their land. Although these areas are not officially or legally registered to indigenous owners, there is a shared understanding of the tenure and boundaries of these clan controlled areas on Tangoa Island. Within these boundaries the clans have some autonomy from the Paramount chief to decide how to use these areas. Decisions are governed by the customary authority/leaders within the clans who may be elected chiefs; or councils made up of elders and their first sons.

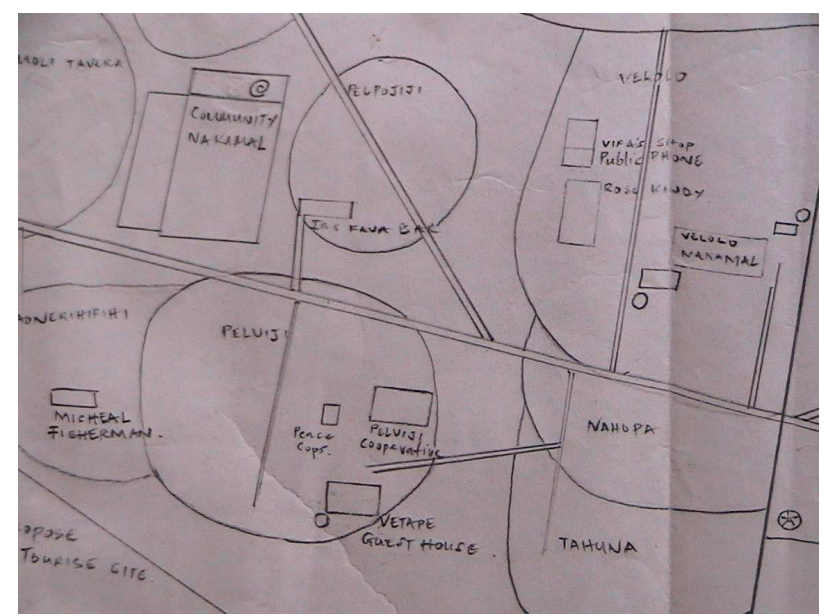

Figure 4.4, Social map of Tangoa Island showing clan areas (made by three men) 


\section{Tangoa household owned}

Gardens and some coconut plantations are owned by individual households. During a transect walk a Tangoan elder explained: "Once you plant your family owns it. People respect that." Triangulation with others revealed that different forms of tenure relate to fruit trees and crops that can be 'owned' or retained in exclusive use for those who plant them - even when the trees or crops are planted in commons or clan owned areas. Customarily, men are considered the chief decision-makers concerning household resources; however data from interviews and seasonal calendar exercises with groups of men and women indicate the management responsibilities and decisions concerning gardens are often shared (to varying degrees between households). One woman explained that in terms of decisions about managing gardens: "I decide what to plant. I take it to the market and see what will sell."

\section{Private leasehold land}

Some plantations within the TRA are individually/privately used and controlled by leaseholders who are non-indigenous individuals or organisations (i.e. church, and private investors). Since the early 1960's the northern side of Tangoa Island has been used by the Taulua Bible Training Center (Presbyterian Church). While the Church uses the land for coconut and cattle, villagers are permitted to fish from the shore, collect shell-fish, crabs and some fruit from this side of the island. This is usually done by the "mammas" (women) and children. The church hires a caretaker for the leasehold on Tangoa Island and subleases an area on the mainland to an Australian investor. This area is called Navota Farm and is predominantly used for coconut plantations and cattle.

While there have been no successful claims by Tangoans for the Church controlled land on Tangoa Island and on the mainland, the Customary Lands 
Tribunal Act of 2001 makes it is possible for customary land owners to win ownership and control of this land. ${ }^{52}$

Table 4.3, Types of tenure, use, and authority to manage in the TRA

\begin{tabular}{|c|c|c|c|}
\hline Type of tenure & Who uses it? & $\begin{array}{l}\text { Who has authority } \\
\text { to manage? }\end{array}$ & $\begin{array}{l}\text { Example of } \\
\text { resources/areas }\end{array}$ \\
\hline Common property & All Tangoans & $\begin{array}{l}\text { Paramount Chief and } \\
\text { Chief's Council have } \\
\text { ultimate NRM } \\
\text { authority. All } \\
\text { Tangoans are } \\
\text { responsible for } \\
\text { abiding, } \\
\text { implementing and } \\
\text { maintaining } \\
\text { management } \\
\text { customs and rules }\end{array}$ & $\begin{array}{l}\text { Marine areas, rivers, } \\
\text { water sources, dark- } \\
\text { bush (forest areas), } \\
\text { water taro patches }\end{array}$ \\
\hline $\begin{array}{l}\text { Communal tenure (clan } \\
\text { owned) }\end{array}$ & Clans & $\begin{array}{l}\text { Clan leaders. (Clan } \\
\text { chiefs, committees or } \\
\text { councils made up of } \\
\text { elders and their first } \\
\text { sons) }\end{array}$ & $\begin{array}{l}\text { Clan village areas on } \\
\text { Tangoa Island }\end{array}$ \\
\hline $\begin{array}{l}\text { Communal tenure } \\
\text { (Tangoa households) }\end{array}$ & Tangoa households & $\begin{array}{l}\text { Heads of the } \\
\text { household (men are } \\
\text { customarily seen as } \\
\text { the heads of the } \\
\text { households, but their } \\
\text { wives also make } \\
\text { important NRM } \\
\text { decisions at the } \\
\text { household level) }\end{array}$ & Gardens, plantations \\
\hline $\begin{array}{l}\text { Private (Non- } \\
\text { indigenous } \\
\text { leaseholders) }\end{array}$ & $\begin{array}{l}\text { Private interests } \\
\text { (investors, or } \\
\text { organisations i.e. } \\
\text { church) }\end{array}$ & $\begin{array}{l}\text { Leaseholders and } \\
\text { their managers/ } \\
\text { caretakers }\end{array}$ & Plantations \\
\hline
\end{tabular}

\subsubsection{Governance Institutions}

\section{The Paramount Chief and his council}

The Paramount Chief is the head decision maker in the community. His role is to make and enforce rules that determine access and use of common property resources, provide leadership and governance, resolve disputes, and manage community funds (e.g. aid/disaster relief). The Chief is supported in his role by

\footnotetext{
${ }^{52}$ For more information about this Act and the process of its implementation see: Simo, J. Report of the National Review of the Customary Land Tribunal Program in Vanuatu. The Vanuatu Cultural Centre, Port Vila. http://www.vanuatuculture.org/projects/050627_customarylandtribunalreport.shtml
} 
the Council of Chiefs. The council is made up of the chiefs or leaders of each different $\operatorname{clan}^{53}$, and representatives of different groups and committees such as a youth group, a women's group, the Congregation Life Committee (church), an environment committee, and a development committee. The Paramount Chief has an Assistant Chief and a Chairman who help coordinate the council. The Tangoa Council of Chiefs and the Paramount Chief makes consensus decisions concerning natural resource management. Figure 4.5 illustrates Tangoa's community governance structure as drawn by one Tangoan man and triangulated by several others.

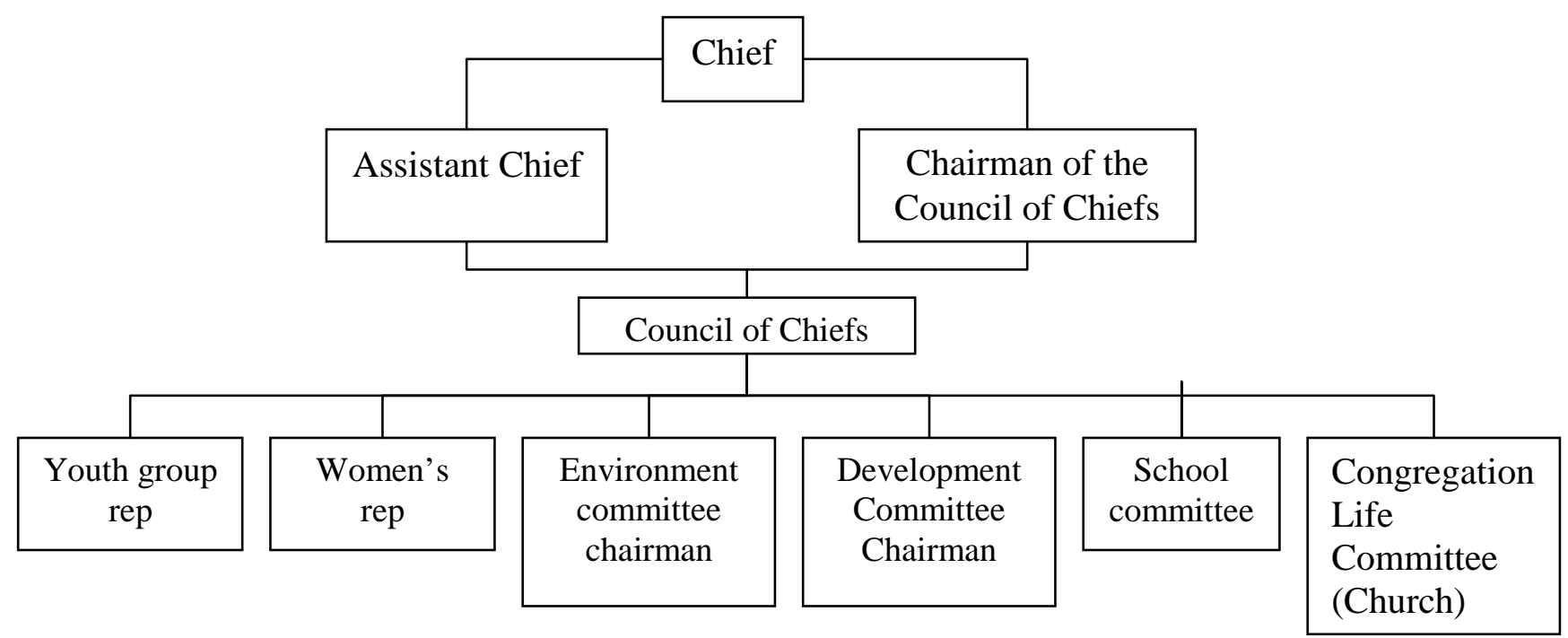

Figure 4.5, Community governance structure

\section{The role of women in decision-making}

Customarily women have a minimal role in decision-making at a community level. They have a women's representative on the Council of Chiefs. This representative, however, is a man. They generally communicate concerns via their husbands. As one informant explained: "They will pressure their husbands to represent them." A representative from the Sanma women's council explained that women's ability to earn money has helped to empower women so that they have more respect and influence the household level. Earning money gives

\footnotetext{
${ }^{53}$ Some clans have elected Chiefs and others have not. Generally the family leaders that are on the Council of Chiefs are nominated through a consensus decision-making process involving the eldest male or eldest son of each family within the clan.
} 
women more bargaining power with their men, which in turn increases their influence at the community level. A Tangoan weaver explained: "Now as my husband is training to be a carpenter, I am making most money for my family with my baskets. He has to listen to me more now!"

\section{Customary law and traditional management practices (TMPs)}

Customary law and practice or "kastom" ${ }^{, 54}$, forms the basis of group tenure and collective resource management. Traditional management practices (TMPs) were discussed in numerous interviews. A vast amount of knowledge about how to use, manage, and monitor resources exists in custom stories, songs, and the unique local language.

This kastom knowledge is reflected in such things as the names of particular places, species of wildlife and plants, and the way weather is forecast. A traditional weather expert explained that certain indicators and events in nature signal and predict change in resource abundance, both natural (e.g. seasonal and cyclic) or human driven. These predictors are customarily used to guide NRM. The most commonly identified example of NRM rules was the use of taboos. Taboos are rules that restrict resource use. They may determine when, where, and how resources can be used, and by whom. There are traditional management practices for soil conservation, conservation of certain species and ecologically sensitive areas, management of resource stocks, building habitats, and NRM practices for cyclone preparation (see table 4.4 for summary and examples of some management practices identified during mapping exercises, transects, and interviews).

\footnotetext{
54 'Kastom' refers to the unwritten ways, thoughts and conduct that are held to be morally good, right and true for the ni-Vanuatu. Kastom refers to the values and rules of behavior upheld by the communities in the rural areas (Kalontano et al. 2003).
} 
Table 4.4, Select natural resource management practices

\begin{tabular}{|l|l|}
\multicolumn{1}{|c|}{\begin{tabular}{c}
\multicolumn{1}{|c|}{$\begin{array}{c}\text { Type of management } \\
\text { practice }\end{array}$} \\
\cline { 2 - 2 } Soil conservation
\end{tabular}} & $\begin{array}{l}\text { Planting pandanas and vemeu along river banks; rules } \\
\text { about not cutting trees near rivers. }\end{array}$ \\
\hline Species conservation & $\begin{array}{l}\text { Restrictions on size of and number of coconut crabs; rules } \\
\text { about when crabs can be harvested }\end{array}$ \\
\hline $\begin{array}{l}\text { Conservation of ecologically } \\
\text { sensitive areas }\end{array}$ & $\begin{array}{l}\text { Taboos on certain marine areas e.g. rules about where } \\
\text { canoes can be landed (to minimize damage to reef) }\end{array}$ \\
\hline $\begin{array}{l}\text { Management of resource } \\
\text { stocks }\end{array}$ & $\begin{array}{l}\text { Rules about where and how trees can be harvested (i.e. } \\
\text { only where there are seedlings to grow in their place) }\end{array}$ \\
\hline Building habitats & $\begin{array}{l}\text { Women build 'crab piles' - mounds of rocks where crabs can } \\
\text { live. Food scraps and grated coconut flesh is thrown onto } \\
\text { the piles to feed the crabs }\end{array}$ \\
\hline $\begin{array}{l}\text { Use of environmental } \\
\text { indicators }\end{array}$ & $\begin{array}{l}\text { Letting environmental indicators (i.e. the flowering of certain } \\
\text { trees or coral) }\end{array}$ \\
\hline Cyclone preparation inform when taboos should be set or lifted \\
\hline
\end{tabular}

\subsection{What are the threats to Tangoa's natural resources?}

Interviews and group research activities generated detailed information about environmental problems, what local people consider to be the immediate causes of resource degradation, the secondary environmental effects, and the consequences for local livelihoods. This information falls under the four broad categories of forest degradation, soil degradation, and degradation of marine and freshwater resources.

\subsubsection{Forest degradation}

Ten interviewees and five focus groups (two from 'problems and solutions cognitive mapping' and three from 'threats identification') identified that unsustainable rates and practices of harvesting timber are occurring. The result is the degradation of the dark-bush, and scarcity of timber resources. The data collected show two immediate causes. The first is population pressure: "Too

\footnotetext{
${ }^{55}$ A traditional weather expert explained that, in a similar way that trees and plants flower in particular seasons, particular corals and marine plants also 'flower', and go through seasonal changes.
} 
many people are taking wood from the dark-bush." The second is declining respect for customary taboos related to the dark-bush: "Before, people would only take a big tree in places where small trees will grow in its place. Now people do not respect that taboo."

Although population growth was a general cause, more specific elements were identified. Clearing dark-bush for gardens, plantations and cattle is reducing the size of dark-bush areas ${ }^{56}$ (see figures 4.6 and 4.7). People identified population growth as an immediate cause: "As families grow, people will keep clearing more bush for gardens." Another element is local people's lack of authority to govern some areas within the TRA as they are under the control of private investors and the Church: "The investor can decide to clear more bush for cattle. Some local people do not want this, but they will still clear the bush for him [investor] because he will pay. If he does not pay us, he will bring other people to do it."

Social conflict can also be a cause of forest degradation. In the past, people have logged trees in dark-bush areas that are under dispute as an act of sabotage against rival land claimants ${ }^{57}$ (see figures 4.6).

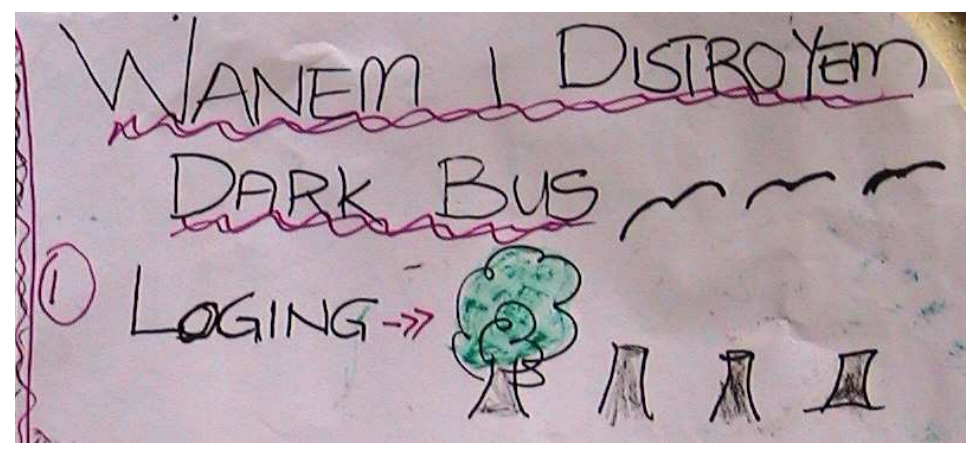

Figure 4.6, Focus group poster (mixed gender) "What destroys the dark-bush: logging"

\footnotetext{
${ }^{56}$ Relatively large scale clearing of dark-bush is occurring to make way for more coconut plantations and cattle. A local investor is extending his plantation and coconut farm in an area close to the TRA. The Tangoa community has provided labour for clearing bush for this investor in the past, which funded the building of the church and paid the Pastor's salary, and has been hired to do clearing again.

57 'Illegal' logging has occurred in dark-bush on disputed land. When a land claim was almost settled, disputed claimers quickly harvested trees. Several informants speculated that the loggers "wanted to benefit while they still had a chance" (thinking that once the claim is settled, they will be restricted from these benefits). Others considered it to be conflict related sabotage. This type of conflict has resulted in resource degradation as well as violence between disputing claimers.
} 


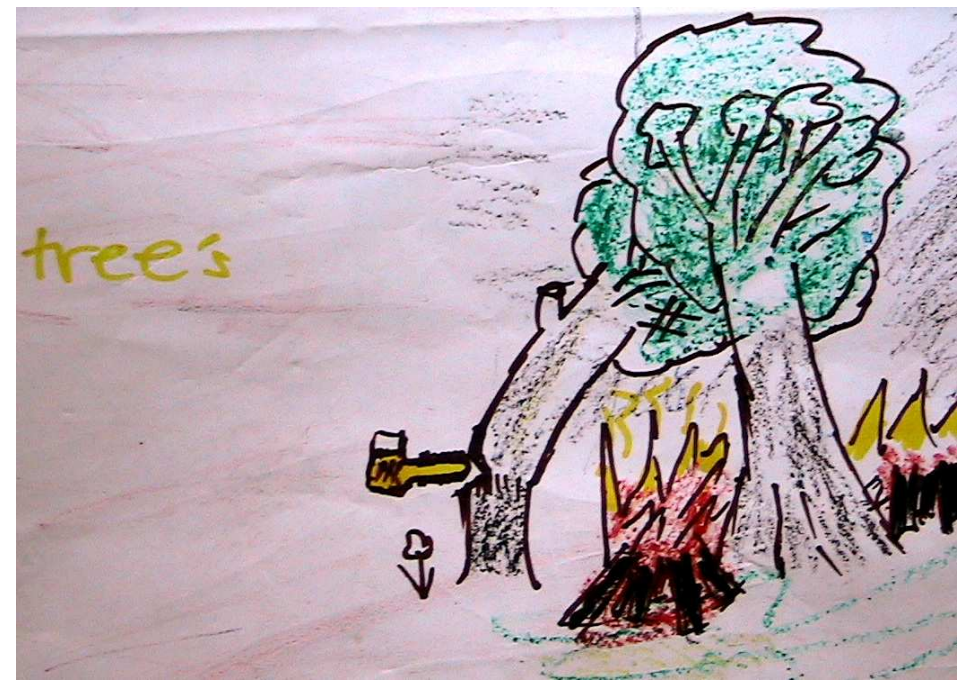

Figure 4.7, Mixed gender focus group illustration of logging

Degradation of dark-bush has secondary environmental and livelihood effects including habitat loss for important wildlife resources such as hunting. Two hunters, one young man and one more senior man, identified how the abundance of particular species has changed over time. Both separately drew trend lines that showed a steady decline in wild animals. The older hunter explained how the use of muskets in the 70s and 80s has had a dramatic impact on flying fox numbers (see fig. 4.8). However both hunters identified loss of habitat and over harvesting of wild animal resources as current causes. 


\section{Abundance of wild animals}

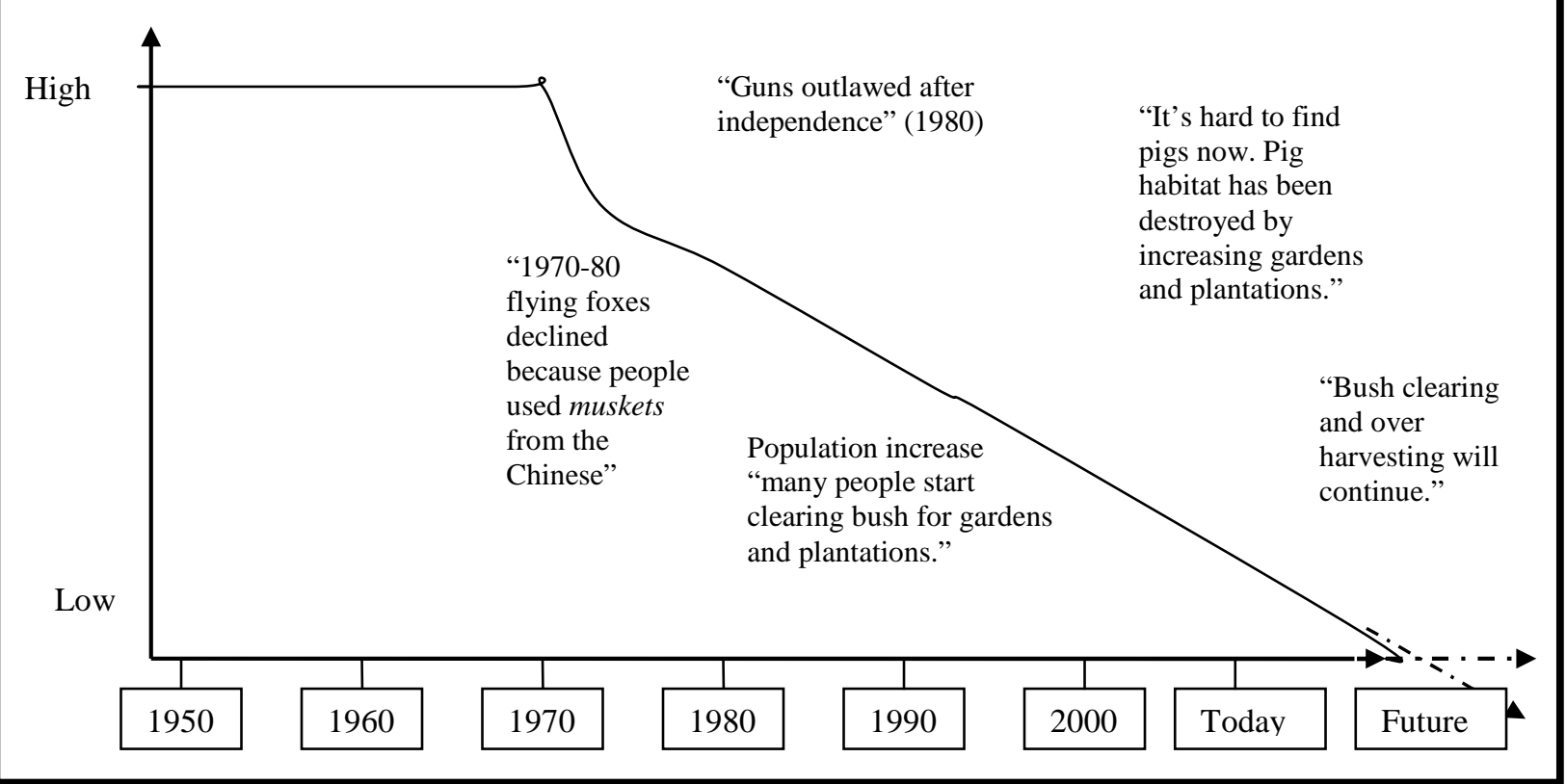

Figure 4.8, Trend analysis of the abundance of wild animals by two informants

Another secondary effect of clearing dark-bush is the degradation of fresh water and marine resources. During the mapping and resource rating exercise, men explained that clearing dark-bush has changed the level of water and direction of river and stream flows. This has caused the drying of swamps where water taro grows. This, in turn, has important impacts on food security as water taro is valuable back-up crop in times of need.

\subsubsection{Soil degradation}

The main cause of soil degradation is increased land-use intensity in the garden areas. Increasing population and limited land area for gardens means that fallow periods (times when gardens are left uncultivated in order to allow them to regenerate) have shortened. While on a transect walk, a man explained: "In the past, people could leave their gardens in fallow for 4-6 years. Now there are more people using the same area. They have to clear and use the same ground every two years." 
Soil erosion is also a problem when bush is cleared for coconuts and cattle, and when coastal or riparian trees are cut. Soil erosion has some important secondary impacts on freshwater and marine resources systems.

\subsubsection{Degradation of marine resources}

Interviewees and focus groups of men and women identified that the abundance of marine resources has declined (see fig. 4.9). The perceived causes were: that there are more people fishing (due to growing population); people are catching more fish to sell at the market for cash (instead of just for subsistence); and because they are using small mesh nets (modern fishing technology) which catch all the small fish. Use of small mesh nets makes it difficult for people to respect a customary taboo which restricts harvesting of small fish.

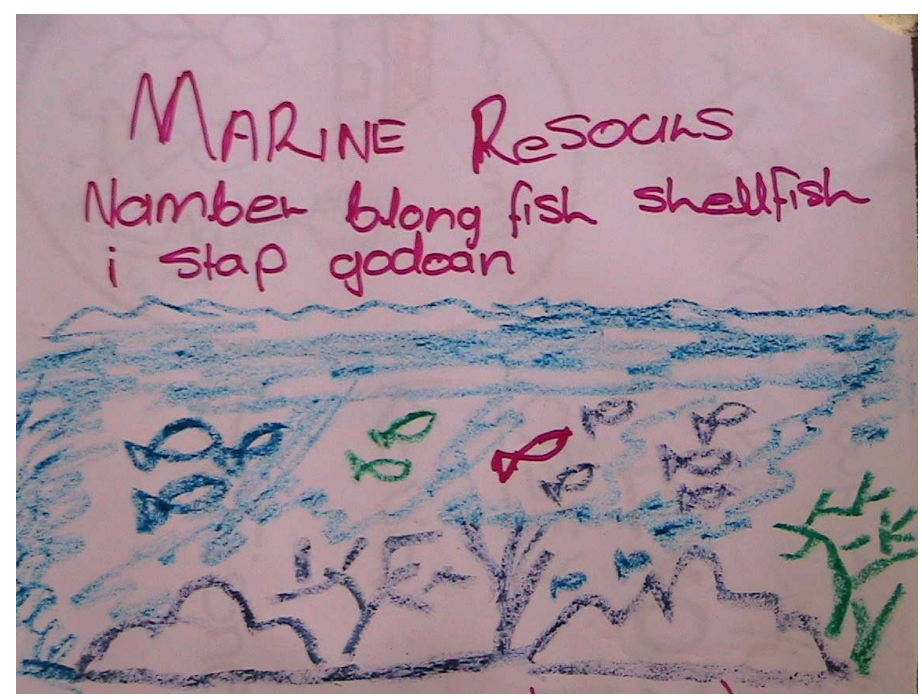

Figure 4.9, Women's focus group poster illustrating degradation of marine resources: "The number of fish and shellfish has gone down"

Based on trend analysis, Figure 4.10 shows the different perspectives of an older fisherman and a younger fisherman. The older considers that a recent marine taboo set by the fisheries department has had no effect: "People break the marine taboo when they need to make cash by selling fish." He also believes that fishing will increase if a local project to build a freezer to store fish goes ahead, enabling access to bigger markets (e.g. Luganville).The younger fisherman expressed that a Fisheries Department taboo on a marine area near Tangoa had helped increase fish numbers, and that the Department's artificial fish breeding 
habitat (a floating raft) might also help to boost numbers. Several others considered this unlikely, as the 'raft' has been broken for over a year and the Fisheries Department has not come to fix it. Also, the raft is not a suitable breeding habitat for some of the most important species that are being affected by over fishing.

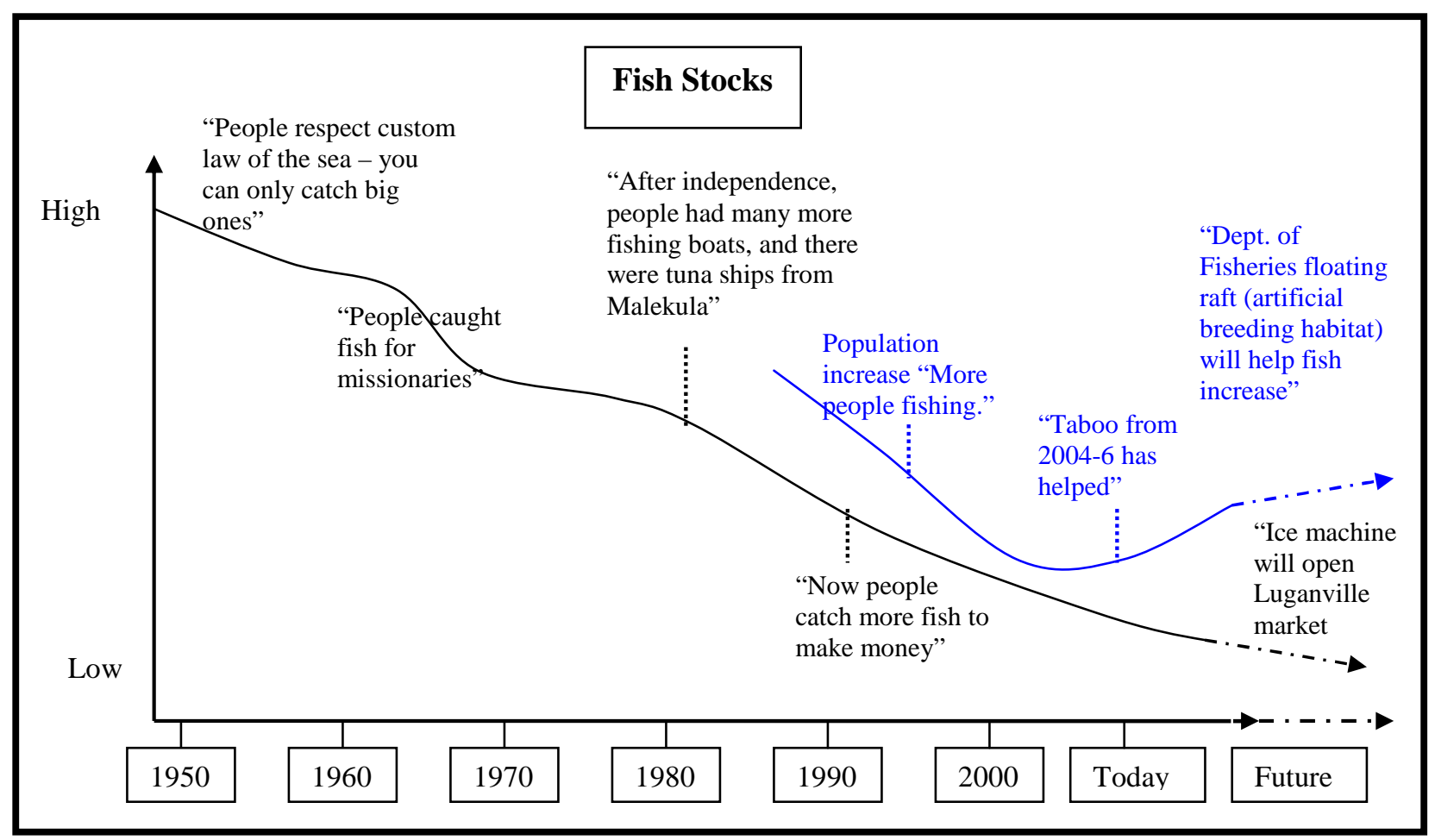

Figure 4.10, Trend analysis of change in fish stocks (by an old fisherman (black line) and a young fisherman (blue line)

Tangoa beach on the north side of Tangoa Island is also being degraded by the harvesting of sand to make concrete (for the modern style of house building) and for landscaping (i.e. paths) in the village. Coral reefs are being damaged by the landing of canoes, as people no longer respect custom taboos that restrict canoe landing to certain areas. Reefs are also affected by sedimentation of rivers from land based activities. Marine resources are also degraded by the disposal of waste into the sea. Dumping of batteries and iron roofing material was seen a particular concern (see fig. 4.11 and note the last item listed translates into "cutting all the trees close to the coast"). Non-biodegradable waste is relatively 
new, arriving with western products and packaging. As a resulte, there are no customary taboos or rules to manage this problem. ${ }^{58}$

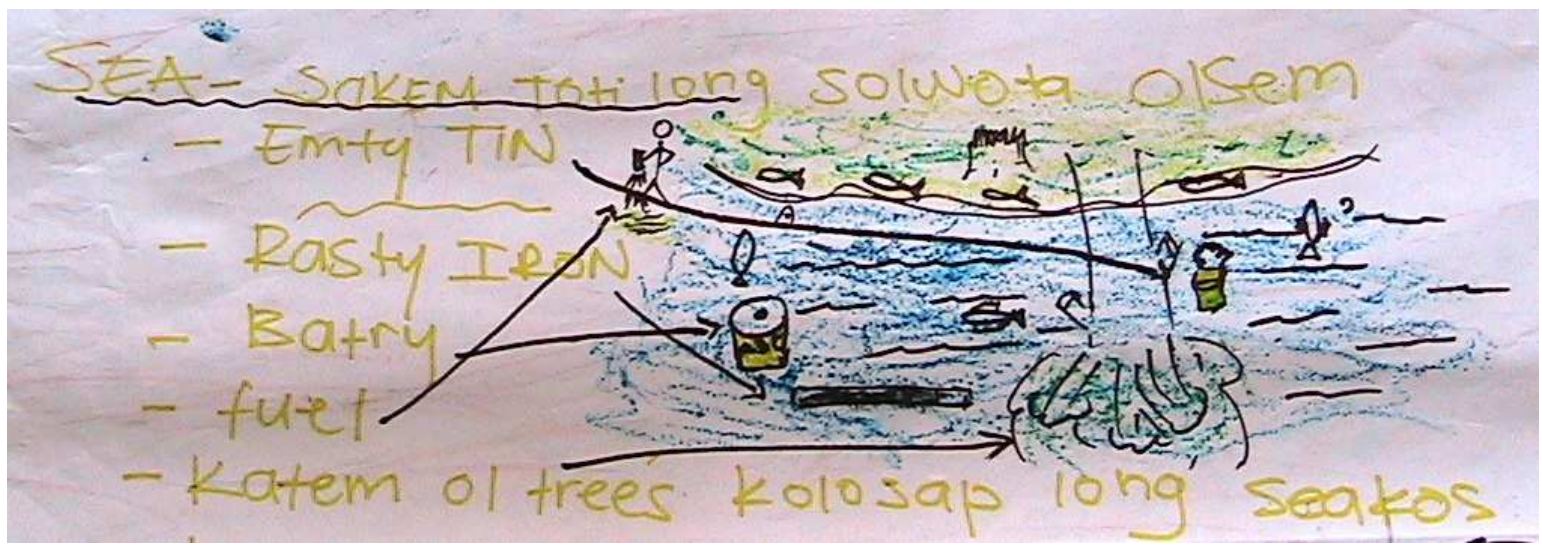

Figure 4.11 Mixed gender focus group poster identifying causes of marine resource degradation

\subsubsection{Degradation of freshwater resources}

Freshwater resources such as noura (freshwater crayfish) are also declining for reasons similar to those for marine degradation above. People are taking too many to sell at the market, and more people are harvesting them. Freshwater resources (as well as coral reefs and marine fish breeding areas) are negatively impacted by increased sedimentation from clearing bush and cutting trees near rivers and along the coast. There is a customary taboo against harvesting trees near rivers and the coast; however people are increasingly breaking the taboo.

The practice of letting cattle near rivers and water sources was identified by focus groups as the cause of water pollution, erosion of river beds, and sedimentation. This damages fresh water resources such as fish, noura, water taro and water cress. The health of local people that drink the water is also affected. Several women perceived that cattle farming on coastal land may also be negatively impacting crab breeding areas. There are no customary rules about farming cattle near rivers and water sources and local people feel that their ability to make rules is overpowered by the cattle owners (private investors). As we came to a river along a transect walk, an informant explained: "Cattle come

\footnotetext{
${ }^{58}$ There lacks an effective waste disposal system on Tangoa. Rubbish is laid out at the back of the island to dry and degrade. Some organic waste is fed to pigs. The non-degradable waste is burned. Increase in imported food goods is increasing the about of waste and modern food packaging (tin cans, plastic etc.) takes a long time to degrade and often ends up in the reefs. Local people explained that cyclones "clean the island" (by bowing all the rubbish into the sea).
} 
in here and trample the area where water taro grow. They make a mess and sometimes people who drink the water get sick. But this is investor land so we can't do anything." See fig. 4.12.

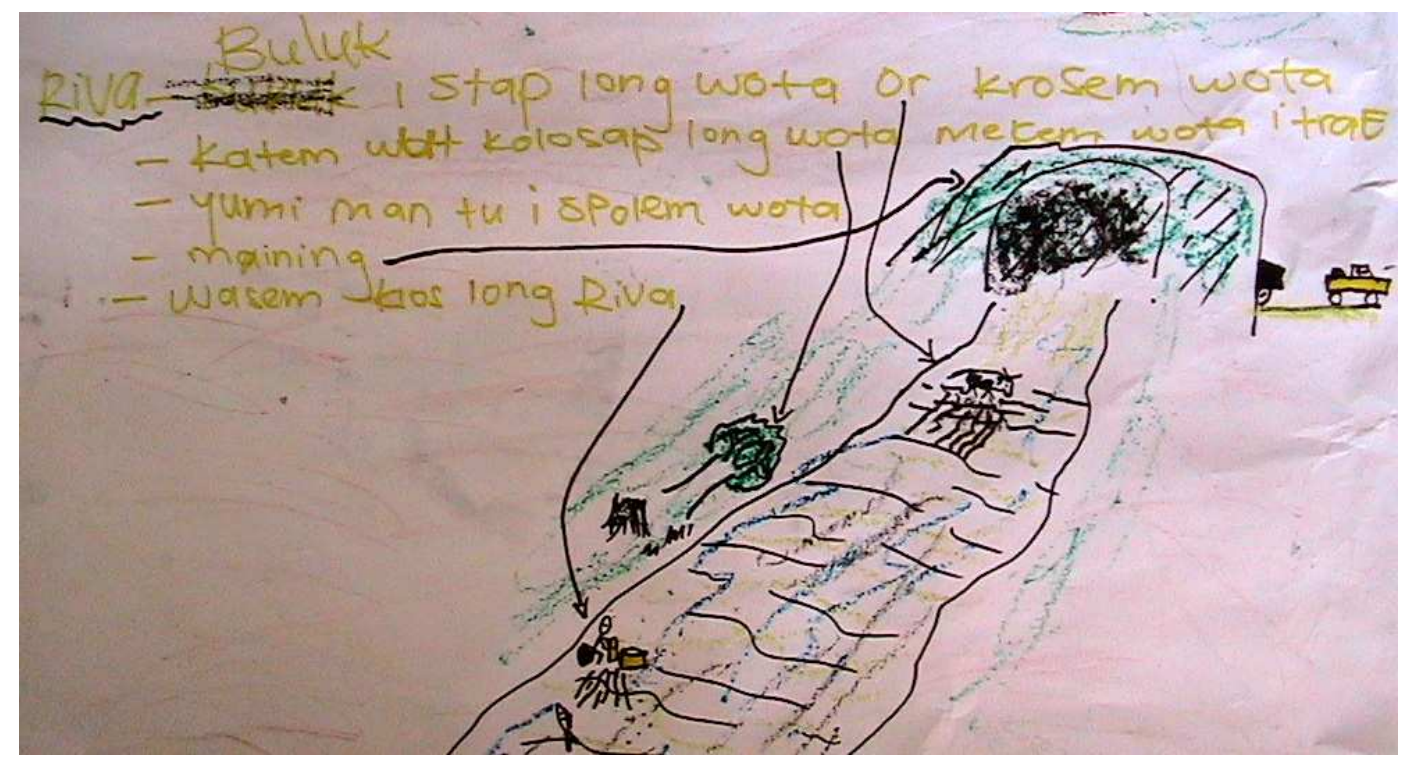

Figure 4.12, Mixed gender focus group poster identifying causes of fresh water resource degradation: Buluk (cattle); Katem wut (cutting wood); mining; wasem klos (washing clothes)

Table 4.5 summarises this section, showing the various resource use practices that local people identified as unsustainable, and the resource types that are affected.

Table 4.5 Resource use practices and resources affected

\begin{tabular}{|c|c|c|c|}
\hline \multirow[t]{2}{*}{ Unsustainable resource use practice } & \multicolumn{3}{|c|}{ Resources affected } \\
\hline & Dark-bush & Soil & $\begin{array}{l}\text { Freshwater } \\
\text { and marine }\end{array}$ \\
\hline Timber harvesting & $\nabla$ & & \\
\hline Clearing dark-bush for gardens & $\nabla$ & & $\nabla$ \\
\hline Clearing dark-bush for plantations and cattle & $\nabla$ & $\nabla$ & $\nabla$ \\
\hline Cattle near water sources and rivers & & $\nabla$ & $\nabla$ \\
\hline Cutting trees by rivers and coast & & $\nabla$ & $\nabla$ \\
\hline Over fishing & & & $\nabla$ \\
\hline Over harvesting of sand from Tangoa beach & & & $\nabla$ \\
\hline Waste disposal problems & & & $\nabla$ \\
\hline Expansion of canoe landing area & & & $\nabla$ \\
\hline
\end{tabular}




\subsection{What are the causes of resource degradation?}

The previous section mentions several unsustainable resource use practices and some of the underlying drivers of these practices. Some of the reasons are related to demography, such as population pressures driving increased resource use, and in turn, resource scarcity. Some are related to economic pressures which are driving an increase in the use of natural resources for money. Other drivers can be considered 'governance issues' including: lack of rules; lack of respect for rules where they exist (i.e. customary taboos); and issues related to whether local Tangoan people have the authority to make rules and govern resources. Table 4.6 indicates which of these drivers relate to the resource use practices outlined in the previous section. This section looks at all the drivers of resource degradation in more detail.

Table 4.6, Locally identified drivers of unsustainable resource- use practices

\begin{tabular}{|c|c|c|c|c|}
\hline \multirow[b]{2}{*}{$\begin{array}{c}\text { Unsustainable resource } \\
\text { use practice }\end{array}$} & \multicolumn{4}{|c|}{ Cause } \\
\hline & No rules & $\begin{array}{l}\text { People } \\
\text { not } \\
\text { following } \\
\text { rules }\end{array}$ & $\begin{array}{l}\text { Lack of } \\
\text { authority } \\
\text { to govern }\end{array}$ & $\begin{array}{c}\text { Population } \\
\text { and } \\
\text { economic } \\
\text { pressures }\end{array}$ \\
\hline Timber harvesting & & $\nabla$ & & $\nabla$ \\
\hline Clearing dark-bush for gardens & & & & $\nabla$ \\
\hline $\begin{array}{l}\text { Clearing dark-bush for plantations and } \\
\text { cattle }\end{array}$ & & & $\nabla$ & $\nabla$ \\
\hline Cattle near water sources and rivers & $\nabla$ & & $\nabla$ & \\
\hline Cutting trees by rivers and coast & & $\nabla$ & & \\
\hline Over fishing & & $\nabla$ & & $\nabla$ \\
\hline $\begin{array}{l}\text { Over harvesting of sand from Tangoa } \\
\text { beach }\end{array}$ & $\nabla$ & & & $\nabla$ \\
\hline Waste disposal problems & $\nabla$ & & & $\nabla$ \\
\hline Expansion of canoe landing area & & $\nabla$ & & \\
\hline
\end{tabular}

\subsubsection{Population pressures}

Population pressures were cited by interviewees, women and youth groups as causes of increased: timber harvesting; clearing of dark-bush for gardens; fishing; harvesting sand, and waste disposal problems. In other words, 
population pressures are affecting every category of natural resource that Tangoans identified as important for their livelihoods. A comparison of national census data from 1999 (Vanuatu National Statistics Office, 1999) with our own census of the Tangoa population in 2006 shows that the number of people living on Tangoa has increased 34\% (from 373 - 498) over seven years.

Population pressures were closely linked with economic pressures. Higher population leads to higher demand for natural resources and money, while at the same time it drives resource degradation and scarcity. Women's focus groups identified that rising population affects the ability for the family to generate enough money so that all their children can go to school (see fig 4.13). The result is that few children (especially females) are able to access education past primary school, and even fewer children complete high school or access higher education.

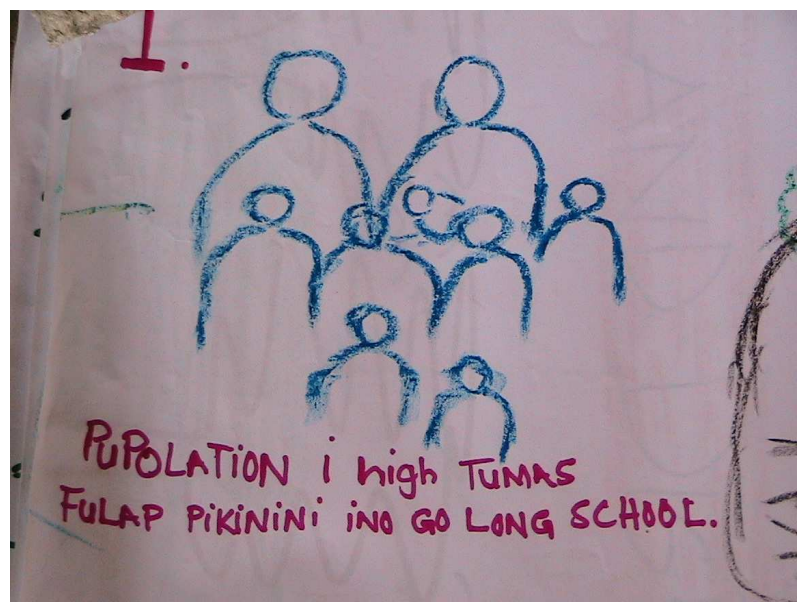

Figure 4.13 Women's focus group problems analysis ("The population is very high, many children do not go to school")

\subsubsection{Economic pressures}

Economic pressures are directly affecting resource degradation as people increasingly need to use natural resources to earn cash. This was cited as a cause of increased fishing, harvesting products from the dark-bush to sell at the market, and engaging in wage labour to clear bush for plantations and cattle. This section first looks at what cash is needed for, then outlines how a growing monetary economy and lack of land contributes to economic pressures. 


\section{Household expenses}

Focus group activities and interviews identified meeting everyday household cash needs as the greatest economic pressure for Tangoa families. Cash is needed for goods from the store (such as such as kerosene, sugar, flour and soap), medical expenses, transport, clothes, and tithe (money for Church). The most problematic economic expense for families is paying school fees. A focus group of women explained that school fees are the most problematic expense because they need to be paid three times a year, which means that money has to be earned and saved for these times. Other expenses such as buying goods from the store are spread evenly across the year. "It is difficult for families to make enough money and save it for school fees. Buying rice is a small cost, paid often, so you don't need to save so much." Fees are due in January, May, and August. 59 The seasonal calendars show that much of the year's work activities, especially in the months of January, April, May, July and August, are focused on earning cash for school fees. Figure 4.14 is a picture of the women's seasonal calendar showing that people cut copra in January for fees due later in the month.

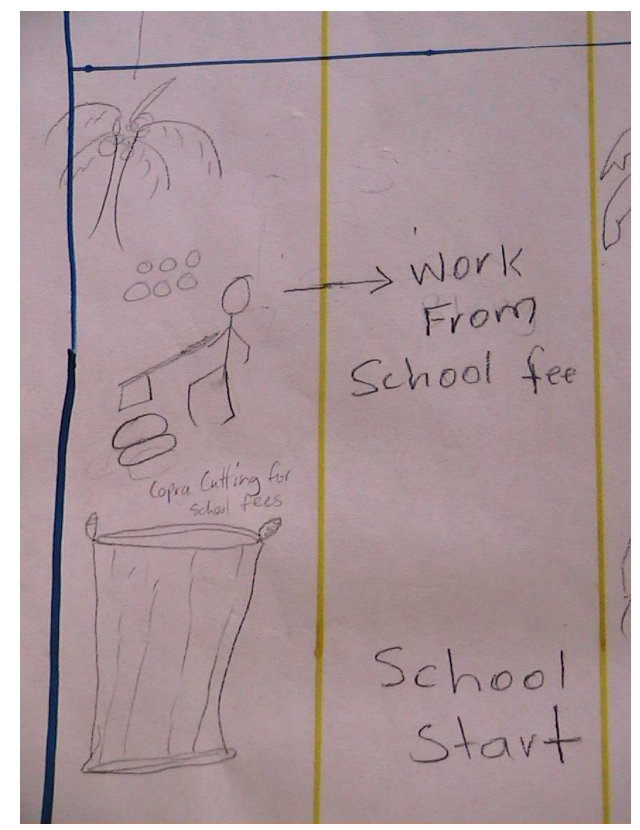

\footnotetext{
${ }^{59}$ The costs for primary school: 1 st term 2000 vatu (\$28NZD) (1st child); 1500 vatu (\$21) (2nd child), 1500 vatu (3rd child). The costs for secondary school are: $17,000 \mathrm{v}(\$ 235)$ term $1 ; 15,000 \mathrm{v}(\$ 207)$ term 2; 15,000 term 3. The cost of sending children to school for year 11 and 12 is $30,000 \mathrm{v}(\$ 2143)$ each term (Woman's group).
} 
Figure 4.14, Women's seasonal calendar - showing activities for January and February

The Sanma Council of Women provided some indication of the economic costs of a typical family in South Santo (see fig. 4.15).

\section{Sanma Women's Council estimate of household expenses}
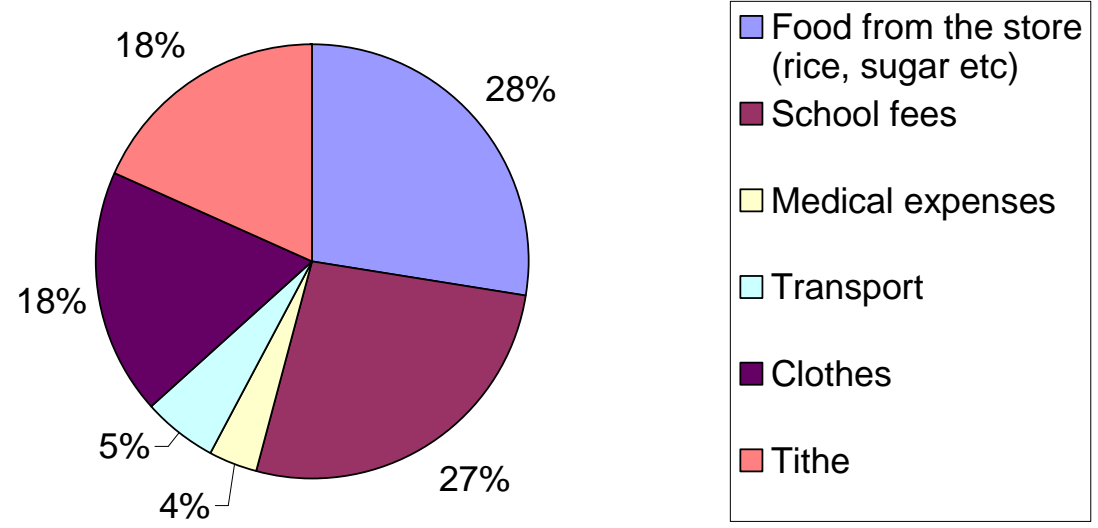

Figure 4.15, Estimate family expenses for households in the Sanma province (Sanma Council of Women, 2006) ${ }^{60}$

\section{Community contributions}

On top of household expenses, families often have to fundraise for school (other than fees) and church. In discussing all the different responsibilities that the church, schools and the various committees require, one woman exclaimed: "It is too much to do, we have to cut copra for school fees, it is too hard to spend time working and fundraise for these things too." Economic difficulties are exacerbated by poor coordination of these responsibilities. Both men and women identified that the various activities often clash because there is no single community calendar.

\footnotetext{
${ }^{60}$ Data sources from Minutes of a Sanma Council of Women Conference held over 20th -24th February 2006 at the Sanma Women's Resource Centre, Luganville, Santo. Estimates were a result of a meeting about budgeting involving 18 women from the Sanma province (mostly from East and South Santo). While the estimates are representative of a wider demographic and are not specific to Tangoa, the Council Secretary explained that all families in Sanma (including Tangoa families) have to pay these costs, transport costs vary a lot but things like school fees and church costs (tithe) are similar for all families in this area of Vanuatu."
} 


\section{Growing monetary economy}

Trend analysis done by a group of two fishermen (fig. 4.16) shows how the monetary economy started to impact livelihoods increasingly in the 80's. Store bought goods, western housing materials and medicines became normal expenses. After independence the need for money increased due to the development of a formal (government led) education system where school fees had to be paid in cash.

Globalisation is one factor contributing to an increased need and desire for money. Tangoans are increasingly exposed to new ideas and value systems through interactions with people from outside their local context, traveling to other places within and outside Vanuatu, the formal education system, and by increasing access to modern media (radio, TV, films, music). Young people are especially keen to have western material goods (i.e. western style clothes, food, technologies, and building materials) as they strive for more 'modern' lifestyles. One Tangoan explained: "Now all young people want block houses [concrete blocks and iron roofs]. They don't want to live like the old days." An elderly woman added: "When a hurricane comes, it will take the iron! The young people will be waiting in the rain, or in our houses, until they can buy a new roof! It is better to have thatch so they make a new one for free." This signals a link between cultural change, increasing monetary economy, and livelihood vulnerability. 


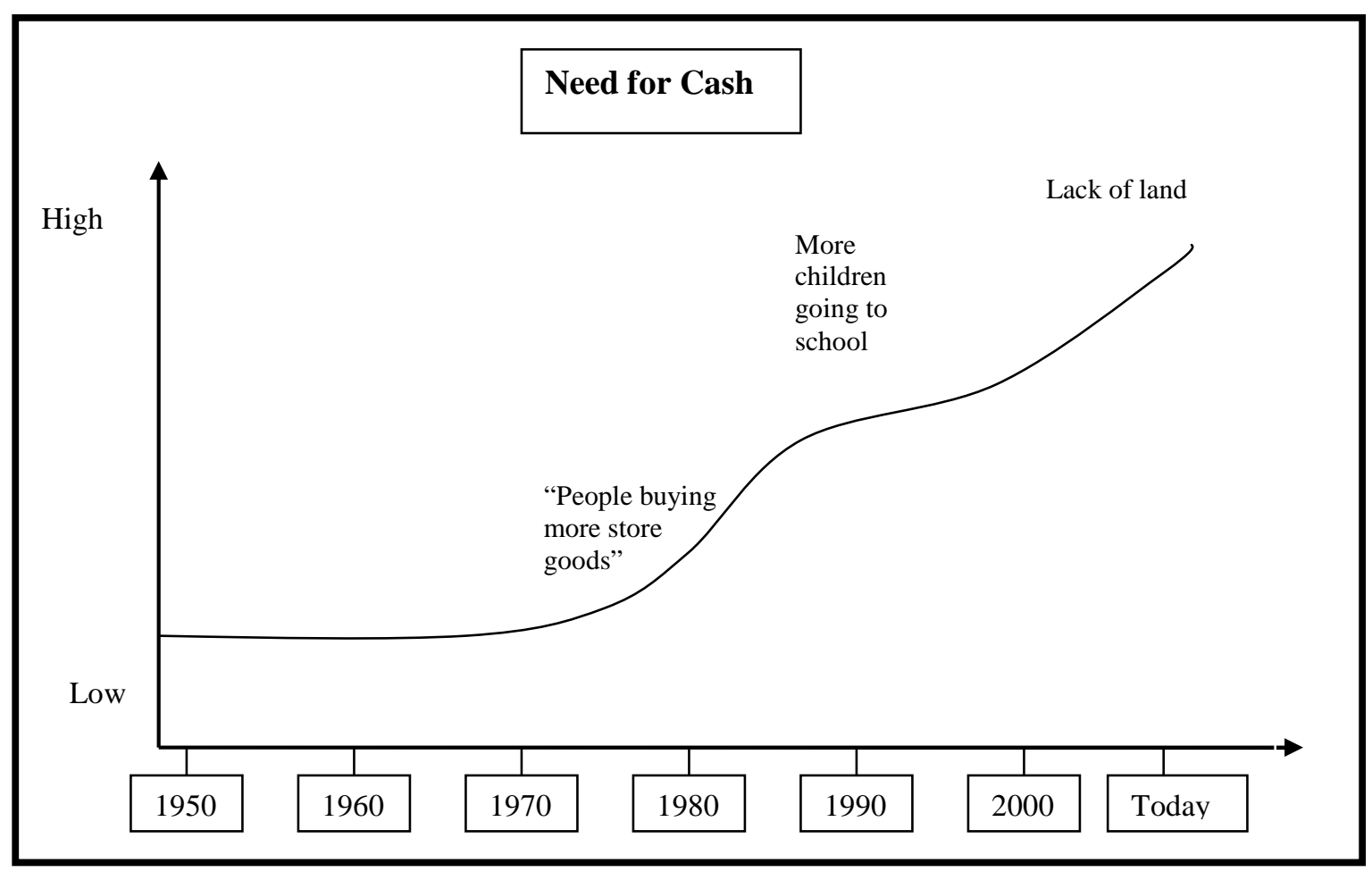

Figure 4.16, Trend line of need for cash for the Tangoa community over time

\section{Problem of lack of land}

More recently, lack of land is a major factor driving a growing monetary economy and the need for cash. The area of land available for Tangoans to use for gardens is limited, and the number of people using the land is increasing (see figures 4.17 and 4.18). ${ }^{61}$

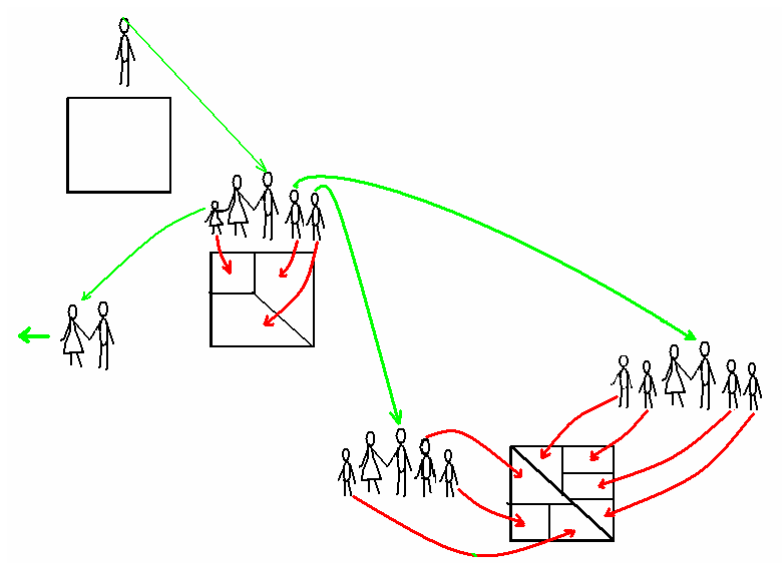

Figure 4.17, Illustration of diminishing land resources per family

\footnotetext{
${ }^{61}$ Other main causes of lack of land were identified as: the Church's control of land and unwillingness to give up Church plantation area for people to make gardens; the complicated and expensive land claims process; and governance problems where i.e. the Chief is unable to resolve disputed for various reasons including that he is involved in the disputes himself.
} 
In discussions about economic pressures and the underlying causes several interviewees explained that as more people struggle to make a living on limited land resources, there has been a transition to more non-gardening based livelihoods. Associated with this change is an increased dependence on cash. One woman explained: "My garden isn't big enough now, so my husband goes fishing most days." Her husband added: "We do not have land so we have to buy food from others, and exchange fish for yams and cabbage."

Land scarcity has a direct impact on agricultural production capacities. The effect of population growth on land and soil resources was a predominant concern for local people, as it has significant economic consequences. Three focus groups of youth and two focus groups of women, as well as ten interviewees expressed concern about lack of land. Many were concerned that their children would not have enough land for gardens. While on a transect walk through the gardens, one man explained: "My three sons have to share this small garden area! This is a problem for many people here."

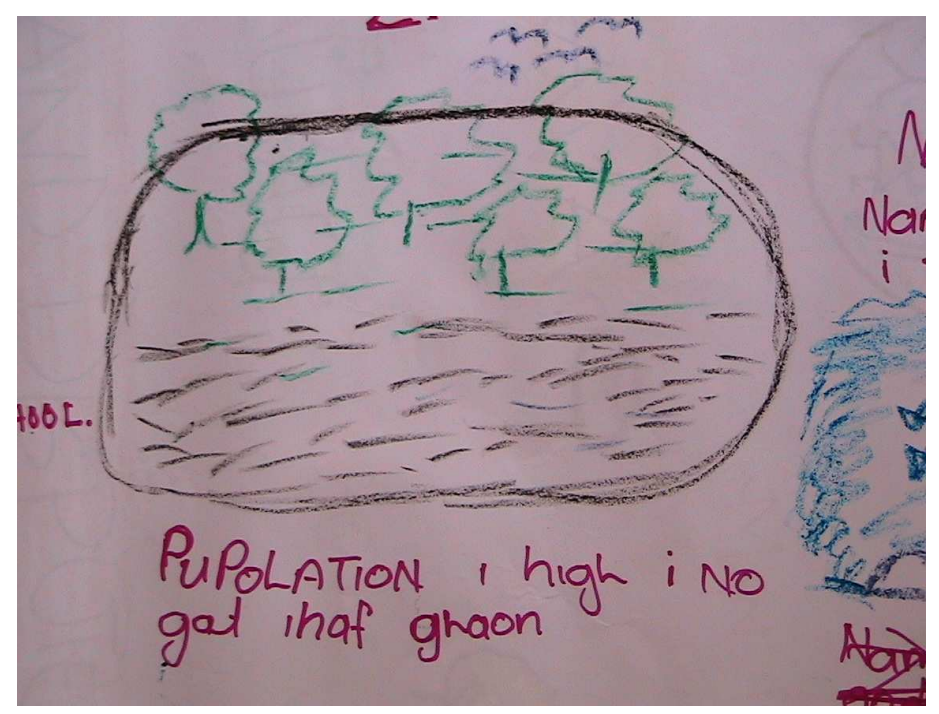

Figure 4.18, Women's group poster identifying issue of increasing land use intensity

Over time, declining soil quality due to more intensive land use has restricted the diversity and quality of crops that can be produced. Some traditionally important staple root crops, such as valued species of yam and taro, no longer grow well in some areas. Soils are increasingly unable to produce economically valuable 
crops such as tomatoes, capsicums, beans and fruit trees. On a transect walk a women working in her garden told us: "This soil is used too much. The yams that come from this ground are small and they do not sell well at the market." Figure 4.19 is a poster made by a mixed gender focus group. Point three on the poster illustrates the reduced size of crops over time. Participants explained that this resulted from soil degradation.

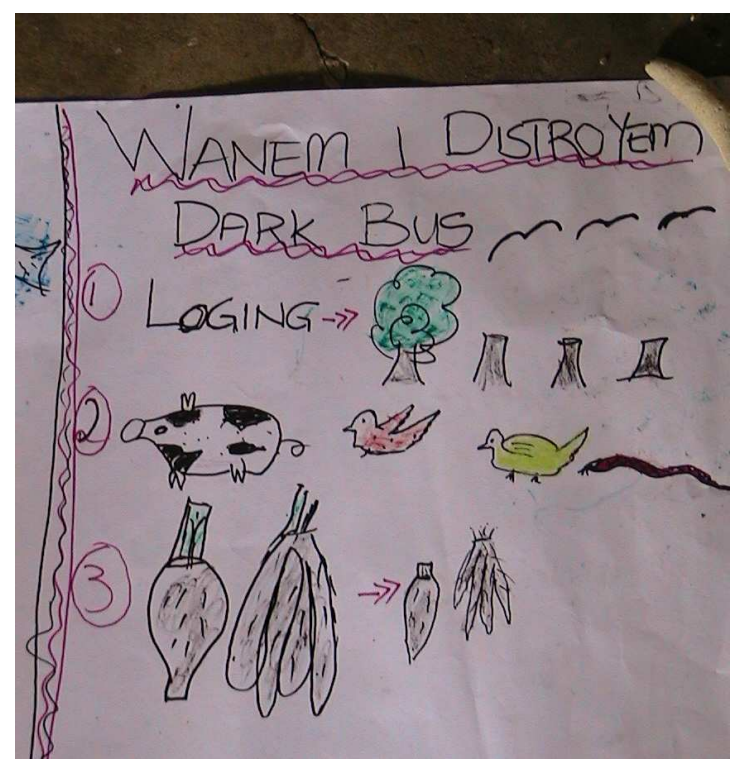

Figure 4.19, Mixed gender focus group poster identifying environmental threats

\subsubsection{Intra-community heterogeneity in economic wellbeing}

While all families experience economic pressures described above, some struggle more than others depending on their resource endowments and entitlements. Several key informants explained how different Tangoan families have different quantity and quality of land. The three clans that have resided in the area the longest all have garden land, and many have their own coconut trees. Local census data show that these three clans make up about $70 \%$ of the Tangoa population. The other five clans that have settled on Tangoa more recently are less well endowed with garden land and coconuts.

Discussions during transect walks through garden areas revealed that the three oldest resident clans also have better quality land. Their gardens are further inland where the soil is more fertile than the coastal soil. A woman at a local market was well endowed with several garden areas that could each be used for 
3-4 years because the soil is rich "red ground". Her garden provides "plenty kaekae" (food) for her family and she sells diverse and valuable crops at the market. During a transect walk two men explained that the variation in soil quality is reflected in variations in health and wellbeing. "People with gardens up near Narongo are strong. They have many kinds of good island kaekae (food). Many Tangoa people are weak and sick. Some can't grow enough for their families in this onetasi ${ }^{62}$ soil, and they have to buy food. They eat too much rice and sugar, not enough island kaekae. You see many people with rotten teeth."

Those who do not have enough quality garden land are generally more dependent on cash generated from working on copra plantations. While many Tangoan families engage in both gardening and plantation work, a distinction can be made between those that have plenty of productive gardening land (up to $70 \%$ of the population) and those that do not (up to $30 \%$ of the population).

Figure 4.20 is a generalised diagram to illustrate what people said about important differences between gardening-based and cash-based livelihoods. It is intended to show why wellbeing varies within the community due to gardening land endowments, and why cash-based livelihoods can be more vulnerable due to poor food security. Please note that the information illustrated in the diagram comes from nine different interviews. Further research such as a village wide socio-economic ranking profile would be required to determine more accurately the relationship between resource endowments, cash dependency and economic vulnerability.

Figure 4.20 shows the flows of labour, food and money for the different livelihoods. A typical subsistence-based livelihood is represented in the diagram by a household that is predominantly dependent on productive gardens for their livelihood. A typical cash-based livelihood is represented in the diagram by a household that is predominantly dependent on generating cash from either owning or working on copra plantations.

\footnotetext{
${ }^{62}$ Onetasi is the local term for the lowland soil which is more sandy and lighter than the dark red colored soil further inland.
} 


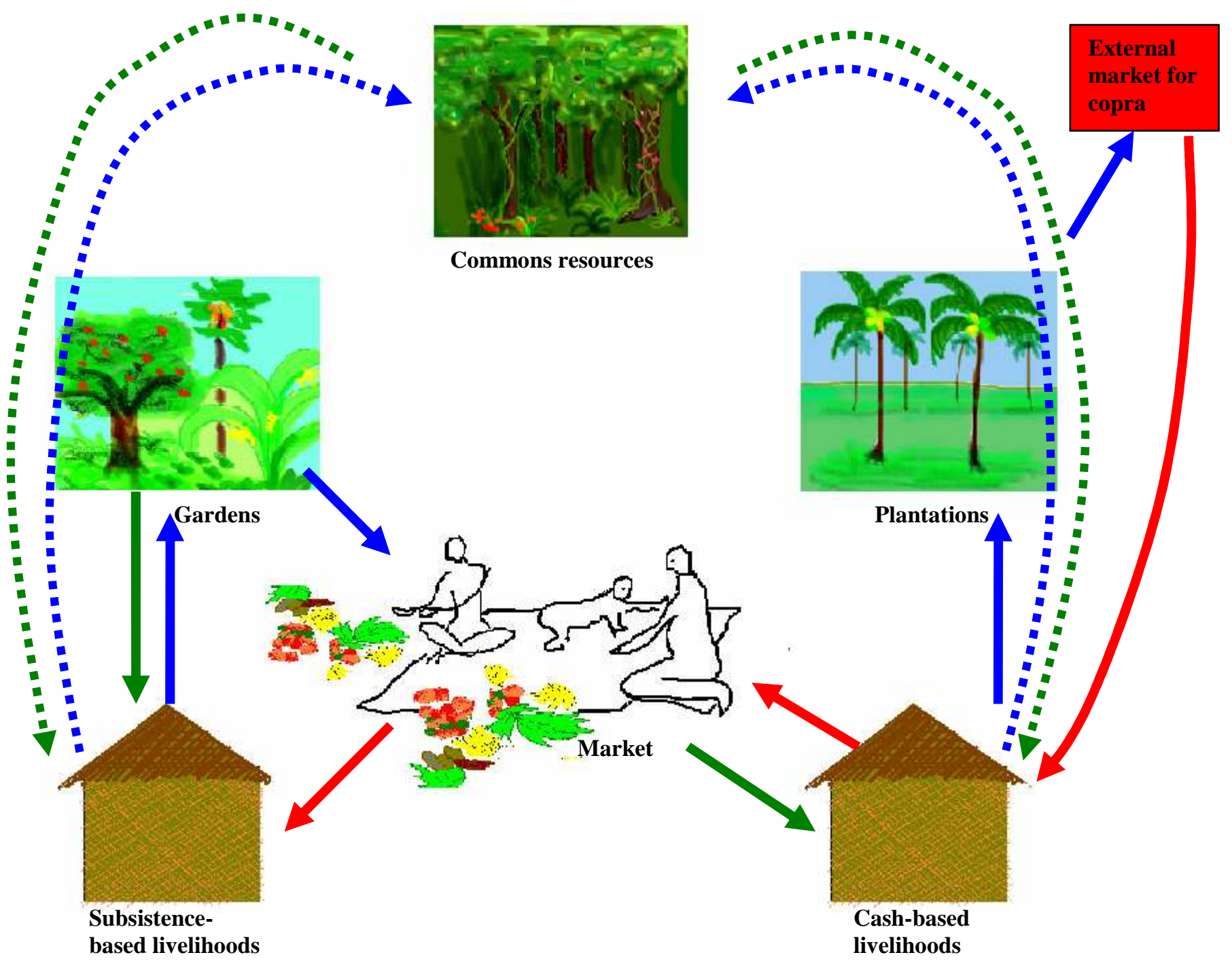

Figure 4.20, Flow of food and money after a cyclone for families with gardens and families without gardens

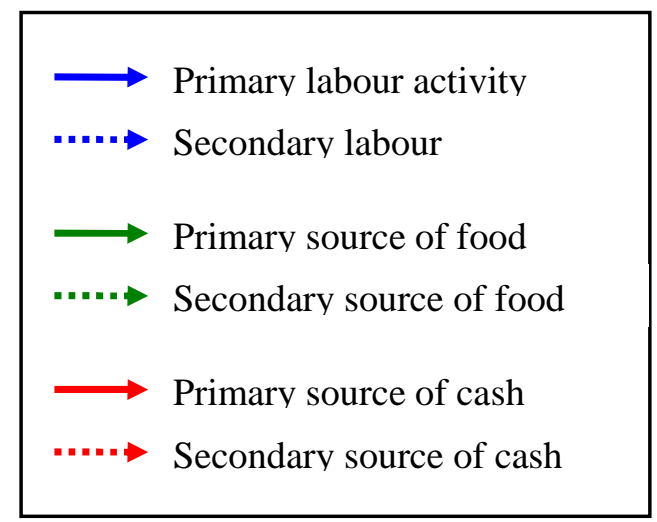


There are several main differences between the two livelihoods. For subsistence-based livelihoods, gardens are the main source of food (solid green arrows) and cash (solid red arrows). These people spend most time gardening and selling produce at the local market (see the solid blue arrows). The main source of food for the cash dependent household is the local market where they can buy it with cash earned from working on copra plantations.

All Tangoans harvest from commons resources for food and cash (dashed blue and green arrows). To keep the diagram simple, I have not shown the use of commons resources for money in this diagram, even though resource rating exercises clearly show the importance of dark-bush, fresh-water and marine commons (section 4.3).

Several different interviews provided information about how the flows of labour, food and money change after a cyclone. The market for copra can collapse after a cyclone. There are more than usual wind fallen coconuts, and sometimes the trees are destroyed. The copra lying on the ground has to be harvested, so the market is flooded with copra which lowers its price. Without gardens and income from plantation work, people harvest from commons resources for food (wild yam, water taro, and fish). They also sell some of what they harvest from the commons at the local market. Those who have gardens are more likely to have enough food to get them through, as some staple crops of taro and yam will survive the cyclone. They may also have housing materials which are planted in gardens in preparation for when they have to rebuild.

Interview data provided enough information to make some generalisations about how resource endowments and cash dependency can determine economic wellbeing and vulnerability However, interviews also revealed that there is variation in economic wellbeing depending on the strategies that people employ to mitigate vulnerability and address economic challenges.

\subsubsection{Local strategies related to economic problems}

Local people have responded to economic pressures by: changing livelihood strategies (e.g. transition from gardening to cash based livelihoods); seeking 
alternative income generating opportunities (exit options); accessing external assistance; and claiming for indigenous land rights.

People want training and advice for new NRM practices and ways to use limited land areas. On a transect walk a woman working in her garden told us that her son wants to plant some whitewood (timber trees): "It is a good idea because he needs new ways to make money for his family." People are also seeking new ways to make money such as small businesses and tourism (see figure 4.21). They identified the need for skills building in trades such as carpentry, cooking and sewing.

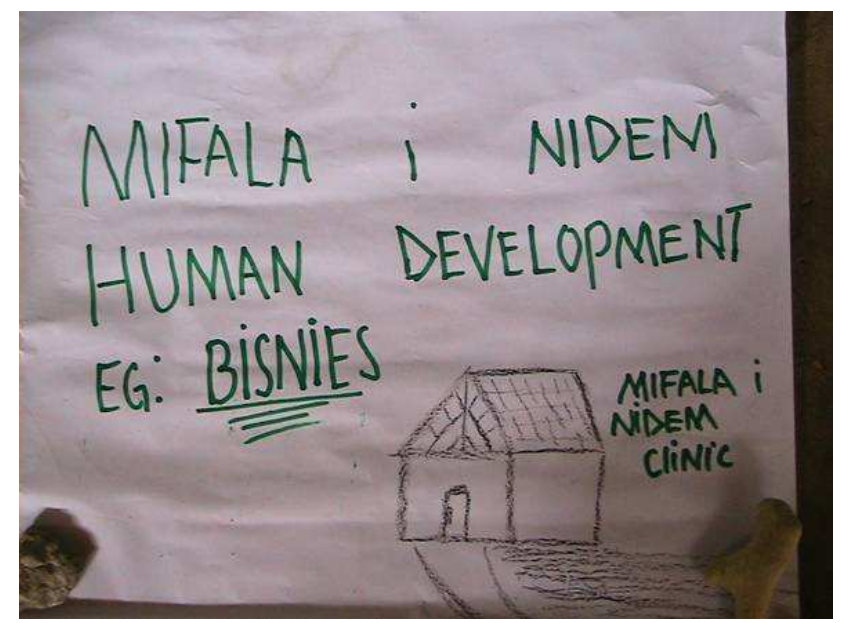

Figure 4.21, Youth-identified development need

Men, women and youth identified the need for more employment opportunities (see fig. 4.22). Related to this are concerns that their children get a good education. During a women's focus group discussion one woman expressed: "It is hard to make enough money from gardening, and working on copra plantations. My sons need a good education so they can get a job." ${ }^{63}$ Women and youth identified the need for family planning services. One women explained: "Families have 5-6 children. That's too many to provide for! We need to have more planning."

\footnotetext{
${ }^{63}$ However, several women highlighted that the lack of employment opportunities (due to low levels of economic development in the area) are external economic constraints that can also be a disincentive for families to send their children to school. "We work hard for many years to pay school fees and for what? There are no jobs for the children!"
} 


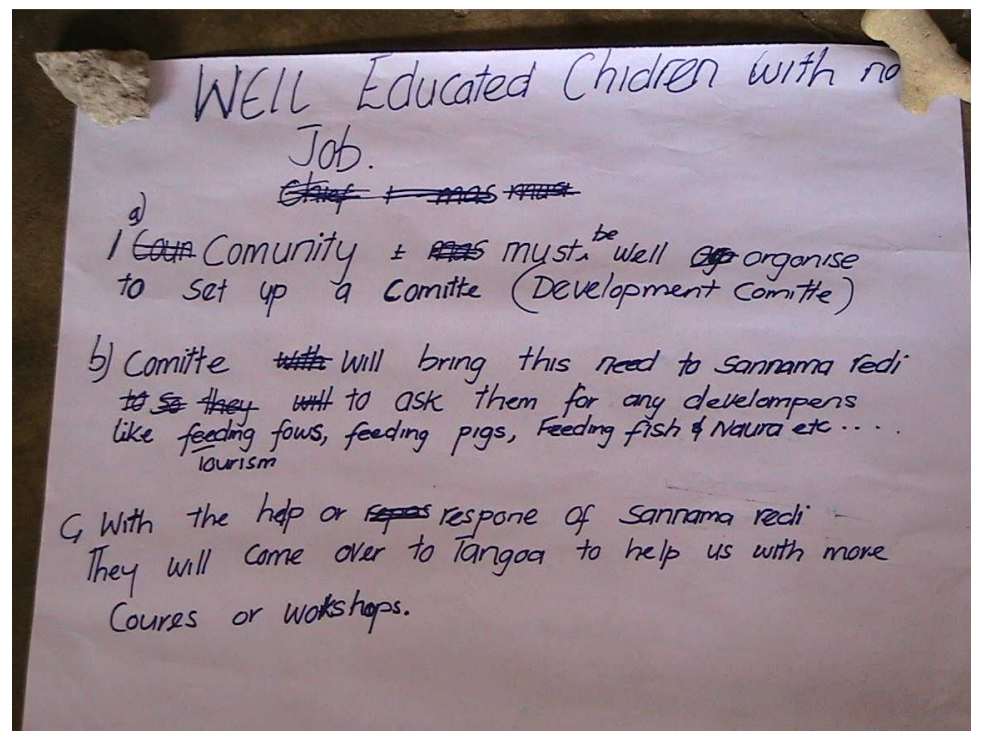

Figure 4.22, Women's focus group poster identifying lack of employment opportunities

Both women and youth groups identified that the Rural Economic Development Initiative (REDI) ${ }^{64}$ could provide access to training as well as financial assistance for projects. Tangoans also look to external actors for financial help to achieve community goals (i.e. building a new water tank) because there is rarely enough surplus cash, after household needs are fulfilled, for such projects. The Fisheries Department and the Environment Unit were identified as possible sources of education about how to manage/develop natural resources. Several members of a particular clan also considered that a Peace Corp volunteer could stay with them and help them with projects.

Claiming land is seen by some as a way to alleviate land shortages and economic pressures. More people are claiming indigenous ownership rights over land. During a transect walk, one man explained: "Ten years ago there, was only one other clan that wanted to claim this land. Now there are five different groups. People in this area are getting desperate for land and will try anything."

\footnotetext{
${ }^{64}$ The Rural Economic Development Initiative (REDI) is the currently the sole government programme specifically aimed at local economic development in rural areas.
} 


\subsubsection{Strategy constraints and barriers to achieving local goals}

There are several strategy constraints and barriers to achieving local goals related to economic pressures. Low economic development in the South Santo region means that besides working on copra plantations, few young people are able to find employment. There are also barriers to accessing external development assistance for training, financial assistance, and education. Interviews with government and NGOs revealed that communities are often required to show that they have a certain amount of organisational and governance capacity before assistance will be provided.

A representative from REDI provincial office in Luganville explained that communities must have "organisational structures for us to work with." A REDI led PRA workshop on Tangoa in 2005 failed because: "Tangoa was too divided and unorganised. There were too many problems with disputes and no strong leadership." The National REDI office in Port Vila explained that it is easier to provide communities with assistance when they have a development committee, and leadership and institutional structures to manage any funds or aid provided. A village water committee is a prerequisite for a new water supply and a health committee for an Aid Post (REDI pers comm.).

A major barrier to claiming land is the land claims process. Local people explained that the process is complicated, time consuming, and expensive. An interview with a member of the Sanma provincial government explained that claimants have to save a lot of money for the process and they have to have a certain level of literacy. They must draw a map of the land and boundaries, write the family genealogy, and write a document describing the land use history. They must also be able to stand up in court and argue their case.

Some representatives from an indigenous organisation in Luganville provided details about the costs of the land claims process. There are three stages to the claims process. First a claim will be notified in a village and there are 21 days for any other claimants to dispute the claim. The claims will be heard at the Village Court (involving an elected Village Court Chairman, Member and Secretary). At this first stage the costs for a day in court are about 5,000 Vatu 
(\$357 NZD). If the claim is not determined, it will go to the Area Court. Area Courts have their own Chief. The cost of each day in the Area Court is approximately 7000 Vatu (\$500). The third stage is the Island Court which is made up of the area Chiefs and numerous court representatives (Sanma province has nine Chiefs and 18 representatives). Each day at the Island Court costs 10,500 Vatu (\$750). The Supreme Court is the final stage. If claimants get this far they have to travel to Port Vila to have their case heard in the Supreme Court.

Another major problem is that there is no limit on appeals until the case is at the Supreme Court level, in which case appeals can only be about whether the court process was followed correctly. This means that a court's decision (at the Village Court or Island Court level) can be appealed an endless number of times by new disputing claimants. The case will then have to be heard again, further raising the court costs to claimants. One Tangoan claimant group had been working for 20 years to claim their land. They got to the Supreme Court, their rights were determined, and at the last moment a rival claimant group successfully appealed on grounds that the court process was not followed correctly. Shortly after the determination was cancelled, all the files were destroyed in a fire and there are no electronic copies of court proceedings.

\subsubsection{Summary of points about economic pressures}

- $\quad$ Economic pressures are a cause of environmental degradation.

- The drivers of economic pressures are population pressures, lack of land, and the growth of a monetary economy.

- $\quad$ Population drives lack of land. Lack of land drives growth of the local monetary economy as people increasingly need cash because they can no longer sustain livelihoods from gardening alone.

- Cultural change also drives growth of the local monetary economy as younger generations strive for more 'modern' lifestyles.

- $\quad$ These underlying drivers make it increasingly difficult for people to meet household expenses and make community contributions. 
- Strategies to deal with economic pressures include claiming land, seeking external funding and training, and alternative income generating opportunities (i.e. employment).

- These strategies are met by constraints including low community cooperative capacity, lack of employment opportunities due to low regional economic development, and ineffective land claims processes.

Figure 4.23 illustrates the relationship between drivers of economic pressures and the various constraints to achieving goals and strategies for overcoming economic pressures.

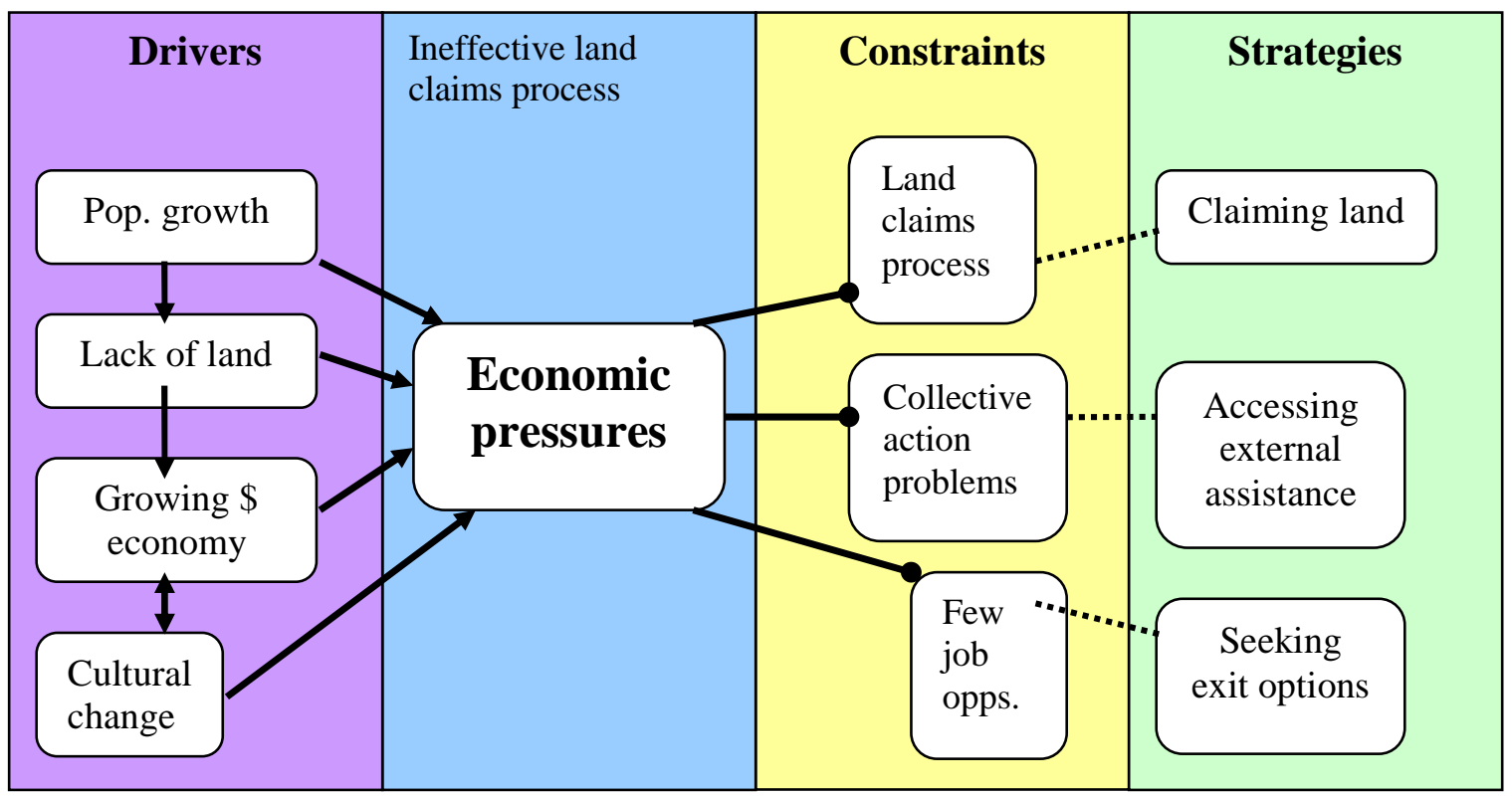

Figure 4.23, Drivers of economic pressures, local strategies and constraints

\subsection{Governance issues}

Governance issues that were identified as causes of resource degradation include: lack of rules to manage resources; lack of respect for traditional rules such as customary taboos where they exist; and issues related to whether local Tangoan people have the authority to make rules and govern resources.

\subsubsection{Lack of rules}

There are no customary/traditional rules to manage some of the more recent environmental problems such as intensive cattle farming near rivers and water 
sources, harvesting of sand for concrete, and disposal of non-organic wastes. Lack of rules about controlling cattle around water sources and rivers was a locally identified cause of degradation of soil resources as well as freshwater and marine resources. Lack of rules about harvesting sand from Tangoa Beach is a perceived cause of depletion of sand resources. Marine resources are polluted by waste disposal practices, which are also non-regulated. Furthermore, some of the customary taboos are no longer effective due to modern use practices (e.g., fine mesh fishing nets make it difficult to catch only large fish), and increasing landuse intensities due to growing population and economic pressures.

\subsubsection{Causal factors}

\section{Leadership problems}

Leadership problems were cited as a central cause of lack of rules to manage resources. As explained in section 4.4.2, it is the Paramount Chief's role to make, and enforce rules concerning community shared resources such as darkbush and freshwater and marine resources. In discussing the causes of resource management problems, several interviewees expressed that there are no new rules established to manage some of the more recent environmental problems that have arisen, and that: "The chief has to make new rules."

\section{Lack of effective institutions}

While the Chief and his council were allocated a large share of the responsibility (and blame) for the resource management problems, key informants identified various other institutional structures, such as a development committee and an environment committee, which could play a larger role. However, data from varied sources indicates that these institutions are not perceived to be effective. Out of 15 women participating in focus group activities, only a few were aware that there already existed a development committee, and these women did not know who was on it or what they have done. ${ }^{65}$ As key informants explained, attempts to establish various committees, such as an environment committee and

\footnotetext{
${ }^{65}$ The women were not aware that a development committee had already been established in 2005, which indicates their lack of involvement in the process as well as the committee's lack of effectiveness.
} 
a water committee on Tanoga have been limited in their success because: “Committees don't know what to do, especially when the chief does not support any ideas that they have."

Information about the qualities of strong leadership and institutions emerged when people talked about the Church structure. Local definitions of an "effective institution" included characteristics of strong leadership and clearly defined roles and responsibilities, effective communication structures and networks, and regular meetings and activities. The Church is the most effective institution for organizing people and facilitating community level cooperation and collective action. The Church has a yearly activities calendar which sets out goals and events such as attending church meetings and celebrations in other areas. The Church organises people to work collectively to raise money for events and to pay for church costs. Through the church structure there are weekly meetings of a women's group, a youth group, a men's/elders group, and weekly meetings of church cell groups which are mixed in age and gender. Each of these groups has leaders and people know their roles. These leaders represent and communicate the needs and concerns of their cell group members to the Pastor and other church leaders.

Problems associated with lack of effective institutions can be illustrated by looking at how water (for house-hold use) is managed on Tangoa. River water is delivered to Tangoa via a gravity fed, polythene pipe running under the channel between the island and Santo mainland. Water is piped from one main storage tank around the village. Water pressure is often low in dry seasons and can stop flowing altogether during drought. Furthermore, large storms often break the pipe from the mainland water source. When this happens people have to carry water in containers from mainland and transport it in canoes to the island.

Many taps leak, and they are seldom ever fixed, which exacerbates water security problems. No rules exist for managing water resources on the island and responsibility for water management is not allocated to any particular person or organisation. An attempt was made to set up a water committee in order to address the water management problems, but the committee is not functioning. 
The Chairman of the committee reported that they only had one meeting when it first was established. Without effective institutions, water management has become a commons dilemma problem. No one feels responsibility to bare the cost of fixing leaking taps for shared benefit.

\subsubsection{Lack of respect for rules}

As explained in section 4.2.2, custom governance systems are the basis for management of Tangoa's commons resources. Therefore sustainable management of commons resources is dependent on the effectiveness of custom governance systems, which is dependent on respect and adherence to custom rules and traditional management practices (TMPs). Lack of respect for rules where they exist (e.g., customary taboos) was identified as a major cause of unsustainable timber harvesting practices. People do not follow custom rules about replanting or only harvesting trees where there are seedlings to grow in their place. Soil, freshwater and marine resources are negatively impacted by the breaking of custom taboos which restrict people from cutting trees near rivers and coastlines. Customary laws that restrict the harvesting of small immature fish, as well as a customary taboo which defined canoe landing areas are disrespected. As a result, fish resources are depleted and the coral reef is damaged.

\subsubsection{Causal factors}

\section{Leadership problems}

Again, leadership problems are perceived as a key cause of declining respect for customary rules. Analysis of data from interviews and group activities indicates that it is the role of the Chief and his council to facilitate cooperation, and gain respect from people so that they will follow him and abide by his rules. ${ }^{66}$ Respect for the chief has declined over time, and people attribute lack of respect for custom rules, to declining respect for their leader. One young man explained: “Taboos are broken because we don't have a strong Chief."

\footnotetext{
${ }^{66}$ Other locally perceived qualities of good leadership include good cooperation with church and other leaders, good communication, and the ability to organize people.
} 
The main causes of lack of respect for the chief are attributed to his failure to carryout chiefly roles. Often he is not living in the Village. ${ }^{67}$ One interviewee explained that: "All people on Tangoa are hard working, but there needs to be strong leadership to organise people. Then we [the Tangoa community] could do alot more." Key informants explained that the Chief often does not attend community meetings, or support plans and initiatives made at meetings. Several interviews and focus groups of youth explained that the Chief cannot provide support for resolving disputes, which is considered one of the most important roles of the Chief. In fact, the Chief is involved in disputes himself. This makes resolution of land disputes particularly difficult and it is a cause of disrespect towards the chief. Figure 4.24 is part of a youth group poster which translates to say: "Land disputes: Many leaders are involved in land disputes, which is a barrier to development."

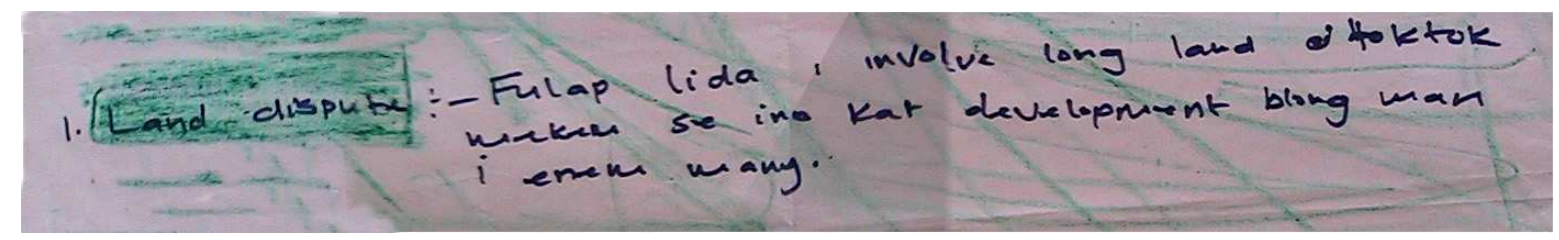

Figure 4.24, Youth group poster identifying the involvement of leaders in land disputes

Several informants also explained that the lack of respect for the Chief might derive from perceptions that he does not have the customary right to be the chief. The current Chief inherited his title from his father, who was chosen by the government to be the Chief. The colonial government chose local people from the local ni-Vanuatu population to be assistants to the government. These people were chosen by the government based on their abilities, and given chiefly titles. These Chiefs were not the "true" chiefs, who are customarily from chiefly decent. Customarily, processes and procedures are necessary to "make a chief" such as pig killing rituals. However these processes were not followed for the current chief.

${ }^{67}$ At the time of the Field work he was ill and living in Luganville Town. 


\section{Loss of traditional ecological knowledge (TEK)}

Loss of traditional ecological knowledge (TEK) and traditional natural resource management practices (TMPs) drives lack of respect for NRM rules. Loss of TEK and TMPs mean that younger generations have less awareness about custom resource management and taboos, and less understanding about why they are important. One man explained: "Young people don't know about the importance of taboos. They see people cut trees near the river and coast and they do the same."

Loss of TEK and TMPs was identified as a problem in thirteen different interviews, and by men's and women's research groups. Loss of TMPs and traditional knowledge about medicinal resources, good gardening practices, and how to prepare for cyclones, were commonly cited examples. ${ }^{68}$

Figure 4.25 is a trend line drawn by one traditional medicine expert. He explained that use of kastom medicine started to decline as modern alternatives became available in the 1970s. As the price of Western healthcare increased in the 1990s, people started to use kastom medicine again. He emphasised that his services as a traditional medicine expert are still needed and relevant today because his medicine works. Triangulated with other interviews (four men and four women) revealed that in contrast to perception of the medicine expert, most people perceive that use of kastom medicine is still declining. This may reflect bias of the medicine expert as he has a vested interest in promoting the continued relevance of kastom medicine, or simply that he continues to use it and treat people with it, but that many other families are using it less.

\footnotetext{
${ }^{68}$ Concern about loss of TK and TMP was related to its negative affects on livelihoods including declining food security.
} 


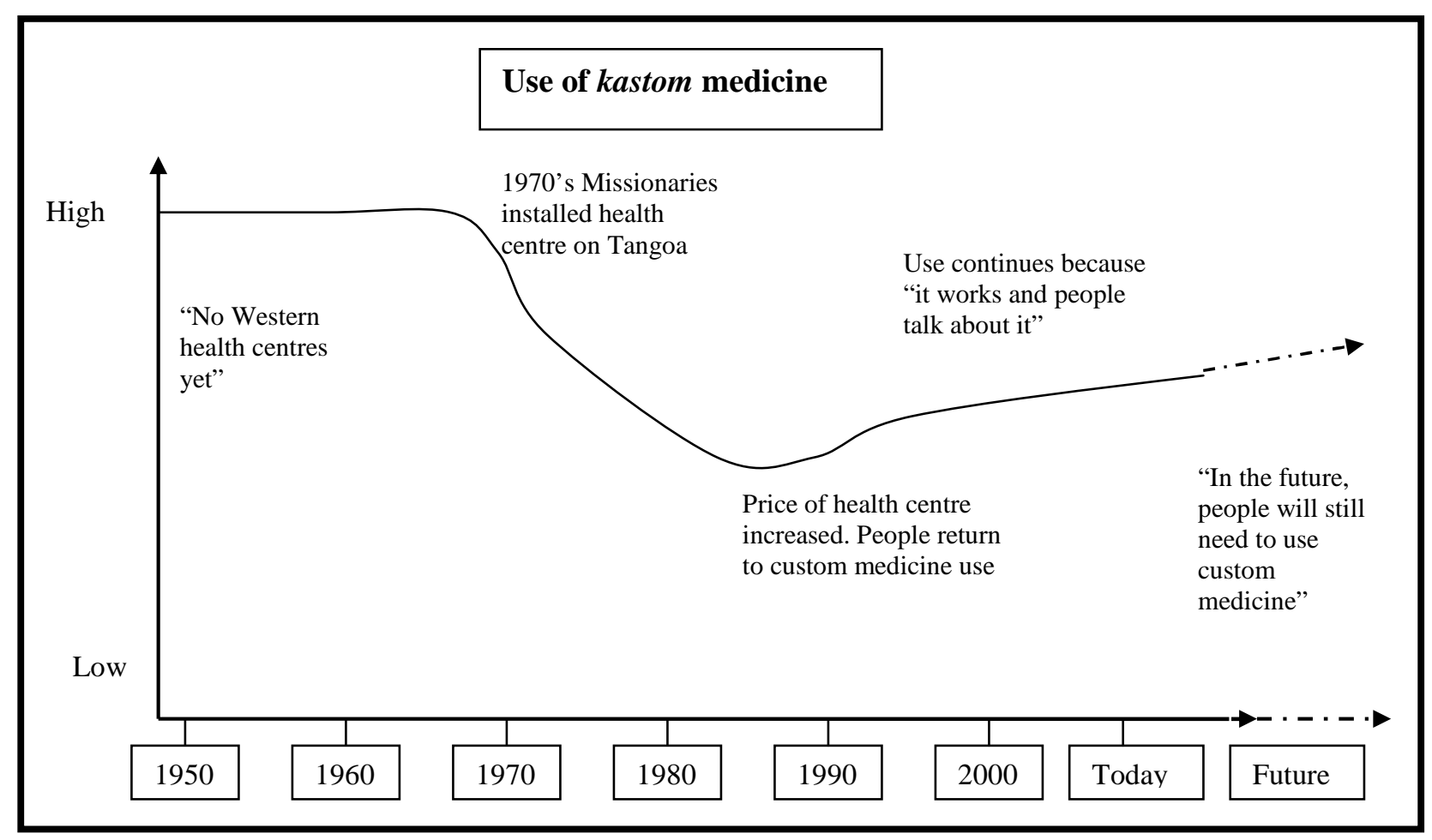

Figure 4.25, Trend analysis of use of customary medicine

Failure of parents to pass knowledge on to children was identified as a direct cause of loss of traditional NRM knowledge and practices in six interviews. Interviews where aspects of social and cultural change were explored highlighted the significant impact of western style education - established by the Missionaries in the 1960s. One elder explained: "In the old day's education would start in the kitchen where parents and grandparents would talk with the children every morning. Then they would spend the whole day in the gardens and in the bush. This changed when children started to go to school every morning." One community elder explained that formal education has become a priority for families, and has crowded out the role of families in informal education: "There is not enough talking about values and traditional practices. Parents don't have time to pass on knowledge."

A general trend of declining respect for tradition and custom is affecting youth culture and young people's interest in custom knowledge about NRM. According to the Nakare Chief, "Young men that are 18-25 years old are lazy. They don't care about custom and they don't think to the future. By the time they get good, the sun is going down and it is too late to teach them custom." Another community elder explained that declining respect for tradition and 
custom is linked to an increase in monetary society: "There are custom laws of the sea but there is not enough awareness. People are more interested in making money."

\subsubsection{Lack of authority to govern resources}

Research clearly shows that Tangoans recognise the need for rules and the detrimental effect from not having, or not following rules. In spite of this, a perceived lack of authority to make rules and govern resources has prevented action to establish the necessary rules. While many Tangoans are concerned about further clearing of bush for plantations and cattle (especially as it reduces the land area that could potentially be used for gardens), clearing has not stopped. As a result, dark-bush is diminishing, soil is degraded and eroded, and freshwater and marine resources are affected by sedimentation. Perceived lack of authority to control the access of cattle to water sources and rivers also increases sedimentation and damages freshwater resources such as water taro, noura, and water cress.

Tenure can determine whether people have the autonomy and locus of control to govern resources. Rights and authority to govern resources can be ambiguous in areas where tenure is in transition. Dark-bush transitions to gardens on a continuum. Once crops and trees are planted, the rights to use and harvest from the planted area, or particular trees, belong to the people/families that planted them. During a mapping exercise, one woman explained that in dark-bush transition areas, it may be ok to gather some resources, but not others: "We collect nalu (weaving material) and wild yam, but trees that have been purposefully planted are owned by the family that planted them, and are not for free use." This pattern of tenure transition means that without strong governance to protect dark-bush, the commons is privatised. This has consequences especially for people that do not have land for gardens, and for women (who only have secondary access through men).

Tangoans also lack autonomy to govern resources where tenure arrangements overlap. Taro patches, water sources, rivers and marine resources within investor leasehold land are considered common property by Tangoans. However, access 
to, use, and management of these resources can be restricted by private leaseholders who have the authority to decide whether to put up fences. Tangoans expressed concern that leaseholder cattle get into taro patches, water sources and rivers, and trample crab breeding areas. However they feel powerless to manage these problems. One man explained: "We can not make rules and put up fences on this [investor's] land. We have to ask permission" A Tangoan women provided another example. A local investor put up fences to keep cattle in his leasehold. However these fences also kept people from using area for gathering crabs and taro plots: "Many people were angry and they took the fences down!"

\subsubsection{Strategies to overcome governance problems}

Ideas about how to improve NRM included strengthening taboos, TEK and TMPs by raising awareness about taboos and encouraging better teaching about taboos in families. In discussions about how natural resource could be managed better, focus groups and interviewees often responded that it is the responsibility of the Chief. Several interviewees also identified that the government's Environment Unit and Fisheries Department could play a role in education about NRM: "Fisheries can come to Tangoa and educate the people about taboos on marine areas and taboos on catching turtles and coconut crabs."

A few key informants explained that claiming land could be one way to gain more control of NRM. If a clan wins a claim: "Then they can elect their own chief to govern that land". Several claimants expressed that if they win their claim it will be easier to set rules and govern dark-bush areas: "People will respect the custom owner." Formal recognition will give them legal rights: "We will have the law behind us."

\subsubsection{Summary of points about governance issues}

- Governance issues cause environmental degradation.

- Governance issues include lack of rules, lack of respect for rules, and lack of authority to govern natural resources. 
- Leadership problems and lack of effective institutions mean that rules have not been established to manage recent environmental problems.

- Institutional change, including change from traditional education systems to a formal western model of education, as well as cultural change, resulting from processes of globalisation, are key drivers of loss of TEK and TMPs.

- $\quad$ Leadership problems and loss of TEK and TMPs drive a declining respect for rules that do exist.

- Overlapping and ambiguous tenure arrangements mean that people do not feel that they have the control or authority to govern some resources that are communally used in the Tangoa resource area.

- Teaching children about the importance of taboos was identified as a strategy to strengthen respect for rules.

- Claiming land was considered a strategy to gain control and authority to govern resources. Legally recognised custom owners would have the authority to elect their own chief and demand respect of NRM rules. However, a difficult land claims process is a major constraint to this strategy. 
These points are summarised in figure 4.26 below.

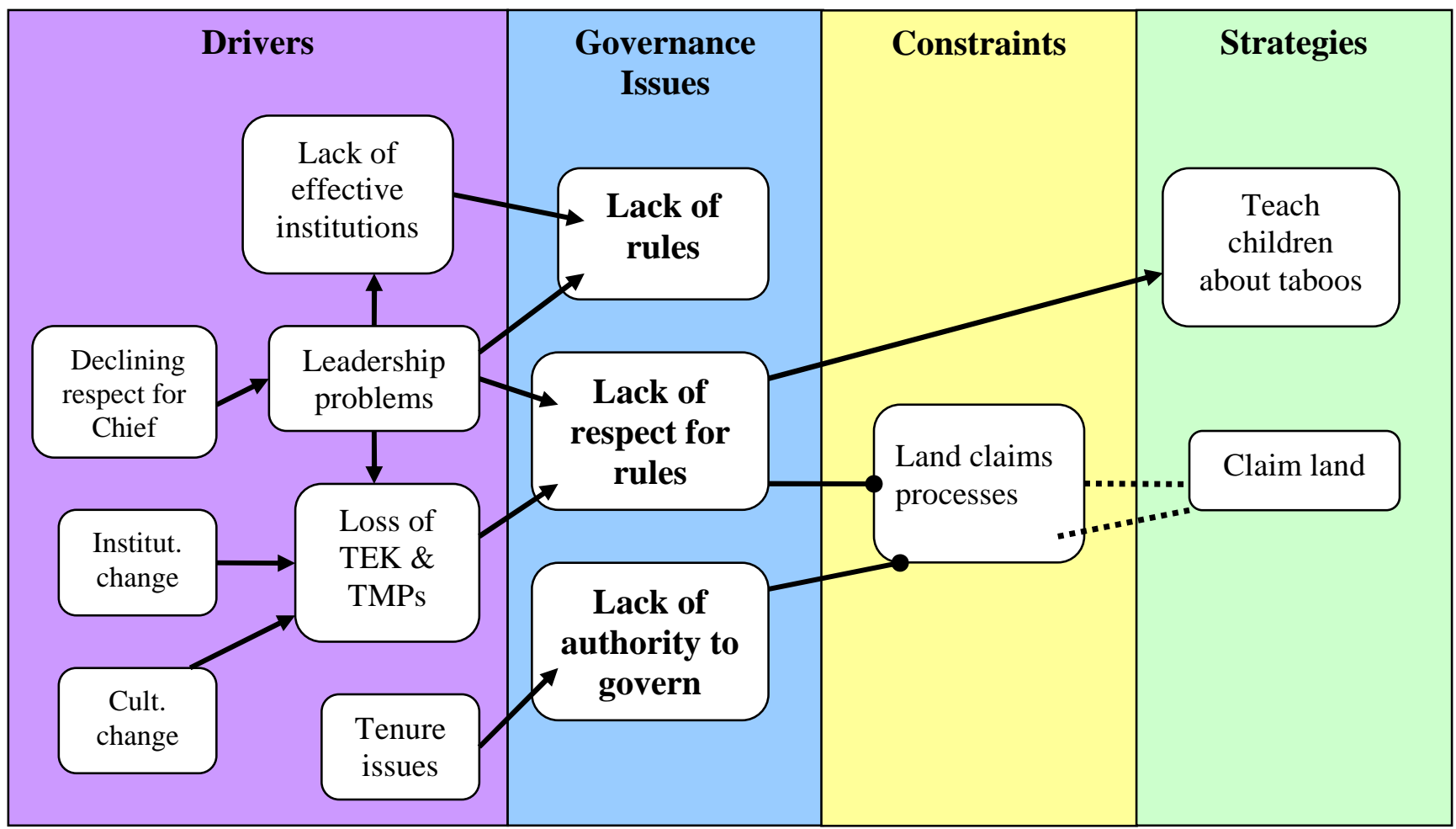

Figure 4.26, Drivers of governance issues, local strategies and constraints

\subsection{Declining social cohesion}

Social problems, such as declining social cohesion, have had a direct negative impact on commons resources including acts of sabotage where trees are cut down. Social problems also undermine social capital and trust, thereby significantly impacting the community's cooperative capacity and the management of commons resources.

Tangoan people perceive that there has been a general decline in cooperation, social cohesion and what one informant termed as a "culture of sharing." Groups of youth and women identified that this is negatively affecting cooperation and respect within the community. Two main indicators of declining social cohesion were identified as an increase in individualism and an increase in disputes, conflicts, and divisions between different Tangoan families and clans.

\subsubsection{Individualism}

Interview data and trend analysis (see fig. 4.28) describe a process of social change from more communal in nature, to more individualistic. This can be seen 
in local perceptions of community cohesiveness: "Everyone was one family [in the 1950s-60s]", and also in changing patterns of social behavior: "People used to share food together on Sundays. The whole community would eat together. Now people share food less, and they don't eat together. They stay in their houses."

Several people used the example of collective action to plant gardens as an indicator of how community cooperation has changed over time. "In the past, when someone needed to make a new garden, people would help and plant gardens together, now only family members help." Key informants also emphasised that social cohesion affects community governance capacity: "The community could still call meetings [when the community was more cohesive]."

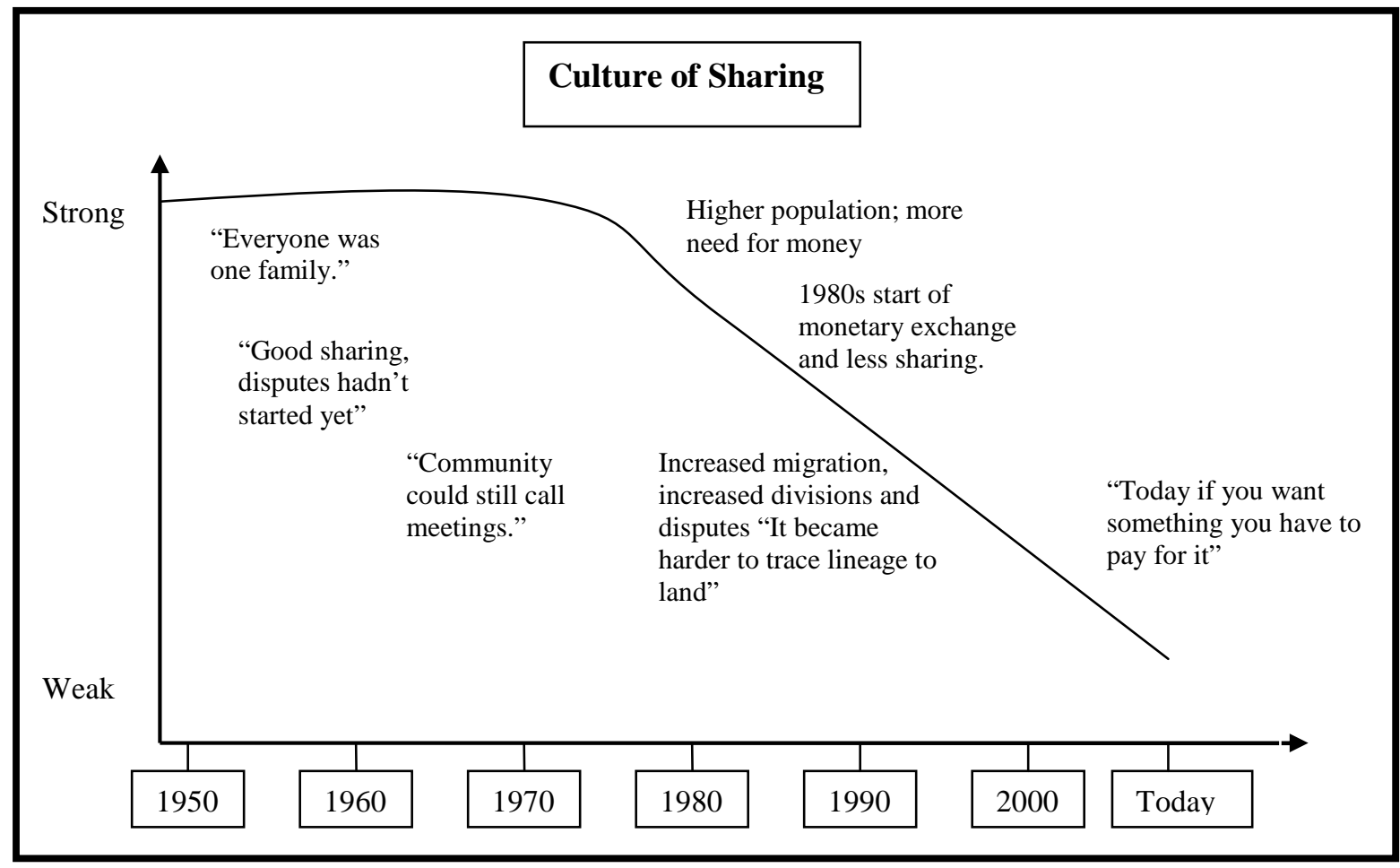

Figure 4.28, Trend analysis of culture of sharing

Sharing and helping each other in times of need has long been a practice that people consider vital for social and livelihood security. This practice is still strong within families today. Evidence of this came from interviews where questions explored how people cope in times of extreme need, such as after a cyclone, as well as data collected during a trend analysis focus group exercise with male elders. One elder explained that: “After a hurricane, it is important to 
help others when you can - give them food, wood and natangora (a plant used for roof building and weaving), let them live in your house - because next time it might be your house or your garden that is destroyed."

While cooperation and reciprocal exchanges in times of extreme need still occurs within families and clans, trend analysis and interviews show that reciprocity is declining between families and different clans. When asked how people help each other after a cyclone one woman said: "You will help your own family first, and they will help you. But you will not get much help from other clans anymore. The relationship is not so good between some families."

Similarly, people used to work together to help clear each others gardens, and cut each others copra, trusting that the assistance will be reciprocated. However: "Some people do not have gardens, and few have their own coconuts, so people only work in groups if they are helping their own family, or for cash." This indicates a link between economic heterogeneity (associated with resource endowments), and individualism.

\subsubsection{Increased conflict, divisions, and disputes}

Increase in conflict and divisions within the community are key concerns, which are largely related to land issues: "The land divides us"; and "The number one problem of Tangoa is this ground." Figures 4.29 and 4.30 show women's group posters identifying social conflict (locally termed: raurau) as a main community problem linked to land disputes. Other locally defined indicators of increased conflict include: increased stealing from gardens; people killing each other's pigs; fighting in gardens; and trees and crops being cut down in acts of sabotage.

Disputes relating to land issues lead to uncertainty and distrust about allocation of benefits from collective action. One informant explained that: "People can't work together for community projects because they don't trust each other. There are too many disputes". This problem is illustrated in the failure to build a clinic on Tangoa: "People are afraid that when the clinic is built, land claimers might arise, and if they win they might benefit more from the clinic or might prevent people from using the clinic." In discussing the non-cooperation for water 
management on Tangoa one man explained that disputes have been so damaging for social relations that: "No one wants to do anything that others will benefit from."

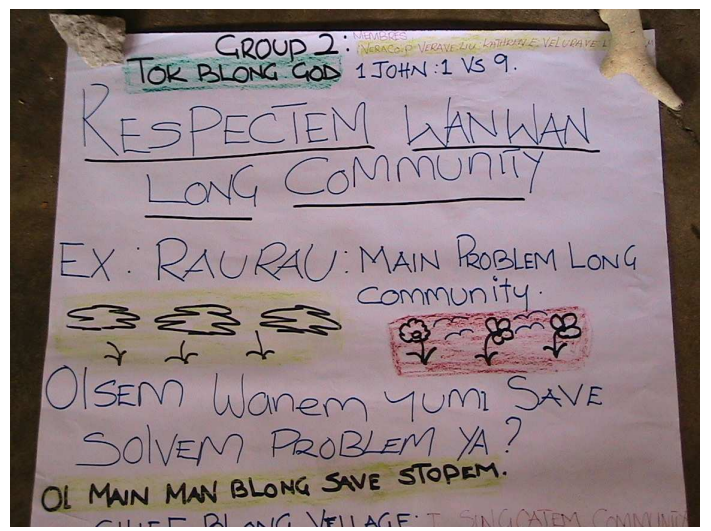

Figure 4.29, Women's group poster identifying social conflict ("raurau") as main community problem

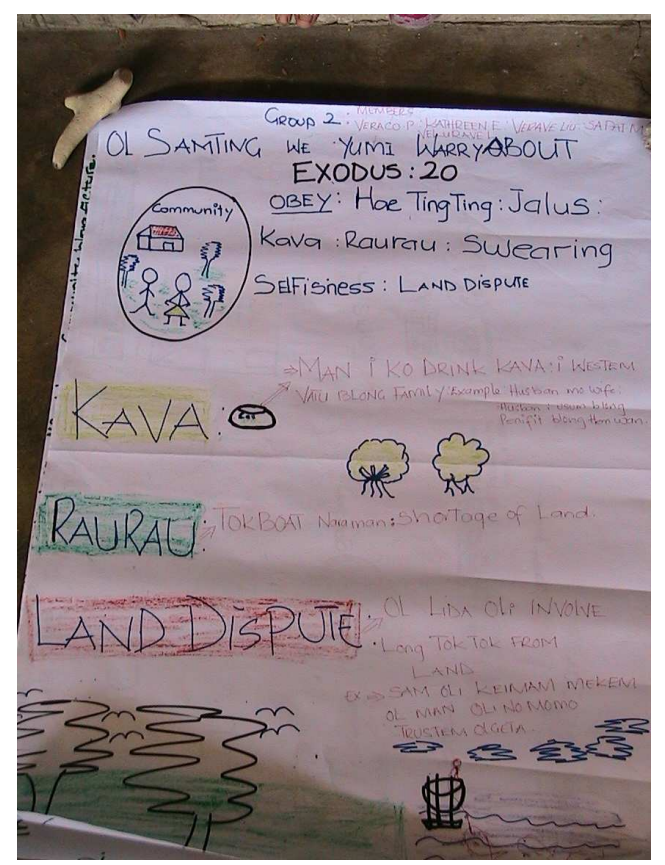

Figure 4.30, Women's group poster identifying link between land disputes, social conflict, selfishness, and lack of trust 


\subsubsection{Causal factors}

\section{Economic pressures}

Multiple data sources (focus groups, interviews, and trend analysis) draw links and positive correlations between increasing economic pressures and declining community social cohesion. Several Tangoans explained how the culture of sharing and reciprocity has declined as people have become more concerned with money: "Now money comes into it all the time, if you want something you have to pay for it." Another informant explained that difficulty providing for families means: "There is not enough left over to share and we have less time to spend with the community. In the past we would do more things together." Economic pressures were also seen to drive individualism: "Families are struggling with too many costs and responsibilities so they decide to just work for themselves."

\section{Governance problems}

Leadership problems are causally linked to social cohesion problems. The importance of a good relationship between the Chief and the Church was emphasised. An elderly woman explains: "When the [previous] chief and church worked well together, everybody helped plant gardens together when needed. These days the Chief does not work with the Church."

Lack of coordination of different and competing economic responsibilities (such as the schools and the church) shows that governance problems (i.e. poor coordination) can contribute to economic pressures, which drive individualism and declining social cohesion. Similarly, the situation where the Chief is involved in land disputes shows that such governance problems inhibit the resolution of disputes and conflicts, thereby further degrading social cohesion.

\subsubsection{Variation in social capital between intra-community subgroups}

While social cohesion problems negatively impact social capital, including trust and cooperative capacity, social capital is still strong in some intra-community sub-groups including women and youth, and certain clans. The various factors 
and determinants that contribute to strong social capital and cooperative capacity in these groups are described in this section.

\section{Cooperation among women}

Data that came from discussions about women's roles in the community highlighted that they are a social group that has highly effective networks for communication, organisation and cooperation. Many men perceived women to be key drivers of collective action, with important roles in achieving goals. They work out the details and plans, which are largely defined by men, and implement them: "Women make things happen." They are also effective in organisations and institutions. A female key informant explained that: "The [bible] translation and school committee are the only ones that work, and it is because women are on them."

Women are particularly skilled at managing money, planning and providing for their families' needs. One Chief described women as "action mamas" because they "move, move, move from sun rise to sun down."

Women have very effective communication networks. One man explains: "If you want to spread information and awareness, talk to some women. They are always talking, and they are the first to hear news and new ideas." Tangoan women also have linking social capital. They utilise wider women's networks including the National Council of Women, to access training for small business generation (i.e. sewing and cooking), budgeting advice, health and family planning workshops, counseling other types of support. ${ }^{69}$

The strong relational social capital of Tangoan women is attributed to high frequency of social interaction and cooperation. In an interview with a group of women, they explained "We work together all the time." Women consider working together, pooling resources, sharing and cooperating to be ways to manage their workloads and meet essential livelihood needs. A group of women

\footnotetext{
${ }^{69}$ The National Council of Women is a nation wide NGO network that has offices at national and provincial levels and holds biannual meetings at provincial levels and more frequent meetings of representatives at more local levels.
} 
weavers explained that: "We take turns going to the market, so that we can share the travel costs. We take all the women's baskets and mats and sell them for each other." They also considered that further developing coordination between women as a principle means to develop their weaving business and access new markets. Their ideas about how to do this included pooling enough resources to travel to markets in the Capital, Port Vila, and establishing networks with women there.

Women also cooperate in order for their concerns and ideas to influence community-level decisions, which are customarily made by men. Gender power relations generally determine that it is not a woman's role to speak in public decision-making forums (i.e. community meetings). A key informant explained that Tangoa women have, on occasion, managed to speak at community meetings: "They work up a lot of support among themselves, deciding together what they want to say, and represent themselves as a collective voice."

Data indicates that women have a strong internal locus of control. They believe that they have the ability to bring about change. Women want to be more involved in community decision-making structures because they feel that they can help solve problems. Women's focus groups talked together about the need for a development committee in order to access external assistance: "We need to make a development committee. Women need to be on the committee so that it works."

\section{Cooperation among youth}

Youth are another social group that has high levels of relational and linking social capital. They interact often socially. They have sports teams (soccer, boxing, and volleyball) and organise tournaments with other communities in the region. They have a very successful string band and have managed to generate money for a tour around Vanuatu. They have high levels of concern about community issues, and in 2003 they were the key motivators and organisers for a 
community meeting to address issues. ${ }^{70}$ They seem to have a strong internal locus of control for action to solve problems. During a resource mapping exercise, men discussed concerns about water quality and the potential impact of a coal mine in the hills above Tangoa's water sources. The next day several youth that were involved in this discussion took the initiative to make posters about concerns related to the mine and put them up around Tangoa Island.

\section{Collection action within particular clans}

The Pelviji clan has achieved several collective initiatives and goals. In comparison to the six other clans on Tangoa, they were the first to elect their own Chief after the paramount Chief recommended that all clans do so. They are also the only clan on Tangoa to have built their own Nakamal. They established a Pelviji cooperative, which is the only shop on the island. They have come close to winning a land claims process and have successfully developed a timber nursery project. Interviews with the heads of each family in the Pelviji clan highlighted some of the factors that have enabled collective action to occur within this sub-group.

Interviews highlighted five key enabling factors of Pelviji collective action: 1) a strong sense of necessity to act; 2) governance capacity, including human resource endowments (skilled and educated leaders); 3) financial resources; 4) accomplished goals and experienced benefits of collective action; and all of the above factors contribute to 5) a strong internal locus of control (confidence in their ability to act cooperatively), which can have a catalytic effect on cooperation within the clan and to others in the community.

\section{Sense of necessity to act}

A sense of necessity has motivated Pelviji initiatives. One Pelviji leader explained: "We believed that it was important to build the strength of our own family by working together on the Nakamal and choosing a leader that can take us into the future." Another member added: "There was a sense in my family

\footnotetext{
${ }^{70}$ At this meeting they presented a petition for the building of a community nakamal, which they considered would be a project that would help solve community problems.
} 
that if we don't do something now, we will never do anything." Motivation to work together through the land claims process was attributed in part to the pressing needs to escape the over crowing on Tangoa Island and increasing social tensions.

\section{Governance capacity leadership of respected individuals and families}

The Pelviji clan is one original Tangoa clans which means that they are relatively well endowed with quality garden land resources, as well as their own coconut plantations. This has contributed to the clan's relative wealth, and access to education. The Pelviji family is endowed with several well educated and respected leaders that provide the support and motivation needed for collective action. These leaders are educated, they possess valued and respected knowledge which is shared with the community, and they have shown that projects that they initiate resulted in benefit for those who participate.

\section{Funds}

Due to several highly educated individuals who have relatively high paying jobs, the clan has access to some extra funds for projects and links to funding sources. For example, one important leader in the family was able to access funds for the timber nursery project through the Department of Forests. ${ }^{71}$

\section{Benefits from collective action}

The Pelviji clan has accomplished goals and experienced the benefits of collective action, which have in turn, further built cooperative capacity in the clan (including increased social cohesion and cooperation). The Pelviji Chief explained: "The opening of the Pelviji Nakamal and the chief making ceremony was very important for my family. It helped to build pride and strength." Initiatives have increased economic security (economic benefits from cooperative store) and built trust in their ability to allocate benefits, as well as providing experience with coordination, role allocation, money management, and communication.

\footnotetext{
${ }^{71}$ Success is also attributed to the fact that the clan recognised land rights for where the Nakamal was built, which allowed them the autonomy to decide how to use the land, and manage it themselves
} 


\section{Strong internal locus of control}

Accomplishments have increased Pelviji's confidence in their ability to act cooperatively and gain benefits from collective action, which has encouraged developing further goals and initiatives. One man explained, "After we built the Nakamal, we knew we could do more. We decided to make a cooperative. Everyone contributed money to set up the shop. Now each Pelviji family has shares and benefits." Human capital also contributes to Pelviji's strong locus of control. They have people with the skills and knowledge needed to progress through a land claims process including: knowledge about ancestral land ownership, literacy (which is necessary in order to document the family tree and land history), the ability to make a map of the land boundaries, and the ability to stand up in court and argue a case.

Pelviji achievements have also influenced other families and clans. "When people saw Pelviji finish building the Nakamal, and electing chiefs, other clans wanted to do the same." A Pelviji leader ran some workshops on Tangoa about timber planting. Initially people from other clans were reluctant to attend timber planting workshops because: "They did not have trust. They thought "this is not for us"." However once people saw that they could benefit from timber planting too, other families have followed Pelviji in planting timber crops in their own clan areas.

\subsubsection{Strategies to overcome social problems}

Youth and women's focus group explained that leadership and communication structures within the community need to be strengthened so that people can "work together" to solve problems. Youth and women's group brainstorming described the role that the Chief, the Pastor, and representatives of women's group, youth group and committee leaders could play in resolving problems and disputes in the community. Figure 4.31 , is a youth group poster showing the different groups and the different leaders that would need to be involved in a community problem solving process. Figure 4.32 is a women's group poster identifying main leaders who can solve problems including the Chief, Pastor and Elders. 

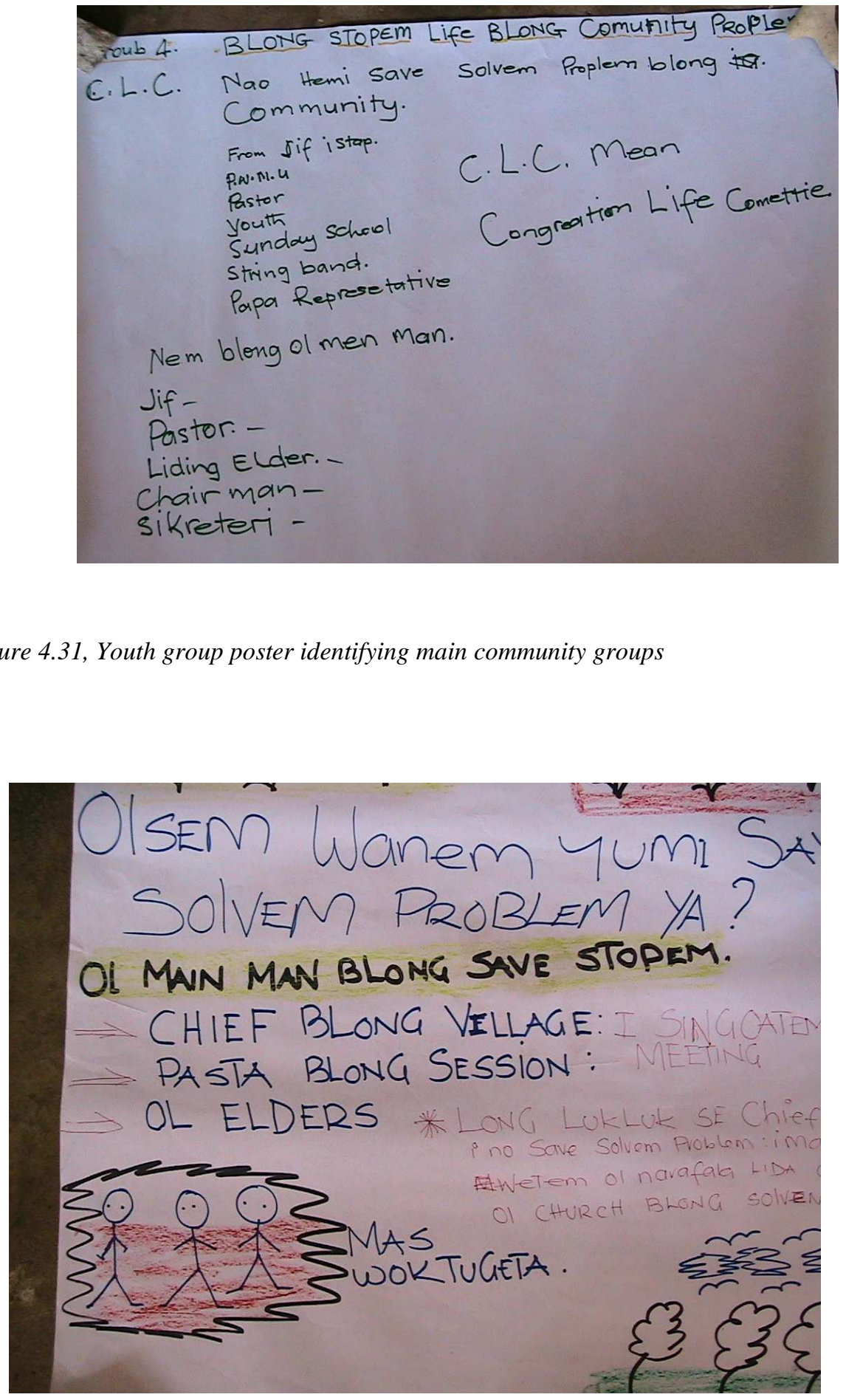

Figure 4.32, Women's group poster identifying main leaders

A group of women brainstormed ideas for an ideal process which could help the community "work together" (see figure 4.33). The women considered an iterative and transparent process of communication, and consensus building would be important. They outlined various steps of such a process: 
1. Chief calls a general meeting for everyone can hear about/talk about how the community needs to try to work together to solve problems within the community and achieve shared goals.

2. Pastor calls meeting of all session members and the congregation life committee $(\mathrm{CLC})^{72}$. People can talk together and come up with ideas about what will make the community work together better.

3. Chief and pastor work together to call a general community meeting to talk about what should be done to help the community.

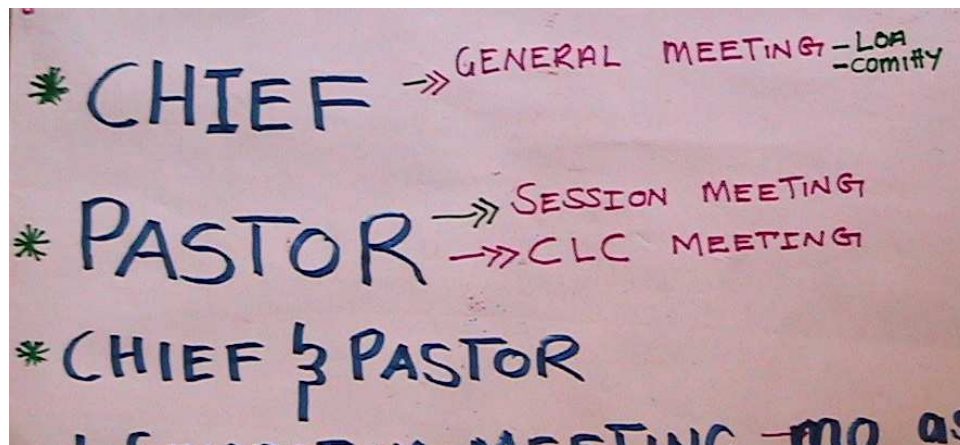

I SINGAOTEM MEETING TMO ASREM TIN TING BLONG COMMUNITY.

COMMUNITY I SEREM TING TING BLONG HEM LONG CHIE

MO PASTOR MO OLI KAM UP LONG ONE TINGTING MO

MEKEM SE COMMUNITY HEMI

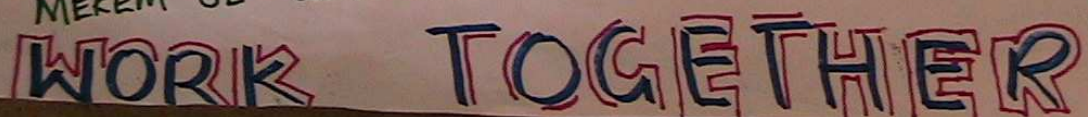

Figure 4.33, Women's ideas about the process required to help the community "work together"

\subsubsection{Summary of main points about social cohesion}

- Social cohesion problems directly and indirectly impact commons management. Conflict and disputes can result in sabotage of resources on disputed land and increasing individualism degrades the community's capacity to work together.

\footnotetext{
${ }^{72}$ The CLC is a Tangoan Church organization.
} 
- As cooperation and respect for custom rules are the foundation for Tangoa's commons management, declining social cohesion is a threat to the resources on which livelihoods depend.

- Economic pressures and governance problems are the two main drivers of declining social cohesion.

- Economic pressures have weakened a traditional 'culture of sharing' as people have become more focused on the needs of their immediate families.

- $\quad$ People have fewer resources to share and less time to spend interacting socially.

- Reciprocity between different families and clans is declining as inequalities in wealth (related to resource endowments) increase.

- Economic pressures drive competition for resources, and in turn, conflicts and disputes.

- Governance problems such as poor leadership make organisation and coordination of activities (e.g. church and school activities) difficult. This exacerbates economic pressures and contributes to individualism.

- Governance problems inhibit the resolution of conflicts and disputes which are both a cause and consequence of declining social cohesion.

- Locally identified strategies to solve social cohesion problems include getting leaders and the community together in a process of communication, planning and action.

These points are summarised in Figure 2.34 below. 


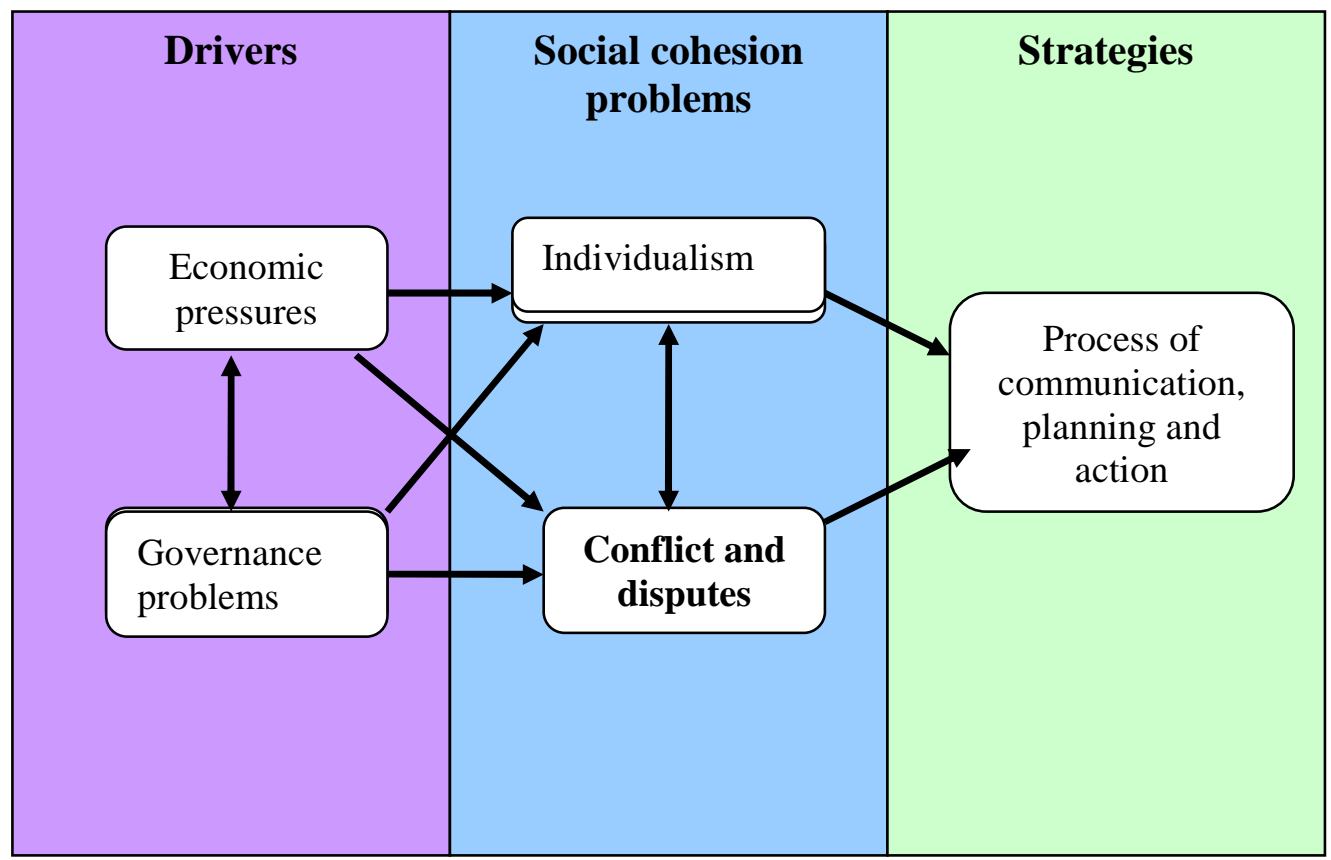

Figure 4.34, Drivers of social cohesion problems, and locally identified strategy 


\section{Chapter 5 - Results Part 2: Relevance of Case-Study Findings for the Wider Context of Vanuatu}

Review of Vanuatu literature and interviews with NGOs, multilateral aid donors, and government employees involved in conservation and development in Vanuatu shows that the problems affecting management of Tangoa's CPRs are relatively common in communities across Vanuatu. The main reason for this is that many of the underlying drivers are related to widespread processes of cultural change associated with globalisation, change in national governance, and institutional structures.

This chapter uses literature and interview data gathered from Port Vila during February 2007, to show the relevance of the case study findings for other communities in Vanuatu. The first two sections provide a brief overview of natural resource use and of community resource management in Vanuatu. The last section looks at the drivers of Tangoa's commons management problems in the wider Vanuatu context. I explore the effect of economic pressures, social cohesion problems, and governance problems on local level commons management in Vanuatu. Finally, I highlight some important factors which were not identified in the case study. These include how Vanuatu's current development pathway and economic development policies may affect local level commons management.

\subsection{Use of natural resources}

As is the case for the Tangoa community, rural livelihoods across Vanuatu are inextricably linked to natural resources. The rural population makes up $77 \%$ of the total population (Vanuatu Statistics Office, 2007). A $80 \%$ increase in the rural population in the 27 years since independence (from about 95,000 in 1980 to 170,815 now) has been supported by use of natural resources and the traditional, largely non-monetarised, rural economy (Baezely and Mullen, 2006; Vanuatu Statistics Office, 2007). About $80 \%$ of Vanuatu households (and 91\% of the rural households) are engaged in some kind of small-scale commercial or subsistence forestry activities (Vanuatu Statistics Office, 2007). Forest resources 
are also important for fuel-wood, herbal medicines, wild meat, edible nuts, thatch grass and other building materials, and plants used for ceremonial purposes and the manufacture of musical instruments (Whyte et al., 2002). An estimated monetary value of forest products for subsistence use could be as high as US\$14 million per year (VDF, 2002). Reef fisheries provide an important source of protein for Vanuatu's coastal communities and $78 \%$ of ni-Vanuatu households fish regularly for their own consumption (Vanuatu Statistics Office, 2007).

\subsection{Community management of natural resources}

Like on Tangoa Island, most community governance systems in Vanuatu make consensus-based decisions about management of collectively owned land, with the guiding authority of the chief (Whyte et al., 1998; 1999). Traditional governance systems in Vanuatu are generally based on customs of reciprocity and cooperation for communal benefit (Kalontano et al, 2003), and resource management is based on traditional ecological knowledge (TEK). Taboos are associated with elabourate traditional practices and rituals underpinned by traditional cosmology, and are sanctioned through supernatural forces. These traditional rules were complied with out of fear and respect for the local deities involved (Hickey, 2006).Traditional beliefs and practices associated with NRM in Vanuatu often follow natural cycles of resource abundance, accessibility, and respect for customary rules enshrined in oral traditions (Hickey, 2006). Garu (pers. comm.) explains, "Life in the custom system hinges on time and way. The way you exploit the natural environment is defined by the time, and the way that will not deprive others from it."

\subsection{Causes of degradation}

\subsubsection{Population pressures}

Population pressures and lack of gardening land are two key drivers of economic pressures as well as social and governance problems in Tangoa. However a recent census carried out by the Vanuatu Statistics Office suggests that the severity of the Tangoa population and land pressures may be one of the most 
extreme cases in Vanuatu. However, population growth is relatively high across the country. Census statistics from 1999 and 2006 show that Vanuatu's population has grown $20 \%$ (from 186,678 to 221,507) over the last six years. Specific census data for Tangoa were unavailable from the agricultural census that came out in 2006, so Tangoa population data from the case study were compared with the Tangoa statistics from 1999. Tangoa population has grown about $34 \%$ over six years. Figure 5.1 shows that population growth varies between the different provinces with the highest growth in the province of Shefa where the capital city - Port Vila, has flowed into it. This reflects high rates of urbanisation (7.3\%/yr; UNDP 1999) as many outer islanders moving to the capital and surrounding areas in search of work. Figure 5.1, also shows that Tangoa has a higher rate of population growth than any of the provinces.

\section{Population increase from 1999 - 2006 for Vanuatu, the provinces, and Tangoa}

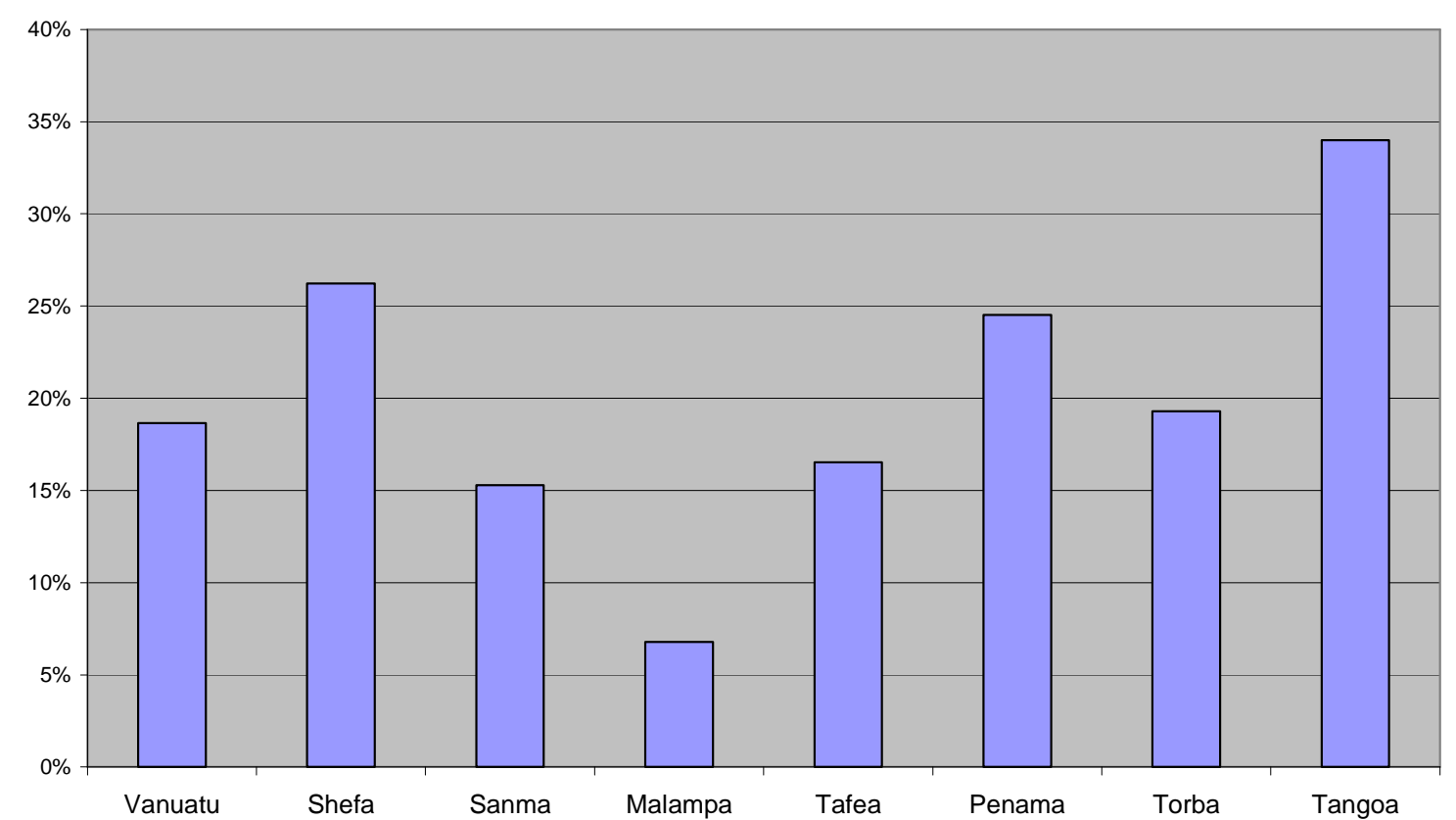

Figure 5.1, Population increase from 1999-2006 for Vanuatu, the provinces, and Tangoa 


\subsubsection{Land and resource endowments}

Without comparable agricultural census data for Tangoa Island, only an estimate is possible for how Tangoan land and resource endowments compare with the rest of Vanuatu. The basis of the estimates is limited data from key informants who provided information about the populations of the most well endowed clans which "all have gardens and most have their own coconuts" (see section 4.6.3) and about the number of Tangoa households with garden land and coconuts. As Tangoa is 'rural', it is most meaningful to compare the Tangoan estimate of households with garden land with the census data for rural Vanuatu households with their own garden plots. The Tangoa estimate is that about $70 \%$ of households have their own garden plots (see section 4.6.3). This is much lower than the $97 \%$ of rural Vanuatu households with garden plots (see figure 5.2). One Tangoan community member explained that many other communities do not experience the shortage of land as much as Tangoa people do, because they do not have such a confined resource area (Viji pers. comms. 2.02.07).

The Tangoa estimate for the number of households that have their own coconut trees is between $65-70 \%$. This compares with the census data which says that $85 \%$ of rural households have coconut trees. $96 \%$ of these rural households with coconuts are smallholders, which means that they operate on a subsistence level and generally with no organised management or record keeping (Vanuatu National Statistics Office (NSO), 2006). ${ }^{73}$

\footnotetext{
${ }^{73}$ Small holding is defined by the Vanuatu's National Statistics Office as "all holdings which do not fall into the category of plantation." (VSO, 2006, p.9)
} 


\section{Comparison of garden land and coconut endowments between Vanuatu and Tangoa}

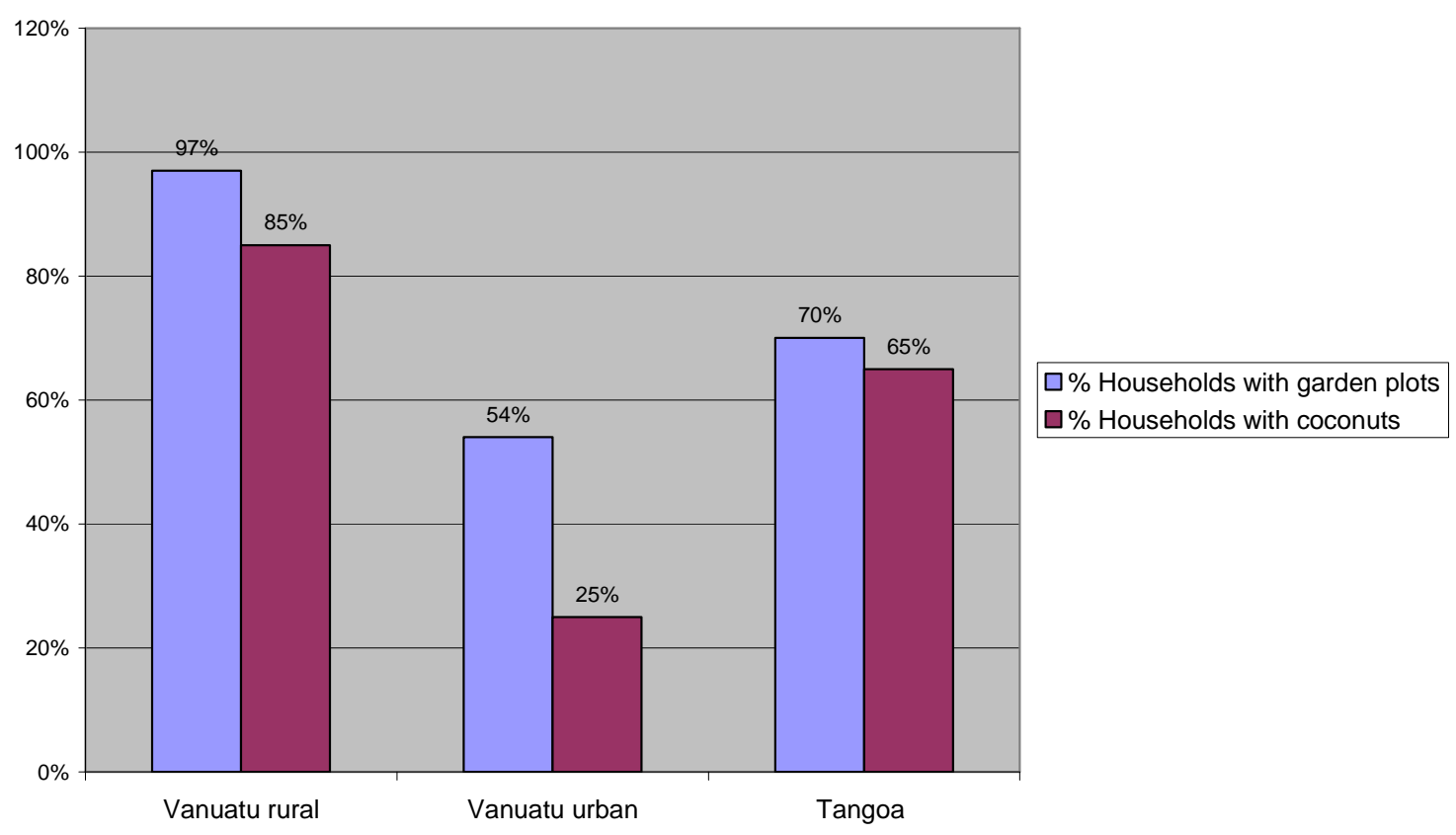

Figure 5.2, Comparison of garden land and coconut endowments between Vanuatu and Tangoa. (Data from NSO, 2006; and Tangoa key informants and local population census)

\subsubsection{Economic pressures}

As seen in the Tangoa case study, economic pressures directly impact commons resource management by changing how resources are used. Economic pressures drive increased demand for resource utilization and a decline in traditional management practices. Selwyn Garu from the National Council of Chiefs explained the close link between natural resource management and natural resource use in Vanuatu:

\footnotetext{
"Environmental conservation has always been a way of life of the rural communities in Vanuatu. Communities' techniques of conservation are not like a park, where you close a particular area off and leave it there. You can't close places because people depend on those places for firewood, trees to make houses, custom leaf medicine from the bush, so you leave the bush but manage it in such a way that it continues to supply what you need." (Garu, pers. comm.).
}

However, a representative from NGO Wan Smolbag explained that as communities face increasing economic pressures and new monetary needs, the 
traditional systems of management are changing: "People will tell you about practices that were used traditionally that help to conserve natural resources, but over time, having to use the resources for money puts a lot more pressure on those resources, and forces people to give up the traditional ways of using resources."

Participatory research with communities across Vanuatu shows that the link identified in Tangoa data between economic pressures and governance problems, is also relatively common in other communities (Kalontano et al., 2003). Increased need and desire for money is having a negative effect on community governance capacity as community leaders struggle to accommodate and provide for the changing needs and desires of their people. Traditional governance systems in Vanuatu are designed around facilitating and managing subsistence socio-economic livelihoods and traditional values, which often clash with modern, capitalist pressures ${ }^{74}$ (Garu, pers comm; Kalontano pers comm.). As Chiefs struggle to provide for the additional community needs and desires, customary systems and values are being weakened and chiefs face declining respect and power (Kalontano et al. 2003).

An increasing need and desire for money negatively impacts community governance systems, in turn impacting environmental management and social systems of reciprocity, thereby increasing livelihood insecurity. Tangoa families that are less well endowed with gardening land are more dependent on cash to buy food, and are perceived to be suffering from poor nutrition as a result (see section 4.6.3). Port Vila based research suggests that this link between transitioning from a gardening-based to cash-based economy and increasing socio-economic vulnerability, can be seen in urban communities that do not have the livelihood security of gardens, or the social security of strong communities such as those living in Port Vila (Regenvanu, 2007). According to Regenvanu (2007) "Port Vila is the one place in the country where the most real poverty,

\footnotetext{
${ }^{74}$ Waddell and Connell (2007: 3) Describe this as a "condition where people are exposed to a bewildering range of new ideologies, lifestyles and goods...increasingly divorced from the needs and values of rural people". Weaver et al (2007, forthcoming) overviews issues surrounding this in a specific Vanuatu context.
} 
homelessness, hunger (malnutrition) and lifestyle diseases are now being experienced."

\title{
5.3.4 Governance problems
}

A comprehensive study of community governance problems in Vanuatu by the Foundation for the People of the South Pacific - Vanuatu (FSP) ${ }^{75}$ shows that some of the governance problems seen in the Tangoa case study are widespread in Vanuatu. Across a range of rural and urban, modern and traditional Vanuatu communities, modern structures of governance are weakening customary community governance and the power and responsibility of traditional leaders (Kalontano et al. 2003). National governance changes since independence have resulted in new institutional structures, including state government departments, police, courts, and new constitutional perspectives about rights (Garu, pers. comm.). New values of individual rights and democracy conflict with customary governance, which is based on underlying communal values and is focused around ensuring the wellbeing of the collective. Selwyn Garu from the Malvatumauri (National Council of Chiefs) ${ }^{76}$ explains that the constitutional governance structure conflicts with customary governance structures, with negative consequences for leadership:

\begin{abstract}
"Everyday, forces from constitutional governance are bombarding custom, and custom is being challenged in such a way that it is struggling."... "Chiefs struggle with changes that come through education, church, NGOs, government, and ideas from outside coming in. Many Chiefs don't know how to deal with the new daily changes. Some just don't have the skills and capacities to manage these changes."... "Custom leadership is very uncertain as to what to do when things go wrong in the community now. If they make a particular decision they may be taken to court by someone else. The courts can
\end{abstract}

\footnotetext{
${ }^{75}$ FSPV produced a research report: Assessing Community Perspectives on Governance in Vanuatu. The report was an output from the "Voices and Choices Project" which involved participatory research with communities across Vanuatu. The project's aim was to explore issues of community governance, identify its strength and weaknesses and develop an understanding of the challenges that are currently undermining both traditional community governance structures and modern adaptations. (see: http://www.devnet.org.nz/conf2002/abstracts/Whyte_Jenny_et_al.pdf (info about project)

${ }^{76}$ The National Council of Chiefs is essentially an administrative structure to support governance at the village level as well as support traditional governance values at the national level. At the National level, the Council works to ensure they are consulted and allowed a chance to discuss and debate the merits of any proposals for custom related bills before they are tabled in parliament (FSP 2005).
} 
take away authority from Chiefs and then all the customary ceremonies and ways of resolving disputes and problems are not valued."

(Garu, pers comms. 12/02/07).

Studies from around the world show that the difficulties Vanuatu communities are experiencing with transitioning governance structures are common for societies undergoing adaptation from chiefly systems to more modern systems (McCarthy et al., 2002; Fuys et al., 2006). Substitute organisations often struggle to fill the leadership roles previously undertaken by the chief (McCarthy et al., 2002).

Studies of community level commons management in Vanuatu show that the strength of traditional community governance systems (e.g., respect for rules and custom) and sustainable resource management are strongly correlated (Hickey, 2006; Kalontano et al., 2003; FSP, 2005; Whyte, 2002). Garu (pers comms. 12/02/07) explains the importance of customary systems and traditional leaders: "In Vanuatu, people need to be able to fall back on the Chief - not only for environmental conservation, but for peace and stability and everything." $\mathrm{He}$ explains that locally developed systems of governance are suited to local contexts, whereas the constitutional systems tend to standardise values, laws and practices, with negative effects on unique cultures: "Vanuatu is a nation made up of many nations. Each community, each society, each particular cultural area has its differences. They believe in different ways of doing things. Customary leaders are needed to deal with their own unique situations."

The difficulty experienced by Tangoans in providing time and money for the different community responsibilities (i.e., for the Church and the schools) is common across many communities in Vanuatu. Kalontano et al. (2003, p.100) describe this as an increased "burden of responsibility", and explain that (as seen in Tangoa data) this is linked with a socio-cultural shift from communalism to individualism. The family, even to the level of the nuclear family, is becoming the focus of individual and household endeavor (Kalontano et al. 2003). This shows that the link between the community governance problems and social 
cohesion problems seen in Tangoa are relevant for many communities, especially those that are struggling to coordinate the new governance structures.

Loss of traditional ecological knowledge (TEK) was identified as a problem that affects respect for custom governance in the Tangoa case study. Studies show that TEK is declining across Vanuatu and has been since the arrival of Western European cultures in the 19th and early 20th century. During this early colonial period, introduced diseases resulted in severe depopulation which had a major impact on Vanuatu people, their cultures, and their TEK (Hickey 2006). TEK was also affected by intensive missionary activity on many islands which resulted in population movements and cultural shifts (ibid). TEK is impacted today by processes of urbanisation and cultural change. Studies show that urbanisation threatens TEK (Usher 2000), and Vanuatu has one of the highest rates of urbanisation in the world (UNDP 1999).

Several interviews indicated that the Tangoan identified link between loss of TEK, growth of monetary economy and related cultural change, is seen in other Vanuatu communities also. Charles Vatu (AusAID) worked for several years to help local people in East Santo establish the Vatthe Conservation Area and he explains:

\footnotetext{
"Knowing the importance of conservation and protection of resources is not a new thing for the elders. Managing the natural environment has always been their way of life. But the youth today are affected by the forces that come with the cash economy. Youth absorb new culture. Transfer of traditional knowledge from elders to young is reducing. In some places the knowledge is being lost because it is not being taught. Formal education takes all the kids to school. They don't spend time with their elders or they don't go looking for this knowledge form their elders."
}

Research from Vanuatu indicates TEK is important (and therefore loss of TEK is a problem) because practices based on indigenous knowledge foster pride, identity and ownership (Whyte et al., 1998; 1999; Environment Unit, 2003). People are more willing to work together for something that is their own, based 
on their own knowledge, rather than something externally driven (Hickey, 2006; Johannes et al, 2004; Whyte, 2002). Western models of conservation, such as marine protected areas, are poorly understood and are largely viewed with suspicion by rural communities. In most cases, these are unsustainable once outside assistance has ended (Johannes and Hickey, 2004).

\subsubsection{Social cohesion problems}

Case study data from Tangoa show that social cohesion problems degrade social capital (see section 4.8). This inhibits the Tangoa community's ability to cooperate for commons management, and to work together to solve problems and achieve goals. Kalontano et al. (2003) found that social cohesion problems are common for many communities across Vanuatu, and that this can be seen in the decline of respect and cooperation. In Vanuatu, respect is shown through the practice of acceptable ways of behavior in society, including either fear or support of leaders. Cooperation includes the concepts of working together, willing participation, support and contribution (Kalontano et al. 2003).

Similar to the case study findings, participatory research with other communities has identified the interrelated factors involved in declining respect and cooperation as: increasing individualism; weakening leadership and governance systems; disputes over land, resource access, and authority; jealousy; and increasing economic pressures, including growing need and desire for money (Kalontano et al. 2003). One environmental NGO explained: "Land disputes are everywhere in Vanuatu"; and "Land disputes are often an indicator of poor respect between people." Informants iterated that land disputes in Vanuatu are both an indicator and driver of social cohesion problems.

As seen in Tangoa, low cooperative capacity can be a barrier to accessing external assistance for development, training, funding etc. Interviews with government representatives and NGOs in Port Vila support this finding for Vanuatu in general. Community governance/cooperative capacity can determine whether government, NGO and donor assistance can be provided, and which communities are chosen as participants in projects. Interviewees described some 
of the indicators that they use to identify and assess community cooperative capacity. One NGO explained: "A strong Chief is an indication that the community as a whole will work together. If he is present at things that he has been requested to be a part of, and if people respond to him well, that's a strong indicator." An individual from the government that does environmental work with communities considered indicators of leadership important: "When I first arrive at a community to do a workshop, if the leader comes and meets me, it is a good sign that people communicate with one another." A volunteer organisation explained that community contributions of money and labour can also be indicators of collective commitment for an initiative: "When the community builds a house for the volunteer, it is a good indicator that having a volunteer is a collective goal, and that the community can work together."

Poor social cohesion is problematic for communities such as Tangoa, which may need to develop new management practices and rules in order to deal with environmental problems that are inadequately managed under customary rules or where the customary systems are weak (see section 4.4.2). One Pt. Vila interviewee who has been working on conservation and development initiatives with his own community explained: "It is difficult for people to change how they use natural resources unless it is a very strong community, or unless they have assurance or proof that it will benefit them."

\subsubsection{Commons management threats associated with Vanuatu's national development policies}

National policies and practices aimed at supporting productive sector growth facilitate investor's access to land and natural resources. This has resulted in a rapid increase of long term leases (Rockell, 2007). The government also seeks to encourage development of the tourism industry and the extractive industries such as logging, and mining (Department of Economic and Sector Planning, 2006). Low government capacity to develop and implement policy means that external investors meet minimal barriers and constraints in their endeavor to exploit natural resources. This section outlines several issues associated with Vanuatu's development policies that may have serious impacts on local communities and commons management. 


\section{Land leasehold sale}

The Vanuatu government seeks to encourage and accommodate external development interests but has to do this within a constitutional framework that outlines the government's responsibilities to uphold the rights of indigenous land owners. Under the 1988 Land Lease Act, different lease categories were defined according to land use, and extension of leases to 75 years became prevalent. ${ }^{77}$ In his thesis on land tenure issues and their effect on development in Vanuatu, Dennis Rockell (2007, p73) argues that there is a struggle of interests between the return of indigenous lands as promised in the constitution and the needs of foreign investors and developers: "The preponderance of 75 year leases appears to be a triumph for the developer."

Privatisation marginalises people from their land and the resources on which they depend. Communities are increasingly selling leasehold interests to alleviate needs for cash, but they do this without understanding what the consequences will be (Garu, pers. comm.; Hickey, pers. comm.). Often land owners do not realise that leasing land can permanently jeopardise their access to, and use of resources. Once their land is leased, they have no control over what happens to it. Investors can do what they like, often degrading and permanently altering natural resources. Furthermore, landowners' ability to benefit from land sales is limited due to poor education about how to use and save money (Hickey, pers. comm., 7.02.07). Often money made from sale of land is gone in several years, and then families have no land on which to support livelihoods.

Once people give up options for subsistence livelihoods they face increased problems and vulnerability associated with urban, cash-based livelihoods. Selwyn Garu explains that the trend of leasehold land may have political ramifications along with the social and cultural impacts: "Life is land in Vanuatu. This mass selling of land like on Santo and Efate, means that communities are refrained from using it. People will feel alienated. This will

\footnotetext{
77 The island of Efate has the highest concentration of leases - approximately one quarter of the island $(26,000 \mathrm{ha})$ is now under registered leasehold. By the 1990 s at least $50 \%$ of alienated land still did not have custom ownership determined (Farran, 2002, cited in Rockell, 2007).
} 
create discontent and a new situation that has never been managed before." (Garu, pers. comm.)

As seen in the Tangoa case study, where there is ambiguity about tenure rights, people feel that they do not have the authority to govern water taro patches within leasehold land. Tenure ambiguity is common in areas of Vanuatu where privatisation of land and resources through longterm leases is occurring. It can cause a decline in customary institutions that manage natural resources. One port Vila Based NGO explained: "Investors are buying up coastal areas for resorts in Efate and East Santo. Local people are often not aware of whether or not they can still manage marine resources in the area, or what their rights are."

\section{Extractive industries and tourism development}

Other examples of how the current development model may be considered environmentally and socially unsustainable include: poorly implemented Environmental Impact Assessment (EIA) process; no mandatory social or cultural impact assessment for development projects; no effective land use planning or zoning; problems with unregistered loggers, and environmentally damaging practices even though there is a Code of Logging Practice ${ }^{78}$ (VDF, 2002); and no official process for undertaking genuine consultation with communities about what kind of "development" they would like to see take place (Regenvanu, 2007). ${ }^{79}$ While Tangoa has not yet faced pressures from logging, mining, large tourism operators etc., many other Vanuatu communities are facing these pressures. ${ }^{80}$

\footnotetext{
${ }^{78}$ The code of logging practice sets operational guidelines and rules and requires loggers to know these and abide by these in order to get a timber extraction license (Vanuatu Forestry Department, 2004)

${ }^{79}$ Vanuatu government has precious little capacity to undertake scenario-planning around future policy and public investment options. The Department of Economic and Sector Planning (DESP), in charge of policy development, is pre-occupied with administration matters including overseeing, literally hundreds of small development projects (Baezely and Mullen, 2006).

${ }^{80}$ The Tangoa community was aware that a community further inland had just agreed to allow a coal mining operation go ahead. While it may be the landowners that have to agree to such a project, many other communities that may be effected by the downstream environmental effects of mining, including water pollution, are not consulted.
} 


\section{Chapter 6 - Discussion}

The purpose of this study is to determine locally identified commons management issues for the Tangoa Community, to put the case study results in the wider Vanuatu context, and to identify opportunities overcoming commons management problems. The research undertaken involves literature review ("literature"), the case study ("case study"), and the wider Vanuatu based research ("Vanuatu research"). My research results contribute to commons research in several ways. In particular, it addresses a gap in identified in the literature about knowledge of the interaction between context and factors at multiple levels. It also contributes to a gap in research on commons management in Vanuatu.

I have developed a model to describe and analyse the findings from the literature, the case study and the Vanuatu research. It is a model of community cooperative capacity for commons management, or for the sake of giving it a title - it is a Cooperative Capacity Model. In the remainder of this discussion, it will simply be called the "model". The model emphasises two central arguments that arise from this study: that the important factors affecting locallevel commons management are context specific; and that local capacity for commons management is affected by drivers at multiple levels. The model is intended to help facilitate the analysis and discussion of the study results.

This discussion chapter has three main sections. In the first section, I describe and explain the model. Throughout the discussion I highlight how the findings link to commons literature. The second section of this chapter acknowledges the limitations of this study, and highlights several gaps where further research is needed. The third section of this chapter builds from the major findings to argue that development needs to be appropriate for particular social, cultural and ecological contexts. Finally, I identify various opportunities and solutions that may support local commons management. 


\subsection{Cooperative Capacity Model}

The case study and Vanuatu research can be summarised in the model, which shows the most important factors involved in Tangoa's commons management. Figure 6.1 is a general illustration showing Important changes that drive local commons problems are influenced by processes that occur in different contexts at the local, national and global levels. The two major determining factors of Tangoa's cooperative capacity are social cohesion and governance capacity. Community cooperative capacity lies in the intersection of these two main factors, and is nested within multiple contextual levels of influence. As described in the introduction, 'cooperative capacity' is the ability for the community to work collectively to achieve shared goals, and solve collective action problems.

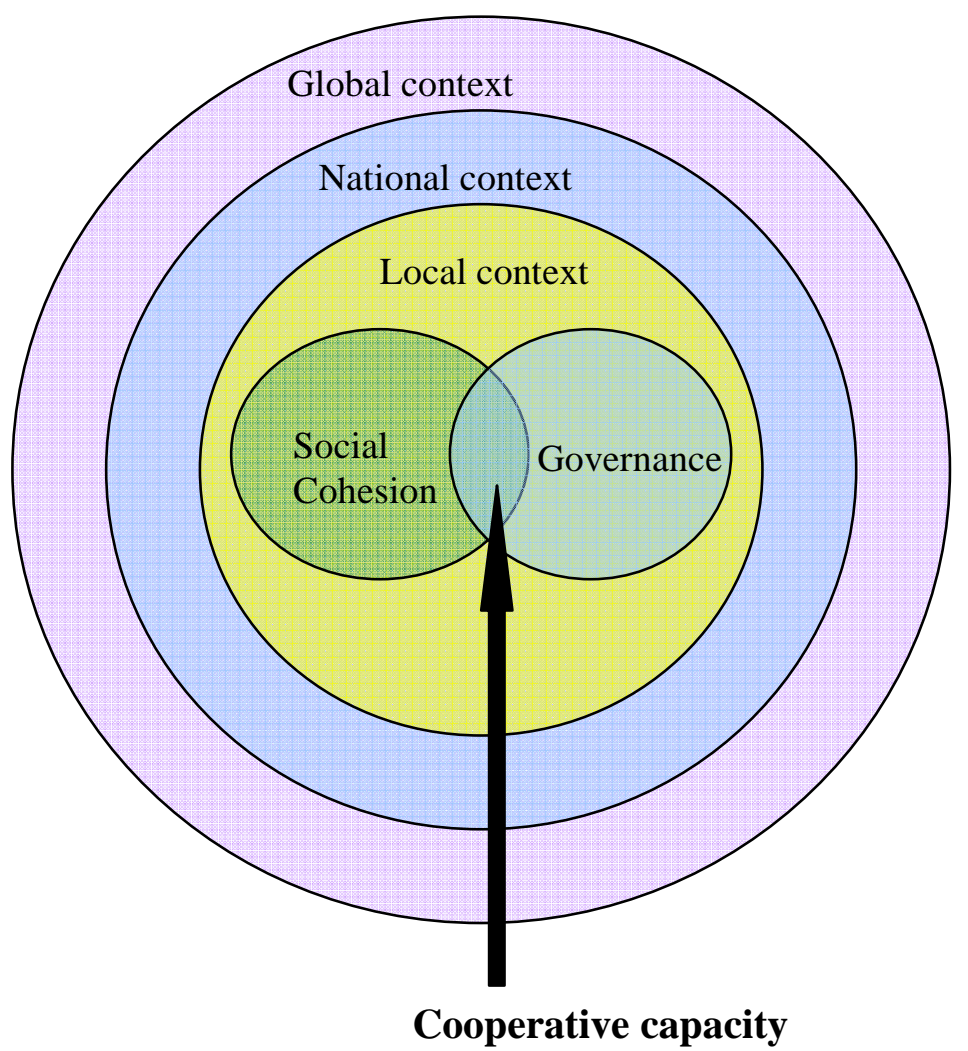

Figure 6.1 Model of community cooperative capacity for Tangoa, Vanuatu

The link between local situations and wider contextual influences explains why Tangoan issues are relatively common across rural Vanuatu. This supports the premise arising in literature that people, places and environments are never 
separate, isolated realities. They are subject to regional and global forces of economic, political and environmental change (Waddell and Connell, 2007). The key drivers at different levels that influence local cooperative capacity are outlined in table 6.1 .

Table 6.1 Global level, national level and local level factors that influence community cooperative capacity

\section{Global level}

- Global transfer of ideas, values, people, cultures, and products

- International market prices of copra
National level

- Cultural change

- National institutional change i.e. formal education

- Constitutional governance structures and values

- Government development policies

- Low economic development i.e. limited income generating opportunities

- Problems with land claims processes

\section{Local level}

- Economic pressures

- Socio-economic heterogeneity

- Cultural change i.e. desire for modern lifestyles

- Loss of TEK

- Declining respect for chiefs and custom governance institutions

- Disputes and conflict

- Exclusion of women from community level decision-making processes and institutional structures

- Tenure ambiguity

Figure 6.2 illustrates in more detail how drivers at multiple levels influence community cooperative capacity for commons management in Vanuatu. The following section will describe the model and explain how the drivers at each level affect the two essential elements of cooperative capacity - social cohesion and governance. The discussion will use the literature, case study and Vanuatu research where they strengthen the analysis. 


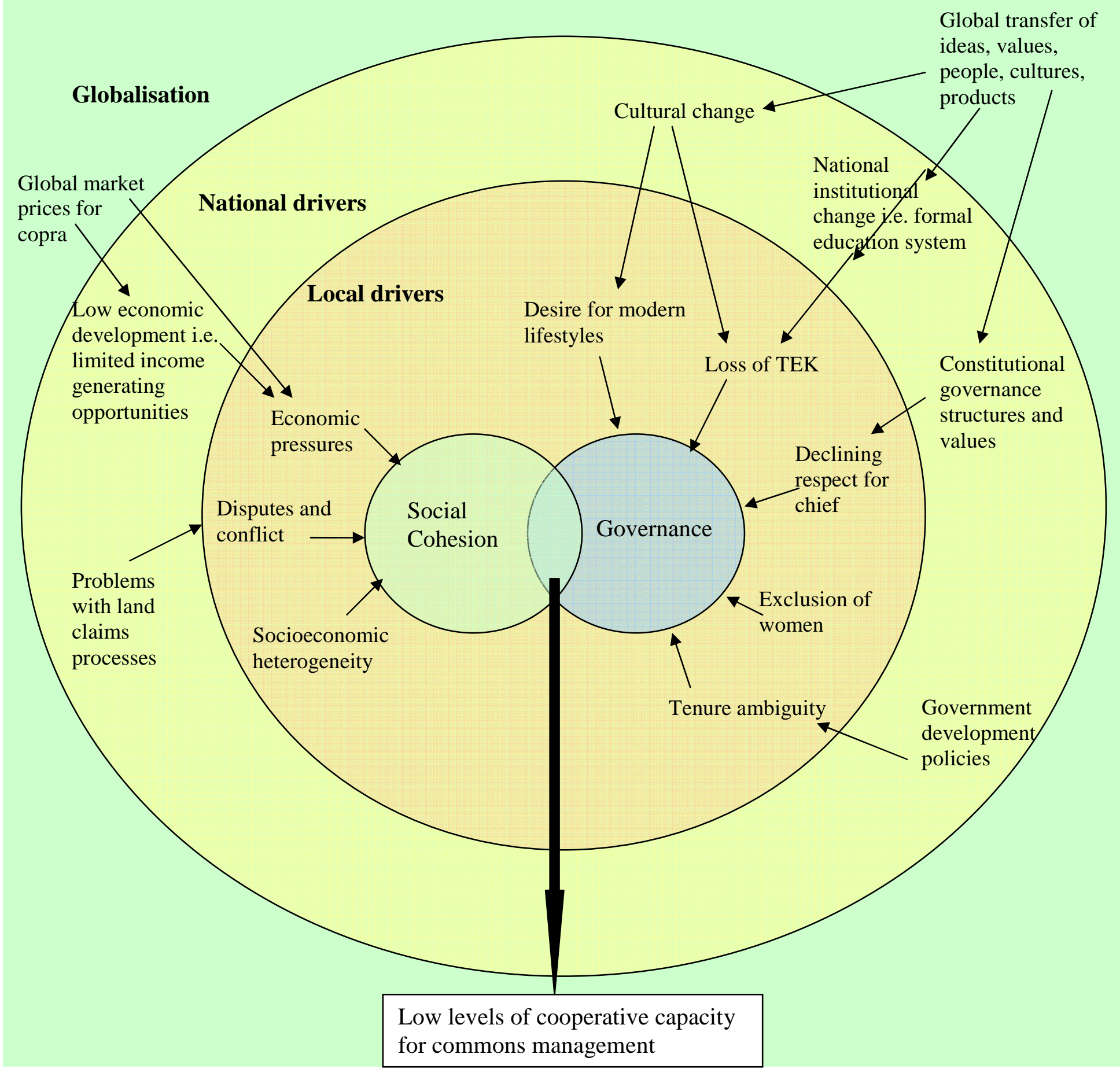

Figure 6.2, Model of cooperative capacity for local commons management in Vanuatu 


\subsubsection{Social cohesion}

Social cohesion is vital for Tangoa's cooperative capacity for commons management. Other studies from around the world have also identified that "a major threat to community-based management is the lack of internal cohesion in the communities themselves." (Neumann, 2005). Social cohesion affects trust and social capital within a community, and can determine people's motivation to work for collective benefits. Commons research provides theoretical and empirical evidence that intra-community social capital is required for innovative change in NRM. As Pretty and Ward, (2001, p.225) explain: "NRM innovation in a collective action setting requires high levels of trust and networking to promote knowledge sharing and confidence in reciprocal support from the group in the face of risk." ${ }^{81}$ The case study data support Ostrom (1990) and Kahan's (2002) emphasis on the importance of trust to enable people to make contingent strategies to cooperate. This can be seen in the case of drinking water management, where no institution or rules have emerged to manage a longstanding problem of shared concern due to people "not wanting to do anything others will benefit from" (section 4.8.2).

In the Tangoa community, the main issues associated with declining social cohesion include increased individualism as well as conflict, divisions, and disputes. As figure 6.2 suggests, national and global level contextual factors influence these local drivers in several ways. Market integration and growing local monetary economy affects social cohesion and intra-community reciprocity (see section 4.8.3). Local people find it especially difficult to address economic pressures and achieve economic development goals due to volatile (and low) market prices for copra and few employment opportunities. Problems with national land claims processes also constrain local resolution of land disputes.

Tangoa results also support the findings of Krishna (2003), that social capital (including trust) is needed for the utilisation of human capital assets within the community. In the Tangoa community there are individuals that could be described as 'organisational entrepreneurs' (Molinas, 1998), or 'village agents'

\footnotetext{
${ }^{81}$ Increasing amounts of capacity for collective action are needed along a scale of remedial measures to change current practices, to innovation (Pretty and Ward, 2001).
} 
(Krishna, 2003) "who act and bring about change" (Sen, 1999 p. 18-19). However, their ability to provide leadership beyond their own clans is limited by lack of trust between clans (see section 4.8.4).

\subsubsection{Governance}

Figure 6.2 indicates that local governance issues include cultural change, leadership problems and lack of governance authority over commons resources within private leaseholder land (section 4.7.4). Strong community governance is important to enable local communities to manage local issues as well as adapt to or control the impacts of external pressures and processes of change (Garu, pers comm.; Kalontano et al., 2003). Emphasis on strong community governance that facilitates cooperative capacity is supported by commons research. Case studies from literature show that cooperative capacity has empowered communities to influence policy at the national level (Shrestha, 2005); to gain greater recognition of their rights to govern commons resources (Galudra, 2005; Kijtewachakul, 2005); and to act collectively against external threats to resource dependent livelihoods (Bachir et al., 2005; Ghate, 2005)

Cultural change comes from formal education, the media and popular culture which actively promote individual interests as distinct from the collective good (Waddell and Connell, 2007). In the Tangoa community cultural change includes the desire for more modern lifestyles, loss of TEK resulting from the crowding out of traditional forms of education and intergenerational transfer of knowledge by modern, standardised education systems. This is seen in other studies where acculturation (the acquiring new language skills, attitudes, and values) associated with integration into new economic markets can cause the loss of traditional knowledge (Benz et al, 2000; Godoy, et al., 2005; Zent, 2001; Neumann, 2005).

Tangoan concern with loss of TEK is related to increased socio-economic vulnerability. For example, young people are not learning about gardening practices that reduce vulnerability to the impacts of cyclones. Some scholars have recognised this link between loss of TEK and socioeconomic vulnerability (Levin, 2000; Loureau et al., 2003; Perrings, 2007). Perrings (2007, p15180) 
explains that globalisation leads to homogenisation of communities "threatening the resilience or robustness, and hence the sustainability, of both the individual communities and the metacommunity."

Respect for kastom and traditional leaders are essential elements of community governance capacity in Vanuatu. Tangoa's governance system is highly dependent on the capabilities of the Chief and the willingness of people to cooperate with one another, the Chief, and kastom rules. While the importance of respect for the collective and for traditional leaders is emphasised in some studies (Fuys et al., 2006), such cultural variables are generally underrepresented. Commons literature places more attention on the particular institutional arrangements i.e. monitoring and sanctions (Ostrom, 1990). This indicates a gap in the literature about less tangible factors such as 'respect' for custom and cultural norms and values.

National level political and institutional changes impact local level governance structures and capacities. As explained in section 5.3.4, traditional community leaders are struggling to adapt to constitutional governance structures and values, and their authority is undermined by central authority structures such as formal courts and tribunals. Vanuatu chiefs are also losing the respect of the people as they struggle to provide for increasing monetary needs. Furthermore, government policies that support privitisation of land and natural resources can challenge the authority of customary systems, and cause tenure ambiguity and uncertainty about management rights and responsibilities. Commons literature has established that local communities need secure access rights and autonomy to govern as basic incentives for the improvement and development of commons management systems, and the emergence of them where they do not exist (Ostrom, 1990, Guys et al., 2006).

There is a strong link between social cohesion and governance in the Tangoa community, and in other communities in Vanuatu. The governance system is highly dependent on cooperation for consensus decision-making and respect of rules for shared resource management. Cooperation is affected by factors such as conflict management and leadership which impact social cohesion. This link is 
represented by the overlap of the two elements in figure 6.2. The relationship is illustrated by looking at how one factor - the exclusion of women from community level decision-making processes and institutional structures - can inhibit both social cohesion and governance capacity. On the other hand including women could enhance these two elements of cooperative capacity.

Women expressed that if they had more influence at the community level they could improve community governance cooperative capacity (Section 4.8.4). International literature supports this and indicates that the exclusion of women is a barrier to building community social capital and cooperative capacity.

Women have different ecological knowledge which is important for natural resource management (Batterbury, 2001) and their participation greatly increases their capacity for collective action (Westermann et al. 2005). Studies have found that compared with men; women have strong social networks and values of collabouration, lower levels of conflict, and higher capacity for conflict management (Agrawal, 2001; Meinzen-Dick, 2006; Westermann et al., 2005; Molinas, 1998). In a study of 104 peasant cooperatives in Paraguay, women's participation in committees enhanced the achievement of collective action goals and initiatives (Molinas, 1998). Similarly, a recent study involving 33 rural programs in 20 countries of Latin America, Africa, and Asia showed that collabouration, solidarity, and conflict resolution all increase in natural resource management institutions where women are present (Westermann et al., 2005). This evidence shows that enabling greater participation of Tangoan women would likely build the cooperative capacity and wellbeing of the whole community.

Youth are another social group within the Tangoa community that has strong social capital which is utilised in regular collective action (sec. 4.8.4) but less is known about this influence. This highlights a gap in commons research about the role of youth in motivating and initiating collective action for natural resource management 


\subsubsection{Cause and effect feed-back loops}

There are feedback loops between various drivers of cooperative capacity as well as between the drivers and their outcomes at the different levels of the model. Some key outcomes of low cooperative capacity in Tangoa and wider communities include: social cohesion and governance problems; economic pressures; resource degradation; conflict; increased livelihood dependence on cash; socio-economic and wellbeing heterogeneity; and livelihood vulnerability. Many of these outcomes, however, are also drivers of low cooperative capacity. The illustration of this view if the model would look very much like figure 6.2 with the arrows pointing in opposite directions.

Kahan's (2002) reciprocity theory and explanation of how cooperation has multiple equilibria are useful to help explain why the state of social cohesion and governance capacity within a community is not always stable. Equilibrium may be reached or a process of change may be triggered where cooperative capacity becomes stronger, or where it declines and weakens. This section will look at feedback loops related to: economic pressure, socioeconomic heterogeneity, and social cohesion; social cohesion, governance, and conflict; resource degradation, women's disempowerment, socioeconomic heterogeneity; and resource degradation and livelihood vulnerability. I have chosen to explain these feedback loops because they illustrate dynamic processes that have significant consequences for both local people and commons resources. Results from all three sources (literature, case study and Vanuatu research) are used in analysis of these relationships, and separate figures are used to illustrated and simplify the discussion.

\section{Economic pressure, socioeconomic heterogeneity, and social cohesion}

Just as economic pressures drive social problems in the Tangoa community, poor social cohesion can be a barrier to addressing economic pressures and achieving economic development goals. Social problems contribute to the difficulties of accessing external assistance from the provincial government's 
REDI program and NGOs such as Peace Corps. Figure 6.3 shows this feedback loop between social cohesion and economic pressures.

There is also a feedback loop between social cohesion and socioeconomic heterogeneity. Social cohesion problems, such as declining reciprocity, can cause increased socio-economic and wellbeing disparities. This is illustrated in the patterns and effects of reciprocity after a severe cyclone. Families without gardens often rely on copra as a main source of income and therefore are severely impacted when copra crops are destroyed in cyclones. When this happens they may not have enough money to buy food or housing materials, and they have to rely on commons resources and on reciprocity from others (sec. 4.6.3).

However, reciprocity is becoming more restricted to intra-family or intra-clan networks. The people that are impacted most severely may only have the support of others in their clan who are also likely to be in similar extreme need. Declining reciprocity results in greater socio-economic and wellbeing inequalities between those who have gardens and those who do not. Garcia et al., (2006) also highlighted the role of reciprocity in providing a safety net for the most vulnerable. Increasing heterogeneity within communities is particularly problematic for natural resource management as it becomes more difficult to devise strategies that will meet increasingly diverse needs and interests (Neumann, 2005). 


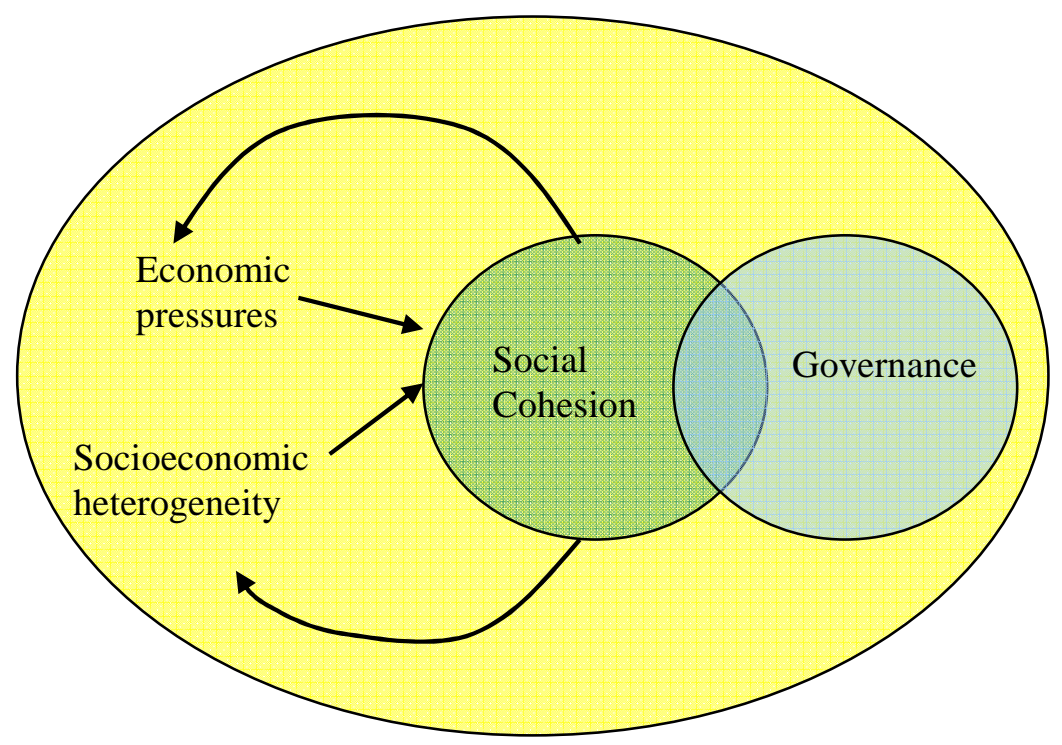

Figure 6.3, Feedback loops between social cohesion, economic pressures and socioeconomic heterogeneity

\section{Social cohesion, governance, and conflict}

Conflict is both a cause of social and governance problems, and an outcome of low cooperative capacity (sec. 4.7.4 and 4.8.2). Declining social cohesion coupled with declining respect for the Chief and custom governance systems, results in increased conflict. When the local traditional leaders lose power and influence, the potential for conflict increases and the ability of communities to solve and manage conflicts decreases. A vicious feedback circle results as conflict continues to degrade social cohesion. See figure 6.4 . 


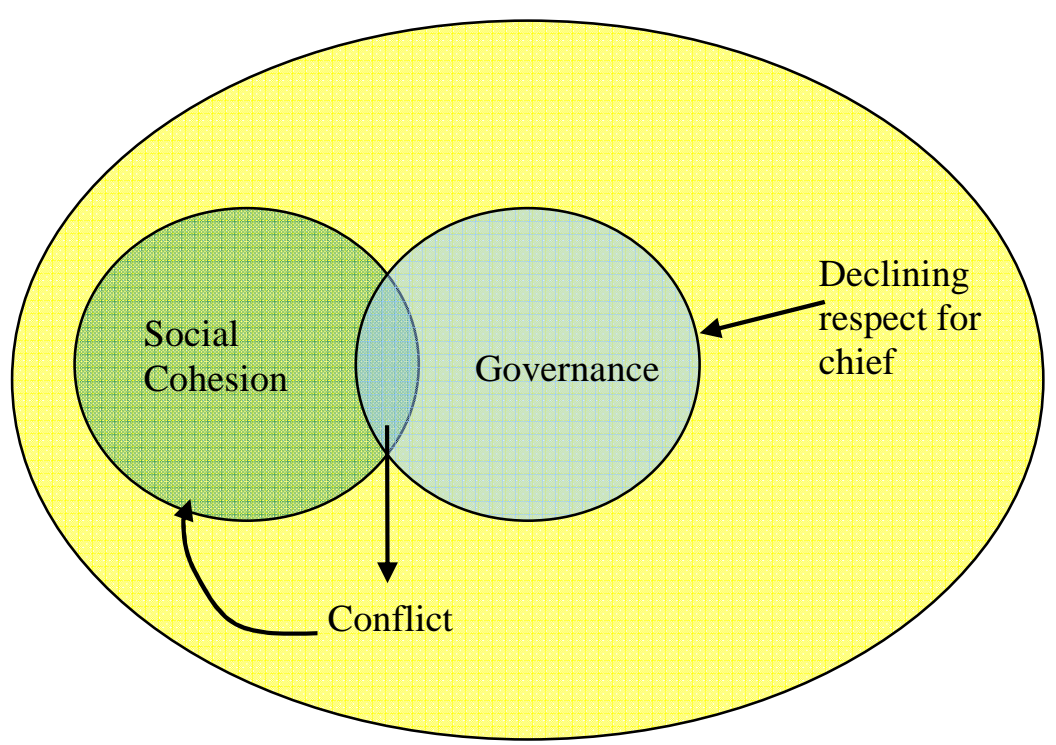

Figure 6.4, Feedback loop between governance problems, conflict and social cohesion

\section{Resource degradation and cooperative capacity}

The consequences of social and governance problems for the resource systems include resource degradation. Resource degradation, in turn, affects social and governance systems. Those whose livelihoods are most dependent on commons resources are likely to be most severely impacted. Commons resources are important for all Tangoans. However families who do not have garden land are more reliant on commons resources for cash and for food security in times of extreme need (refer to fig. 4.20 sect. 4.6.3). Therefore, resource degradation may exacerbate heterogeneity in wellbeing (see figure 6.5).

Degradation of resources that women rely on to earn money may also inhibit women's empowerment, and constrain their further participation in community level decision-making processes (see figure 6.5 above). Women's ability to earn cash is an important source of respect and empowerment at the household level, which in turn enables them to have more influence at the community level (refer to section 4.4.2). Therefore, degradation of resources which are important for women's income (crab collecting areas and dark bush) is also degradation of an important source of empowerment for women. 


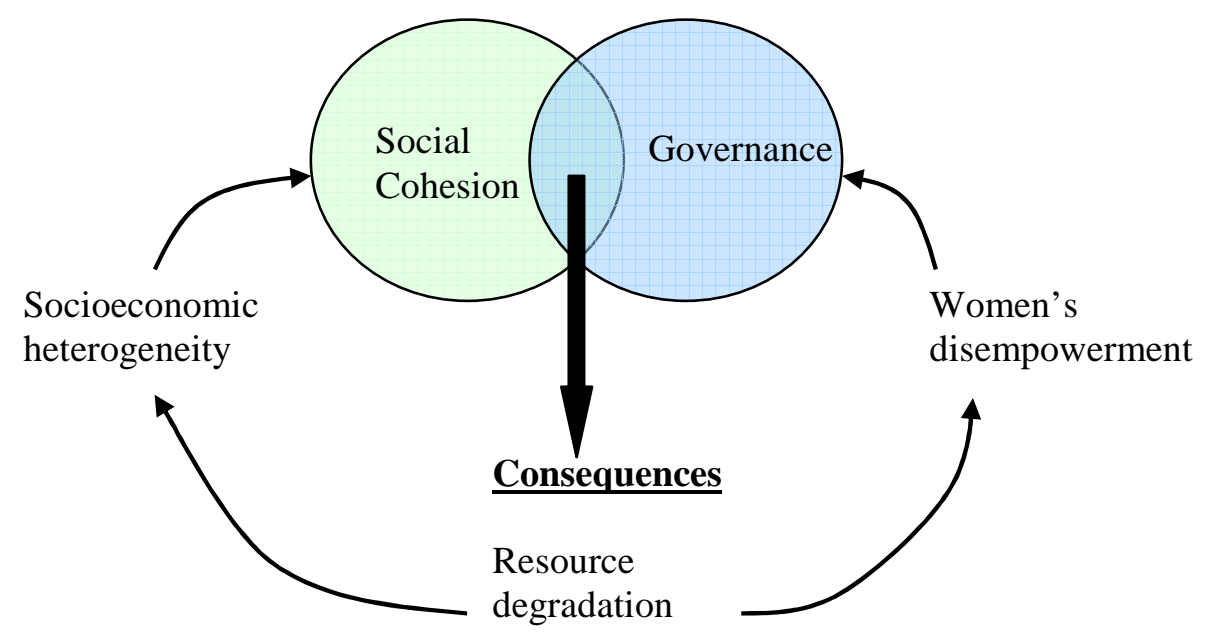

Figure 6.5, Feedback loop between low cooperative capacity and resource degradation

\section{Resource degradation, cash dependency, and increased livelihood vulnerability}

In the case of Tangoa Island, resource scarcity and degradation is one of the factors that drive a transition from subsistence-based to cash-based livelihoods. Lack of gardening land has led to an increased dependency on cash (section 4.6.2). ${ }^{82}$ In other parts of Vanuatu it is caused by Vanuatu government's development policies that encourage privitisation of land and natural resources via long-term leases (section 5.3.6). Increased cash dependency can drive livelihood vulnerability when the economic environment provides few opportunities (i.e. when there is high unemployment); when cash markets are volatile as is the case for copra; and when the value of economic goods is variable (i.e. copra crops affected by cyclones). Figure 6.6 shows that cash dependency and associated economic pressures also affects livelihoods by driving resource degradation and undermining social and governance systems.

A relationship between cash dependency and commons resource governance problems is illustrated in figure 6.6. As Tangoan livelihoods move away from economic self-sufficiency (garden-based livelihoods) to further market integration (cash-based livelihoods) there has been an increased utilisation of

\footnotetext{
${ }^{82}$ When people do not have access to their own gardens they are more dependent on cash generated by labouring on copra plantations, harvesting from the commons i.e. fishing, and small businesses
} 
natural resources for money. This is a well documented pattern in literature concerning the effect of markets on local commons management (Vadez et al., 2004; Mertens et al., 2000). Increased use of commons resources for money is associated with decline in respect for custom NRM rules. For an example, Tangoan fishermen explained that earning cash from fishing took priority over abiding by kastom rules about only harvesting large fish. Use of modern fishing nets which make it impossible to abide by custom rules is evidence of their prioritised decision. This relationship is illustrated by the arrow that points both ways from resource degradation to cash dependency in figure 6.6.

Figure 6.6 illustrates that cash dependency can also increases Tangoan livelihood vulnerability when associated economic pressures further undermine social cohesion (refer back to fig. 6.3). Tangoa data support findings of Garcia et al. (2006) that economic pressures weaken social security systems (i.e. reciprocity). This pattern of increasing livelihood vulnerability related to a transition from subsistence-based to cash-based livelihoods can be seen in communities across Vanuatu (Kalontano, 2003) and around the world (Bury, 2004; Putsche, 2000). 

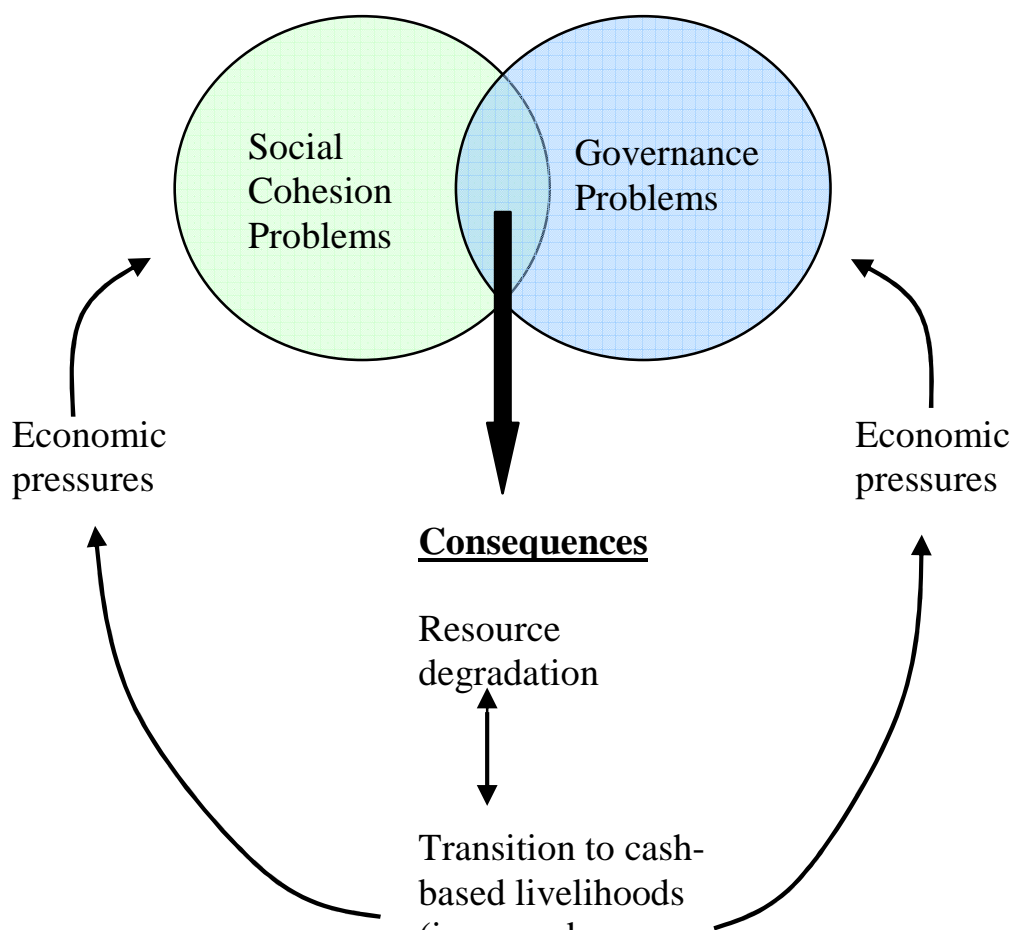

Consequences

Resource degradation

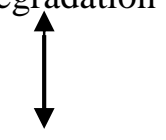

Transition to cashbased livelihoods

(increased dependence on cash)

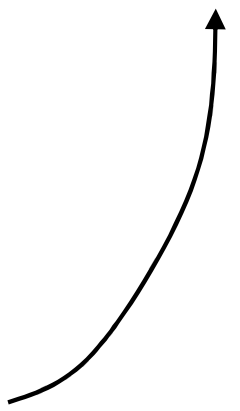<smiles>[3H][CH]</smiles>

Livelihood vulnerability

Figure 6.6, The relationship between resource degradation, cash dependency and livelihood vulnerability

The relationship between resource degradation and increased livelihood vulnerability can be illustrated further by looking at the link between resource degradation and loss of TEK. An example of resource degradation of one particular resource type within the Tangoa resource area - coastal forests, helps to show this relationship. A kastom medicine expert specialises in the use of one particular species of plant for his medicine. He uses the roots, stems, leaves, and flowers to treat a wide range of illnesses some of which include asthma and diabetes. The plant grows only in the coastal forest.

Degradation of the coastal forests not only threatens the livelihood of this traditional medicine man, but also impacts the livelihoods of other Tangoans. As abundance and use of this medicinal plant declines, so does knowledge about the 
plant and how to use it. The consequences of loss of knowledge and use of traditional medicine may be an increase in livelihood vulnerability of the Tangoa community as the health benefits of the plant are lost. Without traditional medicine local people are forced to use modern alternatives, which cost money. Furthermore, the medicine specialist considered that loss of knowledge about the plant could contribute to lack of interest in respecting custom rules that protect its habitat (rules include: a taboo against clearing coastal forests). This relationship is represented in figure 6.7 by the arrow from loss of TEK to governance problems.

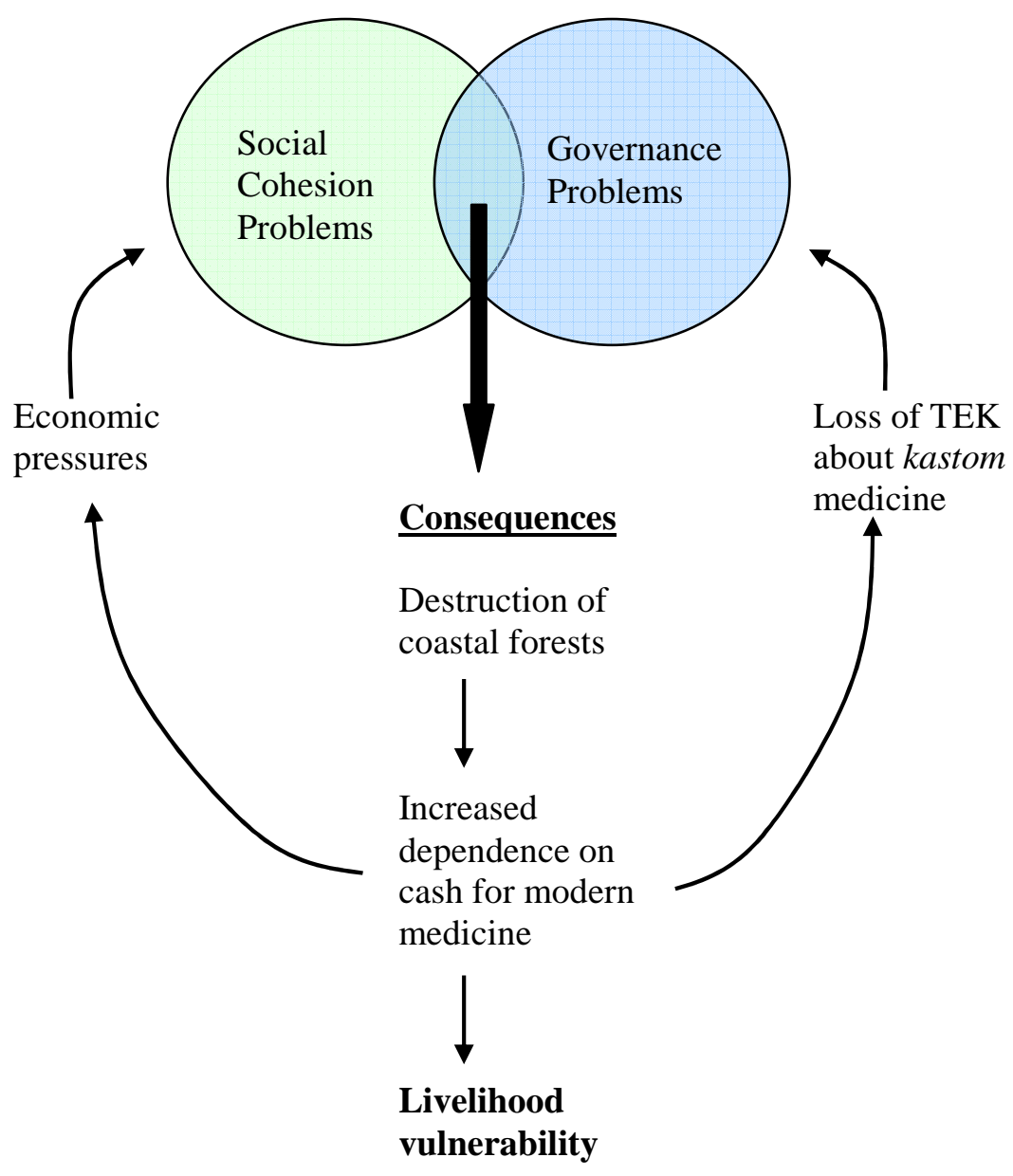

Figure 6.7, Relationship between resource degradation, loss of TEK and livelihood vulnerability

\subsection{Study limitations and areas for further research}


Several limitations of this study are associated with the scope and the chosen methodology, as well as various biases. The scope of my thesis is limited to only one in-depth case study. I was able to comment on the wider relevance of the Tangoa findings by extending the research to the national level with the literature review and interviews. However, more research is needed to be able to accurately assess the wider relevance of local factors and processes identified in the Tangoa case study. Further study of how local contextual variables create unique local situations and how they create commonalities among other local and national issues may better indicate the relative importance of local level action vs. structural change.

Identifying important cultural variables and studying their effect would also require multiple case studies of a cross section of communities at a different stage of cultural change, or studies over long time periods. As cultural change may be having a significant impact on natural resource use, traditional ecological knowledge and respect for leaders, it may be important to generate more understanding about how cultural change is impacting commons management. Other feedback loops in the model are also important to study. Although outside the scope of my thesis, this knowledge may be useful to support and or develop initiatives that can contribute positively to commons management within such a context of cultural change.

The Vanuatu research was also limited in scope. Interviews and literature indicated there was a wealth of information about unsustainable development policies related to specific developments and unsustainable international development aid and assistance. The analysis of that information was beyond the scope of this thesis, but my results and the model indicate that these different levels of policy will impact many of the drivers of cooperative capacity and commons management.

Another limitation is associated with a methodology based on grounded theory. A grounded theory approach was chosen for my case study because I had little previous knowledge about the important factors involved in commons management for Vanuatu and the Tangoa community specifically. The 
limitations of this methodology are that it does not allow systematic information gathering about preplanned or identified factors. Grounded theory allows the important factors involved in commons management to arise from local perspectives and knowledge. If research such as this thesis adds to the base of understanding about commons management in Vanuatu, further research could build from what local people have identified as important. Then perhaps these factors can be studied more systematically and at more depth.

The other limitations involve biases. My position as an "outsider" and a western female researcher, with little previous knowledge of the local culture and language is likely to bias the information provided by the community, as well as my interpretation and representation of it. A major recommendation of this study is that ni-Vanuatu research and researchers should be encouraged to undertake research in their own communities. Supporting ni-Vanuatu researchers is important, as they will be better positioned to understand local cultures. The case study and Vanuatu research shows that there may be a gap in understanding about the role of cultural factors such as respect for custom, and traditional leaders, and the collective.

There are also biases associated with the research, such as those discussed in the methodology chapter related to using an interpreter. Another limitation may arise from sample biases. Information about changing youth culture and the effect this has on respect for custom rules about natural resource management came primarily from adults. Adult perceptions that there is declining respect for rules among youth contrast with the concern about natural resource management problems expressed by youth groups. Further research into young people's goals for the future, and concerns about natural resource management, might be useful to inform how programs can help mobilise youth collective action for commons management. This research may be particularly useful for educational NGOs such as Wan Smolbag, who are well respected by youth for their entertaining and educational participatory theatre.

\subsection{Finding solutions and an appropriate development pathway}


As local commons management problems are interlinked with wider processes and contexts of development and change, researchers and scholars face debates when looking for ways of addressing such problems. Vanuatu is opening open up to foreign investment and land and resource mobilisation with resulting negative effects for livelihoods. These national global influences result in negative effects at the local level. There is loss of autonomy to govern; marginalisation of people from their land and resource base; social and cultural disruption from rapid development of monetary economies (sect. 5.3.6). Low government capacity to control and mitigate against the external negative effects of resource exploitation from investors, means that it is largely up to communities to stand up to such livelihood threats.

This leads me to my final argument - that development needs to be appropriate for particular social, cultural and ecological contexts. Development should be defined by local people. This perspective supports the premise that culture is not a threat to development, but a core element in it (Curry, 2003). The ability of Vanuatu communities to manage change, adapt, and determine their own futures comes from the strength of their social systems and of their governance systems. Therefore an appropriate approach should be to strengthen these systems and mitigate processes that threaten them. There is an increasing emphasis upon the importance of alternative grassroots approaches to development, starting from the empowerment of local communities (Mayo and Craig, 1995, Mohan and Stokke, 2000).

While development should be locally defined and 'bottom-up', local initiatives also need to be supported by people at various levels and institutional structures (Galudra, 2005; Berkes, 2007). Berkes (2007, p. 15192) explains: “The panacea of community-based conservation is probably no more effective than the panacea of exclusively state-based conservation, because they both ignore the multilevel nature of linkages and multiple partners required for any project to be successful." 83 One NGO who has worked with communities to establish a

\footnotetext{
${ }^{83}$ Understanding the significance of these inter-linkages has leaded some to redefine community-based conservation: so that it refers to "governance that starts from the ground up and involves networks and linkages across various levels of organization.” (Berkes, 2007, p.15188)
} 
protected area in Vanuatu explains: "Community ability to achieve local goals and stand up to investment interests depends on the level of capacity at the provincial level as well as in local communities."

This section looks at the 'lessons' from the research results and the analysis of the model to suggest what an approach for communities like Tangoa might look like. This involves a synthesis of local and national perspectives to identify interventions and external support that may help to address the drivers of commons problems.

\subsubsection{Addressing local level economic pressures}

Economic pressures underlie both social cohesion problems and governance problems. In Tangoa, alleviating these pressures is likely to improve community cooperative capacity. Initiatives at the local level could assist communities to achieve their economic development goals. For the Tangoa people, goals include: finding more secure and diverse ways to generate income; developing more efficient market links; accessing training to improve employment opportunities; accessing training and awareness about how limited land can be used more effectively; and accessing family planning services (section 4.6.4).

At the national level, policy could be targeted at development aimed at alleviating local economic burdens. As school fees and medical expenses are two of the main cash expenses for communities across Vanuatu. National initiatives to subsidise these costs or to find alternative payment options are likely to have a significant positive effect.

Information and education to raise communities' awareness about the consequences of selling leaseholds can come from within communities, through national or international programs from NGOs and governments. Organisations such as the Vanuatu Cultural Centre and the National Council of Chiefs are 
already working to improve land policy and to educate communities about the negative effects of selling land, and these initiatives should be supported. ${ }^{84}$

Another national level policy would be to support development of the traditional subsistence economy. The traditional economy includes the customary institutions that sustain subsistence livelihoods. It includes customary systems of tenure, forms of currency, insurance, savings, and exchange. The traditional economy is increasingly recognised as a viable alternative or supplement to a monetary focused approach to development (Bazeley and Mullen, 2006). These customary systems can be developed and applied to satisfy non-traditional basic needs, in particular, access to health and education (Regenvanu, 2007). For example, instead of struggling to save enough cash for school fees three times a year, some communities have arranged exchanges of food and labour for school services (Nari, pers comm.).

Further support could be given to work being done by the Vanuatu Cultural Centre on the traditional economy and its role in future Vanuatu society. The Cultural Centre is looking at how the traditional economy can be further developed, validated, and institutionalised in national development policies. ${ }^{85}$

Incorporating development of the traditional economy into the national development policy may require widening conceptualisations of 'development'. Currently, the government is focused on generating a monetary economy, raising GDP and balancing trade deficits in order to lift Vanuatu from its status of a Least Developed Country. A more encompassing definition of development may need to include additional measures of 'modern' growth: wellbeing; stability; equity; social cohesion; and sustainable livelihoods may enable (Baezely and Mullen, 2006. p.12). The traditional subsistence economy is considered by some as the basis for sustainable, self-reliant development that

\footnotetext{
${ }^{84}$ See the Vanuatu Cultural Center's website for details and related documents including the 'Recommendations to the 2006 Land Summit' made by the Malvatumauri, (the National Council of Chiefs), the National Self Reliance Committee, and the Advocaey Coalition on Economies (ACE): (http:///www.vanuatuculture.org/trm/20060925_lands-summit.shtml)

${ }^{85}$ See the Vanuatu Cultural Center's website for details and related documents including the Vanuatu Self Reliance Strategy

(http://www.vanuatuculture.org/projects/050628_traditionalmoneybankproject.shtml)
} 
will foster equity, environmental sustainability, food security, social security, and good governance (NSRC, and ACE, 2006 ${ }^{86}$ ).

\subsubsection{Empowering women}

Initiatives to empower women can build cooperative capacity. International literature suggests women's greater participation in community level institutional structures will benefit conflict management, community cohesion and community governance (Westermann et al., 2006). Tangoan women play a vital role in providing for the subsistence and income needs of families as well as organising and coordinating community initiatives. Tangoa data indicate a link between women's ability to earn money and their empowerment at a household and community level. Initiatives to empower Tangoan women might include: establishing small businesses in cooking and sewing, and developing strong networks and links to markets for selling baskets and weaving products.

Women's initiatives can be supported through external assistance or by supporting existing networks and organisations that are already mandated to support women's development. One such organisation is the National Council of Women. The Council is a self funded organisation which works to support women's development and build the capacity of women to be involved in decisions from the local to the national level. They have an extremely effective network with 6 provincial Women's Councils, and two municipal offices. The Council has strong communication and support links right into the communities. Many villages have women representatives on area councils. Through this network, workshops and training in such things as leadership, rights, budgeting, small business creation, cooking, and sewing (National Council of Women representative, pers. comm.).

\subsubsection{Addressing community social cohesion issues}

Targeting the underlying drivers of declining social cohesion will improve cooperative capacity. Initiatives could address economic pressures, improve

\footnotetext{
${ }^{86}$ National Self Reliance Committee, and the Advocacy Coalition on Economics (ACE) 'Vanuatu Self Reliance Strategy'
} 
conflict management and dispute resolution processes, and facilitate the utilisation of social capital within the community.

Some community projects can generate social capital. The Tangoa example of the Pelviji clan's collective action achievements shows that social capital can be generated when people experience the benefits of cooperation. One Pelviji man explained that successfully building a Nakamal had a powerful symbolic effect: "It helped people to see they can work together and achieve things." Several interviews with people that have worked with communities to help them overcome social and governance problems reported similar findings. A representative from one NGO explained that targeting funding for projects that can build cooperative capacity may have many positive secondary effects: "Achieving initiatives that require cooperation can build confidence. You have to start with small projects that have a lot of shared support and are easy to achieve. When people achieve their goal, they feel they can do a lot more, and they start working together more."

\subsubsection{Addressing community governance issues}

Various initiatives at the local, regional, and national levels can address governance issues including: local disputes and conflicts, leadership problems, tenure ambiguity, and loss of TEK.

\section{Participatory processes for disputes and conflicts}

Several NGOs such as the Foundation for the Peoples of the South Pacific Vanuatu (FSPV) and Wan Smolbag, as well as the government's Environment Unit, are involved in helping communities overcome governance problems. Participatory processes have been used to facilitate dispute resolution and address other governance issues. A representative from the Cultural Centre explained: "Ultimately communities have to solve their own problems so you have to be insightful enough to see what they need and give that to them. So if it's creating an environment where they can start talking, that's a start." 
The literature suggests building on strengths in the culture by supporting the existing methods of conflict resolution or by creating a new hybrid that is a combination of customary and modern mechanisms (Barsky, 1998; Fisher et al, 1999; Chevalier and Buckles and Rusnak, 1999). A representative from the Government's Environment Unit iterated this point: "If a community has no expertise solving an issue then we can import it from outside. But if they have the resources there to help them solve it themselves, like a respected chief, it is better if they do it themselves."

The Environment Unit has had experience assisting communities understand that disputes can be separated from conservation initiatives. A representative from the Luganville office explained: "You need to help the community see that disputes are about benefits for one particular person or family, and conservation initiatives will benefit everyone." An NGO in Port Vila explained that people are able to put aside disputes when they understand that there is a court process for the disputes, but that in the mean time, they can go ahead and address conservation and development needs. The concept of removing disputes as a barrier to a community's progress was expressed by one person as "disputes, hemi gat wan road blong hem" which translates to "Disputes have their own road."

\section{Building leadership capacity}

In order to adapt to changing social, economic and institutional contexts community leaders may benefit from capacity building in areas of literacy and record keeping, financial management (Kalontano et al. 2003). They may need new skills to enable them to govern communities which are larger and increasingly diverse and complex (ibid). They may also benefit from greater understanding about new constitutional governance values and principles, the role of government institutions and NGOs, and how to communicate with them (Ibid).

The Malvatumauri (National Council of Chiefs) is an administrative structure to support governance at the village level as well as support traditional governance 
values at the National Level. ${ }^{87}$ The Malvatumauri structure reaches from the national level to island councils, area councils, sub-area councils, village councils and the Nakamal (Chief meeting house). The Council structure helps communities strengthen traditional governance systems and builds the capacity of community chiefs. The Council trains village chiefs to deal with the changes and challenges that are affecting communities and provides capacity building to retain the custom values that community governance needs (Garu, pers comm.).

\section{Building awareness and capacity to negotiate tenure ambiguity}

Tangoa data highlight the need for greater awareness about rights and responsibilities for managing resources where ambiguity exists for tenure and governance authority for shared resources on leaseholder land. Communities may benefit from improved systems of support to help them negotiate and communicate with external stakeholders such as leaseholders and investors.

\section{Reviving and developing TEK}

Options to prevent further loss of traditional ecological knowledge include building TEK into school the curriculum, encouraging community-based research and documentation of TEK, and utilising TEK in local ecotourism ventures. Support can be given to several projects already doing work in this area, including the Rethinking Vanuatu Education Initiative and the Landholders Conservation Initiative.

\subsubsection{Avoiding negative effects of external intervention}

Interventions from 'outside' agencies can have a negative impact on local people. Garu (pers comm.) explains that despite honest good intentions, the influence of external people coming into a community can upset community power relations and governance systems. This is reflected in literature that shows how the failure of a development or conservation project can damage community empowerment, respect and trust in each other (Fuys et al, 2006).

\footnotetext{
${ }^{87}$ At the National level, the National Council of Chiefs is working to ensure the National Council of Chiefs is consulted and allowed a chance to discuss and debate the merits of any proposals for custom related bills are tabled in parliament (FSP 2005).
} 
Therefore, the type and implementation of assistance to support local commons management must not further undermine local social and governance systems.

The Vanuatu National Cultural Council has developed regulations for people wanting to do research in Vanuatu. The regulations require that researchers gain permission and involvement of community leaders and that there are tangible benefits from research (Regenvanu, 2006; Scheyvens et al. 2003). The Malvatumauri (National Council of Chiefs) can also provide advice.

Another way to improve development approaches in Vanuatu is to ensure that the valuable knowledge and experience, gained by those that have worked with communities, is effectively utilised. A lot of knowledge has been generated about the processes and approaches that are empowering and effective in building cooperative capacity as opposed to approaches that are potentially disempowering. This thesis has only skimmed the surface of that body of knowledge. However, several interviewees in Port Vila expressed frustration that they do not have the time and resources to transfer the knowledge and experience they have gained to others, or to provide policy advice. External resources and support could be targeted at enabling the transfer and utilisation of knowledge and experience that exists in Vanuatu. 


\section{Chapter 7 - Conclusion and Recommendations}

The sustainability of the Tangoa community is dependent on the successful long-term management of local ecosystems. The purpose of the case study of Tangoa Island was to explain what resources are important for local livelihoods, as well as how those resources are used and managed. The case study results (Chapter 4) described the natural resource use practices that are causing resource degradation. Four main underlying drivers of resource degradation include population pressures, economic pressures, governance issues, and declining social cohesion.

Results of the wider Vanuatu context (Chapter 5) showed that the local Tangoan issues are experienced by many other communities across Vanuatu. The primary reason that the local problems in Tangoa have relevance for other communities is that they arise from a context of wider socio-economic, cultural, political and institutional change. Local social systems, governance systems and commons resources are affected by external influence, such as state development policies, privatisation of commons resources in long-term leases, and institutional changes at the national level in education and governance structures. At the international level there are influences of globalisation.

Chapter 6 presents a model to facilitate discussion about how the results from the literature review, case study, and Vanuatu research interact to answer the objective questions posed by this thesis. The model describes the essential factors involved in cooperative capacity for commons management. The model also assists in the analysis of how factors at multiple levels influence communities, and how various factors interact to reinforce and drive the process of change. The analysis shows how Tangoan livelihoods are affected by the change in their community, and how they might be further affected if the drivers persist and the feedback loops continue.

Some of the lessons learned from this research point to alternative development approaches. My hope is that this study can be used to engage in development 
debates about how to help build local capacity for commons management in a culturally and ethically appropriate way. Assistance can be targeted multiple levels, from local to national in a way that ensures external assistance or intervention does not become a driver of declining cooperative capacity.

My study shows that a grounded theory approach to commons management can be useful to build understanding from a local perspective. Communities engaged in commons management carry out primary production in rural areas, and are historically grounded in their local realities. These communities in general, and Tangoa in particular, have a great deal to contribute to global environmental and development debates in terms of knowledge and experience (Waddell and Connell, 2007). The Tangoa community has shown that they want to protect and enhance what they value, and to manage their challenges and issues. They also perceive that appropriate initiatives to achieve these goals should strengthen the social and governance systems, which are seen as essential for preserving valued knowledge as well as encouraging innovation and change.

One real option for Vanuatu is to choose indigenous rather than Western solutions to its development needs because the country has a strong cultural heritage. Ralph Regenvanu (2007), Director of the National Cultural Council argues that it is both necessary and possible to develop the strength, identity and traditional values that will enable the people of Vanuatu to determine their future and choose development paths wisely. Russel Nari from the Lands Department explains that local level development must build from, and not damage, natural and social endowments: "The two most important things that people possess in this country are the land that we have, and the social relationships that we have with each other. We depend on each other. You break those two things without putting in place a social security net - then Vanuatu will be in trouble." This is supported by scholars who argue that "the maintenance of social and cultural practices may be as important as income gains and poverty reduction for many local communities." (Waddell and Connell, 2007, p.11).

Although Vanuatu communities may have a strong basis to work from, placing all the responsibility on local communities to solve commons management 
problems is unfair. Many of the drivers of local problems are influenced by changes at the global and national level, which are outside the control of local communities. For the individuals and organisation wanting to assist Vanuatu communities, this study has identified various practical ways to support local solutions to commons management problems. These may be considered the 'recommendations' arising from this study:

- Support the work of the Cultural Center in developing, validating, and institutionalising the traditional economy in national development policies.

- Support locally generated projects that can increase social capital and build cooperative capacity.

- Support the work of organisations involved in helping communities retain traditional governance values and strengthen customary processes of dispute resolution. Some of these organisations include: Malvatumauri; The Foundation for the Peoples of the South Pacific Vanuatu; Wan Smolbag; and the Environment Unit.

- Assist national level policy development aimed at alleviating local economic burdens. This may include exploring how major monetary costs of education and healthcare could be subsidised or spread.

- Support networks and organisations such as the National Council of Women to influence and achieve their community goals.

- Improve awareness about rights and responsibilities for managing resources where there is tenure and governance authority ambiguity (i.e. for shared resources on leaseholder land).

- Support work to build community awareness about the consequences of selling leaseholds in land.

- Build systems of support to help local people negotiate and communicate with diverse stakeholders such as leaseholders and investors.

- Support capacity building for community leaders to help them manage changing social, economic and institutional systems.

- Support initiatives to prevent further loss of traditional ecological knowledge.

- Support the work of the Malvatumauri and the Vanuatu National Cultural Council in providing guidelines for researchers and development agents to 
ensure they approach and work with communities in a way that is culturally appropriate, ethical, and which will ensure that communities get tangible benefits from research.

- Enable the utilisation and transfer of knowledge and experience that has been gained by individuals and organisations working with communities. Ensure these individuals and organisations are encouraged to advise and support culturally appropriate approaches to working with communities.

Recommendations for further research:

- Investigate what projects have potential to improve social cohesion and build social capital.

- Support further research and policy development about how external assistance can benefit local communities in sustainable and culturally appropriate ways.

- Encourage collabourative research, particularly where Western researchers can gain access to grants to support fieldwork carried out with ni-Vanuatu researchers.

- Conduct research into cultural change in youth to determine goals, aspirations, and NRM/conservation interests with a view to utilising youth social capital and potential for collective action. This may involve collabourating with NGOs such as Wan Smolbag, who undertakes conservation work with youth.

- Determine options for diversifying and securing income from limited land resources for communities, which may involve research into alternative land use or livelihood options, increasing productivity, or diversification. 


\section{Bibliography}

Acheson, J. M. (2006) Institutional failure in resource management. Annual Review of Anthropology 35 (1): 117-134.

Adhikari B. (2005) Poverty, property rights and collective action: understanding the distributive aspects of common property resource management. Environment and Development Economics 10: 1-25.

Adhikari, B. (2001) Literature Review on the Economics of Common Property Resources - Review of Common Pool Resource Management in Tanzania. Report Prepared for NRSP Project R7857, UK Department for International Development (DFID).

Adhikari, B., and Lovett J.C. (2006) Institutions and collective action: Does Heterogeneity matter in community-based resource management? Journal of Development Studies 42 (3): 426-445.

Agrawal, A. (2003) Sustainable governance of common-pool resources: Context, methods, and politics. Annual Review of Anthropology, 32 (1): 243-262.

Agrawal, A., and Goyal, S. (2001) Group size and collective action: third party monitoring in common-pool resources. Comparable Political Studies 34 (1): 6374.

Agrawal, A., and Gibson, C. (1999) Enchantment and disenchantment: the role of community in natural resource conservation. World Development 27 (4): 629649.

Agrawal, B. (2001) Participatory Exclusions, Community Forestry, and Gender: an analysis for South Asia and a Conceptual Framework. World Development 29 (10): $1623-1648$.

Andreoni, J., Erard, B., Feinstein, J. (1998) Tax compliance. Journal of Economic Literature 36: 818-841.

Angelsen, A, and Kaimowitz, D. (eds.), (2001) Agricultural Technologies and Tropical Deforestation. Wallingford/Oxford: CIFOR.

Angelsen, A., and Wunder, S. (2003) Exploring the forest-poverty link: Key concepts, issues and research implications. CIFOR Occasional Papers No. 40 Bogor, Indonesia: Center for International Research.

Aronson, E., (1995), The Social Animal (7th ed.). New York: WH Freeman.

Bachir, A., Vogt, G. (2005) Cooking stones to extract the juice: Five years of autonomous common property resource management at Takieta. Case study submitted for the joint study Rural Common Property in a Perspective of Development and Modernization. Niger: CRAC-GRN/ SOS-Sahel International. 
Bacho, F.Z.L., and Derbile. E.K. (2005) Institutional reforms, democratic participation and decentralized development in Ghana: the Sissala district as a case study. Journal of Development Studies 2: 7-36.

Bailey, C. (2007) A Guide to Qualitative Field Research. Second Edition. Thousand Oakes, CA: Pine Forge Press, Sage.

Baland, J. M., and Platteau, J. P. (1999) The ambiguous impact of inequality on local resource management. World Development 27: 773.

Baland, J., and Platteau , J.P. (1996) Halting Degradation of Natural Resources: Is there Role for Rural Communities? Oxford: FAO/Clarendon Press.

Bardhan, P. (2000) Water community: an empirical analysis of cooperation on irrigation in south India. University of California, Department of Economics.

Barsky, A. (1998) Cross-cultural issues in community mediation. Paper presented at Bar Ilan University Conference on Mediation and Negotiation

May 1998 - Ramat Gan, Israel. http://faculty.biu.ac.il/ steing/conflict/cross.htm (accessed 24 Oct. 2006).

Batchelor, S.J,. McKemey, K., and Sakyi-Dawson, O. (1999) Barriers to the adoption of efficient energy strategies in Northern Ghana. Project Technical Report. Updated March 27, 2001. http://www.gamos.org/research-and-publications (accessed 21 June 2007).

Batterbury, S., Forsyth, T., Thomson, K. (1997) Environmental transformations in developing countries: hybrid research and democratic policy. The Geographical Journal 163: 126-132.

Bazeley, P., and Mullen, B. (2006) Vanuatu economic opportunities fact-finding mission. AusAID and NZAID.

Beck, T. and Nesmith, C. (2001) Building on poor people's capacities: The case of common property resources in India and West Africa. World Development 29 (1): 119-133.

Benz, B.F., Cevallos J., Santana, F., Rosales, J., and Graf, S. (2000) Losing knowledge about plant use in the sierra de Manantlan Biosphere Reserve, Mexico. Economic Botany 54 (2): 183-191.

Berkes, F. (2007) Community-based conservation in a globalized world. Proceedings of the National Academy of Sciences USA 104 (39): 15188-15193.

Bowles S., and Gintis, H. (2001) Social capital and community governance. In Ostron E., and Ahn T.K. (2003) The Foundations of Social Capital. Edward Elgar.

Brockington, D., and Sullivan, S. (2003) Qualitative research. In Scheyvens and Storey (Eds) Development Fieldwork, a Practical Guide. London: Sage. 
Bronson, J., Bakeo, W. and Ford, R. (1995) Conducting PRA in the South Pacific: Experiences in Natural Resource Management from Vanuatu. Program for International Development, Clark University, USA and the Foundation for the Peoples of the South Pacific, Vanuatu.

Brown, K. (2002) Innovations for conservation and development. The Geographical Journal 168: 6-17.

Buckles, D. and Rusnak, G. (1999) Introduction: conflict and collaboration in natural resource management. In D. Buckles (ed). Cultivating Peace: Conflict and Collaboration in Natural Resource Management. Ottawa, Canada: International Development Research Centre/The World Bank.

Bury, J. (2004) Livelihoods in transition: transnational gold mining operations and local change in Cajamarca, Peru. Geographic Journal 170 (1): 78-91.

Cardenas J.C., Strandlund, J.K., Willis C.E. (2000) Local environmental control and institutional crowding out. World Development 28: 10.

Chambers, R. (1994) The origins and practice of participatory rural appraisal. World Development 22: 953-969.

Chillaurren E., David, G., and Grandperrin R. (2001) Coastal Fisheries Atlas of Vanuatu: A 10-year development assessment. Paris: IRD editions.

Charmez, K. (2006) Constructing Grounded Theory: A Practical Guide through Qualitative Analysis. London: Sage Publications.

Cialdini, R.B., Reno, R., Kallgren, C.A. (1990) A focus theory of normative conduct: recycling the concept of norms to reduce littering in public places. Journal of Personality and Social Psychology 58: 1015.

Cooke, P.A. (2000) Changes in intra-household labour allocation to environmental goods collection: a case study from rural Nepal 1982 and 1997. FCND discussion paper 87, International Food Policy Research Institute, USA.

Cowell, F. (1990) Cheating the government: the economics of evasion. Cambridge: MIT Press.

Creswell, J.M. (2006) Qualitative Inquiry and Research Design: Choosing Among Five Approaches. Second Edition. Sage Publications, Inc.

Curry, G. (2003) Moving beyond postdevelopment: facilitating indigenous alternatives for 'development'. Economic Geography 79: 405-23.

Davidson, C., and Tolich, M. (eds.) (1999) Social Science Research in New ZealandMany Paths to Understanding. Auckland: Person Education New Zealand. 
Dayton-Johnson, J., (2000) Determinants of collection action on the local commons: a model with evidence from Mexico. Journal of Development Economics 62: 181208.

Diekmann, A., and Franzen, A., (1999) The wealth of nations. Environment and Behavior 31 (4): 540-549.

Dowling, R. (2005) Power, subjectivity, and ethics in qualitative research. In Hay. I. (ed.) (2000) Qualitative Research Methods in Human Geography. Melbourne: Oxford University Press.

England, K. (1994) Getting personal: Reflexivity, positionality, and feminist research. Professional Geographer 46 (1): 80-89.

Evans, P. (1996) Introduction: development strategies across the public-private divide. World Development 24 (6): 1033-1037.

FAO (World Food and Agriculture Organisation) (2001) Vanuatu: Forests, trees and land tenure. http://www.fao.org/forestry/site29901/en/vut/page.jsp. (Accessed 22 May 2007).

Fisher, L., Moeliono, I., and Wodicka S. (1999) The Nusa Tenggara uplands, Indonesia: Multiple-site lessons in conflict management. In Buckles D., (ed). Cultivating Peace: Conflict and Collaboration in Natural Resource Management. Ottawa, Canada: International Development Research Centre/The World Bank.

Friedmann, J. (1997) Empowerment, the Politics of Alternative Development. Oxford: Blackwell.

FSP (Foundation for the Peoples of the South Pacific Vanuatu) (2005) Village-based resource management areas (VBRMA) Workshop Report. Port Vila: FSP Vanuatu.

Fuys, A., Mwangi, E., Dohrn, S. (2006) Securing common property regimes in a 'modernizing' world: Synthesis of 41 case studies on common property regimes from Asia, Africa, Europe and Latin America. Rome: International Land Coalition, and Washington DC: CGIAR System wide Program on Collective Action and Property Rights (CAPRi).

Galudra, G. (2005) Land tenure conflicts in Halimun area: What are the alternative resolutions for land tenure conflicts? Case Study submitted for the joint study Rural Common Property in a Perspective of Development and Modernization. World Agroforestry Centre.

Garcia, V., Godoy, R., Vadez, V., Huanca, T., Leonard, W.R. (2006) Personal and group incentives to invest in prosocial behavior, a study in the Bolivian Amazon. Journal of Anthropological Research 62: 81-101. 
Gautam, A.P., and Shivakoti, G.P. (2005) Conditions for successful local collective action in forestry: Some evidence from the hills of Nepal. Society and Natural Resources 18: 153-171

Gelcich S., Edwards-Jones D., Kaiser M.J. Castilla J.C. (2006) Co-management policy can reduce resilience in traditionally managed marine ecosystems. Ecosystems 9: 915-966.

Gerring, J. (2007) Case Study Research: Principles and Practices. Cambridge, Massachusetts: Cambridge University Press.

Ghate, R. (2005) A Community case study: Self-initiated forest management in Saigata. Case Study submitted for the joint study Rural Common Property in a Perspective of Development and Modernization. Nagpur, India: The Institute for Research and Development (SHODH).

Gibson, C., and Becker, C.D. (2000) A lack of institutional demand: Why a strong local community in Western Ecuador fails to protect its forests. In Gibson C., Mcklean, M.A., and Ostrom (eds) People and Forests: Communities, Institutions and Governance. Cambridge, Massachusetts: MIT Press.

Gintis, H., Bowles S., Boyd, R., and Fehr, E. (2005) Moral Sentiments and Material Interests: The Foundations of Cooperation in Economic Life. Cambridge, Massachusetts, MIT Press.

Gneezy, U., Rustichini, A. (2000a) A fine is a price. Journal of Legal Studies 29, p.1.

Gneezy, U., Rustichini, A (2000b) Pay enough or don't pay at all. The Quarterly Journal of Economics August 2000.

Godoy, R., Reyes-Garcia, V., Byron, E., Leonard, W.R., Vadez, V. (2005) The effect of market economies in the well-being of indigenous peoples and on their use of renewable natural resources. Annual Review of Anthropology 34: 121-138.

Grossman, G.M., and Krueger, A.B. (1991) Environmental impacts of a North American free trade agreement. National Bureau of Economic Research. Working Paper 3914. Cambridge Massachusetts: National Bureau of Economic Research.

Guba E., Lincoln, Y. (1994) Competing paradigms in qualitative research. In Denzin, N., and Lincoln, Y. Handbook of Qualitative Research. Thousand Oaks, California: Sage. pp.105-117.

Guest, G. (2002) Market integration and the distribution of ecological knowledge within an Ecuadorian fishing community. Journal of Ecological Anthropology 6: 38-49.

Gunatilake, H.M. (1998) The role of rural development in protecting tropical rainforests: evidence from Sri Lanka. Journal of Environmental Management Journal of Environmental Management 53 (3): 273-292. 
Hardin, G. (1968) The Tragedy of the Commons. Science 162: 1243-1248.

Heller, P. (1996) Social capital as a product of class mobilisation and state intervention: industrial workers in Kerala, India. World Development 24 (6): 1055-1071.

Hickey, F. (2006) Traditional marine resource management in Vanuatu:

Acknowledging, supporting and strengthening indigenous management systems. SPC Traditional Marine Resource Management and Knowledge Information Bulletin \#20. http://www.spc.int/coastfish/News/Trad/20/ (accessed 12 June 2007).

Higgs, R. (1996). Regulating natural resources: the evolution of perverse property rights. In Alston L.J., Eggertsson T., and North, D.C. (eds.) Empirical Studies in Institutional change. Cambridge: Cambridge University Press.

IUCN (2006) 2006 IUCN Red List of Threatened Species. http://www.redlist.org (Accesses March 2007).

Jansen, M.A. and Ostrom, E. (2001) Critical factors that foster local self governance of common pool resources: the role of heterogeneity. Paper Delivered at the annual meeting of the Resilience Alliance held at Chiang Mai, Thailand, August 16-18 2001.

Jayaraman, T.K. and Ward, B.D. (2006) Aid effectiveness in the South Pacific Island Countries - a Case Study of Vanuatu. Discussion Paper No. 110. Canterbury: Lincoln University Commerce Division.

Johannes R.E. and Hickey F.R. (2004) Evolution of village-based marine resource management in Vanuatu between 1993 and 2001. Coastal Region and Small Island Papers 15. Paris: UNESCO.

http://www.unesco.org/csi/wise/indigenous/vanuatu1.htm (accessed 12 May 2007)

Kahan, D.M. (2002) The logic of reciprocity: Trust, collective action and law. John M. Olin Center for Studies in Law, Economics, and Public Policy Working Paper Series, Paper 281, Yale Law School.

Kalontano, A., Vatu, C., Whyte, J. (2003) Assessing Community Perspectives on Governance in Vanuatu. Port Vila: Foundation of the Peoples of the South Pacific International (FSPI).

Kant, S. (2000) A dynamic approach to forest regimes in developing economies. Ecological Economics 32: 287-300.

Karim, R. (1999) Breaking boundaries to participation on local governance, Economic Development and Change 47 (4): 871-897.

Kijtewachakul, N. (2005) Common property and complexity of local rights system in Sopsai Watershed, Nan Province, Northern Thailand. Case Study submitted for 
the joint study Rural Common Property in a Perspective of Development and Modernization.

Krishna, A. (2003) Understanding, measuring and utilising social capital: clarifying concepts and presenting a field application from India. CAPRi Working Paper No. 28. Washington D.C: International Food Policy Research Institute.

Kumar, S. (2002) Methods for Community Participation - A Complete Guide for Practitioners. Warwickshire, UK: Intermediate Technology Publications Ltd.

Kurian, M., and Dietz, T. (2004) Irrigation and collective action: A study in method with reference to the Shiwalik Hills, Haryana. Natural Resources Forum 28: 3449.

La Ferrara, E. (2003) Kin groups and reciprocity: a model of credit transactions in Ghana. American Economic Review 93 (5): 1730-1751.

Leach, M., Mearns, R., and Scoones, I. (1999) Environmental Entitlements: Dynamics and Institutions in Community-Based Natural Resource Management. World Development 27 (2): 225-247.

Levi, M. (1988) The transformation of agrarian institutions: An introduction and perspective. Politics and Society 18: 159-170.

Levin, S.A. (2000) Fragile Domination. Reading, MA: Perseus.

Loreau, M., Mouquet, N., Gonzalez, A. (2003) Biodiversity as spatial insurance in heterogeneous landscapes Proceedings of the National Academy of Sciences. USA (22): 12765-12770.

Lynch, J. and Crowley, T. (2001) Languages of Vanuatu. Canberra: Pacific Linguists.

McCarthy N., Dutilly-Diane, C., and Drabo, B. (2002) Cooperation, collective action and natural resource management in Burkina Faso: a methodological note. CAPRi Working Paper Series 27. http://www.capri.cgiar.org .

MacClancy, J. (2002) To Kill a Bird with Two Stones, A Short History of Vanuatu. Port Vila: Vanuatu Cultural Centre.

Madge, C. (1993) Boundary disputes: Comments on Sidaway. Area 25 (3): 294 - 299.

Maggs, P. and Hoddinott, J. (1999) The impact of changes in common property resource management on intra-household allocation. Journal of Public Economics 72 (2): 317-324.

Margoluis R., and Salafsky, N. (1998) Measures of Success - Designing, Managing, and Monitoring Conservation and Development Projects. Washington, D.C.: Island Press. 
Mayo M., and Craig, G. (1991) Community participation and empowerment: The human face of structural adjustment or tools for democratic transformation?' In Craig, G., and Mayo, M. Community Empowerment - A Reader in Participation and Development. London and New Jersey: Zed Books.

Mearns, R. (1995) Institutions and natural resource management: Access to and control over woodfuel in East Africa. In Binns, T. (ed.) People and Environment in Africa. Chichester: John Wiley and Sons.

Meinzen-Dick, R., Pandolfelli, L., Dohrn, S., and Athens, J. (2006) Gender and collective action: A conceptual framework for analysis. Paper presented at the 11th Biennial Conference of the International Association for the Study of Common Property (IASCP), 19-23 June, 2006. Bali, Indonesia.

Mertens B., Sunderlin, W.D. Ndoye O., and Lambin E.F. (2000) Impact of macroeconomic change on deforestation in South Cameroon: integration of household survey and remotely-sensed data. World Development 28: 983-99.

Mohammad, R. (2001) 'Insider' and/or 'Outsiders': Positionality, theory and praxis', in Limb, M., and Dwyer, C. (eds.), Qualitative Methodologies for Geographers: Issues and Debates. London: Hodder Arnold.

Mohan, G. (2001) Beyond participation: Strategies for deeper empowerment. In Cooke, B. and Kothari, U. (eds.). Participation: The New Tyranny? London: Zed.

Mohan, G. and Stoke, K. (2000) Participatory development and empowerment: the dangers of localism. Third World Quarterly 21 (2): 247-268.

Molinas, J.R. (1998) The impact of inequality, gender, external assistance and social capital on local-level cooperation. World Development 26 (3): 413-431.

Moore, J. (1984). The evolution of reciprocal sharing. Ethological Sociobiology 5: 5-14.

Nagendra, H. (2007) drivers of reforestation in human-dominated forests. Proceedings of the National Academy of Sciences, USA 104 (39): 15218-15223.

National Self Reliance Committee and the Advocacy Coalition on Economics (ACE) (2006) Vanuatu Self Reliance Strategy, Port Vila. http://www.vanuatuculture.org/projects/050628_traditionalmoneybankproject.sh tml.

Neumann, R. (2005) Making Political Ecology. London: Hodder Arnold.

Olsen, M. (1965) The Logic of Collective Action. Cambridge, MA: Harvard University Press.

Opie, A. (1999) Unstructured interviews. In Davidson, C., and Tolich, M. (eds) Social Science Research in New Zealand - many paths to understanding. Auckland: Person Education NZ Ltd. 
Ostrom E., Janssen, M.A., Anderies, J.M. (2007) Going beyond panaceas. Proceedings of the National Academy of Sciences USA 104 (39): 15176-15178.

Ostrom, E. (1990) Governing the Commons: The evolution of institutions for collective action. Cambridge: Cambridge University Press.

Ostrom, E. (2000) Collective action and the evolution of social norms. Journal of Economic Perspectives 14, p.137.

Ostrom, E. (2007) A diagnostic approach for going beyond panaceas. Proceedings of the National Academy of Sciences USA 104 (39): 15181-15187.

Ostrom E., and Ahn T.K. (2003) The Foundations of Social Capital. Edward Elgar.

Patai, D. (1991) US academics and third world women: Is ethical research possible? In Gluck, S.B. and Patai, D. (eds) Women's Worlds: The Feminist Practice of Oral History. London and New York: Routledge.

Perrings, C. (2007) Future challenges. Proceedings of the National Academy of Sciences USA 104 (39): 15179-15180.

Plummer R. and FitzGibbon J. (2006) People matter: The importance of social capital in the co-management of natural resources. Natural Resources Forum 30: 51-62.

Poteete A.R., and Ostrom, E. (2004a) In pursuit of comparable concepts and data about collective action. Agricultural Systems 82: 215-232.

Poteete A.R., and Ostrom, E. (2004b) Heterogeneity, group size and collective action: The role of institutions in forest management. Development and Change 35 (3): 435-461.

Pretty J., Morrison, J.I.L. and Hine, R.E. (2003) Reducing food poverty by increasing agricultural sustainability in developing countries. Agriculture, Ecosystems and Environment 95 (1): 217-234.

Pretty, J., Smith, D. (2004) Social capital in biodiversity conservation and management. Conservation Biology 28 (3): 631-638.

Pretty, J., Ward, H. (2001) Social capital and the environment, World Development 29: 209-227.

Putsche, L. (2000) A reassessment of resource depletion, market dependency, and culture change on Shipibo Reserve in the Peruvian Amazon. Human Ecology 28 (1): 131-140.

Regenvanu, R. (2006) Presentation to the 9th Session of the Intergovernmental Committee on Intellectual Property and Genetic Resources, Traditional Knowledge and Folklore (IGC) of the World Intellectual Property Organisation (WIPO). 24th April 2006. Geneva, Switzerland. 
http://www.vanuatu.usp.ac.fj/sol_adobe_documents/world/vanuatu/Regenvanu.h tm (accessed January 212007.

Regenvanu, R. (2007) The year of the traditional economy - What is it all about?, The Independent, 11 February 2007. Port Vila.

Reingen, P.H. (1982) Test of a list procedure for inducing compliance with a request to donate money. Journal of Applied Psychology 67, p.110.

Richards, M., Kanel, K., Maharjan, M., and Davies, J. (1999) Towards participatory economic analysis by forest user groups in Nepal. ODI, London: Portland House.

Rockell, D.G. (2007) Development possibilities and customary land tenure in the pacific. Masters Thesis. Wellington: Massey University.

Rose, G. (1997) Situating knowledges: positionality, reflexivities and other tactics. Progress in Human Geography 21 (3): 305-20.

Rosenau, P.M., (1991) Post Modernism and Social Sciences: Insights, Inroads and Intrusions. Princeton: Princeton University Press.

Rosillo-Calle, F. and Woods, J. (2003) Individual Country Biomass Resource Assessment Profiles for Fiji, Kiribati, Samoa, Tonga, Tuvalu, and Vanuatu. SOPAC Technical Report 364. London: Imperial College Centre for Energy Policy and Technology.

Salafsky, N., and Wollenberg E., (2000) Linking livelihoods and conservation: A conceptual framework and scale for assessing the integration of human needs and biodiversity. World Development 28: 1421-1438.

Sandler, T. (1992) Collective Action: Theory and Applications. Ann Arbor MI: University of Michigan Press.

Sanma Council of Women (2006) Minutes of a Sanma Council of Women Conference held over 20th -24th February 2006 at the Sanma Women's Resource Centre, Luganville, Vanuatu.

Seabright, P. (1993) Managing local commons: theoretical issues in incentive design. Journal of Economic Perspectives. 7 (4): 113-134.

Scheyvens R., and Storey (Eds) (2003) Development Fieldwork, a Practical Guide. London: Sage.

Schmitt, B., Laurette, D., Leclerc, F. (1992) Intrusions into waiting lines: does the queue constitute a social system? Journal of Personality and Social Psychology 63: 806.

Sheil, D., Puri, R.K., Basuki, I, van Heist, M., Wan, M., Liswanti, N., Rukmiyati, Sardjono, M.A., Samsoedin, I., Sidiyasa, K., Chrisandini, Permana E., Mangopo 
Angi, E., Gatzweiler, Johnson, B., Wijaya, A. (2002) Exploring biological diversity, environment and local people's perspectives in forest landscapes Methods for a multidisciplinary landscape assessment. Bogor, Indonesia: Center for International Forest Research.

Sheil, D. and Liswanti, N. (2006) Scoring the importance of tropical forest landscapes with local people: Patterns and insights. Environmental Management 38 (1): 126-136.

Shrestha, B. (2005) Rural common property under leasehold forestry in Nepal, Case Study submitted for the joint study Rural Common Property in a Perspective of Development and Modernization. Nepal: MODE.

Sen, A. K. (1999) Development as freedom. New York: Knopf.

Somanathan, E., Prabhakar, R., and Mehta, B.S. (2002) Collective action for forest conservation: Does heterogeneity matter? New Deli: Indian Statistical Institute.

Stern, D.J. (2004) The Rise and Fall of the Environmental Kuznets Curve. World Development 32 (8): 1419-1439.

Stevens, S., and Howitt, R. (2000) Cross-cultural research: Ethics, methods, and relationships. In Hay, I. (ed) (2000) Introducing Qualitative Research in Human Geography. Oxford: Oxford University Press.

Strauss, A., and Corbin, J. (1998) Basics of Qualitative Research: Techniques and Procedures for Developing Grounded Theory. London: Sage.

Tisdell, C. A. (2005) Economics of environmental conservation. Northampton, Mass.: Elgar Publishers USA.

Titmuss, R.M. (1971) The Gift Relationship: From Human Blood to Social Policy. New York: Pantheon Books.

Tuhiwai-Smith, L. (1999) Decolonising Methodologies: Research and Indigenous Peoples. London: Zed Books.

UNDP (United Nations Development Programme) (1999) Managing the Transition from the Village to the City in the South Pacific. http://www.unescap.org/huset/pacific/pacific1.htm\#preface (accessed 2 November 2007).

United Nations Economic and Social Commission for Asia and the Pacific (2004) Economic and Social Survey 2004, Bangkok: UNESCAP.

Usher, P. J. (2000) Traditional ecological knowledge in environmental assessment and management. Arctic 53 (2): 183-193. 
Vadez, V., Reyes-Garcia, V., Godoy, R.A., Byron, E., Apaza, L, et al. (2004) Does integration to the market homogenize agriculture? Evidence from Tsimane' Amerindians. Human Ecology 32 (5): 635-646.

Valentine, J. (1997) Tell me about....: using interviews as a research methodology. In Flowerdew, R. and Martin, D. (eds.) Methods in Human Geography. Longman, Harlow.

Van Noordwijk, M., Tomich, T.P. and Verbist, B. (2002) Negotiation support models of integrated natural resource management in tropical forest margins. Conservation Ecology 5 (2): 21.

Vanuatu Environment Unit (2003) Community conservation capacity needs overview Report, NBSAP Project. Port Vila: Vanuatu government.

Vanuatu National Landuse and Planning Office (1998) VANRIS database. Port Vila: Vanuatu government.

Vanuatu National Statistics Office (1999) Population and Housing Census 1999. Port Vila: Vanuatu government.

Vanuatu National Statistics Office (2006) National Agricultural Census. Port Vila: Vanuatu government.

Varughese, G. (2000) Population and forest dynamics in the hills of Hepal: institutional remedies by rural communities. In Gibson, C., McKean, M. and Ostrom, E. (eds.) People and Forests: Communities, Institutions, and Governance (pp.193226). Cambridge, Massachusetts: MIT Press.

Varughese, G. and Ostrom, E. (2001) The contested role of heterogeneity in collective action: some evidence from community forestry in Nepal, World Development 29 (5): 747-765.

Department of Economic and Sector Planning (2006) Priorities and Action Agenda:

"An educated healthy and wealthy Vanuatu." Port Vila: Ministry of Finance and Economic Management, Vanuatu Government.

VDF (Vanuatu Department of Forests) (2002) Report on the application of ITTO criteria and indicators for assessing sustainable management of natural resources in Vanuatu. Submitted to ITTO. Port Vila: Vanuatu Department of Forests.

Velded, T. (2000) Village politics: heterogeneity, leadership and collective action. Journal of Development Studies 36 (5): 105-134.

Waddell, E., and Connell, J. (2007) Between global and local - The contest for development. In Waddell, E., and Connell, J. Environment, Development and Change in Rural Asia-Pacific - Between Local and Global. London and New York: Routledge. 
Wade, R. (1988) Village Republics: Economic Conditions for Collective Action in South India. Oakland: ICS Press.

Walsh, A.C. (1996) Ethnicity, gender and survey biases in Fiji. The Journal of Pacific Studies 19: 145-158.

Weaver, S., Gavin, M., Warrick, O., and Leathers, A. (2007). Socio-Economic Good Practice Guidance for Reducing Emissions from Deforestation in Developing Countries. Phase I Project Report No. 2 for Vanuatu Carbon Credits Project. Wellington: Victoria University. http://www.victoria.ac.nz/geo/research/climate-change/vanuatu-forests/

Westermann, O., Ashby, J., Pretty, J. (2005) Gender and social capital: The importance of gender differences for the maturity and effectiveness of natural resource management groups. World Development 33 (11): 1783-1799.

Western, D., Wright, R.M., and Strum, S.C. (eds.) (1994) Natural Connections: Perspectives in Community Based Conservation. Washington D.C.: Island Press.

Whyte, J. (2002) A review of lessons learned and best practice in integrated coastal watershed conservation and management initiatives in the Pacific Island region. Apia, Samoa: SPREP.

Whyte, J., Siwatibau, S., Tapisuwe, A., Kalotap, J., and Fraser, T. (1998) Participatory resource management in Vanuatu: research report. Port Vila: FSPI.

Woolcock, M. (2001) The place of social capital in understanding social and economic outcomes. Canadian Journal of Policy Research 2: 11-17.

WWF (2001) Vanuatu rain forests (AA0126).

http://www.nationalgeographic.com/wildworld/profiles/terrestrial/aa/aa0126.htm 1 (accessed April 20 2007).

Zak, P.J. and Knack, S. (2001) Trust and growth. The Economic Journal 111 (470): 295-321.

Zent, S. (2001) Acculturation and ethnobotanical knowledge loss among the Piaroa of Venezuela. In Maffi, L. On Biocultural Diversity: Linking Language, Knowledge, and the Environment. Washington. DC.: Smithsonian Institute Press. 
Bibliography 